\title{
IX. Jahresbericht (1909) der Vogelwarte Rossitten der Deutschen Ornithologischen Gesellschaft.
}

\author{
Von Dr. J. Thienemann.
}

\section{Allgemeiner Teil.}

Die Vogelwarte befindet sich in dem neuen Gebäude, dessen Abnahme durch den Königlichen Kreisbauinspektor von Memel am 16. August erfolgte, recht wohl, bis auf das Beschränkt sein im Raum. Die Schränke und Regale sind gefüllt; waren bereits beim Einzuge ziemlich besetzt. Ein regelrechtes Sammeln kann nicht stattfinden. Und doch ist es notwendig auf einer speziell der Ornithologie dienenden Station die Vogelarten nicht etwa in je zwei Vertretern zusammenzubringen, sondern wenn es notwendig erscheint in allen Kleidern, die man kennt, ferner neben den heimischen Brutvögeln Stichproben aus den ziehenden Vogelscharen von Beginn, Mitte und Ende der Zugperioden zu sammeln, weiter Vertreter von solchen Arten aufzustellen, die plötzlich in grofsen Massen erscheinen und von weit her gekommen sind, und dergl. mehr. Auch leere Wandflächen werden im Sammlungsraume recht vermifst, um vorhandene Zugkarten und Tafeln aufzuhängen. Für die zurückgelieferten Ringvögel hatte ich mir ein grofses Schrankfach gewählt; jetzt könnte ich bereits drei besetzen. Da stehen verschiedene Mövenarten und Krähen, die als kleine halbbefiederte Junge den Ring erhielten, jetzt als alte mehrere Jahre zählende Vögel in den verschiedensten Gefiederentwickelungen mit genauer Altersangabe, Storchbeine und Ringe aus Afrika serienweise, ja ein ganzer Ringstorch aus diesem Erdteile, Tafeln mit darauf befestigten Ringen und vermerkten Herkunftsorten und anderes mehr - aber alles sehr gedrängt und zu wenig übersichtlich. Die Liste der neu gesammelten Objekte findet sich am Schlusse dieses Berichtes.

Der Besuch des Museums war sehr gut. Dreiundvierzig Seiten im Fremdenbuche sind mit Namen aus dem Jahre 1909 bedeckt. Darunter mehrfach Schulen und Vereine. 1908 waren es 32 Seiten. Dabei schreiben sich bei weitem nicht alle Besucher ein.

Am 12. September wurde der Station die Ehre zu teil, ihren Gönner uud Förderer, Seine Exzellenz Herrn Staatsminister von Moltke zu empfangen, der in Begleitung des Herrn Oberforstmeisters Boy zur Elchjagd in Rossitten weilte. Vom Landwirtschaftsministerium in Berlin war am 23. Juni Herr Oberlandforstmeister Wesener hier anwesend und besuchte die Station; von der Königlichen Regierung in Königsberg Herr Regierungspräsident von Werder. Herr Geheimrat Prof. Dr. Braun, der als Vertreter des Ministeriums der geistlichen Unterrichts- und Medizinal-Angelegenheiten nunmehr dem Kuratorium der Vogelwarte angehört, weilte im Laufe des August wieder mehrere Tage 
in Rossitten. In seiner Begleitung befand sich Herr Lehrer Alfken aus Bremen, um im Auftrage der Physikalisch-Ökonomischen Gesellschaft in Königsberg in der Umgebung von Rossitten Hymenopteren zu sammeln.

Die getreuen Vogelwartenfreunde, die Herren Assessor Tischler, Rittergutsbesitzer E. Ulmer und Th. Zimmermann waren wieder mehrfach in Rossitten anwesend.

Während der Unterzeichnete zu den Zugzeiten in „Ulmenhorst" wohnte, entwickelte sich dort zuweilen ein reges wissenschaftliches Leben. Der zweite Assistent vom zoologischen Museum in Königsberg, Herr Dr. A. Dampf, war 8 Tage da, um Vogelparasiten, besonders Helminthen, zu sammeln. Es ist notwendig, dafs diese zarten, leicht vergänglichen Geschöpfe sofort nach dem Erlegen ihrer Wirte aufgesucht werden. Dazu bietet der Aufenthalt in Ulmenhorst die beste Gelegenheit. Herr Dr. Dampf wohnte 8 Tage mit in der Dünenhütte, mufste allerdings in der „Küche" schlafen, konnte aber mit reicher Beute abziehen.

Herr Privatdozent Dr. G. Braun aus Berlin benutzte Ulmenhorst als Stützpunkt bei seinen umfangreichen Dünenstudien. Herr Max Steckel aus Königshütte in Schlesien war als photographischer Mitarbeiter an dem Meerwarth'schen Werke: „Lebendsbilder aus der Tierwelt" anwesend, um freilebende Vögel zu photographieren. Es ist ihm auch unter anderem gelungen einen vorbeiziehenden Seeadler auf die Platte zu bringen. Leider zu klein! Zum Teil recht gute Bilder sind aber entstanden.

Herr Dr. von W i ch d orff von der Königlichen Geologischen Landesanstalt Berlin hatte auf der Kurischen Nehrung geologische Untersuchungen anzustellen und suchte ebenfalls Ulmenhorst auf. Dafs mehrfach Herren eintrafen, um den Vogelzug aus eigener Anschauung kennen zu lernen uud Studien zu machen, verdient weiter Erwähnung.

Dem Verfasser war es eine Freude, allen den Besuchern, die mit ernstem Streben hierherkamen, soweit es in seinen schwachen Kräften stand behilflich zu sein. Es machte oft den Eindruck, als ob die Errichtung der weltvergessenen Dünenhütte Ulmenhorst, in unverfälschter Natur auf einem interessanten Stückchen Erde gelegen, einem vorhandenen Bedürfnisse abgeholfen hätte, und dankbar haben wir oft des gütigen Stifters, Herrn Ulmers, gedacht. Die ringsherum angeflanzten Ulmen scheinen trotz des magern Sandbodens gut zu gedeihen.

An die Bibliothek haben folgende Autoren, der Zeitfolge nach aufgeführt, Schriften eingeschickt:

H. Hocke-Berlin.

J. H. Gurney-Keswick Hall.

Rud. Zimmermann-Rochlitz i./S.

Dr. le Roi-Bonn.

Pastor Dr. Lindner-Quedlinburg.

H. Scherren-London. 
Assessor Tischler-Heilsberg Ostpr.

Dr. He u ss für den internationalen Frauenbund fürVogelschutz.

Dr. August Thienemann-Münster i./Westf.

Dr. J. Th. Oudemans-Amsterdam.

Prof. Dr. A. Jacobi-Dresden.

Otto Graf Zedlitz-Trützschler-Schwentnig am Zobten Schl.

Dr. H. Weigold-Helgoland.

Otto Natorp-Myslowitz.

J. L. Bonhote-London.

Pfarrer G. Clodius-Camin.

Herluf Winge-Kopenhagen.

Jakob Schenk-Budapest.

H. Chr. C. Mortensen-Viborg.

Sanitätsrat Dr. Hilbert-Sensburg.

Dr. Richard Biedermann-Imboof.

P. Was muth-Reval.

R. Voigtländ er's Verlag-Leipzig.

Dr. O. Rabes-Halle an der Saale.

Dr. A. D a mpf-Königsberg i./Pr.

Geheimrat Professor Dr. M. Braun-Königsberg i./Pr.

Professor R. Poncy-Genf.

Dr. 0. Hein roth-Berlin.

Prof. Dr. H. Conventz-Danzig.

Pı́f. Dr. E. Rössler-Zagreb.

Dr. K. M. Levander-Helsingfors.

Reg. Rat Prof. Dr. G. Rörig-Grols-Lichterfelde-Berlin.

Vict or Ritter von Tschusi zu Schmidhoffen-Hallein.

Dr. H. Schlieper-Berlin.

Frau M. Hein roth-Berlin.

H. F. Witherby-London.

B. Henneber g-Gielsen.

W. Hennemann-Werdohl.

Geheimrat Prof. Dr. Franz Eilhard Schulze-Berlin.

Departement of Agriculture, Pretoria-Transvaal. (South African Central Locust Bureau Pretoria, South Afrika.)

Giuseppe Monzo-Salerno.

W. R. Ogilvie Grant-London. (Bulletin of the British Ornithologists' Club.)

F. E. Stoll-Riga.

Justizrat Kollibay - Neifse.

W. Ha gen-Lübeck.

Dr. H. Fis cher-Sigwart-Zofingen.

von Pfannenberg (Hüttenvogel)-Gotha.

Harald Baron Loudon-Lisden.

Prof. Dr. M. Braefs-Dresden.

Prof. Dr. F. A. Fo rel-Morges.

Walter Marcuse-London.

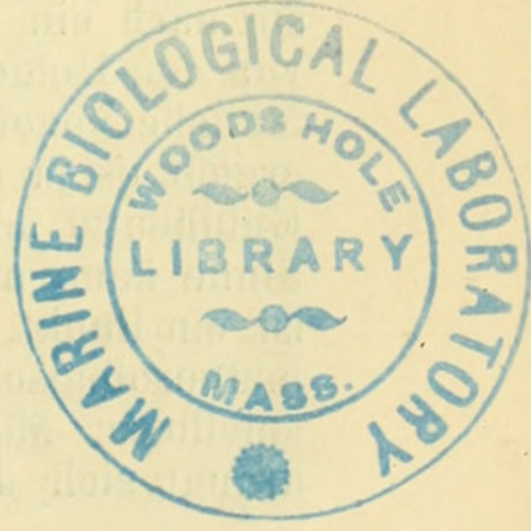

35 
Allen den Herren soll an dieser Stelle verbindlichster Dank ausgesprochen werden.

Bemerkenswert ist eine Reise nach Helgoland, die der Verfasser in diesem Jahre unternehmen konnte. Es war schon längst sein Wunsch, mit der dortigen Königlichen Biologischen Anstalt in persönliche Verhindung zu treten, zumal seitdem durch Dr. Weigold die Ornithologie auf jener Insel wieder zu Ehren gebracht wird. Auf Fürsprache des Herrn Geheimrat Braun und durch Vermittelung des Herrn Universitäts-Kurators Exzellenz v on Windheim bewilligte der Herr Minister der geistlichen Unterrichts- und Medizinal-Angelegenheiten die nötigen Mittel, und so konnte ich am 24. September abfahren, um am 16. Oktober zurückzukehren. Es überlief mich eine Art heiliger Schauder, als ich den klassischen Boden Helgolands betrat, und wenn auch der Vogelzug bei den anhaltenden südlichen und südwestlichen Winden nicht in der flotten Weise vor sich ging, wie wir's gewünscht hätten, so habe ich doch dort viel gelernt, habe aufserdem eine grofsartige Vogelzugsnacht auf dem Leuchtturme mit erlebt und kann mir nach dem selbst Gesehenen, nach den persönlichen Verhandlungen mit Dr. Weig old und nach dem Umgange mit den alten gewitzigten Helgoländer Vogelfängern wohl ein Bild von dem dortigen Vogelleben machen.

Das mufs unbedingt ausgesprochen werden: Helgoland und Rossitten sind in Bezug auf ihre Vogelzugserscheinungen ganz verschieden zu bewerten.

Rossitten liegt mitten in einer viel besuchten Zugstrafse, auf der während der Zugperioden, besonders im Herbste, wochenja monatelang, bei halbwegs günstigem Wetter tagtäglich grofse Scharen von Vögeln in mehr oder weniger geschlossener Kettenform in bequemster Sichthöhe dahinwandern. Helgoland dagegen ist - ja es fällt schwer, den richtigen Ausdruck zu finden. Raststation kann man nicht sagen, denn darunter versteht man für gewöhnlich ein Gelände, das von den Vögeln gern aufgesucht wird, weil es ihnen passende Unterkunftsorte und reichliche Nahrung bietet. Beides trifft für Helgoland nicht zu. Dort müssen die Waldschnepfen mit Felslöchern und die Drosseln mit Steinvorsprüngen als Ruheplätze fürlieb nehmen. Und Futter? Wenn die Vögel dick und feist auf der Insel ankommen, so sind sie nach ein bis zwei Tagen schon sehr abgemagert und werden von den Helgoländer „Feinschmeckern“ nicht mehr gern gegessen. Manche Vogelarten verhungern direkt. Den zugereisten Menschen ergeht es ja ebenso, wenn sie nicht einen ganz abnorm grofsen Geldbeutel mitbringen. Also als Raststation in dem landsläufigen Sinne kann man die kleine Insel nicht bezeichnen. Helgoland ist ein Punkt, der bei dem Zusammentreffen von ganz bestimmten meteorologischen Erscheinungen von manchen Vogelarten in beispielloser Massenhaftigkeit aufgesucht wird. Das Vogelleben drängt sich dort auf einzelne Tage, ja auf Stunden zusammen, 
um dann unter Umständen einer wochenlangen Öde und Leere Platz zu machen. Ich werde dabei den Eindruck eines gewissen Zwanges (Leuchtturm) nicht los. Das steht ohne Zweifel fest, dafs in der Nähe von Helgoland viel besuchte Zugstrafsen vorüberführen, denn wenn das passende „Vogelwetter" eintritt, dann sind die gefiederten Schaaren innerhalb einer Stunde da. Das eine hat Helgoland unbedingt vor Rossitten voraus: Das verhältnismärsig häufige Auftreten von Seltenheiten. Dabei sind in Betracht zu ziehen die grofse Übersichtlichkeit der Insel nnd das Aufpassen der Leute. Dort kann so leicht nichts unbemerkt durchziehen. Wenn z. B. an der entferntesten Ecke der Helgoländer Klippe eine Holztaube sich niedergelassen hat, oder wohl gar geschossen worden ist, so weifs das innerhalb einer halben Stunde die ganze Insel, und alle machen eine Schluckbewegung, um das Wasser loszuwerden, das ihnen im Munde zusammengelaufen ist.

Gerade weil Helgoland und Rossitten in ibren Vogelzugserscheinungen so verschiedenartig gestaltet sind, gerade deshalb ist es wichtig, dafs auf beiden Stationen regelmäfsige Beobachtungen angestellt werden, um Vergleiche ziehen zu können. Möchte es doch gelingen, auf der Königl. Biologischen Anstalt auf Helgoland eine ständige Stelle für einen Ornithologen zu schaffen, und möchte dann die alte Vogelwarte Helgoland, nach der die Vogelwarte Rossitten erst benannt worden ist, in ihrer früheren Blüte wiẻder erstehen.

Zum Schlufs will ich nicht versäumen, dem Direktor der Königlichen Biologischen Anstalt, Herrn Prof. D r. Hei n cke für das freundliche Entgegenkommen zu danken, das er mir während meines Aufenthaltes auf der Insel stets gezeigt hat. Das gröfste Verständnis offenbarte er für unsere Bestrebungen. Es war eine Lust mit ihm über die Beringungsversuche zu verhandeln, die durch seine gütige Unterstützung sofort von Herrn D r. W eig old begonnen werden konnten. Ebenso gebührt Herrn Dr. Weig old mein aufrichtigster Dank. Wie manchen Gang hat er machen müssen um mir vor meiner Ankunft die Wege zu ebnen. Und wie schön war alles geregelt! Wie viele Stunden seiner freien Zeit hat er mir geopfert! Wie viel hat er mir von seinen Erfahrungen berichtet! Vielen Dank!

Es ist ein günstiges und eigenartiges Zusammentreffen, dafs jetzt nicht nur in Helgoland das Streben rege wird, eine Vogelwarte zu gründen, sondern zugleich auch an zwei anderen weitab gelegenen Punkten: in Riga und in Algier. An dem ersten Punkte hat der Naturforscher-Verein in Riga die Angelegenheit in die Hand genommen, in Algier die Société d'Histoire Naturelle de l'Afrique du Nord.

Der Unterzeichnete ist bereits um Einsendung der Satzungen und der Geschäftsordnung der Rossittener Anstalt sowie um Abgabe von Gutachten gebeten worden. Die Vogelwarte Rossitten wünscht diesen Unternehmungen den besten gedeihlichen Fortgang, und 
ich glaube in diesem Wunsche vereinigen sich alle Ornithologen Deutschlands. Man denke sich an der afrikanischen Küste eine ornithologische Station entstehen, die an jener viel benutzten VogelZugstrafse nicht nur regelmäfsig wissenschaftliche Forschunen treibt, sondern auch der dort übligen Massenerbeutung von Vögeln aufklärend entgegenarbeitet; - wäre das nicht von unschätzbarem Werte!

Eine zweite Tour unternahm der Unterzeichnete in Begleitung von Herrn Assessor Tischler und Herrn Rittergutsbesitzer E. Ulmer nach den sogenannten Anlandungen des Königsberger Seekanales. Es ist das ein weites Stück neues Land, das durch Ausbaggern der Fahrrinne zwischen Königsberg und Pillau entstanden ist. Bäume, Buschwerk, Grasflächen Rohrbestände sind nach und nach auf diesem Gelände gewachsen, und es sollte nun mal festgesteltt werden, wie es mit der Vogelwelt dort steht? Da das vorhandene Buschwerk sich fast ausschliefslich aus Erlen und Weiden zusammensetzt, so war von Kleinvogelleben nicht besonders viel zu merken. Aber das konnte mit Sicherheit festgestellt werden, dafs dieses Land des flachen, teils sandigen teils berasten Strandes wegen ausgezeichnete Brutplätze für Möwen, Seeschwalben und alle möglichen Strandvögel bietet. Die Flufsseeschwalbe wurde bereits brütend dort angetroffen, auch eine kleine Kolonie der seltenen $\mathrm{Z}$ w er g se e s $\mathrm{c} h$ w a l be, eine der wenigen, vielleicht eine einzige in Ostpreufsen. Sturmmöwen trieben sich mitten in der Brutzeit dort umher, kleine Gesellschaften von Kampfläufern waren als Brutvögel vorhanden. Es ist die schönste Gelegenheit geboten dort eine Freistätte für Seevögel zu gründen. Nimmt man dazu noch bei den sich notwendig machenden Anpflanzungen Rücksicht auf die Kleinvogelwelt, indem man passendes Strauchwerk z. B. Wildrose, Weifsdorn, verschiedene Ribesarten, Rotbuche, Fichten, Hollunder u. a. wählt, so können dort auf diesen ausgedehnten Flächen See- und Strandvögel, sowie zarte Singvögel in gröfster Sicherheit dem Brutgeschäfte obliegen und ihren Bestand vermehren, denn es kommt als höchst günstiges Moment hinzu, dafs das fragliche Gelände zu Fufs nicht zu erreichen ist, nur per Kahn. So werden also Haarraubzeug und störende Menschen fern gehalten. Nu r g e nüg ende Aufsicht $\mathrm{mufs}$ da sein. Ohne die Anstellung eines Wärters während der Brutzeit wird's wohl kaum abgehen, genau wie auf den mannigfachen Vogelfreistätten an der Nordsee. Dabei kann dieJagd in verständiger und sch onender Weise getrost auf dem betreffenden Gebiete ausgeübt werden, ja es darf sogar wenn erst grofse Möwenkolonien entstanden sein sollten, die Eiernutzung eingeführt werden. Alles das verträgt sich, es mufs nur richtig und sachgemä $\mathrm{s}$ betrieben werden. Jeder kann's nicht.

Es sind übrigens bereits Schritte gethan, die fraglichen Ländereien dem Vogelschutze dienstbar zu machen. Hoffentlich gelingt es, dort eine Vogelfreistätte zu gründen. Das wäre dann 
die erste an den östlichen Teilen der Ostsee, während man an der Nordsee solche Einrichtungen schon längst mit geradezu grofsartigem Erfolge getroffen hat. -

Von freundlichen Zuwendungen für die Anstalt ist zu erwähnen, dafs Herr Kommerzienrat de Neufville aus Frankfurt a. M. 27,50 M. für die Ausstattung von Ulmenhorst gestiftet hat. Herr Prof. K. Storch von der Kunstakademie in Königsberg hat die Zeichnung zu einer passenden geschmackvollen Vignette für die Vogelwarte entworfen, die auf Briefbogen und anderen Schriftstücken der Anstalt zur Verwendung kommt; aufserdem hat der genannte Herr oft genug dem Unterzeichneten mit Rat und Tat beigestanden, wenn es galt, etwas auszuführen, wobei dem künstlerischen Geschmacke Rechnung zu tragen war.

Herr Geheimrat Prof. Dr. A ssmann vom Königlichen Aeronautischen Observatorium in Lindenberg ist der Vogelwarte insofern äufserst gefällig gewesen, dafs er eine Handwinde zum Steigenlassen von Kastendrachen leihweise hierher schickte und auch zwei Drachen besorgte. Es soll versucht werden, mit diesen Instrumenten Versuche über die Höhe des Vogelzuges zu machen.

\section{Dank!}

Allen den Herren im Namen der Anstalt verbindlichsten

Im vergangenen Jahre hat die Vogelwarte durch freundliche Vermittlung des Herrn Geheimrat B ra un den frei lt. Avers-Stempel erhalten, den der Unterzeichnete in seiner Eigenschaft als Universitätsbeamter zu führen hat.

Zum Schlufs will ich noch meines alten bewährten Krähenund Raubvogelfängers $\mathrm{Falk}$ gedenken, der im vergangenen Jahre mit noch 4 Bootinsassen in der See beim Fischen ertrunken ist. Die Rossittener sind ein wagehalsiges Völkchen. In leichten, gebrechlichen Fahrzeugen segeln sie zum Dorschfange meilenweit hinaus aufs Meer, da kommt plötzlich Sturm auf, sie eilen zurück, die Brandung ist inzwischen schon zu stark geworden, und auf dem ersten oder zweiten Riffe schlägt so eine Nufsschale um, und drei oder vier Familienväter sind in den Wellen begraben. Das ist Fatum, durchaus nicht abschreckend für die anderen; es hat so sollen sein. Mein Freund trank allerdings tüchtig Schnaps - nun das gehört hier so zum guten Tone - er prügelte auch seine Frau ordentlich - vielleicht ist das manchmal notwendig gewesen - aber er verstand so schön Vögel zu fangen, hatte so scharfe Augen, konnte so hübsch erzählen, war überhaupt ein guter Kerl. Wie oft habe ich mit ihm in der Fangbude gesessen. Er war es, der mir in einer Stunde einige Neunzig Nebelkrähen fing, die ich mit Ring versehen auflassen konnte; fast alle aufgestiegenen Ringkrähen und Raubvögel, die so hübsche Resultate gebracht haben, stammen aus seinem geschickt aufgestellten Netze; er war auch dabei, als uns an einem Morgen 6 Seeadler an der Hütte besuchten. Mögen ihm Ruhe und Frieden beschieden sein! 


\section{Wissenschaftlicher Teil.}

Die von Tis chler, Ulmer und Zimmermann stammenden Notizen, für deren freundliche Einsendung den drei Herren verbindlichster Dank gebührt, sind mit den Anfangsbuchstaben (T.), (U.) und (Z.) unterzeichnet. Alle Beobachtungen von Tischler, bei denen nichts besonderes bemerkt ist, beziehen sich auf Bartenstein, speziell auf die Umgebung von Losgehnen.

Die Beobachtungen von Ulmenhorst sind wieder im $\mathrm{Zu}$ sammenhange dargestellt worden, um einen Überblick über die Zugperioden zu geben. Besonders bemerkenswerte Erscheinungen, z. B. Züge von Spechten, Kreuzschnäbeln u. a. habe ich bei Behandlung der betreffenden Species angeführt. Nacbrichten über die Witterung suche man aufser in den Ulmenhorst-Abschnitten noch unter den Notizen über die Krähen. Sollte der verehrte Leser Lücken in den Beobachtungen entdecken, und es sind deren leider sehr viele vorhanden, so möge er das freundlichst damit entschuldigen, dafs der Unterzeichnete mehr wie ihm lieb ist an den Schreibtisch gefesselt ist. Die Arbeiten der Vogelwarte haben sich im Laufe der Jahre stark vermehrt; wenn man sich nur nach dem Stations-Postbuche richtet, dann möchte man sagen verdrei- oder vervierfacht. Im Jahre 1901 schlof's ich mit 505 Journalnummern und einem dafür gezahlten Porto von 44,11 M. ab. In diesem Jahre werden es gegen 1800 Journalnummern mit über 200 M. Porto. Da gibt es für eine einzelne Person mancherlei im Zimmer zu tun, und die Vögel treiben unterdessen draufsen was sie wollen.

\section{Aufzeichnungen.}

Uria troille (L.) Trottellumme.

14. Januar. Von Cranz wird eine Trottellumme Uria troille (L.) $\sigma^{\Upsilon} \mathrm{im}$ Winterkleide eingeliefert. Diese Art ist für die Nehrung, ja für Ostpreufsen neu.

Urinator arcticus (L.) Polartaucher.

W. Techler in Szameitschen erhielt 1 Stück am 26. Mai vou Pruschitten bei Demmersdorf (Kreis Gumbinnen). (T.) See. (Z.)

Ceynova (Hela): 1. Mai SW. Einzelne auf dem grofsen

Colymbus cristatus L. Haubensteifsfufs.

Bartenstein: 8. April: viele auf dem See.

16. Mai: Ein abnormes Stück gesehen, das bis auf den dunkeln Kragen weifslich ist; hält sich während der Brutzeit dauernd auf dem See auf; ist mit normalem Stück gepaart.

Nest mit 4 Eiern gefunden.

27. September: Grofse Flüge auf dem See. 

vember.

7. November: Noch einige gesehen, desgleichen am 8 . No-

14. November: Den letzten beobachtet.

Colymbus grisegena Bodd. Rothalssteifsful's. Bartenstein: 10. April: Ein Paar auf dem See.

12. April: Mehrere gesehen.

9. Mai: Noch 1 Stück auf dem See, dann verschwunden. (T.)

Colymbus nigricollis (Brehm.) Schwarzhalssteifsfufs.

5. Mai: Die Taucher auf dem Bruche b. Rossitten haben noch keine Nester gebaut bei diesem späten Frühjahre.

10. Juni: Junge auf dem Bruche; schon mehrere Tage alt.

Colymbus nigricans Scop. Zwergsteifsfufs.

Bartenstein: 25. September: Am See gehört.

28. Oktober: 2 Stück auf dem See beobachtet.

Stercorarius parasiticus (L.) Schmarotzerraubmöve. scharen. (Z.)

Bei Ceynova (Hela) öfter beobachtet unter den Möven-

Larus fuscus L. Heringsmöve.

Larus canus L. Sturmmöve.

Larus ridibundus L. Lachmöve.

30. März: Zum ersten Male Lachmöven über dem Bruche b. Rossitten, der noch ganz mit Eis bedeckt ist.

12. April: Es sind einige offene Stellen im Brucheise, über denen die Lachmöwen schwärmen. Noch nicht viel sind da. Am 13. A pril einige Sturmmöven auf dem Brucheise an eingefrorenen Fischen herumhackend. 22. April: Sehr wenig Lachmöwen über dem Bruche.

5. Mai: Die Lachmöwen haben in der Kolonie auf dem Bruche einige Nester gebaut; noch kein Ei.

7. Mai: Das erste Lachmöwenei auf dem Bruche. 30 Stück konnten gesammelt werden.

10. Juni: Bei einer Revision der Kolonie wird festgestellt, dafs die Möwen nach der Ausnutzung ihrer Kolonie sehr gut nachgelegt haben. Fast keine hellen Eier sind zu finden.

6. August: Auf dem Bruche alle Lachmöwen und FlufsSeeschwalben, bis etwa auf drei Möwen, fort. Das Brutgeschäft ist beendet.

16. August: NW. 5; W. 5; W. 3 . An der See und am Bruche bei Rossitten viel Larus canus.

13. November: Heute und an den vorhergehenden Tagen Südweststürme mit Regen und Graupeln. An der See sind Möwen gezogen, bes. fuscus und canus. 
Larus canus $\mathrm{L}$. zahlreich.

Bartenstein: In diesem Frühjahr am See auffallend

4. April: Mehrere gesehen.

5. April: 4 Stück am See.

In der Folgezeit waren einzelne bis 25 . April stets am See $\mathrm{zu}$ sehen.

(T.)

\section{Larus ridibundus $\mathrm{L}$.}

Bartenstein: 5. April: Die ersten am See.

In der Folgezeit stets einige am See bis in den Mai hinein; noch am 30. Mai einzelne gesehen.

11. Juli: Eine einzelne am See.

21. August: Am See ein Flug von 13. Stück.

\section{Larus minutus Pall. (Zwergmöwe.)}

15. Juli: Auf der Vogelwiese bei Rossitten ein Trupp; ebenso am 13. und 14. August.

Sterna hirundo L. Flufsseeschwalbe.

6. August: Vom Rossittener Bruche alle Seeschwalben fort. Das Brutgeschäft ist beendet.

\section{Sterna hirundo L.}

Bartenstein: 9. Mai: Die erste am See.

16. Mai: Mehrere gesehen. Während der ganzen Brutzeit halten sich einzelne am See auf.

11. Juli: 2 Stück daselbst.

\section{Sterna spec.}

Ceynova (Hela) 3. Mai: W.N.W. 1 Paar Seeschwalben, gröfser als die Flufsseeschwalbe, beobachtet. Auch in den Jahren vorher habe ich wiederholt Gelegenheit gehabt 2 solcher Vögel auf der Wiese zu beoachten, doch waren sie stets so fern, dafs ich auch durch das Glas Weiteres über ihre Art nicht feststellen konnte. (Z.)

Hydrochelidon nigra (L.) (Trauerseeschwalbe.

Bartenstein: 16. Mai: Viele am See.

30. Mai: Einzelne am See.

13. April: 4 Stück am See; ungepaarte!

20. August: Im See den noch ganz frischen Flügel einer wohl von einem Raubvogel geschlagenen jungen Trauerseeschwalbe gefunden. (T.)

Oidemia fusca (L.) Samtente.

6. A u gust: 1 Oidemia fusca $Q$ auf dem Bruche bei Rossitten geschossen. Oberschnabel länger als der Unterschnabel. Auf den Bruch kommt diese Art selten. Die Schnabeldeformation trägt vielleicht die Schuld an dem Aufenthalte an ungewöhnlicher Örtlichkeit. 


\section{Nyrocá fuligula (L.).}

22. April: Ein Pärchen auf dem Bruche bei Rossitten.

\section{Nyroca ferina (L.) Tafelente.}

22. A pril: Im Allgemeinen noch nicht viel Enten auf dem Bruche bei Rossitten. Unter andern auch 1 Flug $\boldsymbol{N}$. terina.

5. Mai: Auf dem Bruche N.ferina in zahlreichen Exemplaren.

10. Juni: Eine terina sitzt auf 13 Eiern auf dem Bruche.

6. August: 1 Tafelente juv., die noch nicht fliegen kann, auf dem Bruche erbeutet.

Am 12. August nach Beobachtung von Tischler viel $N$. ferina auf dem Haff bei Rossitten.

\section{Nyroca clangula (L.) Schellente.} Paaren. (Z.)

Ceynova: 1. Mai: SW. Auf der grofsen See in mehreren

Nyroca hyemalis (L.) Eisente.

22. April: 1 schönes Männchen auf dem Bruche bei Rossitten. Dahin kommen die Eisenten von der See nur selten.

\section{Spatula clypeata (L.) Löffelente.}

5. Mai: Mehrere Pärchen auf dem Bruche bei Rossitten, auch am 10. Juni ein Pärchen. Vielleicht gebrütet? In früheren Jahren habe ich das Nest dort gefunden.

25. August: Löffelenten auf dem Zuge jetzt zahlreich auf dem Bruche anzutreffen.

\section{Anas boschas L. Stockente.}

22. A pril: Mehrere auf dem Bruche bei Rossitten paarweise.

5. Mai: Auf dem Bruche bei Rossitten beobachtet.

10. Juni: Noch auf Eiern sitzend.

6. August: Zwei Anas boschas $0^{\top} 0^{\top}$ geschossen, die bereits wieder flugbar sind. Schwungfederkiele enthalten noch viel Blut.

Anas penelope L. Pfeifente. Rossitten.

22. April: Ein Flug dieser Enten auf dem Bruche bei

Anas acuta I. Spiefsente.

5. Mai: Auf dem Bruche bei Rossitten beobachtet. Verschwindet dann zur Zugzeit.

Anas querquedula L. Knäkente.

22. A pril: Mehrere auf dem Bruche bei Rossitten.

5. Mai: Auf dem Bruche zablreich.

6. A ugust: Eine Anas querquedula $\bigcirc$ ad. geschossen (stark in der Mauser). 


\section{Anas crecca L. Krickente.}

9. November: Auf dem Bruche bei Rossitten ziemlich viel Krickenten. $\mathrm{Zu}$ dieser späten Jahreszeit sammelt sich die Art immer in gröfseren Flügen auf diesem Gewässer.

Auswärtige Beobachtungen über Enten und Säger. penelope.

Bartenstein: 27. März: Auf dem See die ersten Anas

28. März: Auf dem See und teilweise auf den überschwemmten Wiesen einige crecca, ein Flug penelope, noch wenige boschas; mehrfach Mergus albellus in Paaren, Flüge von merganser und clangula.

4. April: Auf dem See Flüge von fuligula und sehr viele clangula; Flüge Mergus albellus und merganser; Anas boschas, penelope, crecca und einzelne querquedula.

10. April: Auf dem See Flüge von clangula, merganser, albellus.

12. April: Grofse Scharen ferina, viele clangula, Flüge albellus, merganser, penelope, crecca, querquedula, einige fuligula.

17. April: Auf dem See clangula.

18. April: Auf dem See clangula, terina, albellus, merganser.

19. April: Merganser, ein Paar albellus, ein Paar Spatula. clypeata, grofse Flüge penelope, viele clangula.

24. April: Viele querquedula - bisher nur immer erst wenig da -, einige clangula, albellus, merganser.

25. April: Mehrfach noch albellus, merganser, penelope, viele clangula, Flüge tuligula und terina.

1. Mai: Auf dem See 2 Paare fuligula.

2. Mai: 3 Fuligula fuligula, davon 2 ( $\sigma^{\top}$ und (†) geschossen.

3. Mai: Ein Paar Spatula clypeata.

9 Mai: Flüge penelope, ferina, fuligula; paarweise: crecca und querquedula, von letzterer Art Nest mit 4 Eiern gefunden. Mehrfach spatula.

16. Mai: Auf dem See 3 Paare fuligula, mehrfach terina, Flüge penelope. 6. Juni.

29. Mai: 5-6 Spatula $\sigma^{\top} \sigma^{\top}$, einzelne terina, desgleichen am

13. Juni: Auf dem See 1 fuligula $\sigma^{\rtimes} ;$ mehrfach spatula, boschas und querquedula, meist $\sigma^{T} \sigma^{\top}$. Dunenjunge von boschas. Dafila acuta $\bigcirc$ mit Dunenjungen. Zum ersten Male das Brüten bei Bartenstein nachgewiesen!

27. Juni: 4 Anas crecca beobachtet, die als Brutvogel in der Gegend sehr spärlich ist.

1. August: 6 querquedula und 3 noch nicht flugfähige boschas geschossen.

8. August: Am See Flüge querquedula.

19. August: Auf einen Schufs geschossen: 1 querquedula $\sigma^{\top}$ ad., 1 crecca $\sigma^{\top}$ ad., letzteres hat in den Weichen noch grau- 
melierte Federn. Ein am 17. August geschossenes $\sigma^{x}$ ad. von boschas trägt das reine Sommerkleid, die Schwanzfedern haben noch Blutkiele; in den Weichen lose, alte graue Federn.

20. August: Geschossen: 1 crecca ㅇ, 1 querquedula $\sigma^{\top}$.

22. August: Aus einem Fluge geschossen: 1 erecca ơ juv., 1 querquedula.

6. September: Ein Flug von etwa 30 terina.

Geschossen: 1 tuligula ơ ad. Es trägt das Sommerkleid, zeigte aber an einem Flügel, der infolgedessen nicht mitgemausert hatte, eine alte Schufsverletzung.

18. September: Auf dem See fuligula und penelope.

19. September: Ein grofser Flug crecca und querquedula, einige terina.

Der Hund fängt ein $\bigcirc$ ad. von boschas mitten in der Mauser, völlig flugunfähig.

20. September: Am See crecca, querquedula, ferina, penelope.

27. September: Noch Spatula clypeata beobachtet.

3. Oktober: 1 boschas $\sigma^{x}$ geschossen, grofsenteils fertig vermausert; nur der Kopf ist noch teilweise braun.

10. Oktober: Auf dem See ein Flug boschas, die $\sigma^{\top} \sigma^{\top}$ meist im Prachtkleid.

24. Oktober: Auf dem See die ersten Mergus albellus. $1 \sigma^{\top}$ von boschas zeigt am Kopf noch braune Federn.

28. Oktober: 1 Anas penelope $\sigma^{\top}$ juv. wird geschossen.

30. Oktober: Wenige crecca. Der Entenzug ist in diesem Jahre auffallend gering.

31. Oktober: Ein Flug fuligula, darunter auch marila.

7. November: Ein Flug von 6 Mergus albellus; 1 Mergus serrator, zum ersten Male auf dem See beobachtet! einzelne Anas crecca.

14. November: Auf dem See viele boschas.

15. November: Der See ist zugefroren. Hunderte boschas auf dem Eise.

16. November: 1 crecca o $^{\top}$ im Anfange der Mauser geschossen.

21. November: Auf dem See, der teilweise wieder offen ist, viele Mergus merganser, auch viele $\sigma^{x} \sigma^{x}$, einige albellus, Flüge boschas. Auf dem Flufs 1 querquedula, ơ im Sommerkleid, und 1 crecca $\bigcirc$ geschossen; ersteres war infolge einer alten Schufsverletzung zurückgeblieben.

25. Dezember: Am See kleine Flüge boschas, ebenso am 26. 12 . (T.)

Am 30. September am frischen Haff die erste Spiefsente. Ende Oktober viel Spiefsenten bis in den November hinein. Am 31. X. ein ausgefärbtes terina $\sigma^{x}$ erlegt. (U.).

\section{Tadorna tadorna (L.) Brandgans.}

W. Christoleit erlegte im Oktober eine junge Brandente bei Neukrug auf der frischen Nehrung. (T.). 
Ceynova (Hela): 3. Mai: 2 Paare auf dem Putziger Wieck beobachtet. Diese Art brütet mehrfach an der gegenüberliegenden Steilküste. (Z.).

Anser fabalis (Lath.) Saatgans.

Am 27. März Wildgänse auf dem Felde bei Rossitten.

Am 23. Oktober schiefs ich bei Rossitten 2 Anser fabalis. Mageninhalt: zerkleinerte Gerste, viel Sand, darunter einige Unkrautsämereien und einige Grasblätter. Mägen stark gefüllt.

Auswärtige Beobachtungen:

Bartenstein: 26. März: In Losgehnen die ersten gehört. Sehr spät!

28. März: Mehrere Flüge.

In diesem Frühjahr nicht sehr zahlreich.

8. Mai: Eine grofse Schar am See.

9. Mai: Einige Flüge gesehen.

10. Mai: Die letzten gesehen.

18. September: Die ersten im Herbst beobachtet.

25. September: Ein Flug am See. Sehr wenig zahlreich in diesem Jahre.

30. Oktober: Vereinzelte am See.

7. November: Noch 2 Stück gesehen. (T.).

Herr Ulmer sieht am 26. September die ersten Gänse bei Quanditten. Am 10. Oktober grofse Gänsezüge daselbst.

Nach Zeitungsberichten vom 27. November 1909, die der Vogelwarte zugehen, sind um diese Zeit bei Trebbin und auf den Höhen bei Buckow in der märkischen Schweiz ganz riesige Schwärme von Wildgänsen anzutreffen.

\section{Cygnus, schwan.}

20. März: Ganz schwacher NO. Die ersten Schwäne ziehend bei Rossitten.

Bei Pillkoppen treibt sich von Mitte Juli an wochenlang ein Schwan, ausgefärbt weifs, am Haffstrande umher. Verschwindet dann.

25. November: N.0. $6 \mathrm{Schwäne} \mathrm{werden} \mathrm{beobachtet.}$

Auswärtige Beobachtungen.

Cygnus olor (Gm.) Höckerschwan.

Cygnus cygnus (L.) Singschwan.

Bartenstein: 4. April: Auf dem See 4 weifse Exemplare von olor.

19. April: Auf dem See 1 weifser Höckerschwan, desgleichen am 24. und 25. April.

2. Mai: Auf dem See 5 weifse olor.

9. Mai: 2 weifse olor, desgleichen am 29. Mai. 
3. Juli. 4 weifse olor auf dem See, am 4. Juli noch 2.

28. Okto ber: Auf dem See ein einzelner Singschwan, weifs . (T.).

19. Juni: Auf dem Frischen Haff am Seekanal 6 und auf der Fischhauser Wieck 24 weifse Schwäne. (T.).

\section{Cygnus spec?}

Ceynova (Hela): 3. Mai: 5 Schwäne auf dem Plutziger Wieck, sie hielten sich dort ca. 10 Tage auf. (Z.).

Herr Ulmer meldet vom 19. Juni 30 Schwäne vom Haff. Sie versuchten zu brüten, wurden aber gestört.

Squatarola squatarola (L.) Kiebitzregenpfeifer.

13. 14. und 16. August: Auf der Vogelwiese bei Rossitten und bei Pillkoppen Squatarola squatarola von Tischler beobachtet.

Answärtige Beobachtungen.

Proe bbernau (Frische Nehrung) 1. Oktober: Drei Vögel dieser Art abends auf der Vordüne hochgemacht; es scheint dafs diese Strandläufer nicht auf dem offenen Strande, sondern aut der geschützteren Vordüne übernachten. 3. Oktober: Zwei Kiebitzregenpfeifer am Ostseestrande erlegt. (Z.)

\section{Charadrius. Regenpfeifer.}

15. Juli: Auf der Vogelwiese bei Rossitten Charadrius hiaticula in mehreren Paaren; umfliegt warnend seine Jungen.

13. August: An der Pelk 3 alte Goldregenpfeifer von Tischler beobachtet, ebenso am 14. bei Pillkoppen mit $C h$. hiaticula zusammen.

Am 18. August bekomme ich von Pillkoppen einen lebenden Charadrius alexandrinus. Diese Art ist hier recht selten. Zum letzten Male im Juli 1904 etwas zahlreich auf der Nehrung vertreten. Auch damals bekam ich ein lebendes Exemplar.

Auswärtige Beobachtungen:

19. April: Bei Thegsten (Kreis Heilsberg) den ersten Charadrius dubius gehört.

2. Mai: Am See bei Bartenstein dubius beobachtet.

19. August: 1 apricarius zieht in Losgehnen nach $\mathrm{S}$.

21. August: Am See 1 apricarius.

12. September: Am See hiaticula.

19. September: 1 hiaticula $\sigma^{\top}$ iuv. am See geschossen, erstes Belegexemplar von dort. Noch einzelne dubius gesehen.

27. September: Am See 1 apricarius. (T.)

Ceynova (Hela): 7. Mai: N. Am Strande des Wieck 1 Paar Charadrius dubius. (Z.) 


\section{Vanellus vanellus (L.) Kiebitz.}

Am 26. März: Kiebitze bei Rossitten, die ersten.

15. Juli: Auf der Vogelwiese bei Rossitten mehrfach Dunenjunge vom Kiebitz.

20. September: Viel Kiebitze am Bruche.

Auswärtige Beobachtungen:

Königsberg: 24. März: Bei Königsberg den ersten gesehen.

Bartenstein: 26. März: In Losgehnen ziehen 4 Kiebitze von SW. nach NO.

28. März: An diesem glänzenden Zugtage (s. Alauda) ziehen vormittags fortwährend Kiebitze einzeln oder in Flügen bis zu 20 Stück nach $\mathrm{O}-\mathrm{NO}$. Einen derartigen Massenzug von Kiebitzen bisher noch nie beobachtet!

29. März: Nur einige Kiebitze ziehen noch.

16. Mai: Am See I Dunenjunges gefangen.

30. Mai: Ein Flug von 12 Stück, wohl alles Alte.

13. Juni: Flügge junge Kiebitze gesehen, aber auch noch 1 Halbdunenjunges gefangen.

27. Juni: Am See mehrfach Flüge, meist iuv.

19. S epte mber: Ein kleiner Flug zu beobachten, desgleichen am 20. September. Die Hauptmasse ist schon fort. Ein Einzelner hielt sich dann noch während des ganzen Oktober am See auf; am 30. Okt.ober zuletzt gesehen (T.)

Ceynova (Hela): Einzelne Paare, die, wie alle Jahre, auf der Kasche brüten. (Z.)

26. März: Bei Quanditten Kiebitze.

Am 21. Oktober wurde noch ein Kiebitz von Allenburg Ostpr. gemeldet.

\section{Tringa. Strandläufer.}

Der Strandvogelzug begann in diesem Jahre ganz aufsergewöhnlich zeitig auf der Nehrung und gestaltete sich recht lebhaft. Ich erhalte in der Zeit von Mitte Juli bis Mitte September gegen 300 Tringen, Totaniden, Charadrien u. a., die ich alle mit king versehen fliegen lasse.

11. April: Herr Möschler sieht auf der Vogelwiese einen Flug von etwa 10 Strandvögeln.

15. Juli: W. 5, W. 6, W. 2. Auf der Vogelwiese für so frühe Jahreszeit viel Strandvögel. Grofse Flüge Tr. alpina in vollständigem Sommerkleide, einige Junge darunter, sonst alles alte mit schwarzen Brustschildern. Ferner darunter zahlreiche Tringa terruginea im schönsten roten Sommerkleide. Wenige Tringa minuta. Aus Pillkoppen erhalte ich heute 17 Tringa alpina lebend, die ich mit Ring versehen fliegen lasse.

16. Juli: W. 1, W. 6, W. 1. Auf der Vogelwiese dieselben Vogelarten wie gestern, nur weniger. 
31. Juli: W. 4, W. 7, W. 7. Aus Pillkoppen werden mir 20 Tringa alpina und 1 Tringa ferruginea lebend gebracht. Es sollen dort in der vorigen Nacht viel Strandvögel angekommen sein. Bei Rossitten nichts davon zu merken.

1. August: W. 6; W. 6 ; W. 5 . Heute aus Pillkoppen 52 lebende Tringa alpina erhalten. Es müssen also viel angekommen sein. Alles sind alte Vögel mit schwarzem Brustschilde und abgenutztem Gefieder, nur ein Junges darunter; ferner auch ein Iringa ferruginea. In diesem Jahre zeitiger und guter Strandvogelzug. Die Strandvögel bevorzugen zur Rast jetzt lieber eine bei Pillkoppen, $12 \mathrm{klm}$. nördlich von Rossitten, gelegene Pallwe, da der Strand der Vogelwiese bei Rossitten mit einer Rohrpflanzung eingefafst ist, die allen Strandvögeln zuwider ist.

3. August: NO. 4, 0.4, NO. 4. Von Pillkoppen wieder 49 lebende Tringa alpina erhalten.

Am 12. und 13. August bei südwestlichen Winden am Bruch und auf der Vogelwiese Tringa alpina und minuta.

14. August; W. 8, W. 8, W. 6. Auf der Vogelwiese und bei Pillkoppen viel Tr. alpina und ferruginea, meist ad.

Am 16. August: NW, 5, W. 5, W.3. Auf der Vogelwiese viele $T r$. alpina ad. und minuta, auch am Bruche solche.

A uswärtige Beobachtungen.

Bartenstein: 11. Juli: Am See eine alpina.

21. A u gust: Kleine Tringen (minuta oder temmincki) am See.

29. August: Flüge von alpina.

5. September: Kleine Flüge alpina und subarcuata. Von letzteren abends 2 juv. geschossen. Bisher nur im Alterskleid vom See erhalten. Ist daselbst nicht häufig.

6. September: 3 subarcuata, 1 kleine Tringa gesehen.

18. September: Ein Flug von etwa 20 alpina, iuv.

20. September: Nachts ziehen über Heilsberg alpina.

27. September: Ein Flug von 5 alpina am See bei Bartenstein.

Totanus Wasserläufer.

1. Juli: 0. 2; N. 5; NO. 7. Ein Flug Kampfläufer von etwa 40 Stück auf der Vogelwiese bei Rossitten. Einer wird erlegt, dessen Kragen vorn schon ganz ausgefallen ist.

15. Juli: W. 5; W. 6 ; W. 2 ; Auf der Vogelwiese um diese frühe Jahreszeit schon viel Strandvogelleben. Kampfläufer und einige Totanus littoreus sind vorhanden.

6. August: SW. 4; W. 4; W. 1; Einige Totaniden auf dem Bruche zu beobachten.

12. August: NW. 6; W. 6 ; SW. 3 ; Am Bruche mehrere Totanus fuscus, ochropus, glareola.

13. August: SW. 4; SW. 5; W. 8 . Auf der Vogelwiese und am Bruche nach Beobachtung von Tischler T. glareola, ochropus und littoreus, Tringoides hypoleucos. 
14. August: W. 8 ; W. 8; W. 6; Auf der Vogelwiese Totanus glareola, 1 T. pugnax. Bei Pillkoppen: 1 Totanus totanus, fuscus, chropus von Tischle r beobachtet.

16. August. NW. 5; W. 5; W. 3; Auf der Vogelwiese und am Bruche nach Tischler's Beobachtung T. glareola, ochropus, littoreus, einzelne fuscus, Tr. hypoleucos.

17. August: Aus Pillkoppen 1 lebenden Totanus totanus juv. erhalten. Hier nicht häufig.

23. August: SO. 2; NW. 5; W. 3; Am Bruche ein ganzer Trupp Totanus fuscus eifrig bei der Nahrungssuche. Zwei erlegte haben im Magen je einen kleinen Fisch (Stichling).

24. August: Ein geschossener Totanus littoreus hat einen kleinen, ganz verschluckten Frosch im Magen. Ein grofser Bissen für den Vogel.

Auswärtige Beobachtungen. ochropus.

Bartenstein: 18. April: Am See 1 Totanus totanus, 1

19. April: Am See 1 hypoleucos, 1 totanus, 1 ochropus.

25. April: 1 totanus läfst den Paarungsruf hören. littoreus.

27. April: An der Alle bei Heilsberg mehrere ochropus, 1

1. Mai: Am See 1 littoreus.

8. Mai: Totanus littoreus läfst den Paarungsruf hören; einige glareola und ochropus.

9. Mai: Totanus littoreus, totanus und glareola lassen den Paarungsruf hören; 1 tuscus; ein Flug pugnax (ㅇํ); einzelne hypoleucus.

16. Mai: Am See sind glareola, einzelne littoreus, 1 fuscus, 1 totanus. Mehrfach pugnax, meist ein $\sigma^{\top}$ mit weifsem Hals und Kopf, aber noch ohne Kragen geschossen.

29. Mai : 1 totanus, mehrfach pugnax, auch $\sigma^{7} \sigma^{7}$; wenig glareola.

30. Mai: 1 totanus; Flüge pugnax, darunter $1 \sigma^{7} \mathrm{ad}$., meist jüngere $\sigma^{\top} \sigma^{\top}$ oder 우오. und $\left.1 \sigma^{\top}\right)$.

6. Juni: 3 totanus; 1 hypoleucus; ein Flug pugnax (우 우

13. Juni: 2 glareola, 1 totanus, ein kleiner Flug pugnax, darunter $\sigma^{7}$ mit schwarzem Kragen.

27. Juni: 3 totanus, ein $\bigcirc$ führt sicher Junge warnt unablässig. Erster Fall des Brütens am See! 1 fuscus, viele Flüge glareola, 2 littoreus. Vielfach pugnax, darunter öfter $\sigma^{\top} \sigma^{x}$; ein Flug von etwa 20 enthält etwa $4 \sigma^{x} \sigma^{x}$, im übrigen sieht aber auch öfters einzelne $\sigma^{x} \sigma^{x}$. Geschossen: $1 \sigma^{x}$ ad. mit weifsem Kragen und $1 \sigma^{x}$ iuv. mit schwarzem Unter- und rostrotem Oberkragen.

3. Juli: Am See hypoleucus.

4. Juli: 2 littoreus, 5 totanus, 1 fuscus, mehrfach glareola, einige pugnax, darunter 1 ऽ. 


\section{Juli: Wenig glareola.}

16. Juli: Nachts zieht über Heilsberg hypoleucus.

18. Juli: Am See totanus, glareola. hypoleucus.

1. August: Wenig Leben am See: wenige littoreus, glareola,

8. August: Wenige glareola und hypoleucus.

9. August: Ein Elug von 5 littoreus, wenig glareola.

19. August: Am See littoreus, glareola.

20. August: Einzelne littoreus, glareola, hypoleucus, pugnax.

21. August: Einzelnefuscus, littoreus, glareola,pugnax, 1 totanus.

22. August: Einzelne littoreus, fuscus.

23. August: Am See alle Totaniden: littoreus, fuscus, totanus, ochropus, glareola, hypoleucus, pugnax. 3 littoreus geschossen, darunter $1 \sigma^{x}$ ad.

25. August: Einzelne littoreus und glareola.

Abends an dem See viel Leben: viel littoreus und glareola, 1 totanus, 1 fuscus, einige pugnax, hypoleucus, ochropus.

30. August: Dieselben Arten wie am Tage zuvor, besonders viele littoreus und pugnax.

5. Sep tem ber: Viele pugnax und littoreus, einzelne fuscus, glareola, hypoleucus.

Abends aufserordentlich reges Vogelleben auf einer Sandbank im See. Die sonst so scheuen littoreus fliegen einem förmlich um den Kopf und fallen trotz vielfacher Schüsse immer wieder ein. Mit Referendar Schütze 12 pugnax juv. und 8 littoreus, darunter 1 ad. geschossen.

6. September: littoreus, fuscus, pugnax, hypoleucus öfters.

11. September: Den letzten ochropus gehört.

12. September: Dieselben Arten wie am 6. September; glareola ist wohl schon fort.

18. September: Noch vereinzelte littoreus und hypoleucus.

20. September: Einzelne littoreus, hypoleucus; 2 pugnax unter Vanellus, die letzten.

25. September: Den letzten hypoleucus gehört.

10. Okt o ber: Noch ein einzelner littoreus; spät!

18. Oktober: 1 littoreus geschossen. Winterkleid zum grofsen Teile fertig. Guter Futterzustand. (T.)

Limosa limosa (L.) Uferschnepfe.

15. Juli: Auf der Vogelwiese bei Rossitten mehrere Uferschnepfen unter zahlreichen Tringen.

Bartenstein: 13. Juni: Am See ein Flug von 5 Stück. Zum ersten Male dort beobachtet! (T.)

14. Juli: Am frischen Haff ein Stück geschossen.

Limosa lapponica (L.) Phuhlschnepfe. ad. erlegt.

10. August: Am Bruche bei Rossitten eine Limosa lapponica 
13. August: Drei L. lapponica von Tischler auf der Vogelwiese beobachtet und ein ganzer Flug am Bruche; am 14. ein solcher bei Pillkoppen.

Numenius phaeopus (L.) Regenbrachvogel.

Numenius arquatus (L.) Grofser Brachvogel.

Am 1. April ersten Brachvogelruf bei Rossitten.

22. April: Ein Trupp Brachvögel, wohl phaeopus, nach N.

15. Juli: Auf der Vogelwiese, wo jetzt schon viel Leben ist, ein Trupp von etwa 12 Stück. Aus Pillkoppen bekomme ich 1 lebenden.

10. August: S.W.4; W. 6; W. 4. In Cranz ziehen nach Beobachtung von Tischler grofse Brachvögel nach S., ebenso am 15. Augnst nachts bei W. Am 13. und 16. August Numenien auf der Vogelwiese bei Rossitten, darunter auch $N$. phueopus; am 17. August bei S.O. nachts ziehende Brachvögel.

14. September: Mitten in den Dünen bei Ulmenhorst einen grolsen Brachvogel erlegt. Ein kleiner Trupp zieht nach Süden. Das erlegte Stück hat den Schlund vollgepfropft von Riesenohrwürmern. (Forficula gigantea). 40 Stück befördere ich $\mathrm{zu}$ Tage. An derselben Stelle schiefse ich 2 junge $\mathrm{Pfuhl}$ schnep fen (Limosa lapponica). Auch diese haben weiter nichts als Riesenohrwürmer gefressen. Die Mägen sind ganz voll von Resten dieser Tiere.

Ich suche an den betreffenden Stellen nach, um zu sehen, wie die Vögel in den Besitz der Ohrwürmer, die man nie frei umherlaufen sieht, gelangen und stelle folgendes fest: Es finden sich kleine frisch aufgeworfene Sandhügelchen vor. Unter jedem mündet ein schräg, nie senkrecht, in den Sand verlaufender Gang nach aufsen. Bei vorsichtigem Nachgraben nach vorherigem Einschieben eines Grasstengels treffe ich schliefslich auf den $\mathrm{Ohr}$ wurm, der mit dem Kopfe nach innen am Ende des Ganges sitzt. Ich finde Gänge von $31 \mathrm{~cm}$ Länge. deren Endkessel $14 \mathrm{~cm}$ tief unter der Sandobertläche liegen. Je ausgedehnter die Wohnung, um so gröfser war immer der Insasse. Wie erwischen die Brachvögel und Limosen diese so tief versteckt sitzenden Kerbtiere? Ein Nachgraben mit den weichen Schnäbeln ist ausgeschlossen. Bei vorsichtigem Vorwärtsschleichen bemerke ich, dafs die Spitzen der kleinen Sandhügel sich bewegen, indem etwas Sand nachfällt. Nun ist das Rätsel gelöst. Die Ohrwürmer sitzen für gewöhnlich flach unter den kleinen Sandhügeln, um bei drohender Gefahr in die Tiefe zu eilen. So müssen also die Vögel diese Kerbtiere immer auf vorsichtigen Birschgängen durch schnelles Zugreifen erhaschen. Damit erklärt sich auch der eigenartige, behutsame Gang der auf der Nahrungssuche befindlichen Brachvögel, der dem Beobachter auffällt.

Die Brachvögel und Limosen werden ausschliefslich durch das Vorhandensein von Riesenohrwürmern in kahles ödes Dünengelände gelockt, das sonst nichts an Nahrung bieten kann. 
A uswärtige Beobachtungen.

Bartenstein: 12. April: 1 arquatus am See, desgleichen am 18. April.

19. April: Nachts ziehen arquatus bei Regen über Heilsberg.

24. April: 7-8 arquatus ziehen am See bei Bartenstein nach 0 ., darunter auch phaeopus; letzterer neu für die dortige Gegend.

9. Mai: Am See 1 phueopus.

16. Juli: Nachts ziehen arquatus über Heilsberg.

18. A ugus t: In Losgehnen ziehen 4 arquatus vormittags nach S.

20. August: Am See 2 arquatus.

22. August: Am See arquatus gehört.

23. August: 1 arquatus fliegt nach $\mathrm{S}$.

26. August: Am See 5 arquatus. (T.)

Gallinago gallinago (L.) Bekassine.

Bartenstein: 5. April: Die erste am See.

25. August: Einzelne am See, ebenso stets in der Folgezeit. bis zum 7. November. Nicht sonderlich häufig in diesem Jahre. Am 27. September ein Flug von 7 Stück. (T.)

Proebbernau (Frische Nehrung): 3. Oktober: WSW. 2 Bekassinen und eine kleine Sumpfschnepfe am Haffstrande erlegt.

Gallinago gallinula (L.) Kleine Sumpfschnepfe.

Bartenstein: 9. Oktober: Wenige am See. In der Folgezeit stets einzelne daselbst bis zum 7. November. (T.)

Otis tetrax L. Zwergtrappe.

Präparator Sondermann erhielt am 27. M a i 1 ơ von Pötschlauken (Kreis Pillkallen) Ostpreufsen. (T.)

Grus grus (L.) Kranich. nach 0 .

Bartenstein: 10. September: Etwa 50 Stück ziehen

4. $0 \mathrm{ktober:} \mathrm{Einige} \mathrm{ziehen} \mathrm{von} \mathrm{W}$. nach 0 .

14. Oktober: Abends ziehen 38 Kraniche von 0 . nach W.

Rallus aquaticus L. Wasserralle. gesehen.

Bartenstein: 4. April: Am See die erste Wasserralle

24. A ugust: Öfters am See, zum Teil noch mit kleinen Jungen. 1 juv. geschossen. (T.)

Crex crex (L.) Wachtelkönig.

16. Ma i: Den ersten bei Bartenstein gehört.

23. Mai: Bei Heilsberg vielfach zu hören.

28. Mai: In Losgehnen jetzt recht häufig. 
9. A u gust: Zum letzten Male den Ruf gehört.

26. Se ptember: Am See auf dem Zuge.

10. $0 \mathrm{kt} \mathrm{ober:} \mathrm{Am} \mathrm{See} \mathrm{noch} 2$ Stück. (T.)

Am. 29. S e p t e m b e r viele bei Quanditten auf dem Zuge. (U.)

Ortygometra poreana (L.). Tüpfelsumpfhuhn.

Bartenstein: 29. August: Am See mehrfach beobachtet.

26. September: noch mehrere gesehen. (T.)

24. September: viele bei Quanditten ziehend.

Gallinula chloropus (L.) Grünfüfsiges Teichhuhn.

Bartenstein: 25. April: Das erste am See.

24. August: Am See vielfach zu beobachten, teilweise noch mit kleinen Jungen.

18. September: Vielfach am See. (T.)

Fulica atra L. Bläfshuhn.

B artenstein: 4. April: Das erste am See gehört.

8. April: Viele auf dem See.

10. April: Vollzählig angekommen.

16. Ma i: Nest mit 3 Eiern.

13. Juni: In Weidenbüschen am See 3 Nester mit 11, 7 und 7 Eiern.

14. November: Das letzte auf dem See.

Pröbbernau (Frische Nehrung): 2. Ok t o ber: SO. Mehrfach auf dem frischen Haff. (Z.)

Ciconia ciconia (L.) Weifser Storch.

18. April: 1 Storch bei Rossitten nach N. ziehend.

24. April: 1 Storch überm Dorfe.

25. April: fünf Störche auf dem Felde.

Das einzige Storchnest was hier in Rossitten (wohl auf der ganzen Nehrung) sich befand, ist durch Umbau der OberförstereiScheune, auf deren Dache es stand, leider zerstört worden. Auf meine Veranlassung bracbten mehrere hiesigen Besitzer im Jahre 1909 Nester auf ihren Strohdächern an, wovon das eine sofort bezogen wurde. Der eine Storch kam aber leider ums Leben, ein zweiter fand sich nicht ein, und so ist noch keine Brut ausgekommen.

5. Juli: Ein grofser Flug Störche, etwa 40 Stück, über den Feldern bei Rossitten.

Herr Adolf Kittler aus Thorn meldet der Vogelwarte, dafs er am 27. 8. 09 zwei Uhr nachmittags vom Mengsdorfer Tale (Hohe Tatra) aus einen starken Zug Störche in südsüdöstlicher Richtung ziehend beobachtet hat. Immer diese südöstliche Richtung!

Für die Beurteilung des Storchzuges sind Zugdaten aus dem Westen oder Südwesten von grofsem Werte. Hier seien einige angeführt, die die Vogelwarte der Güte des Herrn Karl Gerber 
in Spiez in der Schweiz, Kanton Bern, verdankt. Die frühe Ankunftszeit fällt auf:

1) In Seeberg im Kanton Bern traf der erste ein am 15. Februar 1909.

2) In B ett e $\mathrm{n}$ h a u se n, Kanton Bern, Nest auf einem Hausdache, traf das Männchen ein am 2. März; das Weibchen langte am 4. März nachmittags um 3 Uhr an.

Der Storch, welcher in Seeberg am 15. Februar eintraf, hatte von der Kälte noch viel zu leiden; $-2-12^{\circ} \mathrm{C}$. bis zum 1. März; mit dem 2. März trat milde Witterung ein, und damit langten auch vom 2.-4. März die meisten Störche in der Schweiz an.

A uswärtige Beobachtungen.

Bartenstein: 8. April: In Losgehnen der erste Storch auf dem Nest.

12. April: Der zweite Storch stellt sich auf diesem Nest ein.

19. April: Das zweite Paar stellt sich auf einem andern Neste ein.

30. Mai: In Losgehnen 7 ungepaarte Störche.

26. J u li: Aus einem Neste fliegen die gezeichneten Störche aus, aus dem zweiten erst am 19. August.

8. August: 25 Störche kreisen hoch nach 0 .

22. August: Ein Flug von $20-25$ kreist nach W.

25. August: Die gezeichneten Störche sind noch auf beiden Nestern da.

28. August: Von einem Nest sind die Störche fort, von dem andern am 29. August.

29. August: Vormittags ziehen 20 Störche hoch von 0 . nach S.

11. September: 2 Stück ziehen nach S. Spät! (T.).

25. A u gu st: Störche ziehen weg. (U.).

\section{Ciconia nigra (L.) Schwarzer Storch.}

28. S e p t e m ber: Schwarzer Storch bei Qu anditten. (U.)

\section{Botaurus stellaris (L.) Rohrdommel.}

Dieser Vogel war bisher ab und $\mathrm{zu}$ in der Umgebung von Rossitten $\mathrm{zu}$ beobachten, besonders während der Zugzeiten. In diesem Jahre batte er sich dauernd auf dem Bruche niedergelassen und rief Ende Mai und Anfang Juni sehr häufig, namentlich in den Abendstunden. Das Nest ist nicht gefunden worden.

A uswärtige Beobachtungen.

Bartenstein: 26. September: Abends 1 Stück am See.

24. Okto ber: Abends 1 Stück am See gehört, desgleichen am 29. Oktober.

Proebbernau (Frische Nehrung): 3. Oktober: W.S.W. Eine Rohrdommel im Schilf am Haffstrande - wohl auf dem Zuge - erlegt. (Z.). 
28. September: Es ziehen täglich grofse Rohrdommeln am frischen Haff, ebenso den ganzen Oktober hindurch und auch noch Anfang November. (U.).

Ardetta minuta (L.) Zwergrohrdommel.

Bartenstein: 27. Juni: Am See 2 Stück beobachtet. In der Folgezeit dann stets einzeln beobachtet. Am 29. August ausgeflogene Junge beobachtet; sind als Belegexemplar geschossen, hat noch Dunen am Kopf.

30. A ugust: Die Jungen werden gefüttert, rufen dabei heiser ,gaek gaek".

5. Se ptem ber: Zum letzten Male beobachtet.

28. September: Von Ulmer beobachtet.

Ardea cinerea L. Fischreiher.

15. Juli: Auf der Vogelwiese bei Rossitten ein Fischreiher, ebenso am 14. August. Im September häufig am Bruche.

B artenstein: 21. März: In Losgehnen zeigt sich der erste.

28. März: Schon mehrfach zu sehen.

13. Juni: Die ersten flüggen Jungen in Losgehnen.

11. Oktober: Noch mehrfach am See, desgleichen am 17. und 24. Oktober.

1. November: Noch 1 Stück, den letzten, beobachtet. (T.).

Columba palumbus L. ${ }^{1}$ ) Ringeltaube.

Bartenstein: 21. März: In Losgehnen 2 Stück, die ersten, beobachtet.

19. April: Ein Flug von 10 Stück, also wohl noch auf dem Zuge.

Heilsberg: 23. Mai: In der W'iechertshofer Forst bei Heilsberg häufiger Brutvogel. (T.).

Ceynova (Hela): 29. A pril: SW. mehrere kleine Flüge.

Proebbernau (Frische Nehrung): 30. September: WS W. Lebhafter Zug von Columb. palumb.; es scheinen auch einige Columb. oenas darunter zu sein. (Z.).

29. März: Tauben.

2. O k t ob er: sehr starke Ta ubenz üge bei Quanditten (U.).

Columba oenas L. Hohltaube.

26. März: Erste Hohltauben bei Rossitten.

Heilsberg: 23. Mai: In dem Wiechertshofer Forst bei Heilsberg vereinzelter Brutvogel.

Bartenstein: 10. Oktober: In Losgehnen ein Flug von 8 Stück beobachtet.

1) Über Wildtaubenzng auf der Nehrung s. unter den im $\mathrm{Zu}-$ sammenhang dargestellten Beobachtungen von Ulmenhorst. 
Turtur turtur (L.) Turteltaube.

Bartenstein: 1. Mai: Die Ersten gehört.

Perdix perdix (L.) Rebhuhn.

16. März: Ein zerschlagenes frisches Rebhühnerei bei Ulmenhorst, trotz der kalten Witterung. gesehen. ( $\mathrm{T}$.)

Heilsberg: 20. März: Die ersten gepaarten Rebhühner

Ceynova (Hela): 7. Mai: 1 Paar in den Culturen, wahrscheinlich brütend. (Z.)

\section{Coturnix coturnix (L.) Wachtel.}

16. Mai: Die Erste bei Bartenstein gehört.

25. Juli: Wachteln schlagen in Losgehnen noch eifrig.

10. Oktober: Noch 2 Stück in Losgehnen beobachtet. In diesem Jahre etwas häufiger. Im ganzen sind auf der Hühnerjagd 8 Stück geschossen.

T agr a ubvögel.

14. Januar: Ein Rauhfufsbussard (Archibuteo lagopus) auf den Feldern bei Rossitten, sonst sehr tot draufsen.

22. April: Über dem Bruche ein Fischadler (Pandion haliaetus), den ich erst lange beim Fischen beobachte, dann schiefse. Es ist ein Männchen. Länge: $55 \mathrm{~cm}$, Breite: $159 \mathrm{~cm}$, Fittich: $49 \mathrm{~cm}$, Gewicht: 1,740 kgr. Man vergleiche dazu das Gewicht einer viel gröfser scheinenden Larus marinus mit 1,488 und 1,265 kgr, oder eines Archibuteo lagopus mit 1,166 $1,115,1,090 \mathrm{kgr}, 998,913,896,884,821$ gr. Der Adler also viel schwerer. Magen und $\mathrm{Kropf}$ mit Fischfleisch angefüllt. Ho d e n stark entwickelt, wie Haselnüsse.

3. Mai: NW. und N., oft bedeckt. Ich bekomme einen Milvus milvus lebend, der in Pillkoppen im Krähennetz gefangen ist. Einige Raubvögel ziehen.

5. Mai: Eine Rohrweihe schon seit langer Zeit auf dem Bruche. Diese Art nicht nistend hier. verfolgt.

18. Mai: Dicht am Dorfe fliegt ein Seeadler, von Krähen

18. Juli: Gegen Abend einen Rotfufsfalken (Cerchneis vespertina juv.) beobachtet; am 24. A ugust einen solchen erlegt. Er hat im Schlunde einen eben verschlungenen kleinen Frosch, im Magen Überreste von Fröschen. Kurz darauf schiefse ich einen Totanus littoreus, der einen ebensolchen Frosch im Magen hat wie der Falke. Diese verschiedenen Vogelarten und doch dieselbe Nahrung, die jetzt in Fülle vorhanden ist!

10. September: Herr Möschler beobachtet 1 altes ơ vom Rotfufsfalken, ebenso 1 Jungen. Ferner meldet Herr von Tschirschky, dafs er am 10. September einen Rotfufsfalken, 
$\sigma^{\Upsilon}$ ad., bei Körnitz bei Trachenberg (Schlesien) geschossen habe. So zieht also dieser kleine Falke in diesem Herbste häufiger als in den vorhergehenden Jahren. Alte Stücke sind immer eine Seltenheit. Der Rotfufsfalke gehört zu den am zeitigsten ziehenden Raubvogelarten.

12. September: 1 Wanderfalke über Rossitten.

13. September: Jetzt schon öfter Sperber zu beobachten. Raubvogelzüge kommen also jetzt in Gang.

20. September: 5 Raubvögel, wohl Cerchneis vespertina, schrauben sich etwa $100 \mathrm{~m}$ hoch nach S.

9. November: SW. und W. 4. Fischerwirt Fröse in Pillkoppen fängt am Vormittag kurz hintereinander 2 Seeadler juv. im Kräbennetz. Den einen schlägt er leider tot, da er nichts bei sich hat, um den zweiten zu fesseln. Am nächsten Tage bringt er beide. Der tote klaftert: $2,15 \mathrm{~m}$. Den lebenden lasse ich mit Ring versehen fliegen. Über die Raubvögel- besonders Adlerzüge im Laufe des Oktobers siehe unter den zusammenhängenden Darstellungen von Ulmenhorst. In diesem Jahre guter Adlerzug.

17. November: Einige B u s sard e mit Krähen ziehend.

22. November: Einige Bussarde ziehend mit Krähen, ferner ein A d le r beobachtet.

27. November: Ein ziehender Adler beobachtet. Diese Adler sind ohne Zweifel fast durchgängig S e e a d le r.

28. November: Zwei Wa n de rfalke n mit Krähen ziehend. Der eine hat eine Krähe geschlagen.

A uswärtige Beobachtungen.

Bartenstein und Heilsberg: 28. März: 1 Buteo buteo zieht nach 0 .

31. März: In Heilsberg den ersten Turmfalken gesehen, war früher auf dem Schlosse Brutvogel, jetzt nicht mehr.

4. April: In Losgehnen mehrere Paare Turmfalken, ein Paar Buteo, 1 Sperber.

5. April: 1 Archibuteo lagopus gesehen, den letzten.

10. April: 1 Circus cyaneus $\sigma^{\top}$ ad.

19. April: Der erste Milvus korschun am See.

24. April: Am See 1 Circus aeruginosus.

8. M a i: Am See 1 Falco subbuteo.

16. Mai: Am See 2 Milvus korschun. Im Walde ein Paar Buteo buteo.

30. Mai: Am See 1 Circus 우 ad. (cyaneus oder pygargus).

2. Juli: Bei Heilsberg 1 Falco subbuteo.

6. Se ptem ber: Am See 1 Pandion haliaetus.

12. September: Buteo buteo einzeln in Losgehnen umherstreichend, desgleichen vielfach am 24. September.

30. September: 1 Accipiter nisus $\sigma^{\top}$ ad. wird in Losgehnen geschossen. 
17. Oktober: 2 Archibuteo lagopus bei Bartenstein beobachtet, die ersten. In diesem Winter nicht sonderlich häufig, trotz grolsen Mäusereichtums.

24. Oktober: Mehrfach Buteo buteo umherschwärmmend, 1 Circus $\sigma^{\top}$ ad. wohl cyaneus, 1 Accipiter nisus. geschossen.

1. November: 4 Archibuteo gleichzeitig in Losgehnen

7. November: 1 Circus spec. $\sigma^{\nearrow}$ ad. beobachtet.

14. November: 1 Circus spec., braun, geschossen.

Circus macrourus (Gm.) war im Herbst wieder einmal in der Provinz etwas häufiger. Präparator Schuchmann erhielt mehrere junge Stücke im August und September, und W. Christoleit erlegte 1 juv. im Oktober auf der frischen Nehrung.

Präparator Schuchmann erhielt ferner im Herbst 8 Pandion haliaetus; W. Techler in Szameitschen noch Ende November 1 Cerchneis merilla von Prasslauken (Kreis Gumbinnen). (T.).

Hela. Der Raubvogelzug über die Halbinsel war im Frühjahr nur unbedeutend, was wohl in der niedrigen Temperatur der Monate April und Mai und der in diesen Monaten vielfach stürmischen Witterung begründet war.

Es wurden beobachtet:

29. April SW. Vormittags 18 Sperber ziehend in 2 Stunden.

4. Mai NW. Einzelne Turmfalken auf dem Zuge nach 0.

5. u. 6. Mai N. Nur wenige Sperber ziehen.

11. Mai NO. 12. Mai SW. nur vereinzelt Sperber.

13. Mai WSW. Heftiger Wind. Der Wald steckt voll Sperber.

14. Mai SW. Ein Falco subbuteo $\&$ im Dünenwalde erlegt.

15. Mai SO. Sperber u. Turmfalken ziehen in kleiner Zahl.

22. Mai W. Nur wenige Sperber und sehr vereinzelte Turmfalken.

Von Mäusebussarden wurden auch nur einzelne Stücke beobachtet am 29. April bei SW. und am 12. Mai SW. (Z.).

15. Okt o ber: Raubvögel mit Krähen zusammen.

Am 10. November stellten sich im Fischhausener Stadtwalde die ersten Adler ein.

$\mathrm{R}$ a u b vögel in dieser Zugperiode nicht sehr zahlreich (U.).

Asio otus (L.) Waldohreule.

Am 23. 24. 25. Oktober sind diese Eulen auf dem Zuge bei Ulmenhorst anzutreffen.

Asio accipitrinus (Pall.) Sumpfohreule.

Bartenstein: 21. November: Am See ein einzelnes Stück beobachtet; sonst auf dem Herbstzuge nicht bemerkt. (T.).

Syrnium aluco (L.) Waldkauz.

Brütet in der Stadt Heilsberg. Wohl überall die häufigste Bruteule. (T.). 
Proebbernau (Frische Nehrung): 2. Ok tober: SO. Im Walde einen Waldkauz aufgescheucht. (Z.).

\section{Nyctea nyctea (L.) Schneeeule.}

Im November und Dezember wurden mehrere in der Provinz Ostpreufsen beobachtet und erlegt. (T.)

7. März: Ein Stück bei Kuggen erlegt.

Surnia ulula (L.) Sperbereule.

18. Oktober: Eine Sperbereule sitzt früh am hellen lichten Tage auf dem Schuldache von Rossitten. Fliegt von da auf das Kircbdach. Herr Präparator S chuchmann aus Königsberg meldet, dafs ihm eine Sperbereule etwa am 5. Oktober eingeliefert sei. So ist also diese hübsche Eule wieder einmal bei uns eingetroffen; bei weitem aber nicht in der Anzahl wie im Jahre 1906.

Auswärtige Beobachtungen.

Im Oktober mehrfach in der Provinz beobachtet. Präparator Schuchmann erhielt am 4. 10. 1 Stück von Memel und W. Techler Ende Oktober ein Stück von Nimmersatt (Kreis Memel). W. Christoleit erlegte im Oktober eine Sperbereule auf der frischen Nehrung bei Neukrug.

14. Oktober: bei Quanditten ein Stück erlegt.

Nyctala tengmalmi (Gm.) Rauhfufskauz.

W. Techler erhält Ende November 1 Stück von Nassawen (Rominter Heide). (T.)

\section{Glaucidium passerinum (L.) Sperlingskauz.}

Proebbernau (Frische Nehrung). Am 5. Oktober erhielt ich ein ausgestopftes Exemplar vom Forsaufseher Herrn Wieht-Vogelsang, der diese seltene kleine Eule im vorigen Jahre anfangs Oktober im Walde tot aufgefunden hat. Wabrscheinlich war der nahe Telegraphendraht dem Vogel verderblich geworden. (Z.)

\section{Strix flammea (L.) Schleiereule.}

Mitte Oktober 1 Stück von Friedlandshof (Kreis Friedland) erhalten. (T.)

\section{Cuculus canorus (L.) Kuckuck.}

19. Mai: Der erste wird bei Rossitten beobachtet.

9. Mai: Mehrere in Losgehnen gehört, die ersten. 10. Mai bei Kiwitten (Kreis Heilsberg) 1 Stück gehört.

25. Juli: Noch den Ruf in Losgehnen gehört. (T.)

Ceynova (Hela): 13. Mai. WSW. Zum ersten Male Kuckucksruf auf der Halbinsel gehört. (Z.)

Iynx torquilla (L.) Wendehals.

29. April: Der erste Wendehals wird bei Rossitten gesehen. 
A uswärtige Beobachtungen:

27. A pril: In Heilsberg den ersten gehört.

1. M a i: In Losgehnen gehört.

29. Mai: Ein Paar im Gutsgarten von Losgehnen in einem Nistkasten. (T.)

Dryocopus martius (L.) Schwarzspecht

8. Ma i: Im Kreise Friedland beobachtet. Ist in den dortigen Wäldern Brutvogel.

Dendrocopus major (L.) Grofser Buntspecht.

Wenn in manchen Jahren gewisse Vogelarten ganz besonders häufig hier auf der Nehrung durchwandern und dadurch den Zugperioden ein bestimmtes Gepräge geben, so waren es in diesem Jahre neben den Kreuzschnäbeln die grofsen Buntspechte, denen diese Rolle zufiel. In sehr grofser Anzahl traten diese Vögel an manchen Tagen hier auf. An jedem Baume safsen Spechte. Legte man gröfsere Strecken auf der Nehrung zurück, so merkte man, dafs die Häufigkeit nicht lokal beschränkt war, sondern sich über weite Gebiete hinzog, Vergegenwärtigt man sich weiter, dafs der Spechtzug wochen- ja monatelang anhielt, so kann man sich ein Bild davon machen, welch riesige Mengen der Vögel in diesem Jabre hier durchgewandert sind. Es sei an dieser Stelle an die gleiche Zugerscheinung vom Jahre 1903 erinnert. (cf. III. Jahresbericht der Vogelwarte Rossitten, J. f. O. Aprilheft 1904 und Orn. Monatsber. Nr. 11; 1903). Damals begann der Spechtzug in der ersten Hälfte des September und hörte Anfang Oktober auf. Er wurde damals auch auf den ostfriesischen Inseln beobachtet.

Im Jahre 1909 hielt er länger an; setzte in der zweiten Hälfte des August auf der Nehrung ein und war noch Ende Oktober zu beobachten. Wenn auch während dieser Zeit fast immer Spechte hier zu sehen waren, so mögen doch einige Tage genannt werden, an denen ich ein besonders häüfiges Auftreten notiert habe: z. B. 29. August; 12. September; 22. September.

Das Eintreten von Spechtzügen merkt man für gewöhnlich daran, dafs die Vögel zahlreich an den Bäumen umherklettern. In Ulmenhorst konnte ich aber auch das freie Ziehen in der Luft beobachten. In Höhe von etwa 20-25 m sah man die Spechte mit ihrem Bogenfluge schon von weitem über das kahle Dünengelände ankommen, aber nie in Gesellschaften, sondern immer einzeln.

Noch ein Merkmal für das Vorhandensein von Spechtzügen mufs genannt werden, dafs ist das Herumliegen von Überresten dieser Vögel, die von Raubvogelmahlzeiten herrühren. Ganz auffallend oft findet man solche Plätze, wo ein Specht geschlagen und gerupft worden ist. Andere Vögel treten in solchen Zeiten auf den Raubvogelspeisezetteln ganz in den Hintergrund. Woher kommt das? Wenn man Spechte in der Luft hat ziehen sehen, 
kann man sich's erklären. Der Sperber oder Falke wäre töricht, der sich an gewandte Drosseln oder Lerchen, die das Fliegen über freie Strecken gewöhnt sind, heranmachte, wenn daneben ein plumper Specht, dem es sonst nur darauf ankommt, kurze Strecken von einem Baum zum andern zu flattern, immer geradeaus ohne Seitenschwenkung durch die Luft schiefst.

Auch das auffallend bunte Kleid des Vogels spricht bei der Gelegenheit natürlich mit.

Bemerkt soll noch werden, dafs ebenso wie 1903 fast nur jun ge Vögel mit roter Kopfplatte zogen, selten einmal ein Alter.

A uswärtige Beobachtungen.

25. August: bei Bartenstein jetzt überall auffallend häufig, besonders zahlreich im Dezember und Oktober. So viele Buntspechte wie in diesem Jahre sind seit langem nicht $\mathrm{zu}$ beobachten gewesen. Nähren sich vorzugsweise von dem gut geratenen Nadelholzsamen. Auch im Winter noch häufiger als sonst.

Im Kreise Heilsberg gleichfalls im Herbst recht zahlreich.

Proebbernau: (Frische Nehrung). Am 1. Oktober und den folgenden Tagen grofse Buntspechte und Mittelspechte in verschiedenen Stücken in den Gärten im Dorfe angetroffen; sie suchten vornehmlich die Haselbüsche ab.

Auch Herr Ulmer meldet von Quanditten sehr starken Zug des grofsen Buntspechtes im Herbste.

Dendrocopus minor (L.) Kleinspecht.

Bartenstein: 28. März: Im Gutsgarten von Losgehnen ein $\mathcal{O}^{X}$, das den Paarungsruf hören lälst; bei Bartenstein selten!

Picus viridis L. Grünspecht.

8. M a i: bei Tingen (Kreis Friedland) beobachtet, ist daselbst einzelner Brutvogel. In Losgehnen neuerdings nicht selten. (T.)

Alcedo ispida L. Eisvogel.

Bartenstein: 4. April: 1 Stück gesehen.

23. Mai: An der Alle bei Heilsberg 1 Stück beobachtet.

29. Mai: Am See bei Bartenstein 1 Stück, doch nicht Brutvogel; gesehen am 6. 6 .

19. A ugust: An der Schleuse in Losgehnen 1 Eisvogel.

Von August bis November regelmäfsig in einzelnen Stücken am See und Flufs; zuletzt am 15. 11. beobachtet.

Coracias garrulus L. Blaurake.

6. Juni: Herr Möschler beobachtet eine Mandelkrähe bei Rossitten.

23. A u gu st: Zwei Mandelkrähen auf den Telegraphendrähten bei Rossitten. 
Opupa epops L. Wiedehopf.

20. Herr Möschler meldet, dafs er einen Wiedehopf bei Rossitten gesehen hat.

\section{Caprimulgus europaeus L. Ziegenmelker.}

Am 14. A ugust von Tischler in mehreren Exemplaren abends an den Bruchbergen bei Rossitten beobachtet. Ist also jetzt auf dem Zuge. Weitere Notizen über den Zug in der zusammenhängenden Darstellung der Beobachtungen von Ulmenhorst.

Cey nova (Hela): 24. Mai: SO. Bei Regenwetter und Wind traf ich einen Ziegenmelker auf der kahlen Vordüne an. (Z.).

\section{Apus apus (L.) Mauersegler.}

18. Mai: Den ersten bei Rossitten gesehen. Ist erst ganz vereinzelt hier.

Am 6. August machen noch ziemlich zahlreiche Mauersegler mit ihren Jungen Flugübungen hoch in der Luft.

Auch am 10. August.

Am 11. August sehe ich die Flüge von Apus apus nicht mehr. Die Mehrzahl der hier erbrüteten müssen also am Abend des 10., oder in der Nacht vom 10. zum 11. August abgezogen sein. Es herrschte W. 6. Überhaupt sind jetzt plötzlich weniger Schwalben geworden.

17. August. Turmschwalben jagen sich noch. Auch noch einige Junge.

18. August: Noch vereinzelt da.

21. August: Noch ganz vereinzelt da.

22. August: Ganz vereinzelt.

24. August: Nicht mehr gesehen.

26. August: Nicht mehr da.

Auswärtige Beobachtungen:

16. Mai: Die ersten Mauersegler in Losgehnen gesehen. Über dem See stellt sich vormittags plötzlich eine grofse Zahl ein.

17. Mai : Jetzt auch in Heilsberg zablreich.

4. Juli: Viele Hunderte über dem See bei Bartenstein.

20. A ugust: In Losgehnen sind nur noch einzelne zu sehen, die meisten sind schon fort.

25. August: Noch vereinzelte zu sehen.

In Cranz waren am 17. und 18. August Mauersegler noch zahlreich. (T.).

Ceynova (Hela): 15. Mai: SO. Die ersten beobachtet, nur vereinzelte.

17. Mai: Morgens NO. Der Wind ist nachmittags $1 / 24$ nach SO. umgesprungen, und ein Mauerseglerzug setzt alsbald ein, wie ich ihn noch nie zu beobachten Gelegenheit hatte. In eiligstem Fluge kamen die Vögel in Partien zu 10, 15, 20 Stück und mehr von 
NW. in einer Höhe von 10-15 m. daher, in Zwischenpausen von wenigen Minuten. Dieser so interessante Massenzug endete erst gegen $1 / 28$ abends. (Z.).

Dr. le Roi meldet Ankunft für Bonn vom 15. und 19. April. Nur vereinzelte.

\section{Hirundo rustica L. Rauchschwalbe.}

5. M a i: In grofser Zahl über dem Bruche bei Rossitten.

18. A u gust: Schwalben noch ziemlich zahlreich.

21. August: Schwalben immer noch ziemlich zahlreich.

23. August: S0.2, NW.5 W. 3. Um 10 vormittags plötzlicher Windumschlag. Viel weniger Schwalben heute. geworden.

24. August: NW. 2, NW.1, NW.1. Schwalben viel weniger

25. August: Schwalben nur noch ganz vereinzelt. Die Hauptmassen sind weg.

26. August: $0.3,0.3,0.2$. Heute wieder etwas mehr Schwalben wie gestern.

29. August: NW.4, W. 3, SW. 1. Heute noch Schwalben da.

31. August: S. 5, NW. 6, SW. 4, bedeckt. Gegen Abend grofse Ansammlungen von Schwalben über Ulmenhorst. (urbica und rustica). Jedenfalls ziehen sie allemal spät gegen Abend in der Dämmerung ab. Ich beobachte dieselbe Erscheinung am nächsten Tage auch über Rossitten.

7. September: S0. 4, SO.4, SO. 4. Schwalben überm Dorfe gegen Abend.

13. September: 0.3, N. 3, NO.5. Schwalben noch vereinzelt.

20. September: SW.2, W. 1, C. Bis 8 Vormittags Nebel, dann hell. Schwalben (rustica) ganz vereinzelt überm Dorfe.

A uswärtige Beobachtungen.

Bartenstein: 24. A pril: 8-10 Rauchschwalben, von W. kommend, tummelten sich über dem See.

25. April: Sehr viele über dem See.

1. M a i: Zahlreich über dem See mit Uferschwalben.

13. J u li: In Losgehnen fliegt eine gröfsenteils weifse Rauchschwalbe aus, dieselbe wird zuletzt am 24. Juli gesehen.

12. S e p te mber: Ein Paar füttert noch; die Jungen fliegen aus.

19. September: Abends am See in grofsen Scharen.

20. September: Viele am See.

Der Hauptabzug erfolgte in den Tagen vom 21.-24. Septbr. Am 26. Septbr. sind am See noch ziemlich viele zu sehen, am 27. Septbr. nur noch ganz vereinzelte. (T.)

Ceynova (Hela) 4. Ma i NW. Nur wenige.

11. Mai: NO. Ziemlich lebhafter Zug.

12. Mai: SW. Vereinzelte. 
15. Mai: SO. In kleinen Flügen ziehend.

17. Mai: nachmittags S.O. in grofser Zahl.

21. W. Sturm. In kleinen Flügen.

24. Mai : SO. Es ziehen noch immer einzelne Rauchschwalben.

Von Pössneck in Thüringen wird die erste "Schwalbe" vom 4. April gemeldet.

Dr. le R o i meldet Ankunft (rustica) für B on n vom 1. April. (Ein Exemplar).

Kiparia riparia (L.) Uferschwalbe.

21. A u gust: Schwalben noch ziemlich zahlreich, darunter auch Uferschwalben bei Rossitten.

22. August: SO. 4., hell Sonnenschein.

Auf dem Rofsgartenzaun an der Vogelwarte grofse Schwärme von Uferschwalben; nach Hunderten zählend, vielleicht nach Tausenden. Sie schwärmen oft in der Luft umher. Machen Flugübungen zum Abzuge. Soviel habe ich noch nie zusammen gesehen.

23. August: S.0. 2; N.W. 5; W. 3 . Um 10 Vormittags plötzlich Windumschlag.

Die grofsen Flüge der gestrigen Schwalben sind fort. Überhaupt weniger Schwalben heute.

27. August: N.W. 3. Gewitter. Heute wieder viel Uferschwalben auf den Telegraphendrähten.

28. August: N.W. 5. meist bedeckt. Die Uferschwalben von gestern sind weg.

A uswärtige Beobachtungen.

Bartenstein. 1. Mai: Die ersten am See gesehen.

20. September: Unter vielen rustica und einigen urbica keine mehr gesehen. (T.)

\section{Delichon urbica (L.) Mehlschwalbe.}

5. Mai: N.O. 4 ; N. 8 ; N. 5; Die ersten über dem Bruche bei Rossitten beobachtet.

18. August: Schwalben noch ziemlich zahlreich.

21. August: Schwalben immer noch ziemlich zahlreich, auch Uferschwalben, meist urbica.

23. August: S.O. 2; N.W. 5; W. 3; Um 10 vormittags plötzlicher Windumschlag. Viel weniger Schwalben heute.

24. August: N.W. 2 ; N.W. 1; N.W. 1; Schwalben viel weniger geworden.

25. August: N.W. 2 ; 0. 3 ; 0. 4 ; Schwalben nur noch ganz vereinzelt. Die Hauptmassen sind weg.

26. August: 0. $3 ; 0.3 ; 0.2$; Schwalben wieder etwas mehr wie gestern. Hauptsächlich urbica.

29. August: N.W. 4; W. 3; S.W. 1; Heute noch Schwalben da, namentlich urbica, aber nicht viel. 
7. September: S.0. 4; S.0. 4; S.0. 4; Schwalben überm Dorfe gegen Abend. einzelt.

13. September: 0. 3 ; N. 3 ; N.0. 5 ; Schwalben noch ver-

Auswärtige Beobachtungen:

Bartenstein: 25. A pril: Unter sehr vielen Rauchschwalben über dem See eine einzelne Mehlschwalbe.

3. M a i: Vielfach zu beobachten.

20. A pril: Unter vielen rustica am See noch einige Hausschwalben. (T.).

Cey nova (Hela): 15. Ma i: SO. In kleineren Flügen.

17. Mai: Morgens NO., nachmittags SO. Im Mauerseglerzuge in ziemlicher Menge mitziehend.

21. Mai: W. Sturm. Kleine Flüge.

22. Mai: W. Nachmittags 0 . Die Vögel ziehen einzeln und in kleineren Partien. (Z.).

\section{Bombycilla garrula (L.) Seidenschwanz.}

21. N ovem ber: Heute meldet Herr Möschler, dafs er die ersten Seidenschwänze bei Rossitten gesehen hat, etwa 20-30 Stück.

Am 24. D e z e m b er fliegen 3 Seidenschwänze über den Hof. Sonst wenig von diesen nordischen Vögeln gesehen.

A uswärtige Beobachtungen.

Heilsberg: 15. März: Ein Flug von 12 Seidenschwänzen in der Stadt auf Weifsdorn.

24. März: Ein Flug im bischöflichen Garten auf Misteln.

Im Herbst und Winter 1909/10 trotz vieler Beeren nicht beobachtet. (T.).

Von Danzig-Langfuhr werden Seidenschwänze vom 23. Februar gemeldet. 30 Stück.

Muscicapa grisola L. Grauer Fliegenschnäpper.

13. M a i: In Heilsberg die ersten gehört.

29. August: In Losgehnen viele auf dem Zuge.

Muscicapa atricapilla L. Trauerfliegenschnäpper.

22. A p ril: Der erste wird bei Rossitten beobachtet.

Auswärtige Beobachtungen.

26. A pril: Im Kreise Heilsberg 8-10 Trauerfliegenfänger.

8. M a i: In Gallingen singt 1 Stück.

9. Mai: Im Gutsgarten von Losgehnen ein Paar, das sich in einem Nistkasten ansiedelt.

11. Mai: In Heilsberg, namentlich in den Anlagen am Schlofs, nistet der Trauerfliegenfänger ziemlich zahlreich. 
23. Mai: In der Wiechertshofer Forst bei Heilsberg zahlreicher Brutvogel.

28. Mai: Bei Gallingen mehrfach gehört. In Losgehnen häufiger wie in früheren Jahren.

29. A u gust: In Losgehnen einzelne auf dem Zuge. (T.)

Cey nova: 30. A pril SO. Einige am Dünen-Etablissement.

16. Ma i: NO. Mehrfach $\sigma^{\top}$ und $Q$ am Waldrande.

19. Mai: SW. Sturm. Einzelne im Walde Schutz suchend.

12. Juli: Trauerfliegenfänger füttert Junge in einem Nistkasten bei Quanditten. Vor Anbringen der Nistkästen gab es dort diese Art nicht als Brutvogel.

Muscicapa parva Bechst. Zwergfliegenschnäpper.

17. Ma i: Im Walde zwischen Gallingen und Tingen (Kreis Friedland) singt ein $\sigma^{x}$, desgleichen am 19. Juli.

23. Mai: In den Wiechertshofer Forst bei Heilsberg $1 \sigma^{x}$, eifrig singend, auf Fichten und Eichen. (T.)

Lanius excubitor L. Raubwürger.

Lanius collurio L. Rotrückiger Würger.

14. Januar: Ein Raubwürger treibt sich auf den Feldern bei Rossitten umher. Fängt Mäuse.

14. J u li: In einem Neste von Lanius collurio flügge Junge, die aus dem Neste springen.

Auswärtige Beobachtungen.

Lanius excubitor $\mathrm{L}$.

B artenstein: 29. März: 1 Stück gesehen, desgleichen am 11. April und am 19. April.

8. November: Im Herbst den den ersten beobachtet. Nicht zahlreich trotz vieler Mäuse.

15. November: Wieder 1 Stück gesehen, desgleichen am 21. November. (T.)

Corvus corax L. Kolkrabe.

Herr von Streng Bergh off, Jucha Ostpreufsen schreibt mir, dafs am 2. April dort ein Stück im Eisen gefangen worden ist.

Corvus cornix L. Nebelkrähe.

Corvus trugilegus L. Saatkrähe.

Colaeus monedula (L.) Dohle.

Das war ein harter Winter, der Winter 1908/09, besonders ausgezeichnet durch eine lange, ununterbrochene Frostperiode, die die Temperatur nie über den Gefrierpunkt kommen liefs. Vom 10. Januar ab ist die Reihe von Frosttagen bis gegen Ende März nicht unterbrochen worden. Das ergibt eine Serie von etwa 70 Frosttagen. Von 1848 an ist eine über 50 Tage hinausgehende Journ. f. Orn. LVIII. Jahrg. Juli 1910. 
Reihe uur achtmal anzutreffen. Am 11. Februar 1909 zeigte das Thermometer $-29,4^{\circ}$ bei N.O. Dabei war immer eine Schneedecke, manchmal sogar eine sehr hohe, zu verzeichnen. Manche Tiere, z. B. unsere Wildarten, haben furchtbar gelitten. Die armen Hasen magerten zum Skelett $a b$ und gingen massenhaft ein. Sie drangen bis mitten in die Dörfer vor, um irgend etwas Geniefsbares zu finden. Den Obstbäumen ist es schlecht ergangen. Ganz dicke Stämme wurden angenommen.

Besonders viel nordische gefiederte Gäste hat der Winter trotzdem nicht gebracht. Was sollten die schliefslich auch hier, wo alles in Schnee und Eis lag? In der Natur draufsen grofse Ruhe. Bergfinken, Raubfufsbussarde fehlten.

15. Januar: 0. 1; S.0. 4; S.0. 6 ; bedeckt, aber sonst trockenes Wetter. Es findet noch regelrechter Krähenzug nach $\mathrm{S}$ ü den zu statt; truppweise in grofsen Abständen, 30-80 m hoch, besonders am Vormittag. Auch Drosseln ziehen nach S. merken.

Am 28. Februar noch nichts von Vogelzug nach N. zu

Am 1. März, 0. 5; S.W. 5; S.W. 5; ziehen die ersten 10 Dohlen über das Vogelwartengebäude nach Norden.

7. März: noch tiefer Winter. Alles in Schnee und Eis. W. 3 ; W. 2 ; S.W. 1 .

Einige Dohlen ziehen nach $\mathrm{N}$.

12. März: Eis auf dem Haff noch über einen halben Meter dick. Nichts von Zugvögeln zu merken. Ein paar Krähen treiben sich umber.

16. März: 0. 5: 0. 6; einige Dohlen ziehen nach N.; auch die ersten Nebelkrähen.

17. März: S.W. 8 ; S.W. 5 ; S. 3 ; furchtbares Schneetreiben, Schnee liegt hoch. Dohlen ziehen wieder nach S., auch Krähen. Die ersten $\boldsymbol{C}$. frugilegus auf dem Zuge beobachtet.

18. März: S.W. 2; S.W. 3; S.W. 1; Sonnenschein. Etwas Zug. Dohlen und Krähen mehrere $100 \mathrm{~m}$ hoch nach N. (Hier schliefst sich der Bericht über den ersten Aufenhalt in Ulmenhorst vom 23. März an. Ebenso ist Näheres über den Herbst krähenzug aus dem Ulmenhorst-Berichte zu ersehen.)

3. Mai: N.W. 1; N. 3; N.W. 4; schwacher Krähenzug.

5. Mai: Vegetation noch sehr weit zurück. Wiesen und Saaten zeigen nur einen schwachen grünen Schimmer. Spätes Frühjahr! Eine C. cornix vom Nest geschossen.

9. November: S.W. 1; W. 4; S.W. 7; früh Eis gefroren. Corvus cornix ziehen bis nachmittags.

13. November: Heute und an den vorhergehenden Tagen Stürme mit Regen und Graupeln; gegen Abend und in der Nacht ein furchtbares Wetter. Sturm wie selten. Am 14. November früh auch noch Sturm, aber helles Wetter. Gegen Mittag legt sich der Sturm. Das Barometer ist mit grofsem Ruck plötzlich gestiegen. Sofort starker Krähenzug. 
15. November: leichter Frost, hell, Sonnenschein. S. 4; SO. 2; 0. 4; Etwas Krähenzug. Auch an den nächsten Tagen, sobald es hell und nicht zu windig ist, etwas Krähenzug.

17. November: N.0. 8; N.0. 9; N.0. 9; Einige Schwärme ziehender Krähen. In Pillkoppen soll ein Mann 70 Krähen gefangen haben.

18. November: N.0. 9; N.0. 8; N.0. 8; ein Schwarm ziehender Krähen Vormittag; auch am 19. November, N.0. 5; N.W.5; W. 5; nur ein Schwarm. Jetzt immer am Seestrande ziehend.

20. November, N.W. 8; N.W. 7; W. 2; Krähen vor- auch nachmittags; jetzt immer schwarmweise mit grofsen Unterbrechungen ziehend.

21. November: S. 4 ; S.0. 1 ; N.0. 8 ; nur einige Schwärme ziehender Krähen gesehen.

22. November: N. 8; N. 6; N. 5; einige Krähenschwärme.

23. November: N.0. 3; N.0. 3; S.O. 2; Mittags hell, Sonnenschein. Krähen sehr hoch ziehend.

24. November: S.W. 4; S.W. 7; S.0. 3; etwas Schneefall. Ungefähr 20 Krähen gesehen von Falk. So läfst der Krähenzug jetzt immer mehr nach.

26. November: S.W. 1; S.W. 7; N. 9; 1 Krähenschwarm sehr hoch ziehend.

27. November: N. 8, NO.4, NO.1. Wenig Krähen sehr hoch ziehend.

28. November: SW. 2, S. 4, 0.4, früh etwas Schneefall. Starker Kräbenzug da der Wind nachgelassen. Ich sehe die Krähen bei dem Schneewetter sogar vom Fenster aus immer nach S. ziehen, ganz niedrig, teilweise nur einige Meter hoch.

29. November: NO.5, N0.4, N0.4. 1 Schwarm Krähen ziehend.

17. D e z e mb er: S. 3, S. 3, S. 3, hell. Herr Möschler meldet dafs den ganzen Tag über Krähen in gröfseren Trupps gezogen sind.

24. Dezember: SW.3, SW.2, SW. 3. Etwas Krähenzug.

Auswärtige Beobachtungen.

Bartenstei n: Im Winter 1908/09 Saatkrähen sehr spärlich. 1 Stück am 28. Februar. Erst von Mitte März an werden Saatkrähen etwas häufiger.

22. März: Schwärme von Saatkrähen und Dohlen streichen umher.

25. März: In Losgehnen ziehen vormittags sehr viele Saatkrähen, in gröfseren und kleineren Scharen, auch einzeln, nach SO.

28. März: (Wetter bei Alauda).

Unmengen von Saatkrähen ziehen, meist sehr hoch, nach SO., darunter auch Dohlen und vielfach Nebelkrähen.

29. März: Nur wenig Nebelkrähen und Dohlen ziehen noch.

18. A pril: Eirige Saatkrähen ziehen. Dohlen nisten in sehr grofser Zahl auf Kirche und Schlofs in Heilsberg, einzeln in alten 
Linden bei Tingen (Kreis Friedland). 1 o vom 7. Juni aus Heilsberg zeigt fast gar keinen Halsfleck und ziemlich dunkle Unterseite.

19. September: Saatkrähen bei Bartenstein in grofsen Scharen umherstreichend, desgleichen am 20. September.

17. $0 \mathrm{k}$ t o b e r: Schwärme von trugilegus und einigen monedula streichen umher.

23. Oktober: Grofser Scharen von Saatkrähen und Dohlen auf den Feldern.

24. Oktober: Wenig cornix ziehen.

15. November: Grofse Dohlenschwärme streichen umher, wie überhaupt in diesem Winter. Auch Saatkrähen sind vielfach zu sehen.

22. November: 3 Dohlen geschossen, von denen die eine deutlichen Halsring, die zweite einen angedeuteten, die dritte fast gar keinen besitzt.

24. November: 4 Dohlen geschossen, alle mit deutlichem Halsring.

13. D e z e m b er: 1 trugilegus juv. geschossen. Überwintert in diesem Jahre nicht selten. (T.)

Ceynova (Hela): 28. A pril W. Sturm. Einige Nebelkrähen ziehen gegen Wind - rückwärts. 29. April SW. Schwacher Zug. 3. Mai WNW. Wenige auf dem Zuge. 5. Mai NW. Kleine Flüge; ebenso den 6. un 1 . Mai. 8. Mai 2 Paare bauen Horste im Dünenwalde. 9. Mai NO. Schwacher Zug.

21. Mai Sturm aus W. Ein kleiner Flug - 8 Stück Dohlen zieht gegen den Wind - rückwärts.

Proebbernau (Frische Nehrung) 29. September: SW. Krähen ziehen in kleinen Flügen. 3 . 0 k t ober WSW. Lebhafter Zug in Flügen bis zu 50 Stück. 4. Oktober S. Kleine Flüge ziehen über dem Walde. (Z).

27.-29. März starker Krähenzug bei Quanditten.

Seit Mitte September Krähenzug ebenda.

15. $0 \mathrm{k}$ t $\mathrm{o}$ be $\mathrm{r}$ Krähenzug. (U.)

Pica pica (L.) Elster.

Bartenstein: 17. Okt ober: Am See 3 Stück beobachtet. Bei Bartenstein selten. (T.)

Ceynova (Hela): 29. A pril SW. Das erste in 4 Jahren beobachtete Stück auf der Halbinsel.

Proebbernau (Frische Nehrung): 3. Oktober WSW. Ein Paar im Walde am Dorfe. (Z.)

\section{Garrulus glandarius (L) Eichelheher.} 6 Stück.

Bartenstein: 19. April: Im Gutsgarten von Losgehnen

27. S e pte m b er: Zahlreich jetzt zu beobachten. Überhaupt während des Herbstes und auch im Winter noch häufig. (T.) 
Ceynova (Hela): 5. Mai NW. Zwei Vögel dieser Art ziehen nach 0 .

Proebbernau (Frische Nehrung): Mehrere Exemplare; wie es scheint sind die Vögel auf dem Zuge. (Z.)

Am 8. November und Ende November sehr viel Eichelhäher bei Quanditten auf dem Zuge. (U.)

\section{Oriolus oriolus (L.) Pirol.}

31. Ma i: W. 2, W. 5, W. 1. Herr Möschler sieht den ersten bei Rossitten.

Bartenstein: 16. Mai: Mehrere in Losgehnen gehört, die ersten.

23. Mai: In der Wiechertshofer Forst bei Heilsberg nicht selten. (T.)

Ceynova (Hela): 13. Mai WSW. Ein schönes $\sigma^{7}$ im Walde bei dem Dorfe beobachtet.

\section{Sturnus vulgaris L. Star.}

19. März: Der erste Star am Dorfe. Nur ein einzelnes Stück. Noch tiefer Winter.

21. Dezember: Gestern und heute sehe ich 4 Stare bei Rossitten. Scheinen ganz munter.

Auswärtige Beobachtungen.

Bartenstein: 18. März: In Losgehnen wird der erste Star gesehen. Auffällig spät! In den folgenden Tagen sind dann wieder keine zu sehen, erst am 25. März zeigt sich eine ganze Anzahl.

28. März: Stare sind jetzt ziemlich zahlreich.

30. März: Abends viele am See.

31. März: Tausende am Gutshause von Losgehnen.

12. A pril: Kleine Flüge übernachten im Walde auf Fichten. Massenansammlungen zur Brutzeit finden in diesem Jahre nicht statt.

9. Juni: In Heilsberg die ersten ausgeflogenen Jungen.

12. Juni: In Losgehnen sind die jungen Stare durchweg ausgeflogen.

22. August: Die Alten singen wieder an den Nestern.

29. August: 1 juv. geschossen: Kopf und Rücken noch braun.

19. Septem ber: Abends am See grofse Scharen.

27. September: Grofse Flüge auf den Feldern.

17. Oktober: Grofse Flüge treiben sich umher.

18. Oktober: Viele Stare morgens an und auf dem Hause, also wohl noch Brutvögel.

24. Oktober: Am Hause noch einige; die meisten sind fort.

31. Oktober: Abends ein Flug von etwa 30 Stück am See.

7. November: Noch einen einzelnen beobachtet.

Mitte Dezember hielten sich nach W. Techler noch 3 Stare in Gertschen (Kreis Gumbinnen) auf. (T.) 
Proebbernau (Frische Nehrung): 2. Oktober SO. Auf den Ebereschen im Dorfe in kleinen Schwärmen.

3. Oktober WSW. Grofse Scharen auf dem Zuge.

4. Oktober S. Lebhafter Zug nach W.

26. M ärz: Stare bei Quanditten. (U.)

\section{Pastor roseus (L.) Rosenstar.}

2. Juni: Ein Rosenstar setzt sich dicht an dem Vogelwartengebäude auf einen Gartenpfahl und singt. Er wird vom Museumsdiener auf 15 Schritt beobachtet. Eine Täuschung ist ausgeschlossen. Als mir der Fall gemeldet wird, gehe ich sofort selbst auf die Suche, finde den Vogel aber nicht mehr.

\section{Passer domesticus (L.) Haussperling.} Rossitten.

11. Juni: Die ersten ausgeflogenen jungen Sperlinge in

Im Oktober und in der Folgezeit zeigt sich in Heilsberg ein $\$$ mit teilweise weifsen Armschwingen und Schwanzfederu. Ein ähnliches Stück wurde auch in Losgehnen im Oktober gesehen.

Passer montanus L. Feldsperling.

Proebbernau (Frische Nehrung): 30. September und in den folgenden Tagen mehrfach im Dorfe beobachtet.

Coccothraustes coccothraustes (L.) Kernbeifser.

23. Ma i: In der Wiechertshofer Forst bei Heilsberg einzelne beobachtet.

23. August: Vielfach in. Gutsgarten von Losgehnen. (T.)

Fringilla coelebs L. Buchfink.

Fringilla montifringilla L. Bergfink.

13. Februar: Buchfinken am Futterplatz bei Rossitten. Auch vereinzelt einmal 1 Bergfink. Von letzteren sehr wenig da.

7. März: Noch tiefer Winter. Die nordischen Buchfinken noch immer am Futterplatze. Am 31. März ersten Buchfinkenschlag gehört.

12. August: NW.6, W. 6, SW. 3. Frinyilla coelebs schon seit einiger Zeit auf dem Zuge.

16. August: NW.5, W.5, W. 3. Viel Buchfinken im Walde auf dem Zuge.

17. 0 ktober: SW. 4, S. 5 ; S. 4, meist bedeckt. Finken und andere Zugvögel rastend.

30. Dezember: Im Garten sind etwa 10 Fringilla coelebs. eingetroffen, mit einigen Bergfinken vermischt. Das sind nordische Ich habe solche nordische Buchfinken gefangen und im Käfig gehalten, um ihren Gesang kennen zu lernen. Es folgte eine grofse Enttäuschung. Alle sind Stümper im Gesange. Der 
Schlag wird nie zu Ende geführt. Gerade die charakteristischen Endsilben, wonach der Schlag benannt wird, fehlen oder sind ganz verkümmert.

31. Dezember: Die gestrigen Finken sind noch da.

A uswärtige Beobachtungen.

Barteustein: 1. Januar: 10-12 Buchfinken und 1 Bergfink in Losgehnen beobachtet. Buchfinken überwintern 1908/09 auffallend zahlreich; auch Bergfinken sind im Winter öfters zu sehen.

24. Januar: 15-20 Buchfinken, wohl alles $\sigma^{7} \sigma^{x}$, und 2 Bergfinken; von letzteren $1 \sigma^{\top}$ geschossen.

15. Februar: In Heilsberg 1 coelebs

28. Februar: Ein Flug von etwa 20 coelebs in Losgehnen, auch alles Wintervögel. Auf dem Fasanenfutterplatz etwa 10 montifringilla. 1 coelebs $\sigma^{\top}$ tot aufgefunden.

29. M ärz: Nachts Frost, SO., am Tage meist heiter. Vielfach ziehen Buch- und Bergfinken, dieselben fallen aber auch schon morgens auf Bäumen ein.

30. März: In Heilsberg singen viele Buchfinken.

4. A pril: Nachts Frost, kühl; lebhafter SW.; böig. Einige Buch- und Bergfinken ziehen in Losgehnen.

5. April: Nachts $-3^{0}$, heiter; kalter W., $780 \mathrm{~mm}$. Einige Buchfinken ziehen.

9. April: Flüge von Buchfinken auf den Feldern, desgleichen am 10. April solche von Buch- und Bergfinken.

17. April: Bei Dietrichswalde ein Flug Buchfinken, meist 우, aber auch einige $\sigma^{\top} \sigma^{x}$.

18. April: Heiter, $+10^{\circ}$, mittags S., gegen Abend SW. Etwas Zug von coelebs und montifringilla, Anthus pratensis und Corvus cornix.

19. April: SO., $+9^{0}$; nachmittags Regen. Wenig coelebs und montitringilla, Anthus pratensis und trivialis ziehen.

24. April: Finkenflüge auf den Feldern. ziehen.

25. April : $+13^{\circ}, 0$. heiter. Einige coelebs und montitringilla

6. Se p te m ber : Bei Tingen viel coelebs auf Stoppelfeldern

12. September: Heiter, warm, N. Vielfach ziehen coelebs Anthus pratensis und einzelne trivialis; ziemlich hoch.

19. September: $+20^{\circ}$ R., O., heiter. Coelebs, Anthus pratensis, Alauda vielfach ziehend. Viele Finken noch auf den Feldern.

20. September: Bedeckt, W., warm. Es ziehen einzelne coelebs, Anthus pratensis und trivialis, Alauda arvensis.

26. September: Klar, warm, still. Guter Zug von coelebs und Anthus pratensis (hoch), ferner von Alauda arvensis. Mehr einzeln ziehen montitringilla, die ersten, Anthus trivialis, Lullula arborea, einmal Acanthis cannabina.

27. September: Morgens starker Nebel, S., etwas kühler; am Tage bedeckt, wiederholt Regen. 
Nach dem Fallen des Nebels vormittags guter Zug von coelebs und Anthus pratensis, vielfach trivialis, montifringilla, Alauda, einmal Lullula.

Mittags Finkenflüge auf den Feldern.

3. O ktober: Klar, warm, still. Bei Heilsberg ziehen coelebs, montifringilla, Alauda.

9. Oktober: Bedeckt, warm, still. Bei Mengen und Tingen Flüge von coelebs auf Stoppelfeldern.

10. Oktober: Trübe, morgens neblig, warm, still. Wenig Zug von coelebs, montifringilla, Alauda, Lullula. Nachmittags auf einem Stoppelfeld grofser Flug von coelebs und montifringilla.

11. Oktober: Morgens dichter Nebel, still, $+7^{0}$; um 11 Uhr klärt es sich auf.

Als es etwas heller wird, ganz schwacher Zug von coelebs montifringilla, Alauda.

Um $11^{1 / 2}$ bei Dietrichswalde und Gallingen grofse Flüge von coelebs und montitringilla auf Stoppelfeldern.

16. Oktober: Heiter, warm, SO. Abends viele coelebs und montifringilla auf Stoppelfeldern.

17. Oktober: Heiter, warm, SO. Mäfsiger Zug von coelebs, montifringilla, Alauda, Anthus pratensis.

18. Oktober: S., heiter, warm. Mäfsiger Zug von coelebs, montitringilla, Alauda, Lullula, Anthus pratensis.

23. Oktober: Etwas kühler, heiter, SW. coelebs-Flüge abends auf Stoppelfeldern.

24. Oktober: Heiter, lebhafter SO. Schwacher Zug von montifringilla und Alauda.

31. Oktober: Kühl, lebhafter SO. Nur noch ganz vereinzelte coelebs ziehen.

1. Nove m b er: Warm, heiter, still. Ganz vereinzelte coelebs, Anthus pratensis, Alauda und cannabina ziehen noch.

7. November: Bedeckt, milde, S. Ganz vereinzelte coelebs ziehen noch, öfters cannabina und chloris.

8. November: $+5^{\circ}$, bedeckt, $S$. Noch immer einzelne ziehende coelebs, öfters cannabina und chloris.

14. November: Schneetreiben, $-2^{0}$; nachmittags klar, stiller. Noch einzelne coelebs, 1 Alauda, Lullula, wiederholt cannabina. 15. November: Morgens $-6^{0}$, klar, leichter 0 ; am Tage bedeckt. Einzelne coelebs, 1 Alauda, wiederholt cannabina.

Im Winter 1909/10 Buchfinken öfters gesehen, doch nicht so zahlreich wie im Jahre zuvor. Am 28. November in Losgehnen 1ㅇ. (T.)

Wie der Raubvogelzug, so war auch der Frühjahrzug der Buchfinken infolge der kalten und oft stürmischen Witterung bei Ceynova (Hela) nur gering. Beobachtet wurden: 28. April W. Einige $\sigma^{\top} \sigma^{\top}$ und $Q Q$ auf den noch nicht bestellten Kartoffeläckern. 10. MaiNO. Wenige auf dem Zuge. 13. Mai SSW. Buchfinken ơ $0^{\Upsilon}$ und 우오 in grölserer Zahl fallen bei heftigem Winde aus 0 . kommend auf den Kartoffeläckern ein. - Pröbbernau (Frisch. Nehrung). 
30. September SW. kleine Flüge auf den Äckern; 3. Oktober WSW. lebhafter Zug. (Z.)

Der K leinvogelzug hört mit dem ersten Schnee bei Quanditten ziemlich auf. (U.)

Vom 15. N ovem ber meldet Herr Revierförster W. Wies e von A ugusten h of bei B ergen auf Rügen sehr starke Züge von Buch - und Bergfinken.

\section{Chloris chloris (L.) Grünling.}

Bei dem strengen Winter 1908/09 in Rossitten oft zahlreich am Futterplatze.

B a r t e $n$ s t e in: Im Winter 1908/09 recht zahlreich, 1909/10 nur spärlich, dabei ist ersterer sehr schneereich und streng, letzterer schneearm und mild. sehr zu.

Von Mitte März an nimmt die Zahl durch die Zurückkehr

Herbstzug cf. Fringilla coelebs.

\section{Acanthis cannabina (L.) Bluthänfling.}

Bartenstein: 14. Februar: 1 Hänfling unter Buchfinken und Grünlingen.

28. Februar: Mehrere Stücke, sicher noch Wintervögel, unter Buchfinken.

Erst von Mitte März an beginnen Häntlinge häufiger zu werden, am 21. März ist schon eine deutliche Zunahme zu bemerken.

28. M ärz: Hänflinge ziehen vielfach nach 0 , desgleichen am 29. März.

Herbstzug cf. Fringilla coelebs.

21. N o vem b er: Wiederholt Flüge umherstreifend.

28. November: bei hohem Schnee ein Flug auf dem Gutshof von Losgehnen. (T.)

\section{Acanthis linaria (L.) Birkenzeisig.}

Chrysomitris spinus (L.) Erlenzeisig.

11. J a nuar: Ein Schwarm Erlenzeisige im Walde, sonst tot draufsen; ebenso am 15. Januar. Ich vermisse Birke nzei i ige, zumal, wie die Notizen aus Ulmenhorst sagen, im Herbst so sehr viel nach Süden gezogen sind.

8. J u li: Früh ein Erlenzeisig $\sigma^{x}$ im Garten auf den Fichten. Ohne Zweifel Brutvogel hier in Rossitten. Das geht auch daraus hervor, dafs man die Vögel in der Folgezeit häufig zu Gesicht bekommt.

A uswärtige B e obachtungen:

Acanthis linaria (L.) Birkenzeisig.

B artenst ein: Im Winter 1908/09 äufserst spärlich. 10. A pril: Die letzten in Losgehnen beobachtet.

Im Herbst und Winter 1909/10 garnicht beobachtet. 


\section{Chrysomitris spinus (L.) Erlenzeisig.}

B artenstein: 28. Mär z: Frlenzeisige überall in Massen. Heilsberg: 29. Mai: In der Wiechertshofer Forst bei Heilsberg mehrfach gesehen.

Fischhausen: 19. Juni: In Fischhausen mehrmals gehört.

B arten stein: 20. A u gu st: In Losgehnen einige beobachtet. Brutvögel.

24. August: Ebendaselbst Flüge von 10-12 Stück, sicher

Cranz: Bei Cranz waren Erlenzeisige im August vielfach zu beobachten, jedenfalls nisten sie in den Wäldern auf dem südlichen Teile der Nehrung. beobachten.

B artenstein: 27. September: In Losgehnen vielfach zu

31. Oktober: Jetzt recht zalhreich, wie überhaupt im Winter $1909 / 10$.

25. Dezember: Grofse Schwärme beobachtet, desgleichen am 26. Dezember. (T.)

11. März: Erlenzeisige bei Quanditten.

Carduelis carduelis (L.) Stieglitz.

Bartenstein: 10. Oktober: In einem grofsen Finkenschwarm nach einige Stieglitze.

18. Oktober: Mehrfach auf dem Zuge.

5. Dezem ber: Einige beobachtet. 2 erlegte gehören nicht zu maior Tasz. (T.)

Carpodacus erythrinus (Pall.) Karmingimpel.

23. Mai: Den ersten Carpodacus $\left(\sigma^{\top}\right)$ gesehen. Soll schon am 19. beobachtet worden sein, was sehr wahrscheinlich ist.

10. Juni: Bei Kunzen, wo der Vogel früher so häufig war, nur ein graues, singendes $\sigma^{x}$ beobachtet. Das Ausholzen der Büsche hat die Art sehr dezimiert. Im Dorfe singt der Carpodacus fast ununterbrochen.

19. Juni: Bei einer Tour nach den Anlandungen des Königsberger Seekanales ein Nest vom Karmingimpel gefunden, das vollständig fertig, aber noch unbelegt ist. Beide Alte waren daneben. Der Standort war in einem Erlengebüsch bei Peyse am frischen Haff.

Am 19. Juli sind die Jungen des betreffenden Nestes flügge. Einer noch im Neste, einer daneben.

5. August: In diesen Tagen sehe ich öfter junge ausgeflogene Karmingimpel bei Rossitten.

Es war hier in Rossitten ein Karmingimpelpärchen ansässig, das seinen Nistplatz stets in der Nähe eines Waldteiches hatte. Es ist dasselbe Pärchen, das im VI. Jahresberichte p. 518 unterm 5. Juli erwähnt wird. Das Nest stand meist sehr offensichtig und wurde leicht gefunden. In diesem Jahre konnte es trotz eifrigen Suchens von seiten des Herrn Präparator Möschler nicht entdeckt werden. Nachdem die Ringversuche nunmehr verschiedene 
untrügliche Beispiele gebracht haben, dafs auch Kleinvögel den alten Nistplatz immer wieder aufsuchen, darf angenommen werden, dafs dieses Pärchen zu Grunde gegangen ist. Das sind Lücken, die die gefährlichen weiten Wanderungen in den Vogelbestand reifsen.

Auswärtige Beobachtungen:

2. Juli: Im Sinsertal bei Heilsberg ruft $1 \sigma^{x}$ im Weidengebüsch. (T.)

\section{Pyrrhula pyrrhula (L.) Grofser Gimpel.}

Im Winter nicht häufig. Am 31. Dezember bei Kunzen

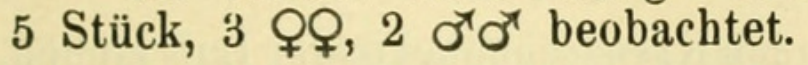

Auswärtige Beobachtungen.

B artenstein: Im Winter 1908/09 nur recht spärlich, dagegen 1909/10 ziemlich häufig.

18. April: Ein Paar noch im Gutsgarten von Losgehnen, verweilt dort bis 24 . Mai; dann verschwunden, hat aber wohl in der Nähe gebrütet, da im August sich wieder eine Familie zeigt.

9. Mai: In Lohsgehnen im Walde Gimpel gehört.

10. Mai : Im Dietrichswalde mehrere.

23. Mai: In der Wiechertshofer Forst bei Heilsberg $1 \sigma^{x}$ beobachtet, sicher dort Brutvogel.

29. A ugust: In Losgehnen eine Familie beobachtet; 1 juv. im reinen Jugendkleid geschossen.

19. September: Wiederholt Gimpel beobachtet, jedenfalls auch noch Brutvögel; 1 geschossenes juv. steht ganz im Anfang der Mauser.

10. Oktober: $\sigma^{T}$ juv. geschossen, mitten in der Mauser; Brustseiten schon rot; auf dem Kopfe kommen schwarze Federn zum Vorschein.

31. Oktober: Gimpel sind jetzt öfters zu sehen, wie auch in der Folgezeit. (T.)

Loxia curvirostra L. Fichtenkreuzschnabel.

Loxia curvirostra pityopsittacus Bchst. Kiefernkreuzschnabel.

In diesem Jahre hat ein sehr ausgedehnter Kreuzschnabelzug stattgefunden, der in der ornithologischen Literatur des Jahres 1909 viel behandelt worden ist. Eine übersichtliche $\mathrm{Zu}$ sammenstellung hat von Tschusi gegeben.

Den Verlauf des Zuges auf der Kurischen Nehrung habe ich bereits in Reichenow's Ornithologischen Monatsberichten, Februarbeft 1910 ausführlich beschrieben und darf jetzt darauf hinweisen. Hier mögen nur die Hauptdaten folgen:

Der Beginn des Zuges auf der Nehrung fällt in den Anfang des Juli. Von da an wurden oft Flüge von Kreuzschnäbeln in und über Rossitten beobachtet, so am 31. Juli; 11. August; 16. August; 29. August; 1., 4., 14., 17., 18., 20. September. (Hier tritt infolge einer Reise eine Unterbrechung in den Beobachtungen ein). 
Bei meinem Aufenthalte in Ulmenhorst vom 17. Oktober an war mir Gelegenheit geboten den Zug der Kreuzschnäbel, wie er in der Luft vor sich ging, genau zu verfolgen. Fast täglich zogen diese Vögel nach Süden; immer in kleinen Trupps, nie in grofsen Schwärmen; stets lockend; und zwar ziemlich hoch, selten unter $80 \mathrm{~m}$, gewöhnlich in Höhe von etwa $100 \mathrm{~m}$ und darüber, manchmal mehrere $100 \mathrm{~m}$ hoch.

Noch am 6. November, als der übrige Kleinvogelzug schon ganz aufgehört hatte, Kreuzschnäbel nach S. ziehend.

Am 11. Dezember sind im Rossittener Walde grolse Flüge gewesen.

Am 15. D ez e m b e $r$ höre ich Kreuzschnäbel in der Luft ziehen. am Hause.

Am 16. Dezember sind 6 Stück am Futterplatze dicht

Ganz verschwunden sind die Vögel den ganzen Winter über nicht.

A uswärtige B e obachtungen.

1 or singt.

23. A ugust: Mehrfach Kreuzschnäbel gehört, ebenso in den Monaten September und Oktober. Häufiger als in den letzten Jahren, doch kein Massenzug. Auch bei Heilsberg im Oktober öfters zu beobachten.

8. Nove m b e r: In Losgehnen 1 우 geschossen.

14. November: Einige beobachtet, ebenso am 15. November. Am 6. Dezember im Walde gehört. Mitte Oktober stellte sich in Szameitschen bei Gumbinnen ein Flug auf Sonnenblumen ein. W. Techler erhielt mehrere, darunter ein $\sigma^{x}$ ad. mit 2 rötlichen Querbinden, entsprechend der Form rubrifasciata Brehm. Das von Tischler untersuchte Stück unterscheidet sich sonst in nichts von einem gleichzeitig erlegten gewöhnlichen $\sigma^{T}$ von curvirostra. Es handelt sich offenbar nur um eine individuelle Variation. (T.)

Bei Quanditten beobachtet Herr Ulmer wenig Kreuzschnäbel, da ein schlechtes Samenjahr. Kreuzschnäbel werden der Vogelwarte ferner noch gemeldet: Vom 3./9. 09 von der Ostküste Englands, vom 15. November von Bergen anf Rügen.

Passerina nivalis (L.) Schneeammer.

15. Januar: An der Vordüne ein Flug Schneeammern nach Süden ziehend.

16. Fe b ruar: Ein Flug Schneeammern auf dem Haff.

28. Februar: Eine einzelne Schneeammer auf dem Haff.

7. März: Ein Flug Schneeammern an der Vogelwarte.

12. März: Ein Flug Schneeammern.

A uswärtige B e obachtungen.

Bartenstein: 15. November: 1 Stück zieht nach S.

29. November: Einzelne auf dem Zuge. (T.)

10. und 12. März: Schneeammern bei Quanditten. 
Emberiza calandra L. Grauammer. gehört.

Bartenstein: 17. Januar: Zum ersten Male den Gesang

Bei Thegsten und Heilsberg ist die Grauammer häufiger Brutvogel.

21. Nove mber: Einige Grauammern übernachten am See bei Bartenstein im Rohr.

29. November: An Getreideschobern sehr grofse Flüge von Hunderten; auch viele citrinella. (T.)

Im Januar und F ebruar viel Grauammern bei Quanditten.

Emberiza citrinella L. Goldammer.

Emberiza schoeniclus (L.) Rohrammer.

20. Januar: Goldammern seit etwa 6 Tagen im Hof und Garten in Rossitten. Kamen ganz plötzlich. Sie sind ohne Zweifel vom Norden hier eingetroffen.

Am 27. März erster Rohrammer bei Rossitten.

Am 1. A pril erster Goldammerschlag.

23. A ugust: 1 Goldammernest, direkt auf dem Boden stehend, mit 3 ziemlich flüggen Jungen. Späte Brut. Ob zweite Brut?

Emberiza hortulana L. Ortolan.

Bartenstein: 25. April: Die erste Gartenammer gesehen.

1. Mai: Ersten Gesang gehört.

2. Mai: Vielfach beobachtet.

Heilsberg: 20 Mai: bei Heilsberg an der Chaussee nach Bartenstein einige gehört.

24. Mai: An der Chaussee von Heilsberg nach Guttstadt auf $500 \mathrm{~m} 5$ singende $\sigma^{x} \sigma^{x}$ gehört.

5. J u n i: bei Thegsten und Mengen (Kreis Heilsberg) singen mehrere $\sigma^{x} \sigma^{x}$, auch in der Folgezeit. (T.)

Embriza schoeniclus (L.) Rohrammer.

Auswärtige Beobachtungen.

Bartenstein: 28. M ärz: In Losgehnen mehrfach gesehen, die ersten.

9. M a i: Am See Nest mit 3 Eiern gefunden.

12. Se ptember: Viele am See.

24. Oktober: Mehrfach noch am See.

1. November: Nur ganz vereinzelte noch zu beobachten.

7. November: Die letzte gesehen. (T.)

\section{Anthus. Pieper.}

28. März: S.0. 1; W. 4; SW. 1; Die ersten Pieper gehört, jedenfalls Wiesenpieper.

22. A pril: Ein Trupp Wiesenpieper bei Rossitten.

Anthus pratensis (L.) Wiesenpieper.

Bartenstein: 28. März: In Losgehnen vielfach Wiesenpieper gesehen, aber nicht ziehend. 
4. April: Am See viele auf dem Eise.

18. April: Einige ziehen, desgleichen am 19. April. Herbstzug cf. Fringilla coelebs. (T.)

\section{Anthus trivialis (L.) Baumpieper.}

Bartenstein: 19. April: Einzelne ziehen, die ersten.

25. April: Vielfach beobachtet, auch singend.

2. Mai: Vielfach auf den Feldern.

23. A ugust: Streicht schon umher. Herbstzug cf. Fringilla coelebs. (T.)

Anthus campestris (L.) Brachpieper.

23. Mai: Bei Neuhof (Kreis Heilsberg) $1 \sigma^{x}$ gehört.

5. Juni: Bei Mengen (Kreis Heilsberg) 1 singendes $\sigma^{\top}$, das sich auch in der Folgezeit öfters hören läfst.

7. Ju ni: Bei Tingen (Kreis Friedland) $1 \sigma^{x}$.

19. Juni: Bei Peyse und Neplecken (Kreis Fischhausen) je 1 ơ gehört.

5. Se ptember: In Losgehnen ein Flug von etwa 10 Stück auf einem gepflügten Felde. (T.)

Motacilla alba L. Weifse Bachstelze.

Am 26. März erste weifse Bachsteize bei Rossitten.

Bartenstein: 22. März: In Losgehnen 2 Stück, die ersten. gesehen, desgleichen 1 Stück in Dietrichswalde.

28. März: Schon vielfach zu sehen.

4. April: Am See viele auf dem Eise.

12. Juni: In Heilsberg die ersten ausgeflogenen Jungen.

12. September: Viele am See bei Bartenstein.

11. Oktober: Noch mehrfach am See.

18. Oktober: Die letzte beobachtet.

Mitte Dezember hält sich eine einzelne noch auf der Domäne Neuhof bei Heilsberg auf. (T.)

26. März: bei Quanditten.

Budytes flavus (L.) Kuhstelze.

Bartenstein: 19. April: Auf einem gepflügten Felde die erste gelbe Bachstelze gesehen.

25. April: Jetzt häufig zu sehen, auch in Flügen von 12 bis 15 Stück.

8. Mai: Am See ein Flug. (T.)

Budytes flavus (L.) Kuhstelze.

Budytes borealis (Sund.) Nordische Kuhstelze.

Ceyn ova (Hela). Am 14. Mai SW. und 16. Mai NO. waren die alljährlich im Frühjahr dort auf den Wiesen bei den Schafen sich einfindenden Kuhstelzen zu beobachten. Wie öfters waren auch Budytes borealis (Sund) darunter, ein Stück erlegt.

(Z.) 
Alauda arvensis L. Feldlerche.

21. März: NO. $2 ; 0.3 ;$ O. 5 ; Die ersten Lerchen auf den Feldern bei Rossitten beobachtet. In diesem späten Frühjahre also fast 4 Wochen später als sonst.

31. D ezember: $\mathrm{Zu}$ dieser späten Jahreszeit noch 2 Feldlerchen auf dem Acker vor dem Hunde aufstehend.

Auswärtige Beobachtungen:

Bartenstein und Heilsberg: 21. März: 0., klar, abends bedeckt. In Losgehnen wiederholt einzelne Feldlerchen unter Lockrufen hoch nach 0 . streichend, die ersten in diesem Jahre. Auffällig spät!

22. März: Bedeckt, still, $+3^{0}$. Wiederholt Feldlerchen gesehen. Ersten Gesang gehört, auch bei Bischofshain und Heilsberg.

28. März: Grolsartiger Zugtag wie im Binnenland selten! aufklärend.

Trübe $+5^{\circ}$, W., vormittags zeitweise Regen, nachmittags

Hunderte, ja Tausende von Lerchen ziehen einzeln und in Flügen, vielfach singend, nach 0 , meist hoch. Die ganze Luft ist voll von ziehenden Lerchen. Der Zug dauert von 6-11 Uhr vormittags; nachmittags nichts.

Von Kleinvögeln ziehen noch öfters Hänflinge und einzelne Heidelerchen. Ferner sehr guter Zug von Saatkrähen und Kiebitzen (siehe diese Arten).

29. März: Nachts Frost, SO., am Tage meist heiter. Lerchen ziehen garnicht, dafür aber vielfach Buch- und Bergfinken, die am Tage vorher noch garnicht zogen, ferner wiederholt Hänflinge und einzelne Heidelerchen. Herbstzug cf. Fringilla coelebs. (T.)

22. März: bei Quanditten. (U.)

\section{Lullula arborea (L.) Heidelerche.}

Am 26. März erste Heidelerche bei Rossitten.

9. November: Ein Flug Heidelerchen am Bruche bei Rossitten.

Bartenstein: 28. März: In Losgehnen ziehen einzelne Heidelerchen, die ersten, nach 0 .

29. März: Einzelne ziehen.

7. Juni: Bei Trautenau (Kreis Heilsberg) singt $1 \sigma^{x}$, sicher dort Brutvogel. Daselbst noch am 12., 19. und 26. Juli den Gesang gebört. Herbstzug cf. Fringilla coelebs. (T.)

Galerida cristata (L.) Haubenlerche.

22. März: Bei Bischofshain singt eine Haubenlerche; die Art ist dort ebenso wie in Heilsberg im ganzen nur spärlich vertreten.

Eremophila alpestris (L.) Alpenlerche. 15 Stück. 
B artenstein: 8. November: Ein Flug von 10-15 zieht nach S. (T.)

Sitta europrea L. Kleiber.

Heilsberg: 7. J an uar: Zum ersten Male den Paarungsruf gehört.

In der Wiechertshofer Forst bei Heilsberg ziemlich häufiger Brutvogel. (T.)

Parus. Meise.

Trotz des strengen Winters verhältnismäfsig wenig Meisen am Futterplatze.

A uswärtige Beobachtungen.

Parus caeruleus L.

J'arus palustris L.

Parus maior L.

Parus borealis Selys.

Parus ater L.

16. J a n u r: Zum ersten Male in Heilsberg den Frühlingsruf von maior gehört.

19. A pril: Im Kiwitter Walde (Kreis Heilsberg) pfeift Parus borealis, daselbst noch am 6. September beobachtet.

26. April: Im Gallinger Walde (Kreis Friedland) pfeift ein $\sigma^{7}$ von Parus borealis; daselbst die Art noch am 26. Juli gehört.

14. M a i: In der Damerau bei Heilsberg 1 Parus borealis ơ.

23. Mai : In der Wiechertshofer Forst bei Heilsberg 1 borealis beobachtet.

19. Juli: Im Gutsgarten von Losgehnen 1 borealis.

1. A u gu st: Im Walde von Losgehnen borealis.

8. August: Am See ein pfeifendes $\sigma^{7}$ von borealis.

12. S e p t em ber: In Losgehnen maior, ater, caeruleus auf dem Zuge.

19. September: ater auf dem Zuge, am 26. September auch noch caeruleus. umber.

10. Oktober: ater und caeruleus streichen zahlreich

17. Oktober: maior auf dem Zuge

24. Oktober: palustris läfst den Frühlingsruf hören.

8. N ovember: Einige borealis im Losgehner Walde. (T.)

Proebbernau (Frische Nehrung): 1. Oktober SW. An diesem und dem folgenden Tage ziehende Kohl- und Blaumeisen im Dorfe. (Z.)

Aegithalus caudatus (L.) Schwanzmeise.

19. Oktober: Gegen Abend ein Flug bei Ulmenhorst durch die Büsche nach S. ziehend. 
Auswärtige Beobachtungen.

23. Mai: In der Wiechertshofer Forst bei Heilsberg ein Paar beobachtet.

17. Oktober: In Losgehnen einen Flug beobachtet. In der Folgezeit öfters zu sehen. (T.)

Regulus regulus (L.) Gelbköpfiges Goldhähnchen.

20. September: früh Nebel bis $8 \mathrm{Uhr}$, dann hell; SW. 2 ; W. 1; C. In den Büschen Goldhähnchen mit vielen Rotkehlchen zusammen.

22. September: 0.4; NO. 3; NO. 4. Sehr viel Goldhähnchen mit Rotkelchen und grofsen Buntspechten zusammen in den Dorfgärten.

Auswärtige Beobachtungen.

Bartenstein: 19. September: Vielfach auf dem Zuge, desgleichen am 26. September.

10. Oktober: Viele in den Büschen.

18. Oktober: Vielfach auf dem Zuge, desgleichen am 24. Oktober. (T.)

\section{Troglodytes troglodytes (L.) Zaunkönig.}

23. Mai: In der Wiechertshofer Forst bei Heilsberg als Brutvogel ziemlich häufig.

19. September: Zaunkönige in Losgehnen auf dem Zuge, desgleichen am 20. und 26. September, 17. und 18. Oktober. (T.)

15. Oktober: Zaunkönige bei Quanditten. (U.)

Accentor modularis (L.) Heckenbraunelle.

Bartenstein: 18. September: 1 Stück gehört.

26. September: Wiederholt auf dem Zuge, desgleichen am 27. September, 10. und 11. Oktober.

18. Oktober: 1 Stück beobachtet.

8. Novem ber: Zuletzt noch 1 Stück beobachtet.

Sylvia nisoria (Bchst.) Sperbergrasmücke.

26. Mai: Heute die erste Sylvia nisoria in Rossitten.

Sylvia atricapilla (L.) Mönchsgrasmücke.

28. Mai: 0. 7; 0. 4; 0. 3. Die erste gesehen. Viel Sylvien angekommen.

29. Mai: O. 2 ; NO. $3 ;$ O. 2 . Auch heute viel Sylvien angekommen.

12. August: Sylvien auf dem Zuge schon seit einiger Zeit.

Auswärtige Beobachtungen über Sylvien:

29. A pril: In Heilsberg singt die erste curruca.

2. Mai: In Losgehnen curruca vielfach beobachtet.

9. Mai: Die erste Sylvia in Losgehnen gehört. 
10. Mai: Bei Dietrichswalde die erste atricapilla gehört.

12. Mai: In Heilsberg singt atricapilla.

16. Mai: In Losgehnen sind jetzt atricapilla und sylvia häufig geworden. Die erste simplex gehört,

20. Mai: Bei Heilsberg die ersten nisoria gehört.

23. Mai: In der Wiechertshofer Forst bei Heilsberg atricapilla recht zahlreicher Brutvogel.

28. Mai: In Losgehnen nisoria jetzt recht häufig.

25. Juli: In Losgehnen noch Gesang von simplex gehört.

29. August: Curruca vielfach in Losgehnen auf dem Zuge.

12. September: Curruca und atricapilla in Losgehnen einzeln noch auf dem Zuge. (T.)

Ceynova (Hela) 13. Mai: WSW. Sehr windiges Wetter. Mehrere Dorngrasmücken mit Finken und Rotschwänzchen suchen die Kartoffeläcker im Dorfe ab.

20. Mai: W. Sturm. Ein Mönchsgrasmücken-Weibchen in den Erlenbüschen.

22. Mai W. Einzelne Paare am Dünen-Etablissement. (Z.)

Acrocephalus. Rohrsänger.

20. September: Schwacher SW. und W. Bis 8 vormittags Nebel, dann hell. In den Rohrbeständen des Bruches sind ganz besonders viel Sc hilfrohrsäng er (Acr.schøenobaenus) anzutreffen. Überhaupt reiches Vogelleben heute.

Auswärtige Beobachtungen.

Bartenstein: 1. Mai: Am See die erste arundinaceus einige schoenobaenus.

2. Mai: Schoenobaenus vielfach beobachtet; am 3. Mai wesentlich häufiger geworden.

9. Mai: Den ersten streperus gehört.

16. Mai: Schoenobaenus u. streperus sind jetzt häufig geworden.

23. Mai: Bei Heilsberg an der Alle die ersten palustris gehört. Die Art ist bei Heilsberg recht verteilt. Auch in Gärten der Stadt ist der Gesang oft zu hören.

28. Mai: In Losgehnen palustris jetzt recht zahlreich.

5. Juni: Im Gutsgarten von Losgehnen singt auf Ahorn anhaltend 1 streperus, verschwindet dann aber wieder.

12. September: Am See vielfach noch schoenobaenus.

26. September: Nur noch ganz vereinzelte schoenobaenus sind zu sehen. desgleichen am 27. September. (T.)

Locustella naevia (Bodd.). Heuschreckensänger.

14. Mai: Im Sinsertal bei Heilsberg den ersten gehört.

16. Mai: In Losgehnen 1 Stück gehört.

23. Mai: An der Alle bei Heilsberg schwirrte $1 \sigma^{x}$. In Losgehnen haben etwa 3-4 Paare genistet, meist im Roggen. 

3 ๙ $^{\top}$.

14. Juni: Bei Neuhof (Kreis Heilsberg) schwirren im Roggen

19. Juni: Am frischen Haff bei Neplecken $1 \sigma^{x}$ gehört. (Kreis Fischhausen).

26. Juni: Bei Gallingen (Kreis Friedland) auf einer Waldblöfse ein schwirrendes $\sigma^{7}$.

11. Juli: Um $12 \mathrm{Uhr}$ nachts ist in Losgehnen $1 \mathrm{o}^{\mathrm{T}} \mathrm{zu}$ hören, aufserdem noch Acrocephalus arundinaceus, schoenobaenus palustris; Crex crex.

8. August: In Losgehnen im Roggen ein sehr aufgeregtes Paar, rufen laut „tick tick", das $\sigma^{x}$ schwirrt auch.

9. September: $2 \sigma^{x} \sigma^{x}$ schwirren noch anhaltend, das eine sitzt dabei häufig auf Roggengarben. Soeben ausgeflogene Junge mit ganz kurzen Schwänzen verstecken sich gleichfalls unter Roggengarben; sie rufen laut „zii zii" und leise "tick tick". (T.)

Locustella fluviatilis (Wolf). Flufsrohrsänger.

16. Mai: Den ersten in Losgehnen gehört.

23. Mai: In der Wiechertshofer Forst bei Heilsberg schwirren nahe der Alle 3 ơơ $^{x}$.

29. Mai: In Losgehnen jetzt recht häufig, etwa 20 schwirrende $\sigma^{x} \sigma^{x}$ gehört, auch in der Folgezeit.

1. Juni: In Sinsertal bei Heilsberg in unmittelbarer Nähe der Stadt' schwirrt ein $\sigma^{T}$.

2. Juni: Nachts um 1 Uhr läfst sich anhaltend ein schwirrendes $\sigma^{x}$ in Heilsberg hören, aufserdem noch folgende Arten: Erithacus philomela, Acrocephalus pulustris, Muscicapa atricapilla, Apus apus.

6. Juni: In Losgehnen hat sich $1 \sigma^{\top}$ in einer Weifsbuchenhecke im Gutsgarten dicht bei Gebäuden angesiedelt.

19. Juni: Bei Wischrodt (Kreis Fischhausen) schwirrt $1 \sigma^{x}$.

26. Juni: Bei Tingen und Dietrichswalde (Kreis Friedland) je $1 \sigma^{x}$ gehört.

1. August: $1 \sigma^{\Upsilon}$ schwirrte noch in Losgehnen.

Hippolais hippolais (L.) Bastardnachtigall.

29. Mai: 0. 2; NO. 3; 0. 2. Die erste gesehen bei Rossitten. Mit viel Sylvien zusammen.

A uswärtige Beobachtungen.

16. Mai: Mehrere in Losgehnen gehört, die ersten.

17. Mai: In Heilsberg schon vielfach zu hören.

Phylloscopus. Laubsänger.

25. A pril: Ersten Laubsänger bei Rossitten, jedenfalls rufus, beobachtet; nur 1 Stück.

23. Mai: 02 , NO.1, 0.5. Heute sind viele Kleinvögel angekommen, darunter auch Laubsänger. 
12. August: Laubsänger schon seit einiger Zeit auf dem Zuge anzutreffen mit Sylvien zusammen.

3. September: SW. 3, W. 5, W.5, zuweilen Regenschauer abwechselnd mit Sonnenschein.

Kleinvögel ziehen sehr lebhaft von Busch zu Busch, darunter besonders viel La ubsänger; einmal in einem Busche auf einem kleinen Flecke bis 10 Stück.

12. Se ptember: NO. 3 ; N. 4 ; N. 4 .

Viel Laubsänger auf dem Zuge, ebenso am 13. September.

20. September: SW.2, W. 1, C. Viel Laubsänger und Rotkehlchen im Dorfe.

A uswärtige Beobachtungen.

Phylloscopus sibilator (Bchst.) Waldlaubsänger.

27. A pril: In der Wiechertshofer Forst bei Heilsberg vielfach gehört, die ersten.

2. Mai: In Losgehnen vielfach beobachtet. (T.)

Phylloscopus trochilus (L.) Fitislaubsänger.

29. A pril: Bei Heilsberg den ersten gehört.

2. Mai: In Losgehnen vielfach beobachtet.

25. A ugust: Überall viele auf dem Zuge, namentlich am See.

12. September: Vielfach auf dem Zuge, zusammen mit rufus.

20. Septembnr: Noch einzelne beobachtet. (T.)

Phylloscopus rufus (Bchst.) Weidenlaubsänger.

Bartenstein: 10. April: Der erste singt in Losgehnen.

19. April: Noch nicht sehr zahlreich.

25. A u gust: Überall häufig, namentlich am See, desgleichen am 29. August.

12. September: Sehr viele am See, desgleichen am 19. und 20. September.

26. September: Noch vielfach $\mathrm{zu}$ beobachten, desgleichen am 27. September.

10. Oktober: Mehrfach noch beobachtet, ebenso am 11. Okt.

17. Oktober: Noch einzelne am See zu beobachten auch singend.

18. Oktober: Die letzten gesehen, auch Gesang noch gehört.

Phylloscopus sibilator (Bchst.) 28. A pril W. Sturm. Einzelne im Walde bei Ceynova (Hela). 30. April SO. Vereinzelte an der Signalstation.

Phylloscopus trochilus (L.) 30. September. Mehrfach im Dorfe Proebbernau (Frische Nehrung).

Phylloscopus rufus (Bchst.) 10. Mai NO. Einzelne Weidenlaubsänger im Walde bei Ceynova (Hela). 17. Mai NO. Mehrfach im Walde.

Turdus Drossel.

15. Januar: O. 1, SO. 4, SO. 6. Drosseln, namentlich T.pilaris, ziehen mit Krähen zusammen regelrecht truppweise nach Süden. 
Am 3. Februar bei furchtbarem Schneesturm mehrere Wachholderdrosseln am Futterplatz, mit Amseln zusammen. Die Drosseln bleiben den ganzen Februar hindurch da. Es herrscht strenger Winter.

21. November: S. 4, SO. 1, N0. 8, Schnee. Im Walde ziemlich viel Drosseln.

26. Dezem ber: Mild. W. Regenschauer. Sehr tot draufsen. Einige Drosseln fliegend.

Auswärtige Beobachtungen.

Turdus viscivorus $\mathrm{L}$.

" pilaris $\mathrm{L}$.

" musicus L.

" iliacus L.

Turdus merula L.

Bartenstein: 20. Februar: Im Gutsgarten von Losgehnen eine Amsel, desgleichen am 1. März, ein Q

28. M ärz: Eine einzelne Misteldrossel.

29. März: Einige Singdrosseln, die ersten, singen im Walde. Wiederholt kleine Flüge von Rot- und Wachholderdrosseln.

31. März: Bei Heilsberg eine Singdrossel.

4. A pril: In Losgehnen kleine Flüge von Rotdrosseln.

10. April: Öfters Flüge pilaris und iliacus.

12. April: 1 Amsel singt abends anhaltend in Losgehnen. Zum ersten Male dort den Gesang gehört, da die Amsel bei Bartenstein als Brutvogel anscheinend fehlt. Der Gesang wird noch bis zum 18. April regelmäfsig gehört, dann verstummt er plötzlich. In der Folgezeit sind Amseln dann nicht mehr zu beobachten.

19. April: Einige pilaris ziehen; 1 viscivorus.

25. April: Einige pilaris ziehen.

27. April: In der Wiechertshofer Forst bei Heilsberg singt musicus sehr zahlreich.

9. Mai: In Losgehnen singt eine Rotdrossel im Walde.

23. Mai: pilaris nistet ganz vereinzelt in der Wiechertshofer Forst bei Heilsberg. Daselbst ein Nest von musicus mit 5 Eiern gefunden.

28. Mai: Bei Trautenau (Kreis Heilsberg) nistet ein einzelnes Paar pilaris. pilaris.

23. August: Im Gutsgarten von Losgehnen mehrere

27. September: Kleine Flüge von pilaris bei Bartenstein auf den Feldern.

10. Oktober: Vielfach in Losgehnen musicus in den Büschen, desgleichen am 17. und 18. Oktober. Am 17. Oktober auch einzelne iliacus.

24. Oktober: Noch vereinzelte musicus beobachtet.

7. November: Einzelne pilaris ziehen. 
21. November: Im Walde 1 merula.

13. Dezember: Einzelne pilaris auf dem Felde; nicht häufig trotz des milden Winters. (T.)

Im Herbste sehr wenig Drosseln bei Quanditten

\section{Turdus merula L. Amsel.}

31. Januar: Am Futterplatze bei Rossitten drei Amseln, eine davon $\sigma^{x}$ mit gelbem Schnabel.

3. Februar: Furchtbarer Schneesturm, gegen Abend Regen. Am Futterplatze jetzt immer mehrere Amseln. So viel noch nie hier gewesen. Die Vögel sind den ganzen Februar durch zu beobachten. Ohne Zweifel sind das nordische Vögel, die der strenge aufsergewöhnlich lange anhaltende Frost herbeigeführt hat.

31. Dezember: 1 Amsel gesehen. Vor einigen Tagen war ein schönes altes $\sigma^{\top}$ mit gelbem Schnabel im Garten.

\section{Saxicola oenanthe (L.) Steinschmätzer.}

9. Mai: Ich sehe den ersten Steinschmätzer.

24. August: Steinschmätzer in kleiner Anzahl auf den Triften. Schon seit längerer Zeit.

31. August: Wenig Steinschmätzer.

13. September: 0.3, N.3, N0.5. Viel Steinschmätzer auf dem Zuge.

Auswärtige Beobachtungen.

Bartenstein: 26. April: In Losgehnen ein Flug von 7-8, auch $0^{7} \sigma^{x}$.

1. Mai: Bei Trautenau (Kreis Heilsberg) 1 q. Bei Heilsberg ebenso wie bei Bartenstein als Brutvogel fast ganz fehlend. 18. A u gust: Der erste bei Bartenstein auf dem Herbstzuge; auch auf dem Zuge nur sehr spärlich.

Patrincola rubetra (L.) Braunkehliger Wiesenschmätzer.

26. April: Zum ersten Male bei Rossitten beobachtet.

Auswärtige Beobachtungen.

Ceynova (Hela): 13. Mai WSW. Im Vergleich zu früheren Jahren nur wenig beobachtet. Es fingen sich an dem sehr windigen Tage leider auch einige Wiesenschmätzer in den Reusen; die Dorfjugend war natürlich sehr bald hinterher, doch erhielten die Gefangenen auf meinen Einspruch die Freiheit wieder.

26. April: Das erste Braunkehlchen bei Heilsberg gesehen

2. M ai: In Losgehnen vielfach beobachtet.

9. Mai : Jetzt recht häufig geworden.

Bei Heilsberg recht häufiger Brutvogel.

Erithacus phoenicurus (L.) Gartenrotschwanz.

25. A pril: Die ersten bei Rossitten gesehen. Nur wenige. 3. September: SW. 3, W. 5, W. 5. Zahlreich von Busch zu Busch ziehend. 
13. September: 0.3, N.3, NO.5. Der Kleinvogelzug setzt in diesem Herbste recht zeitig ein. Jetzt sind schon immer Gartenrotschwänze mit Laubsängern zusammen zu beobachten.

A us wärtige B eobachtungen.

Bartenstein 25. April: Das erste gesehen.

2. Mai: Vielfach beobachtet.

10. Mai: In Gallingen singt 1 Stück.

16. Mai: Mehrere im Walde, noch auf dem Zuge. Bei Bartenstein, Heilsberg und Königsberg als Brutvogel nicht sonderlich häufig.

22. Augu st: Der erste in Losgehnen auf dem Herbstzuge.

29. August: Einzelne auf dem Zuge, desgleichen am 19. und 20. September. (T.)

Ce y nova (Hela): 30. A p ril SO. Einzelne in den Büschen am Walde. 13. Mai WSW. Stürmisches Wetter. Viele Rotschwänzchen $\sigma^{x}$ und $\&$ fallen auf den Äckern im Dorfe ein. 4 in den zum Trocknen aufgestellten Reusen gefangene befreie ich und lasse sie fliegen. 22. Mai W. Vereinzelte $\sigma^{\top}$ und .

Erithacus rubeculus (L.) Rotkehlchen.

Am 27. März: Erstes bei Rossitten.

20. Sept e mber: Schwacher SW. und W. Bis 8 vormittags Nebel, daun hell. Viel Rotkehlchen im Dorfe.

22. September: O. und NO.3, hell, Sonnenschein. Sehr viel Rotkehlchen in den Dorfgärten.

11. D eze mber: Jetzt immer ein Rotkehlchen im Garten. Frifst die ausgehängten Beeren.

A uswärtige Be obachtungen.

Bartenstein: 4. April: In Losgehnen vielfach Rotkehlchen, die ersten, gesehen.

26. September: Gesang gehört.

10. Oktober: Vielfach in den Büschen, desgleichen am 17. und 18. Oktober.

24. Oktober: Noch einige beobachtet.

14. November: Das letzte beobachtet.

Erithacus cyaneculus (Wolf). Weifssterniges Blaukehlchen.

Bartenstein: 18. April: Am See 2 Stück geschossen. $\sigma^{x}$ ad. mit weifsem Stern und O.

24. August: Am See 1 Blaukehlchen.

29. August: $1 \sigma^{\top}$ juv. geschossen. (Stern weifs, rostgelblich angeflogen, Kehle unten blau, rostrotes Brustband).

12. September: $1 \sigma^{x}$ juv. am See geschossen, kein Blau an der Kehle. (T.) 
Erithacus philomela (Bechst.) Sprosser. ersten.

Bartenstein: 3. Mai: $2 \sigma^{\top} \sigma^{\top}$ in Losgehnen gehört, die

8. Mai: Vielfach zu hören.

16. Mai: Häufig geworden.

28. Mai: Recht zahlreich in diesem Jahre.

\section{Der Frühjahrszug in Ulmenhorst.}

In diesem Jahre konnte ich zum ersten Male den Früh jah rsVogelzug in Ulmenhorst wahrnehmen, der in mancherlei Beziehung ganz anders verläuft, wie der Herbstzug. Mehr zu sehen bekommt man im Herbste; dafür sind im Frühjahr recht oft die bekannten Rückzüge $\mathrm{zu}$ beobachten, die immer ein besonderes Interesse beanspruchen dürfen.

Der Aufenthalt in der Hütte ist im Frühjahre ungleich beschwerlicher als im Herbste, da oft recht unfreundliche Witterung eintritt.

Weitere Vergleiche müssen noch unterbleiben bis Jahresreihen von zusammenhängenden Beobachtungen aus beiden Zugperioden vorliegen.

23. März: Windrichtung und -stärke: 0. 4; NO. 4; NO. 4. (Die Ablesungen an den Instrumenten finden früh, mittags und abends statt).

Temperatur: 0,$4 ; 1,4 ; 0,7^{\circ} \mathrm{C}$.

Noch hoher Schnee überall. Das Haff vollständig zugefroren; der erste milde Tag nach langem Winter.

Der erste Zugtag. Sofort sind Stare da. Ein kleiner Flug. Durch Ausräumen der Kästen werden sogleich Anstalten zur Brut getroffen, denn die Ankunft hat sich lange hingezogen. Auf den Feldern wenig Lerchen. Bei Ulmenhorst guter Krähenzug, auch besonders viel Dohlen. An Kleinvögeln Finken und Lerchen. D rosseln in kleinen Flügen. Zughöhe für alle Arten etwa 20-50 Meter.

24. März: Windrichtung und -stärke: N. 1; W. 2; W. 3.

Temperatur: 0,$4 ; 1,0 ; 0,4^{\circ} \mathrm{C}$.

Nebel, es schneit von Mittag an.

Nichts von Zug.

25. März: Windrichtung und stärke: NW. 1; SO. 1; SO. 3.

Te m p er a tur: 0,$2 ; 1,3 ; 0,9^{\circ}$. Bedeckt aber ziemlich klare Luft.

Krähen ziehen von früh an, aber sehr hoch, mehrere 100 Meter hoch. Auch Dohlen. Wenn man nicht mitten in der Zugstrafse wohnte, würde man nichts vom Zug merken. Gegen Mittag läfst der Zug schon nach. Nach dem Uhu kommen die Krähen aus solcher Höhe nicht herunter. Kleinvögel ziehen am Vormittag nicht. 
Da wird gegen 1 p. ${ }^{1}$ ) der Wind stärker, etwa Stärke 4, und geht nach SO. herum, und nun setzt plötzlich ein mächtiger Zug ein, meist Nebelkrähen, wenig Saatkrähen und Dohlen. Zughöhe 20-50 Meter. Der Zug wird immer stärker und hält ganz abnorm lange an, etwa bis 6 p., ja $1 / 47$ p. ziehen noch ein paar Krähen in der Dämmerung nach Norden, obgleich gegen 6 p. feiner Sprühregen einsetzt. Man merkt den Vögeln ihr Streben an vorwärts zu kommen. Auf den Uhu stofsen die Krähen wie toll.

Mit den Krähen zusammen viel Hänflinge ( $A$. linaria) u. F e ldl e rchen, auch einige kleine Starflüge, einige Bus sarde (buteo u. lagopus).

Immer noch hoher Schnee ringsum. Man sinkt zuweilen bis an den Leib ein. $\mathrm{SO}, 4$.

26. März: Windrichtung und -stärke SO. 4; SO. 5;

Temperatur 1,$1 ; 3,2 ; 1,5^{\circ} \mathrm{C}$.

Guter Krähenzug schon von früh an, besonders $C$. cornix, etwas trugilegus und monedula.

Höhe 20-40 Meter; kommen gut nach dem Uhu. Unter den 24 erlegten $C$. cornix befindet sich ein Exemplar mit schwarz geschupptem Rücken, das ich aber nicht für einen Bastard von $C$. cornix und $C$. corone ansprechen möchte, weil das Grau zu hell ist.

An Raubvögeln werden bemerkt: Bussarde vereinzelt, 2 Wanderfalken, Turmfalken (letztere als die ersten in diesem Jahre). Die Raubvögelzüge sind also auch bereits im Gange.

Von Kleinvögeln: Feldlerchen, Heidelerchen, (letztere die ersten in diesem Jahre), wieder viel Hänfling e wie gestern, $\mathrm{Z}$ eisige, auch einige Buchfinken ( $F$. coelebs) (die ersten auf dem Zuge), ferner einige Kiebitze (die ersten). Diese letzteren fliegen nicht stetig nach Norden, sondern kehren zuweilen um. Einige kleine Flüge $\mathrm{H}$ o hl t a u b en (oenas) (die ersten in diesem Jahre).

Die Meisen machen sich an den um Ulmenhorst hängenden Nistkästen $\mathrm{zu}$ schaffen.

27. März: Windrichtung: SO. 4; SO. 3; SO. 1.

Temperatur kalt 0,$9 ; 1,2 ; 0,9^{\circ}$. Etwas dunstig.

Am Vormittag guter Krähenzug, niedrig, 10-30 Meter hoch. Nachmittags läfst der Zug nach und geht mehrere 100 Meter hoch vor sich. Das erste Rotkehlchen bei Ulmenhorst; ein Dompfaffenweibchen.

Bis jetzt bestanden die Hauptzüge bei Ulmenhorst aus K rähen. Vogelleben war bis jetzt blofs in der Luft zu bemerken, da die Erde noch zu sehr verschneit war. Heute zeigen sich

1) Anm. : Der Kürze halber werden ofter die üblichen Abkürzungen a. $($ ante meridiem $)=$ vormittags. p. (post meridiem) $=$ nachmittags. n. $=$ nachts. $12 \mathrm{a}=$ mittags benutzt. 6 a heilst also $6 \mathrm{Uhr}$ vormittags. 
zum erstenmal einige Kleinvögel auf dem Erdboden: Buchfinken, Meisen, ein Rotkehlchen, Goldhähnchen, Stare. Nachmittags gehe ich nach Rossitten. Auf der Feldflur ist der Schnee bereits sehr geschwunden; viel freie Stellen. Stare, Lerchen, Kiebitze auf der Flur. Eine Schar Wildgänse steht vom Felde auf, die ersten, die ich sehe in diesem Jahre.

$\mathrm{Zu}$ den guten $\mathrm{Krähenzugtagen} \mathrm{vom} \mathrm{23.,} \mathrm{25.,} \mathrm{26.} \mathrm{und}$ 27. März 1909 ist folgendes zu bemerken: Unterm 22. März 1909 teilt mir Herr A. Viebig aus Berlin-Wilmersdorf freundlichst mit, dafs er seit mehreren Tagen, besonders in den Mittagsstunden von 11-2 Uhr täglich unendliche Scharen $\mathrm{Kräh}$ en beobachtete, welche in Höhen von vielleicht 100-500 Metern ausschliefslich über Berlin die Richtung nach Osten hielten. Er fährt wörtlich fort: „Bald einzeln, bald truppweise geht der Zug ununterbrochen ostwärts. Wie breit sich nun diese Flüge ausdehnen, vermag ich nicht zu sagen, doch immerhin erscheint es mir mitteilenswert, dafs ich gestern Mittag in Zehlendorf West am Schlachtensee gleichfalls die nach Ost gerichteten Krähenflüge bemerkte, und zurückgekehrt nach hier auch hier den Zug konstatierte. Das ergibt eine Breite von vielleicht $10 \mathrm{~km}$, und in Berücksichtigung dieser Breite müssen sich die Vögel auf hunderttausende und abermals hunderttausende summieren, welche in den genannten Tagen über die hiesige Gegend nach Osten zogen."

Darauf teilte ich dem Herrn meine auf die fraglichen Tage bezüglichen Beobachtungen von Ulmenhorst mit, worauf unterm 9. April 09 folgendes Schreiben eintraf: „,Die von Ihnen angegebenen Daten 23., 25., 26., 27. März als gute Krähenzugtage stimmen derart vorzüglich in der Hinsicht mit meinen Beobachtungen überein, dafs ich sehr davon überzeugt bin, dafs es sich um dieselben auch von mir gesehenen Krähen handelt. Hier beobachtete ich den Krähenzug ca. am 17., 18., 19., 21., 22. März. Am 23. nur noch ganz vereinzelte Tiere. Sonntags am 21. war ich zufällig mit meiner Frau in einer Grunewaldkolonie und sah dort gleichfalls den Zug, gleichzeitig aber eine hier ansässige N ebelkrähe Nistmaterial tragen, während einige 100 Mtr. hoch die Zugkrähen nach Osten flogen ....."

Dazu ist von groísem Interesse eine Nachricht, die mir Herr Professor Dr. Eckstein aus Eberswalde unterm 6. 4. 09 freundlichst zugehen liefs. Sie lautet: „Fehlanzeige! Hier im Binnenlande wird der Rückzug der Krähen überhaupt nicht beobachtet. Während im Herbst täglich tausende vorüberziehen, beobachtet man im Frühling nicht einen Trupp. Ich habe vor meinem Fenster die Zugstrafse und beobachte täglich, aber im Frühjahr ist sie verlassen. Unsere nordöstlichen zahlreichen Wintergäste (Krähen) sind weg, die einheimischen sind nicht in der Nähe der Stadt zuhause. ...."

Wenn ich die eben mitgeteilten Berliner und Eberswalder Berichte miteinander vergleiche, so werde ich in meiner Ansicht 
bestärkt, die ich schon öfters zum Ausdruck gebracht habe, dafs nämlich Vogelzug, und sogar starker Vogelzug sehr unbemerkt und heimlich vor sich gehen kann. Sitzt man nicht gerade in der betreffenden Zugstrafse, so merkt man nichts davon. Die Zugzeiten der einzelnen Arten gehen vorüber, die Vögel kommen nicht, man meint sie müssen noch erscheinen, und dabei sind sie anderwärts längst durchgezogen. In diese Lage kommt der praktische Vogelzugbeobachter sehr oft. Auf diese Weise erkläre ich mir auch die auffallende Tatsache, dafs die Frühjahrsrückzüge gewisser Vogelarten (Rotfufsfalken, St eppenweihen, Tannenhäher, Sumpfohreulen) oft nicht bemerkt werden, obgleich diese Vogelarten im Herbst in grofsen Massen aufgetreten sind.

Was die Annahme der Identität der Berliner und Rossittener Zugkrähen anlangt, so steht ihr von Seiten der Ergebnisse der Ringversuche keinerlei Hindernis im Wege, ja sie wird durch diese Versuche nur gefestigt, da Ringkrähen von Rossitten ziemlich häufig in der Provinz Brandenburg, ja besonders in der weiteren Umgebung von Berlin angetroffen worden sind, und da die südlichste Ringkrähe für Deutschland von Prettin an der Elbe, also weit südlich von Berlin, herstammt. SW. 1.

28. März: Windrichtung und -stärke: SO. 1; W. 4;

T'em peratur 1,$1 ; 2,2 ;-0,5^{\circ}$. Bedeckt.

Ich bin in Rossitten. Bis gegen 11 a. sehr guter $\mathrm{K} \mathrm{r}$ ä h e $\mathrm{nz} \mathrm{ug}$. 29. März: Windrichtung und-stärke SO. $3 ; 0.4 ; 0.5$. Temperatur $-1,6 ; 2,6 ; 2,4^{0}$. SW. 1.

31. März: Windrichtung und -stärke SO. 3; SW. 4;

Temperatur 1,$7 ; 9,7 ; 4,0^{\circ}$.

Der Schnee ist seit dem 27. März fast ganz geschwunden.

Nichts besonderes von Zug zu bemerken. Einige Krähen ziehen hoch. Auch einige Gänseflüge. Rotkehlchen sind mehr angekommen, auch Drosseln T. musicus und viscivorus gesehen, ebenso Goldhähnchen. Gröfsere Star- und Lerchenflüg e auf den Feldern, allerdings nicht so viel, wie in andern Jahren um diese Zeit.

Abends gegen 9 Uhr den Ruf ziehender Gänse gehört. Es ist auffallend, wie spät abends gerade diese Vögel noch ziehen. Sie gehören zu den auch bei Nacht wandernden Vogelarten.

1. April: Windrichtung: S; S.S.O; S.O.

Windstärke: $6,7 \mathrm{~m} ; 4,6 \mathrm{~m} ; 6 \mathrm{~m} .{ }^{1}$ )

1) Bei diesen Angaben ist die Windstărke mit dem Windstårkemesser genau in Metern pro Sekunde festgestellt. Bei den anderen Angaben ohne „m." ist die Notierung nach Beaufort's Skala 0-12 erfolgt. Die Feststellungen beziehen sich auf Vormittag, Mittag und Abend. 
Tem per atur: 2,$1 ; 8,3 ; 5,8^{\circ}$ Früh bedeckt, kühler wiegestern, aber ziemlich klare Luft. Von 7 a. an findet ein regelrechter Rückzug nach Süden statt, und zwar ebenso stark, als wenn er normaler Weise nach Norden zu vor sich ginge. Besonders sind es K le invögel, die wieder dem Süden zustreben. In einer Höhe von 15-20 Metern ziehen Finken, vor allem aber Drosseln (musicus) Schwarm auf Schwarm vorüber, einige K iebitze, auch einzelne T a uben (oenas und palumbus), aber wenig Krähen. Man fragt sich unwillkürlich, ob schlechtes Wetter kommt? Auf eine Anfrage teilt mir Herr Professor D. von Kaygorodoff aus Petersburg freundlichst mit, dafs am 1. u. 2. April längs der Baltischen Küste Ehstlands starkes Schneegestöber geherrscht hat. Da haben wir den Grund der Rückzugserscheinung. Und wie steht's in solchem Falle mit der Vorausahnung der Vögel? Wir sagen oft, wenn wir Vögel bei guter Witterung in umgekehrter Richtung ziehen sehen: sie ahnen den Eintritt schlechten Wetters; dabei kommen sie aus Gegenden, wo die ungünstige Witterung bereits eingetreten ist. -

In den Büschen Kohlmeisen, die sich viel an den Nistkästen zu schaffen machen. Es fällt auf, dafs diese fern von menschlichen Wohnungen sich aufhaltenden Waldmeisen auf dem Dunghaufen sofort Knochen und Fleischreste annehmen.

Ferner in den Büschen Rotkehlchen und Zaunkönige, die jetzt auf dem Zuge sind. 2 weifse Bachstelzen besuchen häufig au der Hütte aufgehängte Nistkästen. Das ist ohne Zweifel dasselbe Pärchen, das im vorigen Jahre sofort nach Errichtung der Hütte auf dem Hausboden genistet hat. Auf den Bäumen Erlenzeifsige; teilweise auch nach Süden ziehend.

Gegen Mittag hellt das Wetter auf; schöner warmer Sonnenschein. Einige Krählie'n ziehen nach Norden. Spät gegen Abend ein kleiner Flug Gänse nach Norden. 2 Waldschnepfen ${ }^{1}$ ) beobachtet.

Gegen 6 Uhr p. setzt Regen ein, und nun erfolgt in der Nacht bei uns der Wetterumschlag, der durch den Vogelrückzug angedeutet wurde.

2. April: Windrichtung: N.W; N.W; N.W.

Windstärke: $12 \mathrm{~m} ; 7,6 \mathrm{~m} ; 8,3$;

Temperatur: $-0,5 ; 1,1 ;-2,1{ }^{0}$.

Man beachte den starken Wind und die plötzliche Abkühlung. Eis gefroren. In der Nacht schneit und graupelt es, und diese Schnee- und Graupelschauer dauern auch den Tag über fort, abwechselnd mit Sonnenschein. Ein paar Krähen nach Süden ziehend, sonst nichts in der Luft. In den Büschen nichts von

1) Der Waldschnepfenzug vom Herbst 1909, woraber mir durch das Entgegenkommen der Königlichen Regierungen wieder ein umfangreiches Material vorliegt, soll in einem spateren Berichte ausführlich behandelt werden. Ich lasse ihn deshalb in den folgenden Notizen weg. 
Rotkehlchen und andern Kleinvögeln, nur ein paar Meisen und Drosseln.

3. April: Windrichtung: N.W; N.W; N.W.

Windstärke: $8,4 \mathrm{~m} ; 10,7 \mathrm{~m}$.

Temperatur: $-1,4 ;-1,5 ;-1,0^{\circ}$.

In der Nacht schneit es wieder; dasselbe Wetter wie gestern. Boden hart gefroren. Nichts von Vogelzug nach Norden, nur ab und zu ziehen immer noch gröfsere und kleinere Trupps K lei n vög e l (Finken und Stare) auch einige Krähen nach Süden. Das Wetter wird immer rauher, Schneeschauer nehmen zu. Alles Kleinvogelleben was an den vorhergehenden Tagen bereits in den Büschen herrschte (Zaunkönige, Goldhähnchen, Drosseln, Finken, Rotkehlchen) ist wieder geschwunden. Es liegt an manchen Stellen eine dünne Schneedecke.

4. April: Windrichtung: NNW; NW; NNW.

Windstärke: $7,3 \mathrm{~m} ; 7,9 \mathrm{~m} ; 7,3 \mathrm{~m}$.

Tem peratur: $-0,5 ; 0,8 ;-1,1^{0}$.

Der Wind hat etwas nachgelassen, auch Schnee- und Graupelschauer nicht mehr, aber immer noch kalt und häfslich früh.

Leichte Schneedecke liegt noch. Von Mittag an wird es ganz schönes Wetter, Sonnenschein. Abend und nachts schöner Mondschein. Früh gegen $9 \mathrm{Uhr}$ einige wenige $\mathrm{Kr}$ ähen $\mathrm{u}$. Dohlen niedrig nach Norden ziehend, sonst nichts von Zug. Keine Klein vögel in den Büschen. Aufser einem Rotkehlchen, dafs dageblieben ist, drei Heidelerchen und einer Rohrammer nichts bemerkt.

5. April: Windrichtung: W; W; WNW.

Windstärke: $5,3 \mathrm{~m} ; 4,7 \mathrm{~m} ; 6,0 \mathrm{~m}$.

Temperatur: 1,$3 ; 3,4 ;-0,1^{0}$.

Das schlimme Wetter ist vorüber, Sonnenschein aber etwas kühl. Am Vormittag einige Kräh en hoch nach Norden wandernd, sonst nichts vom Zug. K le invögel nicht vorhanden. In der Nacht schöner Vollmond.

6. April: Windrichtung: W; W; W.

Windstärke: $4,4 \mathrm{~m} ; 6,8 \mathrm{~m} ; 5,8 \mathrm{~m}$.

Temperatur: 1,$3 ; 3,7 ; 2,4^{\circ}$.

Bis 9 a. schönes Wetter, Sonnenschein, dann droht Regen, gegen Mittag klart es wieder auf. Ein Paar Krähen hoch nach Norden, ebenso ein Flug Gänse, einige Tauben und Starschwärme nach Süden. Das ist alles vom heutigen Zuge. Keine Kleinvögel.

7. April: Windrichtung: WNW; NW; NW.

Windstärke: $6,3 \mathrm{~m} ; 5,8 \cdot \mathrm{m} ; 3$.

Temperatur: 3,$2 ; 5,2 ; 1,6^{\circ}$.

Klar, Sonnenschein. Früh etwas Krähenzug, der Mittag nachläfst, dann aber bis Abend truppweise anhält. Die erlegten Nebelkrähen sind lauter Junge. 
Von Raubvögeln ziehen einige Sperber und eine graue Weihe nach Norden, auch einige Tauben und ganz wenig Lerchen und Stare. Durchaus kein reger Zug. In der Nacht Mondschein.

8. April: Windrichtung: NW; NW; W.

Windstärke $4,1 \mathrm{~m} ; 3 ; 4$.

Temperatur: 2,$6 ; 4,7 ; 3,5^{\circ}$.

Früh heller Sonnenschein. Von 9 a. bedeckt, aber schön warm. Ganz guter Krähenzug, etwa 50-80 m hoch. Auch ziemlich viel Buchfinken, fast nur Männchen. Ganz wenig Stare. Der Zug drängt sich nur auf die ersten Morgenstunden zusammen. Die Krähen bekommen es plötzlich sehr eilig, beachten den ausgesetzten Uhu nicht mehr, der Zug läfst gegen 9 a. schon sehr nach und ist um 10 a. fast ganz vorüber.

9. April: W indrichtung und -stärke: NW. 2; NW. 4; N. 6. Temperatur: 2,$4 ; 3,31,1^{\circ}$.

Regnerisch. NW. 7.

10. April: Windrichtung und -stärke: NW. 7 ; NW. 7 ;

Temperatur: 2,$1 ; 3,5 ;-0,4^{0}$. NW. 2.

11. April: Windrichtung und-stärke: NO. 4; NW. 3 ;

Temperatur: $-0,4 ; 1,0 ;-1,5^{\circ}$.

Graupelschauer.

12. April: Windrichtung und stärke: NO. 4 ; NO. 3 ; NO. 2.

Temperatur: $-2,5 ; 0,6 ;-1,4^{0}$.

In der Nacht $-5,8^{\circ}$ Kälte.

Vom 9.-12. April bin ich zum Osterfeste in Rossitten. Am 9. in den Vormittagstunden ganz wenig Krähenzug. Am 10. u. 12. kein Zug.

Es fehlt bis jetzt immer noch der intensive Zug wie in andern Jahren. Das Haff immer noch nicht eisfrei, am Rande nur ein breiter offener Streifen. Auch auf dem Bruche noch Eis mit offenen Stellen, über denen wenig Lachmöwen schwärmen.

13. April: $W$ indrichtung und -stärke: $0.6 ; 0.6 ;$ NO. 4. Temperatur: $-1,1 ; 1,1 ; 0,3^{\circ}$.

Von 10 a. an Schnee mit Regen gemischt, kalt, schlechtes Wetter.

Ich bin wieder in Ulmenhorst.

Kein Zug, kein Vogelleben draufsen, alles tot.

In der Nacht dunkel, es schneit immer noch.

14. April: Windrichtung: NNO; W; SW. ${ }^{1}$

Windstärke: $3,0 \mathrm{~m} ; 2,8 \mathrm{~m}$.

Temperatur: 0,$7 ; 1,7 ; 0,4^{\circ}$.

Den ganzen Tag über Sprühregen, zuweilen mit Schnee vermischt. Ein trübseliges Wetter. 
Absolut tot draufsen, kein Zug. Eine A msel an der Hütte, zwei Kohlmeisen und einige recht grofse Erlenzeisig$\mathrm{schwärme}$ ist alles, was beobachtet wird.

Nacht dunkel, fast windstill.

15. April: Windrichtung: WNW; W; W.

Windstärke: $4,4 \mathrm{~m} ; 4 ; 9,8 \mathrm{~m}$.

Temperatur: 0,$9 ; 1,7 ; 1,2^{\circ}$.

Wieder trübe, von Mittag an Schnee u. Regen bei zunehmendem Winde, schlechtes Wetter. Früh um 8 etwa $10 \mathrm{Krähen} \mathrm{nach}$ Norden, ferner $9 \mathrm{Störche,} \mathrm{ein} \mathrm{roter} \mathrm{Milan} \mathrm{und} \mathrm{ein} \mathrm{Starflug.}$ Aller Zug ruht. Ganz tot draufsen. Ein Flug Erlenzeisige in den Bäumen, sonst nichts. Wann wird wieder einmal Zug eintreten? Wo bleiben die Vogelscharen, die Anfang April nach Süden gewandert sind? Auf dem Haff noch Eis. An der Hütte immer noch an manchen Abhängen kleine Flecken von altem Winterschnee.

Nacht dunkel, ohne Sterne, immer noch schwacher Regen.

16. April: Windrichtung: WNW. $12,9 \mathrm{~m}$; NW. 8 ; NW. 8.

Temperatur: 0,$7 ; 0,4 ; 1,5^{\circ}$.

Schneetreiben mit Sturm und Regen, ein schreckliches Wetter. Von Zug keine Spur. Der Sturm hat das Haffeis auf die andere Seite getrieben. Das Haff also auf der Nehrungsseite heute zum erstenmal eisfrei.

Ich gehe Nachmittag nach Rossitten. Bei dieser Wanderung merkt man so recht den Unterschied zwischen $\mathrm{Zug}$ und Rast hier auf der Nehrung. Bei Ulmenhorst kein Vogel zu sehen; es zieht also nichts. In der Oase Rossitten, wo sich Nahrungsquellen befinden, Kiebitze, Stare, Lerchen, Drosseln, $\mathrm{K} r a ̈ h$ en auf den Feldern, aber alle in geringer Anzahl in diesem Jahre. NO. 4.

17. April: Windrichtung und -stärke: NW. 5; NO. 6;

Temperatur 1,$7 ; 4,4 ; 1,0^{\circ}$.

Das Unwetter ist vorüber, nur noch kalter Wind aber Sonnenschein.

Ich sehe in Rossitten einige Krähen und Finken ziehen, aber nur bis gegen 11 a., dann ist schon aller Zug vorüber.

18. April: Windrichtung und -stärke: NW. 2; NW. 2; NO. Temperatur: 2,$2 ; 5,7 ; 0,0^{\circ}$.

Der erste schönere und vor allem wärmere Tag. Um 9 a. setzt etwas Zug ein. Krähen, auch Kleinvögel. Saatkrähen ziehen in grofser Höhe ihre Kreise, sich so nach Norden vorwärts bewegend, wie sie es an schönen Frühlingstagen zu tun pflegen. Die Krähenfänger kommen zurück, weil die Vögel aus solcher Höhe nicht fallen.

Von Raubvögeln ist nichts gezogen.

19. April: Windrichtung und -stärke: $0.4 ;$ NO.4; NO. 5 m. Temperatur: 0,$4 ; 3,5 ; 2,5^{\circ}$. Regen, kein Zug. 
20. April: Windrichtung und - stä rke: N. $5 ;$ N. 5 ; N. 3 m.

Te m p erat ur: 0,$3 ; 2,3 ; 1,6^{\circ}$. Schneeflocken früh, kein Zug.

21. April: Windrichtung und -stärke: N. 4; NW. 5; NNW. $7 \mathrm{~m}$.

Temperatur: $-1,0 ; 2,3 ; 0,7^{0}$. Meist bedeckt. Mittags wieder nach Ulmenhorst. Zug findet nicht statt. Im Laufe des Nachmittags kommen wohl einige kleine Trupps Nebelkrähen, auch drei ziehende Sperber werden beobachtet, aber was ist das gegen die Züge in andern Jahren!

Drosseln und Rotkehlchen sind etwas mehr angekommen und treiben sich auf den Triften und in den Büschen umher, auch einige Buchfinken und Heidelerchen. Die Nacht dunkel, ohne Sterne. Schneeflocken.

Im allgemeinen ist folgendes zu bemerken: Seit dem 27. und 28. März ist kein guter Zugtag wieder zu verzeichnen gewesen, mit Ausnahme etwa des 8. April. Es herrscht andauernd scharfer West, Nordwest und Nord; ein kaltes Wetter. Vegetation noch ganz zurück. Man friert und mufs tüchtig heizen. Viel Nachtfröste. Wann sollen die noch ausstehenden grofsen Krähenund Raubvogelzüge vor sich gehen? Sind die Vögel einzeln und verstohlen nach Norden in ihre Brutgebiete gelangt? Jedenfalls war das bis jetzt eine traurige Zugzeit.

22. April: W indrichtung und-stärke: N. 6,4 m; NNW. $6,8 \mathrm{~m} ;$ N. $5 \mathrm{~m}$.

Temperatur: $-0,2 ; 1,5 ;-0,4$.

Sonnenschein, aber sehr kalt. Von der Nacht her liegt noch etwas Schnee. $\mathrm{Ab}$ und zu zieht einmal ein Trupp Erlenzeisige, auch ein Trupp Hänflinge ${ }^{1}$ ) nach Norden. 2 Turmfalken streichen ganz niedrig über die Düne und setzen sich immer, als ob sie ermüdet wären. Man fragt sich, ob der R a ubvogelzug etwa in der Weise ganz unbemerkt vor sich geht, dafs die Stücke ganz einzeln ziehen? Sonst nichts von $\mathrm{Zug}$ zu bemerken. Drosseln und Rotkehlchen sind wieder weniger geworden. Die einheimischen Buchfinken schlagen. Ich gehe nach Rossitten.

24. April: Windrichtung und-stärke: 0.3 ; SO. 2 ; SO. 1 .

Temperatur: 1,$0 ; 5,3 ; 4,5^{\circ}$.

Heute bei den östlichen Winden etwas Zug bei Rossitten beobachtet: Krähen und Raubvögel. Auch etwas Vogelleben auf den Bäumen und auf den Triften: D rosselflüge (besonders iliacus) zusammensitzend und singend; Rotkehl chen.

25. April: Windrichtung und-stärke: 0. 3; SO. 4; SW. 3:

Temperatur: 3,$9 ; 10,9 ; 7,4^{0}$.

Die eingetretenen östlichen Winde und die wärmere Temperatur bringen Leben in die Vogelwelt. Zug bricht los. Krähen,

1) Ũber Hănflingszüge im Frühjahre siehe Năheres in Reich en ow's Ornithologischen Monatsberichten Aprilheft 1910. 
Raubvögel, Kleinvögel ziehen. In Sarkau werden viel Krähen gefangen. Viel Rotkehlchen und Drosseln in den Büschen und auf den Triften. Letztere in Trupps zusammensitzend und singend (iliacus). 5 Störche auf dem Felde.

Um 3 p. fahre ich nach Ulmenhorst zurück. Es ist noch etwas Zug als ich hinauskomme: einige Krähentrupps, mehrere Sperber, eine graue Weihe, mehrere Finkenflüge nach $\mathrm{N}$.

Gegen 4,25 p. Gewitter in der Ferne, dann warmer Regen.

Um 9 Uhr nachts ziehen Blä Ssh ühner (Fulica atra) rufend nicht sehr hoch über Ulmenhorst nach $\mathrm{N}$.

26. April: Windrichtung: SW. 4,2 m; SW. 4,2 m; S0. 2,9 m.

Temperatur: 7,$8 ; 9,4 ; 6,1^{\circ}$.

Ziemlich warm, sonnig, erster schöner Frühlingstag.

K rähen ziehen über den Haffdünen ziemlich lebhaft, aber sehr hoch, sodafs man vom Zuge nicht viel merkt; etwa $200 \mathrm{~m}$ hoch, Kopf nach N., Zugrichtung NNO., Wind von SW. Unter den Krähen kommen ab und zu Sperber, Rauhfufsbussarde und $M$ äusebussarde. Sperber verhältnifsmäfsig am häufigsten, sehr hoch.

Nach dem Uhu stofsen weder Krähen noch Raubvögel.

5 Störche nach $\mathrm{N}$.

Auffallend ist, dafs in den Morgenstunden Kleinvögel (Stare, Drosseln, Finken, Zeisige) ziemlich lebhaft wieder nach S. ziehen.' Auch 2 Kraniche nach S.

Gegen $1 / 210$ Uhr früh hört schon aller Zug auf und ruht für den ganzen Tag, nur Kleinvögel ziehen immer noch Truppweise nach Süden. Dabei herrscht hier das schönste Wetter. Im Laufe des Nachmittags geht der Wind nach SO. herum.

Das Bachstelzenweibchen trägt Hälmchen in den an der Hütte hängenden Kasten. Ohne Zweifel dasselbe Pärchen vom vorigen Jahre.

Gegen 8 Uhr abends bei Mondschein fulica atra rufend nach N. ziehend.

Um 10 Uhr nachts Himmel mehr bewölkt, der Mond ist weg. Dichte Wolken.

27. April: Windrichtung und -stärke: SO. $5 \mathrm{~m}$; SO. 2; SO. $4,4 \mathrm{~m}$.

Temperatur: 6,$9 ; 13,6 ; 9,7^{\circ}$;

Meist bedeckt, ab und zu Sonnenblicke. Um 9 a. Nebel in Höhe der Haffdüne, ziemlich warm. Es sieht früh nach Regen oder Gewitter aus. Gegen Mittag schwindet der Nebel ab und zu. Gegen Abend Fern-Gewitter im Osten, auch Wetterleuchten. Nun ist der SO. Wind da und doch kein guter Zug. Dagegen findet immer noch, wie gestern, Rückzug nach Süden zu statt, namentlich von Kleinvögeln, aber auch von einigen Krähen.

Wenige Krähen nach $\mathrm{N}$. ziehend, ebenso ein Bussard, ein Sperber, ein Baumfalke, einige Eichelhäher, aber das ist immerhin kein guter Zug.

Jonrn. f. Orn. LVII. Jahrg. Jali 1910. 
Gegen Mittag, etwa von 1-2 Uhr, fliegen etwas mehr Raubvögel: $\mathrm{Sp}$ er ber, Turmfalken, die beiden Bussardarten, auch ein paar Krähen nach $\mathrm{N}$.

Vorm Uhu 3 C. cornix geschossen, deren Geschlechtsteile ich untersuche:

Nr. 1 O, Eierstock ganz schwach entwickelt, wie Gries. Nr. $2 \sigma^{x}$, Hoden schwach entwickelt etwa $4 \mathrm{~mm}$ lang, wie Schrotkörner Nr. 4 oder 5. Nr. $3 \sigma^{x}$, Hoden sehr stark entwickelt, etwa $14 \mathrm{~mm}$ lang, wie weifse Bohnen. Nr. 1 und 2 jedenfalls nordische Stücke, Nr. 3 eine einheimische Brutkrähe. Die jetzt ziehenden und erlegten Krähen sind lauter Junge vom vorigen Jahre. Im Frühjahre ziehen die Jungen nach den Alten; umgekehrt wie im Herbste.

2 Kraniche beobachtet; 1 Storch nach N. 1 Tringoides hypoleucos nach $\mathrm{N}$. fliegend.

Mehrere Pärchen weifse Bachstelzen bekämpfen sich an der Hütte. Drosseln und Rotkehlchen noch in den Büschen. Einen Laubsänger gesehen.

Abends schöner Mondschein, ein prächtiger warmer Abend. Ich höre in der Luft Flügelschläge, die von Enten oder Bläfs$\mathrm{hühnern} \mathrm{herrühren.} \mathrm{Letztere} \mathrm{vernehme} \mathrm{ich} \mathrm{auch} \mathrm{rufen.}$

28. April: Windrichtung und -stärke: WSW. $3,7 \mathrm{~m}$; SW. 3 ; SW. 4.

Temperatur: 6,$4 ; 8,7 ; 6,2^{\circ}$.

Trübes regnerisches Wetter. Dunstig.

Zunächst nichts besonderes von Zug zu bemerken. Einige Kleinvögel züge zichen wieder nach Süden. Einige Sperber, ein roter Milan nach Norden. Gegen Mittag wird das Wetter etwas heller, es kommen einige $\mathrm{Kräh}$ en; ein Wanderfalke über dem Uhu. Eine erlegte Corvus cornix hat ganz schwach entwickelte Hoden.

Bei dem herrschenden Südwestwinde ziehen die Krähen immer mehr über der Haffdüne. Nachmittag nach Rossitten zurück. Eine Rohrweihe über dem Bruche.

Im allgemeinen mag noch folgendes bemerkt werden: Der Frühjahrszug 1909 war sehr mäfsig. Hervorragende Zugtage, an denen die Fülle der Vogelscharen geradezu überwältigend auf den Beobachter einwirkt, sind überhaupt nicht vorgekommen. Die Witterung war zu ungünstig. Es darf die Regel aufgestellt werden, dafs östliche Winde und warme Temperatur im Frühjahre für die Kurische Nehrung Vogelzug bringen. Nun entsteht die Frage, wo und wie die Vogelscharen, die im Herbste 1908 über die Nehrung nach S. gewandert sind, im Frühjahre 1909 in ihre nördlichen Brutgebiete gelangt sind? Über die Kurische Nehrung nicht, wenigstens nicht in Sichthöhe. Das steht fest. Hier sind viel zu wenig Vögel durchgekommen. An der litauischen Haffküste entlang, wie eingezogene Erkundigungen ergeben, auch nicht In Vermutungen will ich mich nicht einlassen. Man wird schon nach und nach hinter die Wahrheit kommen. 


\section{Der Herbstzug in Ulmenhorst.}

In diesem Jahre konnte ich schon im September einige Zeit in Ulmenhorst zubringen. Der Vogelzug hat um diese Zeit ein ganz anderes Gesicht, als im Oktober. Es fehlen in dieser frühen Jahreszeit vor allem die Massenzüge von Krähen und Raubvögeln. Dafür treten mehr die Züge von Kleinvögeln (Laubsängern, Rotschwänzchen u. a.) von Busch zu Busch in die Erscheinung.

3. September: Windrichtung und -stärke: SW. 3; W. 5 ; W. 5 .

Temperatur: 14,$1 ; 15,0 ; 12,9^{\circ}$.

Zuweilen kleine Regenschauer, aber helles Wetter. Es ziehen sehr lebhabt von Busch zu Busch: Laubsänger (sehr viel, manchmal in einem kleinen Busche 10 Stück auf einem Fleck), Gartenrotschwänzchen, Stein- und Wiesenschmätzer. Ferner Pieper, Trauerfliegenfänger, auch Kuckucke und grofse Buntspechte. Von Ziegenmelkern liegen manchmal mehrere Stück auf kleinem Fleck zusammen. Uferschwalben ziehen dicht über den Abhängen der Wanderdünen (nur etwa $1 / 2$ Meter hoch) nach Süden. Man bemerkt die Vögel erst, wenn man selbst auf der Düne steht, so verschwimmt die fahle Rückenfärbung mit dem Gelb der Dünen. Am Haff 2 Austernfischer.

Gegen Abend wimmelt es förmlich in den Büschen von Kleinvögeln, namentlich von Laubsängern. Um nun zu beobachten, ob sich die Vögel abends erheben, um weiterzuziehen, stelle ich mich mit dem Gesicht nach Norden gewendet auf der schmalen Nehrung quer vor. Es wird dämmrig, Garte nrotschwänzchen schnickern laut wie vor dem Schlafengehen, dann wird es ganz dunkel, alles ist ruhig. Sind nun die Kleinvögel etwa unbemerkt fortgezogen? Ich untersuche das Buschwerk und jage die Vögel dutzendweise heraus. Aus einem von der Düne fast verwehten Weidenbusche von etwa $3 \mathrm{qm}$ Gröfse allein gegen 20 Stück. Es ist auffallend, dafs die Tiere bei der Dunkelheit sehr unsicher abstreichen. Alles rastet also, und zwar an Stellen, die die betreffenden Vögel aufserbalb der Zugzeiten nie als Schlafplatz wählen würden. Das Wetter ist schlecht geworden. Sprühregen, starker West. In der Dämmerung fliegen $\mathrm{Z}$ i eg enmelker, Insekten fangend, umher. Also auch sie ziehen nicht weiter.

Kein Mondschein, starke Bewölkung, um $10 \mathrm{Uhr}$ nachts regnet es noch.

4. September: Windrichtung und -stärke: SW. 4; S. $4 ;$ SO. 4 .

Temperatur: 13,$0 ; 15,9 ; 14,4^{0}$.

Früh noch ganz trübe. Im Laufe des Tages wird es etwas heller, aber der Himmel den ganzen Tag über bedeckt. Abends um 9 Uhr halb bedeckt, einige Sterne. 
Dieselben Kleinvögel von gestern sind noch da (Laubsänger, ferner viel graue Fliegenfänger, Gartenrotschwänzchen, Baumpieper, einige Finken, auch $2 \mathrm{Hei-}$ delerchen) und bleiben auch den ganzen Tag über da. Dabei findet den ganzen Tag hindurch in der Luft ein regelrechter Zng von gelben Bachstelzen (juv.) und Piepern in Flügen von 10 bis 50 Stück statt. Höhe etwa $30-40$ Meter. Zuweilen fallen einige Flüge ein.

Auch Schwalben ziehen, besonders gegen Abend, regelrecht nach S., nicht eilig, öfter umherschwärmend, besonders urbica und riparia, darunter nicht selten $\mathrm{Tu} \mathrm{rm} \mathrm{sch} \mathrm{w} \mathrm{a} \mathrm{l} \mathrm{b} \mathrm{e} \mathrm{n} \mathrm{(Apus);}$ auch ein Trupp Kreuzschnäbel etwa $80 \mathrm{~m}$ hoch lockend nach S. Unter den Me hls chwalben ein Albino mit gelbem Anfluge (juv. schwarze Augen), den ich erlege. Wie fällt ein solcher Vogel unter seinen normal gefärbten Stammesgenossen in der Luft auf! Es ist nicht zu verwundern, dafs die Raubvögel zunächst auf solche Tiere Jagd machen. Die grauen Fli e g e nfänger, gelben Bachstelzen, Turmschwalben, Mehlschwalben sind nach den zur Prüfung gesammelten Stücken lauter Junge. So werden jetzt die Jungen ziehen und im Oktober kommen jedenfalls die Alten.

Ferner beobachtet: mehrere Kuckucke, zwei schwarzbraune Milane, mehrmals Strandvögel (Totanus ochropus sicher erkannt), einige Steinschmätzer (S. oenanthe), braune Exemplare. Grofse Buntspechte und Ziegenmelker nicht gesehen.

Um festzustellen, ob die oben unterm 3. September genannten Kleinvögel abends weitergezogen sind, gehe ich in der Nacht hinaus und scheuche aus den Büschen wieder eine Anzahl Vögel auf, meist wohl Laubsänger und Rotschwänzchen; aber bei weitem nicht so viel wie gestern. Sie sind also immer noch da. S0. 8.

5. September: Windrichtung und -stärke: SO. 8; SO. 5;

Temperatur: 12,$7 ; 19,5 ; 16,6^{0}$.

Helles sonniges Wetter, abends umzieht sich der Himmel. Gewitterstimmung.

Die gestern und vorgestern beobachteten Keinvögel sind noch da. Viel Trauerfliegenfänger sind noch dazugekommen, lauter graue. Ein zur Probe erlegtes ist ein junges Exemplar. Es werden wohl alles Junge sein. Auch Buchfinken sind mehr dazu gekommen. Ein erlegtes Stück ist ein in der Mauser stehendes junges $\sigma^{x}$, das an den Brustseiten rote Federn bekommt. Auch von dieser Art werden jetzt fast ausschliefslich Junge ziehen, höchstens einige $Q \mathcal{Q}$ darunter. Auch Goldammern sind angekommen.

In der Luft ziehen nicht viel Vögel. Aus einem an der Vordüne eingefallenen Flug gelber Bachstelzen schiefse ich ein schönes altes $\sigma^{\top}$ von $\boldsymbol{B}$. borealis. Im Laufe des schönen Vor- 
mittags sind die meisten Laubsänger weitergezogen. Am Nachmittag werden nur noch wenige bemerkt. Sie sind also von Busch zu Busch am Tage weitergewandert. Schwalben (urbica und riparia) schwärmen nur am Vormittag umher und ziehen in dieser gemächlichen Weise weiter nach S. Darunter garnicht selten Turmschwalben (Apus), und zwar alte. Von dieser Art findet also immer noch regelrechter $\mathrm{Zug}$ statt, während unsere heimischen Brutvögel längst weg sind.

Ein kleiner Trupp Kreuzschnäbel hoch nach S. Gegen Abend ein Ziegenmelker an der Hütte Insekten fangend. Einen sehr geschätzten Ruheplatz für auf dem Zuge befindliche Ziegenm elker bildet der ein Stück abseits von der Hütte befindliche Müll- oder Kehrichthaufen. An mehreren aufeinander folgenden Morgen werden 1 oder 2 dieser Vögel dort angetroffen. Von den umherliegenden Knochen, Lumpen, Federn und dergl. heben sich die Nachtschwalbenkörper nicht ab, und so ist es vorgekommen, dafs ich ihnen beinahe frühmorgens den Inhalt des Abfalleimers über den Pelz goss. SW. 1 .

6. September: Windrichtung und -stärke: W. 4 ; W. 6 ;

Temperatur: 13,$1 ; 13,9 ; 12,0^{\circ}$.

Heller Sonnenschein. K leinvögel noch anwesend: Finken, beide Arten Fliegenschnäpper, wenig Laubsänger, auch grofse Bủntspechte.

Über Rossitten gegen Abend Schwalben zu beobachten (urbica, riparia, ganz vereinzelt rustica). Kreuzschnäbel in kleinen Trupps über Rossitten nach $S W$. Viel Steinschmätzer (S. oenanthe) (braune) und Wiesenschmätzer ( $P$. rubetra) auf der Palwe auf dem Zuge befindlich; von Bäumchen zu Bäumchen fliegend. NO. 7 ; NO. 7 .

14. September: Windrichtung und -stärke: NO. 7 ;

Temperatur: 13,$1 ; 14,3 ; 14,5^{0}$.

Bis Mittag Regen; bedeckt. Die Vögel rasten heute auf den Feldern. Die ersten Nebelkrähen sind da; auch sie rasten. An einer mit Gras bewachsenen feuchten Stelle mitten in den Dünen 4 Limosa lapponica juv.; nicht weit davon 1 Numenius arquatus. Diese Vögel sind nur der vorhandenen Riesenohrwürmer wegen in solchem toten Gelände anzutreffen. Siehe oben die Notizen über Numenius. Ein kleiner Trupp Brachvögel nach $\mathrm{S}$. ziehend.

Nachts Himmel bedeckt.

15. September: Windrichtung und -stärke: NO. $5 \mathrm{~m}$; NNO. $5 \mathrm{~m}$; NO. 5 .

Temperatur: 11,$8 ; 17,5 ; 14,1^{\circ}$.

Schönes helles Wetter, den ganzen Tag Sonnenschein.

Das Bemerkenswerte an diesem Tage ist, dafs sowohl früh, als auch nachmittags grölsere Flüge von Tannenmeisen ( $P$. ater) 
(bis zu 50 Stück) nach S. sowohl, als auch nach N. ziehen und in den Gehölzen einfallen. Sonst findet kein Zug in der Luft statt. In den Büschen wenig Kleinvögel: einzelne Rotkehlchen als Vorläufer, die schon gestern bemerkt wurden; ferner Pieper, Finken, Laubsänger. Einige Sperber, grofse Buntspechte, 1 Flug Tauben (palumbus). Von letzteren eine Alte erlegt. Kropf ganz leer; im Magen nur kleine Steinchen. Ein Ziegenmelker abends an der Hütte.

16. September: Windrichtung und -stärke: N0.6,5 m; NO. 5 ; NO. 5 .

Temperatur: 10,$1 ; 14,5 ; 15,5^{0}$.

Bis 7 a. Sonnenschein mit Unterbrechungen. Dann umzieht sich der Himmel und bleibt den ganzen Tag über bedeckt. Die Wolken ziehen ganz niedrig mit dem angegebenen Winde. Gegen 4 p. Regentropfen.

Vogelleben und Zug nur in den ersten Vormittagstunden, etwa von 1/25-8. Dann Ruhe, tot draufsen.

Bemerkenswert ist, dafs heute alles nach N. zieht: Starflüg e (ziemlich viel), Zeisigflüge (spinus), S chwalben (rustica) (mäfsig viel); dann vor allem grofse Buntspechte, einige Pie per und Heidelerchen. Ein Sperber nach S.

In den Büschen wenig der jetzt ziehenden Kle invög el. Die ersten Drosseln (musicus) als Vorläufer; Goldhähnchen, 1 Eichelheher, Ringeltauben.

Auf dem Dach der Hütte findet sich eine verirrte $\mathrm{Haus}$ t a ube ein. Das ist nun schon das zweite derartige Stück, das die Ulmenhorst-Hütte als einzige menschliche Niederlassung in weitem Umkreise als Zufluchtsort aufsuchte.

17. September: Windrichtung und -stärke: $0 N 0.4,5 \mathrm{~m}$; $0.4 ; \mathrm{SW} .1$.

Temperatur: 16,$5 ; 19,4 ; 16,2^{\circ}$.

Meist bedeckt, gegen Mittag aufklärend, Sonnenschein. Ein schöner warmer Herbsttag. 6 p. Donner. Wetterleuchten im W. Wenig Vogelleben und nur in den ersten Morgenstunden. Um 5 a. noch nichts zu sehen. Etwa von 5,30 a. an einige Startrupps und Schwalben (rustica) ziehend, und zwar wieder nach N. Einige Ringelta u b enflüge nach N. sowohl, als auch nach S. Eine juv. aus einem nach N. ziehenden Schwarm herausgeschossen. Einige Sperber nach S.

Mehrere Regenpfeifer im Laufe des Tages pfeifend über Ulmenhorst ziehend.

Einige Kreuzschnäbel hoch ziehend.

Wenig Kleinvögel in den Büschen.

Ein paar mal Krähen (C. cornix) über dem Uhu. Die diesjährigen Jungen sind jetzt stark in der Mauser des Kleingefieders. Die Alten mausern die Schwungfedern.

$\mathrm{Z}$ i e g enmelker gegen Abend nicht gesehen.

In der Nacht Sternhimmel. 
18. September: Windrichtung und -stärke: SSO. $2,5 \mathrm{~m}$; $0.2 ;$ NO. 4 .

Te mperatur: 14,$4 ; 18,7 ; 16,1^{0}$.

Früh gleich nach Sonnenaufgang Himmel bezogen. Gegen 9 a. aufklärend; es wird ein heller warmer Tag.

Von 6 a. an ziemlich lebhafter $\mathrm{Kl}$ einvog el zug, und zwar meist normalerweise nach S.: meist $\mathrm{P}$ ieper und $\mathrm{Finken}$; ferner Stare und Schwalben (immer nur rustica). Grofse Buntspechte mehrfach nach S. ziehend, zuweilen ziemlich hoch, aufser Schufsweite. Zwei erlegte sind ein $\sigma^{x}$ ad. und ein $\bigcirc$ ad. So sind dem grofsen diesjährigen Zuge dieses Vogels doch auch einige alte beigemischt. Zum bei weitem gröfsten Teile sind es aber Junge mit roter Kopfplatte.

Mehrere Motacilla alba, Chrysomitris spinus und Stare sehe ich zuweilen auch nach $N$. ziehen. 3 Sperber, $1 \sigma^{T}$ juv. erlegt. Kreuzschnäbel in der Luft gehört. Keine Tauben.

Gegen $8 \mathrm{Uhr}$ vormittags hat der Zug nachgelassen und ist um 9 Uhr ganz vorüber.

Durch eine Reise nach Helgoland ist hier eine grofse Lücke in den Beobachtungen zu verzeichnen.

17. Oktober: Windrichtung und -stärke: SW. 4; S. 5 ; S. 4.

Te m perat ur: 11,$9 ; 16,3 ; 12,1^{0}$.

Vögel rasten heute. W ild t a u be n und $\mathrm{F}$ in ke n bemerkt. S. 1 .

18. Oktober: Windrichtung und -stärke: S. 3; S. 3;

Te m p eratur: 10,$8 ; 15,7 ; 10,9^{\circ}$.

Hell, warmer Sonnenschein.

Sehr guter Krähenzug; ferner mäfsig viel Sperber, Rauhfufsussarde, viel Tauben (palumbus und oenas), viel Finken (coelebs), Heidelerchen, Pieper, Kreuzschnäbel, wenig Stare nach S. ziehend.

In den Büschen viel Goldhähnchen, einige Zaunkönige.

Gegen 3 p. hört der Zug schon auf.

19. Oktober: Windrichtung und -stärke: S. 2 ; S. 1; S. 2.

Tem peratur: 10,$0 ; 17,5 ; 12,7^{\circ}$.

Hell, Sonnenschein, abends Wetterleuchten.

Derselbe gute Zug wie gestern, auch dieselben Vögel. Gegen Abend ein Flug Schwanzmeisen durch die Büsche nach S. ziehend.

20. Oktober: Windrichtung und -stärke: SW. 2; SW. $2,8 \mathrm{~m} ;$ S. 2 .

Temperatur: 13,$5 ; 14,0 ; 12,4^{0}$.

Früh bedeckt, dunstig, um 10 a. mehr aufklärend, auch Sonnenschein.

Zunächst früh nach Sonnenaufgang kein Zug. Gegen 8 einige Krähen, Kreuzschnäbel, Meisen, wilde Gäuse nach S.; Seetaucher (Urinator) vom Haff nach der See fliegend. 
Als das Wetter gegen $10 \mathrm{Uhr}$ heller wird, ziehen sofort mehr Krähen, auch einige Finkenschwärme. Gegen Mittag wird es noch klarer, es setzt ganz guter Zug ein, aber nicht so gut und höher wie gestern und vorgestern, aber dieselben Vögel wie an den beiden genannten Tagen. 1 Wanderfalke beobachtet. Viel Goldhähnchen in den Büschen. Mehre Haussperlinge auf den Bäumen an der Hütte.

Nachts sternenhell.

21. Oktober: Windrichtung und -stärke: SSW. $3,4 \mathrm{~m}$; SSW. $3 \mathrm{~m}$; SO. 4.

Temper atur: 11,$0 ; 13,6 ; 11,9^{\circ}$.

Früh zunächst dunstig, im Laufe des Tages heller werdend.

Gegen 6,15 a. 5 Sperber, 2 Rauhfu $\int$ sbussarde, einige Krähen, einige Pieper ziehend. Dompfaffen in den Bäumen gehört. Als es nachmittags heller wird, fangen die $\mathrm{Krähen}$ in mäfsiger Zahl an $\mathrm{zu}$ ziehen und setzen ihre Wanderung bis zur Dämmerung fort. Dieses Einsetzen des Zuges erst am Nachmittage und Anhalten bis zur Dämmerung ist oft ein Zeichen dafür, dafs am nächsten Tage guter Zug stattfinden wird. Auch Sperber, Rauhfufsbussarde, Wanderfalken uud Kleinvögel in mäfsiger Zahl ziehend. Zughöhe etwa $30-80 \mathrm{~m} .1 \mathrm{~W}$ anderfalk en erlegt.

Des dunstigen Wetters wegen im allgemeinen schwacher Zug.

22. Oktober: Windrichtung und -stärke: SSO. $5,8 \mathrm{~m}$; SSO. 6,2 m; SW. 2.

Temperatur: 8,$9 ; 11,3 ; 9,5^{\circ}$.

Früh kühl, ziemlich klar. Mittags umzieht sich der Himmel, der Wind schlägt nach W. um, es folgt Regen.

Um 6 a. fangen schon $\mathrm{F}$ in ken an zu ziehen. Dann setzt gegen $7 \mathrm{Uhr}$, als die Sonne über die Düne steigt, ein grofsartiger Krähenzug ein, der bei dem Gegenwinde niedrig, nur etwa 3-20 m hoch, vor sich geht. Ferner ziehen Unmassen von Buchfinken (meist $\sigma^{\top} \sigma^{\top}$ ), Heidelerchen, Feldle rchen, Stare, einige Kreuzschnäbel, ein Dompfaffe, aber keine Pieper. Auch ein Flug Gäns e.

Unter den Krähen befinden sich Raubvögel in mäfsiger Zahl: Sperber, Rauhfufsbussarde, 1 Wanderfalke, mehrfach Merlinfalken (ausgefärbte $\sigma^{\top} \sigma^{\top}$ ).

Der Zug hält in dieser Stärke bis gegen 2 Uhr nachmittags an. Dann geht der Wind mehr nach Westen herum, der Himmel umzieht sich, es fängt gegen $3 \mathrm{p}$. an zu regnen. Der Zug hört ganz auf. Als das Wetter anfängt umzuschlagen merkt man es den Vögeln schon an, dafs sie nicht mehr gern vorwärts wollen; sie fallen am Waldrande ein und schliefsen sich zu grofsen Flügen zusammen, um dann erst die weiten kahlen Strecken nah S. zu zu überfliegen.

In den Büschen sehr wenig Kleinvögel: Goldhähnchen, einige Za u nkönige, 1 Picus major ad.; Drosse ln fehlen fastganz. 
Gegen Abend als es schon ziemlich dämmerig ist, eilen bei dem Regen einige kleine Starflüge noch nach S.

$\mathrm{Im}$ allgemeinen hat man von diesem günstigen Zugtage folgenden Eindruck: Vormittags bei dem günstigen Wetter streben die Vögel mit Macht vorwärts. Sie kümmern sich weder um den ausgesetzten Uhu, noch um die angebundenen Lockkrähen, da sie schon $\mathrm{zu}$ abnen scheinen, dafs sie durch schlechte Witterung bald aufgehalten werden. Sobald der Wetterumschlag erfolgt ist, hört der Zug ganz plötzlich auf.

23. Oktober: Windrichtung und -stärke: SSW. $2,9 \mathrm{~m}$; SW. 4 ; S. 5 .

Temperatur: 8,$1 ; 12,1 ; 10,0^{\circ}$.

Der Wind schlug im Laufe des Vormittags manchmal mehr nach 0 . um, dann gegen Abend wieder mehr nach S.

Ein schöner heller Herbsttag.

Ein hervorragender Zugtag: Krähen, besonders Sa atkrähen auch Dohlen, daneben Nebelkrähen in Unmassen. Die Sa tkräh en immer in grofsen vereinigten Scharen, An R a ubvögeln sehr viel Sperber, ferner Rauhufsbussarde, Wanderfalken. Auch Eichelheher mehrfach in der Luft ziehend. Charakteristisch ist von dem Tage, dafs verhältnismälsig wenig Kleinvögel zogen. Goldhähnchen mehrfach. Das war mal ein Tag, wie man ihn gern hat, bei dem einem das Herz weit wird. Ein Leben um und über Ulmenhorst! Leider konnte ich diesen interessanten Tag nicht so recht ausnutzen, weil ich auf mehrere Stunden dienstlich nach Rossitten fahren mufste. Bei der Rückkehr gegen Abend machte ich noch eine Doublette auf Wildgänse (Anser fabalis).

24. Oktober: W ind ri ch tung: und -stärke: SSO. 3,8 m; SSO. $6,2 \mathrm{~m}$; SSO. 5 .

Temperatur: 8,$8 ; 13,1 ; 10,4^{\circ}$.

Heller schöner Tag; meist Sonnenschein, kühler Wind, der im Laufe des Tages stärker wird. Früh $1 / \mathbf{g}^{6}$, als es noch ganz dämmerig ist, noch nichts von Zug. Gegen 6 a. einige Stare nach S. Dann guter $\mathrm{Krähenzug,} \mathrm{besonders} \mathrm{viel} \mathrm{Corvus}$ frugilegus, und zwar ziehen heute fast nur Krähen, sehr wenig andere Vögel, von denen folgende zu nennen sind: Sperber, und Rauhufsbussarde, 1 graue Weihe, Drosseln ( $T$. viscivorus), einige Starflüge, ganz wenig Tauben und Kleinvögel (Finken, einzelne Pieper). Zughöhe von allen Vögeln 4-30 m. Den Uhu beachten die Krähen und Raubvögel wenig.

In den Büschen Goldhähnchen. 1 Lanius excubitor beobachtet. 1 Waldohreule geschossen, die einen Star in den Fängen trägt, den sie aber nicht selbst gefangen hat, denn der Kadaver ist ganz kalt und steif.

Nacht mond- und sternenhell. Mehrfach Drosseln in der Luft ziehend gehört. Man vernimmt den Lockton. Sie können nicht hoch gewesen sein. Etwa $50 \mathrm{~m}$ hoch. Herr A. Viebig 
meldet von Berlin-Wilmers dorf vom 24. und 25. Oktober dafs nur morgens ca. 1 Stunde lang etwas Krähenzug gewesen ist Richtung Südwest, dem frischen Wind direkt entgegen. Flughöhe etwa $75 \mathrm{~m}$.

25. Oktober: Windrichtung und -stärke: SSW. $3,1 \mathrm{~m}$; SSW. 1 ; SSW. 1.

Temperat ur: 8,$1 ; 10,4 ; 8,3^{\circ}$.

Bis $10 \mathrm{Uhr}$ vormittags einigermafsen hell. Dann umzieht sich der Himmel. Den ganzen Tag trübes Wetter. Der Wind wird im Laufe des Tages schwächer.

Früh 6,45 einige Kleinvögelschwärme, auch Stare, mehrere Sperber; 6,50 die ersten Krähen; es entwickelt sich mäfsiger Krähenzug, der bei dem schwachen Winde etwas höher wie gestern vor sich geht, 50-100 m hoch. Der Uhu wird viel attackiert. Die Krähen haben grofse Lust sich zu setzten. Als der Himmel nachmittags immer bedeckter wird, fallen die Krähen am Waldrande ein und wollen nicht vorwärts.

Kleinvögel ziehen mehr als gestern: Finken, Stare, Heidelerch en, auch einige Trupps Kreuzschnäbel, Zeisige (spinus), einige Drosseln.

Raubvögel wenig ziehend: Sperber und Rauhfufsbussarde. 6-8 Schwäne nach S. ziehend; ebenso einige Wildt a u benflüge, meist oenas.

In den B üschen D rosseln, die in den letzten Tagen ganz fehlten. Sie sind vorige Nacht mit Waldschnepfen zusammen angekommen; ferner Goldhähnchen, mehrere D $0 \mathrm{~m}$ $\mathrm{pfaffen}$, einige Zaunkönige und Rotkehlchen.

1 Crex crex zu so später Jahreszeit noch bei Ulmenhorst auf einem Gelände angetroffen, das für Wachtelkönige wenig geeignet erscheint. Mageninhalt: Weidenblättchen und 2 Steine. Der Vogel ist in guter Leibesverfassung.

Mehrere W a ld o h reulen (Asio otus) in den Büschen sitzend und auch abends fliegend. Diese Art ist also jetzt auf dem Zuge.

Abends in der Dunkelheit Drosseln in der Luft ziehend. In der Nacht Himmel bedeckt, Mond durch die Wolken sichtbar.

26. Oktober: W indrichtung und -s tärke: WSW. $2,4 \mathrm{~m}$; WSW. $3,8 \mathrm{~m}$; W. 1 .

Temperatur: 8,$0 ; 10,6 ; 7,5^{\circ}$.

Zunächst bedeckt. Dann gegen 10 a. aufklärend, teilweise Sonnenschein. Von 2 p. an wird es wieder trübe.

Um 2,13 Uhr Nachmittags eine eigenartige Erscheinung am Himmel: um die Sonne ein grofser Ring in den Regenbogenfarben, ferner oberhalb der Sonne eine Nebensonne sichtbar.

Um 6,25 zwei K rähen, ferner je ein Flug Dohlen, Stâ re und Wildtauben (oenas) nach S. Dann setzt von etwa $8 \mathrm{Uhr}$ an recht guter Krähenzug ein, der bei diesem schwachen westlichen Winde höher, meist etwa $50-80 \mathrm{~m}$ hoch, vor sich geht. Den N ebelkrähen ziemlich viel Dohlen und auch Sa atkrähen bei- 
gemischt. Nach dem Uhu kommen sie recht gut, ziehen also mit Mufse, bäumen auch gern auf. Der Krähen- und Dohlenzug zieht sich heute bis spät abends hin, noch um 4 p. guter Zug, aber hoch. Die letzten kommen gegen $1 / 25 \mathrm{Uhr}$ und fallen teilweise im Walde zum Übernachten ein.

Raubvögel nicht sehr viel ziehend: einige Sperber, $1 \mathrm{M}$ ä use bussard, (A. lagopus wohl gar nicht), Wanderfalken, und was von besonderem Interesse: 2 S eeadler juv. 80-100 m hoch über die Hütte nach S. ziehend, einer mittags um 12, einer um 3 Uhr. Ein schöner Anblick! Me rlinfalken garnicht mehr gesehen. Wildtauben-und Starflüge nicht viel. Der heutige Zug wird ganz von den Krähen und Dohlen beherrscht. In den Büschen sind die Drosseln und Rotkehlchen von gestern noch vorhanden, auch ein paar Amseln (1 juv. erlegt); viel Zaunkönige und Goldhähnchen, einige Eichelhäher, eine Certhia.

Abends beobachte ich, wie die D rosseln in der Dämmerung abziehen. Gegen $3 / 45$ Uhr mehrere nach S., etwa $40 \mathrm{~m}$ hoch; Dann höre ich sie auch noch mehrfach in der Luft als es schon ganz dunkel ist (musicus und iliacus). Danach müfsten also morgen die meisten Drosseln von Ulmenhorst verschwunden sein, und wir werden sehen, dafs das auch tatsächlich zutrifft. Auch in der Nacht um 10 (Himmel bedeckt, Mond scheint durch die Wolken, żiemlich hell draufsen, einige Regentropfen) noch Drosseln in der Luft ziehend gehört.

27. Oktober: Windrichtung und -stärke: fast windstill oder ganz leichter NW; ONO. 2,5 m; NO. 2.

Temperatur: 3,$0 ; 10,5 ; 8,5^{\circ}$.

Früh Reif; sehr kühl.

Es wird ein herrlicher klarer Herbsttag.

Früb 6,45 einige Wild tau ben nach S. Dann fangen Krähen an zu ziehen, und zwar bei dem klaren windstillen Wetter sehr hoch, etwa 200-400 m hoch. Manchmal sieht man sie nur noch als kleine Pünktchen in der Luft. Das ist so ein Tag, wie er schon öfter von mir erwähnt worden ist, an dem man bei oberflächlicher Beobachtung nichts oder wenig vom Vogelzug merken würde, obgleich man mitten in der Zugstrafse sitzt. So geht der Krähenzug den ganzen Tag über vor sich mit Satkrähen und Dohlen gemischt, und auffallender Weise bis spät in die Dämmerung hinein.

$\mathrm{R}$ a u bvögel ziehen nicht viel, und auch hoch. Es werden einige $S$ perber und $R$ a uh fu $\int \mathrm{s} b u$ ssarde, 1 Wanderfalke und auch wieder 2 Seeadler bemerkt. Die letzten beiden Arten ziehen weniger hoch, wie die erstgenannten; die S e e ad l e r etwa $150 \mathrm{~m}$ hoch. So sind also gestern und heute verhältnismäfsig häufig Adler durchgekommen. Einige Tauben hoch ziehend. Klein vögel ziehen heute fast gar nicht in der Luft. Ich bemerke ganz früh am Morgen nur einige Flüge Gold hähn- 
chen ganz gegen ihre sonstige Gewohnheit recht hoch (etwa $60 \mathrm{~m}$ hoch) von einem Gebüsch zum andern fliegen. Auch ein Flug Kreuzschnäbel etwa $80 \mathrm{~m}$ hoch nach $\mathrm{S}$.

In den Büschen ist es stiller geworden. Von den gestern erwähnten D rosseln und Zaunkönigen ist der gröfste Teil in der Nacht weitergewandert. Abends gegen 5 Uhr höre ich wieder D rosseln in der Luft ziehen. Sie brechen also in der Dämmerung auf. Mittags gegen 11 wird von andrer Seite beobachtet, wie 2 D rosseln aus grofser Höhe herniedersausen, dafs ein raketenähnliches Geräusch entsteht.

Es werden in den Büschen beobachtet: einige Dompfaffen, 2 Certhien, 1 Eichelheher, der den Bussard- und Dohlenruf sehr hübsch nachahmt. Fin Lanius excubitor in den Dünen. 4 Heidelerchen auf der Palwe. Su $\mathrm{m}$ p fohreulen sind immer noch auf dem Zuge. Aus einem Gebüsch scheuche ich 6 Stück auf und zwei Eulen, die jedenfalls derselben Art angehören, sehe ich spät in der Dämmerung gegen den hellen Himmel nach S. ziehen.

Wie schon bei den Krähen bemerkt, ist es auffallend, dafs sich heute der Zug bis in die späte Dämmerung hinein erstreckt. Mehrere Starflüge und Gänse werden noch ganz spät abends bemerkt.

Nachts sehr hell, fast Vollmond, sternenklar. Von ziehenden Vögeln nichts bemerkt, auch gegen die lange mit dem Glase beobachtete Mondscheibe nichts gesehen.

28. Oktober: Windrichtung und -stärke: OSO. $5,3 \mathrm{~m}$; SO. $5,2 \mathrm{~m}$; SO. $5,4 \mathrm{~m}$.

Temperatur: 8,$6 ; 11,1 ; 8,6^{\circ}$.

Früh zunächst noch bedeckt, etwas trübe, dann gegen 9 a. aufklärend; es wird im Laufe des Tages immer heller, meist Sonnenschein. Sobald es heller wird, ziehen mehr Vögel.

6,35 a. $3 \mathrm{~K}$ räh en als erste Zugvögel. 6,40 folgen mehr, jedenfalls von einem in der Nähe befindlichen Schlafplatze herstammend. Von 7,45 an noch mehr. Als das Wetter gegen $1 / 29$ aufhellt, kommt der $\mathrm{Kr}$ ähenzug erst recht in Gang und bält den ganzen Tag über in märsiger Stärke an. Höhe etwa 50-60 m. Nach dem Uhu kommen die Krähen gut. Den Nebelkrähen sind Dohlen und auch Satkrähen beigemischt.

Raubvögel: Sperber ziemlich viel, $50-60 \mathrm{~m}$ hoch; öfter Rauhfufsbussarde, auch Mäus ebussarde, l Wanderfalke. Ferner 2 Tauben.

Kleinvogelzug wenig. Der mufs wohl zum gröfsten Teil zu Ende sein. Früh 6 Uhr 35 Min. aufser Krähen ein Trupp Finken vorüberziehend; ferner Kreuzschnäbel, Erlenzeisige, gelbe Bachstelzen, Pieper. Einzelne Flüge dieser Vögel sind auch den Tag über, wenn auch nicht häufig, zu beobachten. Kreuzschnäbel heute mehrfach, dazu noch Dompfaffen; 
Stare, ein paar Heidelerchen. Goldhähnchen von Busch zu Busch ziehend. Auch ein Trupp Misteldrosseln.

In den Büschen ein Flug Blaumeisen, 1 Eichelheher.

Heute hält wieder auffallender Weise der Krähenzug bis in die späte Dämmerung hinein an. Nach $5 \mathrm{p}$., als es schon ganz dunkel ist, K rähentrupps nach S. Im vorigen Jahre solch spätes Ziehen nicht beobachtet. $\mathrm{Ob}$ in diesem Jahre die Krähen mit dem Zuge noch im Rückstande sind und vorwärts drängen?

Die Nacht mond- und sternenhell. Starker SO.

Durch Herrn Lehrer W. Hennemann in Werdohl in Westfalen geht über den 28. Oktober folgende Notiz ein: „Heute vormittag zogen von $9^{3} /$ bis $11^{1 / 4}$ Uhr bei schwachem südwestlichen Winde und bedecktem Himmel, $+91 /{ }^{0} \mathrm{R}$., fast ununterbrochen grofse Scharen Krähen (Corvus spec.?) in westsüdwestlicher Richtung über unser Dorf. Sie zogen etwa $80-100 \mathrm{~m}$ hoch. Nach dieser Zeit kamen nur noch einige kleinere Scharen durch, z. B. 121/ Uhr gegen hundert Stück ...."

29. Oktober: Windrichtung und -stärke: SSO. $6 \mathrm{~m}$; S0. $4 \mathrm{~m}$; SO. $2,9 \mathrm{~m}$.

Temperatur: 7,$3 ; 11,3 ; 9,8^{\circ}$.

Wieder ein schöner heller Tag. Windstärke sehr schwankend, früh gegen $10 \mathrm{Uhr}$ ganz plötzlich von $6,6 \mathrm{~m}$ pro Sekunde auf 2,9 m abflauend. Meist Sonnenschein, etwas kühl.

Früh 6,45 einige $\mathrm{Kr}$ ähen und Kleinvögel, $4 \mathrm{Stare}$. Der Krähenzug kommt dann gut in Gang als die Sonne über die Düne steigt. Es ziehen meist $C$. cornix, wenig $C$. frugilegus, etwas mehr Dohlen. Die geschossenen $C$. cornix sind jetzt meist Alte. Man kann heute recht deutlich beobachten, wie die Stärke des Windes die Höhe des Vogelfluges beeinflufst. Früh bei dem starken Wirde Zughöhe $3-20 \mathrm{~m}$; sobald der Wind nachläfst 50-60 m. Auch die Zugbahn wird von der Windstärke beeinflufst. Früh hielten die $\mathrm{Kräh}$ en die Vordüne, dort vor dem starken Winde Schutz suchend, nachmittags die Mitte der Nehrung. Nachmittags ist der Zug wie immer schwächer als am Vormittage.

Raubvögel: Ziemlich viel Sperber; in diesem Jahre meist hoch, aufser Schufsweite ziehend. Rauhfufsbussarde mehrfach, 1 Merlinfalke beobachtet. Nachmittags wieder ein Seeadler ziemlich niedrig nach $\mathrm{S}$. ziehend. Auch in Nidden heute ein Seeadler im Krähennetze gefangen. Die Vogelwarte bekommt ihn leider nicht zum Markieren.

Kleinvögel wenig ziehend: ein paar mal Heidelerchen, Buchfinken, Kreuzschnäbel und Misteldrosseln.

In den Büschen wenig Leben: Zaunkönige fast alle fort. Goldhähnchen sehr wenig da. Es hat jetzt kein neuer Zuzug von Kleinvögeln stattgefunden.

Den Hauptzug stellten auch heute die Krähen. 
30. Oktober: Windrichtung und -stärke: SSO. 6,7 m; SSO. $5,6 \mathrm{~m}$; SO. 4 .

Temperatur: 9,$0 ; 11,7 ; 8,4^{0}$.

Heller Tag, meist Sonnenschein, aber starker, kühler Wind.

Märsiger $\mathrm{Kräh} e \mathrm{nzug}$. Er beginnt um die Zeit gegen $1 /{ }_{2} 8 \mathrm{Uhr}$ als die Sonne höher steigt; nicht in Kettenform, sondern mit Zwischenräumen truppweise; bei dem starken Winde nur $3-20 \mathrm{~m}$ hoch.

$\mathrm{R}$ a u b vög e l: Spe r b e r mehrfach, die beiden Bus sard a r te n vereinzelt. $\mathrm{T}$ a $\mathrm{u}$ b e $\mathrm{n}$ selten.

K leinvogelzug findet jetzt nur noch in den Morgen-

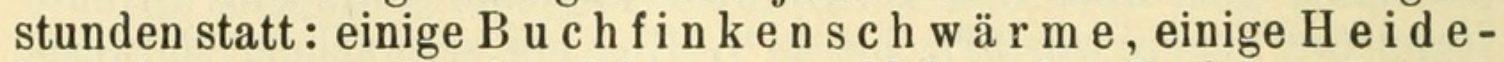
lerchen, vereinzelt $\mathrm{Pi}$ eper. Mehrmals Goldammern nach S. ziehend. Aus einem ziehenden Starfluge erlege ich $2 \sigma^{x} \sigma^{x}$ ad., $1 \sigma^{x}$ juv., 1 @ juv. Junge und Alte also noch zusammen wandernd.

In den Büschen ganz wenig $\mathrm{Kle}$ invögel; einige Gold $\mathrm{hähnchen,} \mathrm{ein} \mathrm{Trupp} \mathrm{Schwanzmeisen,} \mathrm{einige} \mathrm{Kohl-}$ $\mathrm{m}$ e is e n.

Gegen $1 / 2_{2}^{4}$ Uhr nachmittags ist der Zug ganz vorüber. Ich mufs nach Rossitten fahren.

31. Oktober: Windrichtung und -stärke: SO. 5; SO. 5; SO. 5 .

Temperatur: 5,$5 ; 8,9 ; 7,0^{\circ}$.

Heller Tag. Ich bin in Rossitten.

Nach Aussage der Fänger ist sehr guter $\mathrm{Krähenzug}$ gewesen; niedrig; bis in die Dämmerung hinein.

Auch viel $R$ a u b vögel. Die Vogelwarte bekommt aus den Krähennetzen 2 lebende $R$ a u h f fs bussarde und $1 \mathrm{~W}$ ander falken. Bei dem einen Fänger ist ein Seea dler am Netze gewesen. Vor einigen Tagen ist auch in Preil ein S e e a der gefangen worden.

Gegen Abend wieder nach Ulmenhorst. In der Dämmerung noch ein Zug Gänse nach S.

1. November: Windrichtung und -stärke: SSO. $3,5 \mathrm{~m}$; SW. $2,4 \mathrm{~m}$; WSW. $2,4 \mathrm{~m}$.

Temperatur: 6,$1 ; 8,2 ; 8,2^{\circ}$.

Früh hell, gegen 10 umzieht sich der Himmel, der Wind wird schwächer und geht mehr nach S. und dann mehr nach W. herum.

7 a. einige $\mathrm{Kräh}$ en und Kleinvögel nach S. Als die Sonne hochkommt mehr Krähen, nicht in Kettenform, sondern in Trupps, zunächst nur $20-40 \mathrm{~m}$ hoch, als der Wind dann schwächer wird $80-100 \mathrm{~m}$ hoch. Unter 3 erlegten $C$. cornix 2 ad., 1 juv. Meist jetzt Alte. Gegen Mittag hat aller Zug schon aufgehört.

Raubvögel: Früh binnen einer Viertelstunde $3 \mathrm{~W}$ and erfalken vorüberziehend. Einer treibt sich am Walde umher und 
fahndet auf Beute. Wenig Sperber und Bussarde. Ein Zug Gänse früh.

Kleinvogelzug jetzt sehr gering, nur Kreuzschnäbeltrupps ${ }^{1}$ ) heute oft nach S., oft so hoch, dafs man sie nur hört. Einige Buchfinkenflüge, ein paar kleine Startrupps.

In den Büschen tot: nur ein paar Kohlmeisen, 1 Certhie. Goldhähnchen und Zaunkönig e fast alle fort. D rosseln gar nicht, Rotkehlchen fast garnicht vorhanden.

Nachmittags bei dem trüben ruhigen Wetter gar kein Zug mehr.

Nacht dunkel, ohne Sterne. 10 p. schwacher Regen.

2. November: Windrichtung und -stärke: NO. $3,7 \mathrm{~m}$; 0. $2,1 \mathrm{~m} ; \mathrm{SO} .2$.

Temperatur: 7,$8 ; 7,8 ; 7,6^{\circ}$.

Bedeckt. Ein trüber Tag. Von $10-11$ a. Sprühregen. 6,45 a. zieht noch nichts. Von $1 / 8$ an, also später als sonst ziehen Krähen, nicht viel, hoch, mehrere $100 \mathrm{~m}$. hoch, Richtung bei diesem Winde N.-S., sonst immer NNO.-SSW. Nach dem Uhu kommen einige; die erlegten sind alles Alte. Gegen Mittag ist schon aller Zug vorüber.

Raubvögel: Einige Sperber und Bussarde. An einer in der Nähe von Ulmenhorst gelegenen Krähen-Fangstelle fällt ein Seeadler ein.

Früh und spät abends in der Dämmerung je ein Flug Gänse.

K leinvögel in der Luft sehr wenig: einige recht grofse Trupps Heidelerchen, einige $\mathrm{Buch}$ finken flüge etwa $100 \mathrm{~m}$ hoch nach Süden. Mehrfach Kreuzschnäbel nach S. ziehend.

In den Büschen herrscht Leben. In der vorigen dunkeln Nacht sind viel Kleinvögel angekommen, besonders $\mathrm{Zau} \mathrm{n} \mathrm{k} \mathrm{ö} \mathrm{nig} \mathrm{e,}$ etwas Rotkehlchen, Goldhähnchen und Certhien; Drosseln wenig; die ersten geschlossenen Erlenzeisigschwärme in den Baumkronen. Schneeammern und Bergfinken gehört; 1 B a umpieper. 1 Bekassine abends in der Dämmerung über Ulmenhorst fliegend. Früh S e ta ucher (Urinator) mehrfach von der See nach den Haff fliegend.

Nacht dunkel, ohne Sterne, fast windstill.

3. November: Windrichtung und -stärke: SSW. $4,2 \mathrm{~m}$; SSW. $4,3 \mathrm{~m} ;$ S. 4.

Temperatur: 8,$2 ; 8,5 ; 8,0^{\circ}$.

Immer bedeckt. Ein trüber, dunstiger, feuchter Tag. Solche Tage sind Feinde der Vogelzugserscheinungen.

Von $1 / 28$ Uhr an einige $\mathrm{Krähen}$; nur in den ersten Vormittagsstunden. Eine erlegte $C$. cornix ist eine ju v. Also sind doch immer noch Junge unter der Ziehenden.

1) Über den diesjăhrigen aufsergewöhnlich starken Kreuzschnabelzug auf der Kurischen Nehrung siehe Reichnow's Ornithologische Monatsberichte Februarheft 1910. 
Raubvögel: ganz wenig: ein paar Sperber und Rauhfufsbussarde, 1 Wanderfalke. 1 Zug Gänse früh

K le invögel ganz wenig: Finken, ein Flug $\mathrm{He}$ idelerchen, ein paar kleine Startrupps. Bemerkenswert ist, dafs heute früh zahlreiche Drosseln in gröfseren Flügen nach S. wandern, darunter die ersten $T$. pilaris in gröfserer Zahl. Das sind nun schon Spätherbst- oder Wintererscheinungen. In den $\mathrm{B}$ ü s c h e $\mathrm{n}$ ist das Leben von gestern mehr geschwunden. Die meisten $\mathrm{Z}$ a u $\mathrm{nk}$ ö $\mathrm{n}$ g e von gestern sind in der Nacht abgezogen. Einige $\mathrm{M}$ e isen, Goldhähnchen, Certhien. Die letztere Art jetzt jeden Tag auf dem Zuge zu beobachten, auch eine charakteristische Erscheinung für diese späte Jahreszeit.

$\mathrm{Z}$ eisigschwärme in den Bäumen.

Seetaucher früh vom Haff nach der See fliegend. Der Vogelzug läfst immer mehr nach.

4. November: Um das schnelle Abflauen des Windes am heutigen Tage zu zeigen, sollen die sämtlichen Feststellungen über Windrichtung und -stärke angeführt werden: $7 \mathrm{Uh} \mathrm{r} 45$ a.: NW. $10,6 \mathrm{~m} ; 9 \mathrm{Uhr} 15$ a.: NW. $9 \mathrm{~m} ; 10 \mathrm{Uhr} 15$ a.: NNW. $7,3 \mathrm{~m}$; $11 \mathrm{Uhr} 30$ a.: N. $3,4 \mathrm{~m} ; 1 \mathrm{Uhr} 45$ p.: NNW.; 4 Uhr 15 p.: NO. $2,6 \mathrm{~m}$ p. S.

Tem perat u r: 7,$2 ; 9,2 ; 6,5^{\circ}$.

Wetter sehr veränderlich. Ganz früh sehr trübe. Regenschauer. Von 9 a. an klarer, ab und zu Sonnenschein. Der Wind nimmt schnell ab; sehr klare Luft. Gegen 12,15 p. stärkerer Regen.

Um 8 a. ziehen einige $\mathrm{Krähen.} \mathrm{Als} \mathrm{es} \mathrm{dann} \mathrm{aufhellt,}$ kommen etwas mehr, immer truppweise, und auffallenderweise bei dem starken Winde mehrere $100 \mathrm{~m}$ hoch. Oben weht nach dem Ziehen der Wolken zu urteilen derselbe Wind wie unten. Zugrichtung NNO.-SSW.

Um 10 a. hört der Zug schon fast ganz auf, wahrscheinlich weil gegen Mittag wieder Regen kommt.

Die Krähenfänger fangen nichts. So hat auch der ersehnte NW. keine Beute gebracht.

Raubvögel: 1 Sperber, 2 Bussarde sehr hoch.

K leinvögel gar nicht in der Luft. Wind zu stark. Nur einige male Kreuzschnäbel hoch nach S.

In den $\mathrm{B}$ ü s ch e $\mathrm{n}$ g a n $\mathrm{z}$ wenig Kleinvögel: ein paar $\mathrm{Z}$ a u nkönige, Goldhähnchen, Certhien, Rotkehlchen, das ist alles.

S e e ta u cher wie jeden Tag fliegend.

Nachmittags noch ein paar Krähen ziehend, sonst nichts von $\mathrm{Zug}$.

Drosseln in der Dämmerung ziehend gehört. Eisenten schon vor längerer Zeit auf der See gehört.

$\mathrm{Nacht}$ dunkel, ohne Sterne. 
5. November: Windrichtung und -stärke: NNO. $3,4 \mathrm{~m}$; NNO. $2,4 \mathrm{~m}$; NNO. $2,4 \mathrm{~m}$.

Temperatur: 4,$6 ; 7,4 ; 6,9^{\circ}$.

Früh bedeckter Himmel, aber sehr klare Luft. Gegen Mittag etwas aufklärend, zuweilen Sonnenschein. Dicke Wolken ziehen verhältnismäfsig niedrig in der Richtung des am Erdboden festgestellten Windes. Zuweilen Regen drohend.

Um 10 a. einige Kräh en; von Mittag an mehr. Sehr hoch in kleinen Trupps. Nach den früher mit aufgehängten Vögeln angestellten Versuchen etwa $1500 \mathrm{~m}$ hoch. Man sieht sie nur bei ganz scharfem Hinsehen. Der Zug aber gar nicht bedeutend.

Kreuzschnäbel mehrfach ziehend, sonst nichts von ziehenden K le in vög eln, aufser einem Fluge $\mathrm{H}$ e idelerchen. $1 \mathrm{~W}$ anderfalke an der Hütte, 1 Sperber, sonst keine Raubvögel.

Eine interessante Beobachtung gegen Mittag an einem Fluge Wildgänse. Kamen sebr hoch von N. nach S. angezogen und verschwanden plötzlich hinter einer Wolke, um bald danach wieder hervorzukommen. In dem Falle waren also Zugvögel üb e $r$ den Wolken gezogen, wobei allerdings zu berücksichtigen ist, dafs das Verschwinden nur kurze Zeit anhielt. Ich habe etwas derartiges bis jetzt noch nicht gesehen.

In den B üsche n kein Vogelleben: ein paar Zaunkönige, Rotkehlchen, M eisen, 1 Dompfaffe, 1 Drossel. Erlen z eis ige, Bergfinken gehört. Eine umherstreichende Ring eltaube. zu sein.

Im allgemeinen ein toter Tag. Der Zug scheint nun vorüber

Nachts schönster Sternhimmel.

0. $1 ;$ S. 2 .

6. November: Windrichtung und -stärke: $0.1,8 \mathrm{~m}$;

Temperatur: 2,$7 ; 4,5 ; 3,4^{\circ}$.

Früh Reif. Es hat Eis gefroren. Minimum in der Nacht : $0,5^{\circ} \mathrm{C}$. Zunäcbst früh schöner heller Sonnenschein. Von 10 a. ab Nebel.

Zunächst zieht früh trotz des Sonnenscheins nichts. Die Krähen fangen jetzt immer erst etwas später an. Um 7,45 kommen einige. Von $8 \mathrm{Uhr}$ an aber mehr, sehr hoch, wie gestern nachmittag. Heute sehr schwacher Wind und klare Luft, da geht der Vogelzug immer sehr hoch vor sich. Man sieht fortwährend einzelne Krähen in grofser Höhe nach S. wandern.

2 Gänse sehr hoch ziehend.

1 Hühnerhabicht, 1 Sperber nach S. Ein paar K lei nvögel: Heidelerchen, B uchfinken, 2 Drosseln, Kreuzschnäbel, auch ein paar Goldammern. Interessant war mir ein Flug Feld sperling e (Passer montanus), der nach Süden flog. Auch an der Hütte treffe ich sowohl einen Haussperling, als auch einen Feldsperling in den Bäumen an. Bisher hatte ich immer geglaubt, dafs die Sperlinge auf der Rossittener Oase isoliert von der Aufsenwelt leben. So scheint Journ. f. Orn. LVH. Jahrg. Juli 1910. 
es aber doch, als ob Verbindung mit der Aufsenwelt besteht. Vielleicht verlassen eine Anzahl Sperlinge Rossitten, wenn im Herbst und Winter die Nahrung knapp wird. Wenn sie nach Süden zu den Weg über Land wählen, so müssen sie eine Strecke von 35 Kilometern überfliegen, ehe sie das Nahrung spendende Festland erreichen. In den B ü s $\mathrm{c}$ h e n kein Vogelleben: ein paar Zaunkönige, 1 Certhie, 1 Picus major gehört. Von 10 a. an Nebel, nichts mehr von ziehenden Vögeln bemerkt. Der Zug in Ulmenhorst ist vorüber, ich gehe nach Rossitten zurück. In der Folgezeit sind nur noch Krähenzüge zu erwarten, die manchmal recht lebhaft werden, wenn Schnee kommt. Vielleicht ziehen dann auch von anderen Vögeln mehr, wie man denkt. Jedenfalls werde ich es durchsetzen können, nach und nach zu je der Jahreszeit dauernden Aufenthalt in Ulmenhorst zu nehmen, um über jeden Monat genau orientiert zu sein. Heute mufs ich aber um anderer Arbeiten willen die Dünenhütte verlassen.

Da mir der Reise nach Helgoland wegen die Beobachtungen von Ende September und aus der ersten Hälfte des Oktober gänzlich fehlen, so möchte ich kein abschliefsendes Urteil über die Herbstzugperiode 1909 abgeben. Jedenfalls waren, so lange ich in Ulmenhorst wohnte, zuweilen recht gute Zugtage zu verzeichnen. Viel Vögel sind nach Süden durchgewandert. Das eine scheint mir schon jetzt festzustehen, dafs der Beobachter im Frühjahr mehr mit der Witterung zu rechnen hat, als im Herbste. Wenn im Herbste nur halbwegs sogenanntes "schönes Wetter" ist, dann bekommt man Vögel zu sehen. Im Frühjahre werden ganz besondere Winde verlangt.

Am Schlufs dieses Abschnittes möchte ich noch einige Beobachtungen anfügen, die nicht Vögel, sondern andere Tier$\mathrm{klas}$ sen betreffen und mir bemerkenswert erscheinen. In den letzten Jahren ist eine Veränderung in der Fauna der Rossittener Oase vor sich gegangen, und zwar auf künstliche Weise durch Einschleppung. Eine dicht bei Rossitten gelegene grofse Wanderdüne, der vielbesuchte ,schwarze Berg“, eine Sehenswürdigkeit unseres Nehrungsdörfchens, ist durch Kiefernanpflanzungen festgelegt worden. Wohl kann man jetzt auf einem festen Lehmwege hinaufgelangen, man hat $\mathrm{zu}$ beiden Seiten die schachbrettartigen, regelmälsigen, aber schablonenhaft wirkenden Besteckvierecke, man kann sich an dem Gedeihen der kleinen Bergkieferpflänzchen freuen, aber die weiten, gewaltigen glatten Sandflächen fehlen, und der Berg bleibt wie alle Berge immer derselbe, seine Gestalt ändert sich nicht, sein Gipfel hat immer dieselbe Form. Wie war das früher grausig schön, wenn unser schwarzer Berg bei Sturm ,,lebte“, wenn er durch die hochgepeitschten Sandwolken rauchte, wenn er bei anhaltenden Ostwinden seine Haube aufsetzte und wenn man den alten Freund bei einem Besuche nicht wieder erkannte, so hatte er sein Gesicht verändert. Ja, die Kultur 
dringt überall vor; wo man jetzt hinschaut in Rossitten: überall Kultur. Des freuen wir uns wohl und haben Nutzen davon, aber ein gutes Stück Urwüchsigkeit und Poesie geht damit verloren.

Das zur Festlegung des schwarzen Berges notwendige Besteckreisig wurde in grofsen Kahnladungen aus den Wäldern des Festlandes herbeigeschafft. Mit diesem Reisig sind allerhand neue Tierarten eingeführt worden, die früher in der durch Sandwüsten isoliert gelegenen Rossittener Oase ganz oder fast ganz fehlten; vor allem Kriechtiere, nämlich Eidechsen, Blindschleichen, Ringelnattern und auch Kreuzottern. Es mag diese Tatsache für spätere Forschungen hiermit festgelegt werden. Am 8. September 1908 wurde mir die erste hiesige Kreuzotter gebracht, die sogar im Dorfe selbst gefangen worden war. Es ist ein schönes schwarzes, der Varietät prester angehöriges Exemplar.

Am 25. März und 16. Ju ni 09 wurde mir je ein Exemplar der Wasserspitzmaus (Crossopus fodiens) überbracht, die ich früher nie hier bemerkt hatte. Das eine Stück wurde in einer Tonne erbeutet.

Am 16. und 22. Juni 09 fing sich auf ein und demselben hiesigen Gehöfte je eine ganz dunkel gefärbte $R$ atte. Ich schickte das eine Stück, das in der Sammlung der Vogelwarte steht, zur Ansicht an Herrn Prof. Matschie, der es als Schwärzling der Wanderratte (Mus decumanus) bestimmte. Das andere Exemplar kam an das zoologische Museum in Königsberg.

Im November 09 wurde in Rossitten ein kleines Maus wies el (Foetorius vulgaris) erbeutet. Bis dahin hatte ich nur immer das Hermelin (Foetorius erminea) bemerkt.

Wie weit das Auftreten dieser Säugetiere auf Einschleppung zurückzuführen ist, will ich dahingestellt sein lassen. Jedenfalls ist es auffallend, dafs plötzlich fast zu gleicher Zeit mehrere Tierarten hier auftraten, die bis dahin fehlten.

Mit der gänglich isolierten Lage der Rossittener Oase wird es in absehbarer Zeit auch vorüber sein, da die angrenzenden kahlen Dünengebiete nach und nach aufgeforstet werden. Nachdem dann Zuleitung geschaffen ist, werden wir alle möglichen Tiere hierher bekommen, die jetzt noch fehlen. - In der Nacht vom 16. zum 17. August 09 langten grofse Flüge von Nonnenfaltern auch in Rossitten an. Die Nonnenplage in Ostpreufsen war und ist ja jetzt grofs.

Am 1. Mai 1909 fingen Pillkoppener Fischer im Lachsgarn eine junge Kegelrobbe lebend und brachten sie mir. Ich hielt sie zwei Tage lang auf meinem eingezäunten Gehöft, ehe sie an den Königsberger Tiergarten abging. Es ist immer sehr interessant, Tiere, die man sonst nur in zoologischen Gärten zu sehen gewohnt ist, frisch gefangen $\mathrm{zu}$ beobachten, 
wenn sie noch keine Gefangenschafts-Gewohnheiten angenommen haben. So auch diese Robbe. Ich hätte nicht geglaubt, dafs ein so plump aussehendes Tier soviel Klugheit und Schlauheit zeigen würde, obgleich ja die Robben als geistig hochbegabte Tiere bekannt sind. Meine gefangene Robbe blieb weder stumpfsinnig auf einem Flecke liegen, noch bewegte sie sich wie andere frisch gefangene Tiere erfolglos an der Umzäunung hin und her, sondern batte in kurzer Zeit 2 Lücken im Staketzaun ausgekundschaftet und strebte auf diese Stellen mit eiserner Konsequenz immer wieder hin, sodals ich meine liebe Not hatte, sie immer wieder zürückzubringen. Die Schreckstellungen und Schrecklaute einer frisch gefangenen Robbe sind geradezu fürchterlich, und die Fischer haben auch eine ganz barbarische Angst vor diesen Tieren. Alles ist aber nicht so schlimm, wie es tatsächlich aussieht. Ein wirkliches Zufassen und Zubeifsen fand sebr selten statt, obgleich ich dem hier besprochenen Tiere, und auch schon anderen Robben, die ich im Laufe der Zeit lebend erhielt, oft genug Gelegenheit dazu gab. Aber der Rachen mit dem Respekt gebietenden Gebifs wird weit aufgerissen, dazu ein grausiges Schnarchen und Röcheln und die klugen menschenähnlichen feuchten Augen! Die Fortbewegung auf dem Lande geht bei der Flucht viel schneller vor sich als man vermutet.

\section{Bericht über den Ringversuch im Jahre 1909.}

Der Versuch nimmt immer grölsere Dimensionen an. Die Vogelwarte hat wieder viel $\mathrm{zu}$ danken für die Förderung, die der Versuch aus den weitesten Schichten der Bevölkerung des In- und Auslandes in so reichem Mafse erfahren hat. Wieviel Gefälligkeiten mufsten der Anstalt erwiesen werden, wieviel Briefe und Karten waren zu schreiben und nach Rossitten zu schicken, wie oft mufste die Presse aufklärend eingreifen, ehe der Unterzeichnete in den Stand gesetzt war, die nachfolgenden Datenreihen aufzuführen, die uns, so hoffe ich, wieder ein Stückchen in der Erkenntnis der Vogelzugerscheinungen vorwärts bringen werden. Also vielen Dank! Wie oft laufen jetzt Briefe auf der Vogelwarte ein, durch die begeisterte Anhänger der ornithologischen Wissenschaft ihre Kräfte in den Dienst der guten Sache stellen. Das ist herzerfreuend und gibt Mut.

Es sollen nun die Vögel aufgezählt werden, die im verflossenen Jahre auf der Vogelwarte Rossitten selbst markiert wurden :

1 Haubensteifsfufs (Colymbus cristatus).

5 Eismöwen (Larus glaucus).

1 Mantelmöwe ( " marinus).

4 Heringsmöwen (", fuscus).

160 junge Lachmöwen (, ridibundus).

12 Zwergmöwen ( " minutus).

219 junge Flufs-Seeschwalben (Sterna hirundo). 
3 Kiebitzregenpfeifer (Squatarola squatarola).

1 Goldregenpfeifer (Charadrius apricarius).

2 Sandregenpfeifer ( ", hiaticula).

1 Flufsregenpfeifer ( " dubius).

9 Isländische Strandläufer "(Tringa canutus).

207 Alpenstrandläufer (" alpina).

13 Bogenschnäblige Strandläufer (", terruginea).

1 Kampfläufer (Totanus pugnax).

6 Rauhfufsbussarde (Archibuteo lagopus).

1 Gabelweihe (Milvus milvus).

2 Seeadler (Haliaetus albicilla).

1 Mauersegler (Apus apus).

18 Mehlschwalben (Delichon urbica).

2 junge Nebelkrähen (Corvus cornix).

12 "Stare (Sturnus vulgaris).

1 " Bachstelze (Motacilla alba).

1 ," Blaumeise (Parus caeruleus).

1 Steinschmätzer (Saxicola oenanthe).

\section{Zusammen 684 Vögel.}

Nach auswärts wurden folgende Ringe ausgegeben (es soll dazu wieder bemerkt werden, dafs diese Ringe unentgeltlich und portofrei von der Vogelwarte geliefert werden):

1333 für Störche.

1308 „ Krähen, Raubvögel.

950 " Möwen und andere Vögel in dieser Gröfse.

952, Drosseln, Stare.

Zusammen: $\frac{665 \text { " K K }}{5208 \text { Stück. }}$

Da ich nur in seltenen Fällen Nachricht über die Verwendung der Ringe erhalte, so vermag ich, wie ich schon in den zwei vorhergehenden Jahresberichten ausführlich auseinandergesetzt habe, keine Prozentsätze der zurückgemeldeten Ringvögel anzugeben.

Erbeutet, zurückgeliefert oder zurückgemeldet wurden folgende Vögel:

5 Nebelkrähen (C. cornix).

22 Störche (Ciconia ciconia). Dazu kommen noch 4 Ringstörche, die beobachtet worden siud, ohne dafs die Nummer festgestellt werden konnte.

12 Lachmöwen (Larus ridibundus).

71 Silbermöwen (, argentatus).

4 Strandvögel (Tringen und Totaniden).

2 Flufsseeschwalben (Sterna hirundo).

l Schwalbe (D. urbica).

2 Purpurreiher (Ardea purpurea).

1 Mäusebussard (Buteo buteo). 
2 Rebhühner (Perdix perdix).

6 Dompfaffen (Pyrrhula pyrrhula).

Zusammen 128 Vögel. Der vorige Jahresbericht wies 31 zurückgelieferte Vögel nach.

Es sollen nun die im verflossenen Jahre zurückgemeldeten Ringvögel aufgeführt werden:

\section{Nebelkrähen (C. cornix).}

Seit dem Jahre 1907 habe ich Nebelkrähen in gröfseren Mengen nicht mehr aufgelassen, weil mir andere Vögel erst mal wichtiger erschienen und ich mit den vorhandenen Mitteln rechnen mufs; was jetzt an diesen Vögeln eingeliefert wird, stellt eine Nachlese aus den Zugperioden 1903 bis 1906 dar. Alle jetzt eingehenden Ringkrähen haben darum, wie die folgenden Notizen zeigen, den Ring recht lange getragen. Die im VIII. Jahresberichte herausgegebene Nebelkrähen-Zugkarte wird durch die diesjährigen Einlieferungen nicht verändert. Alle Fundorte fallen in das dort angegebene Besiedelungsgebiet. Auffallen mufs es, dafs von den fünf diesjährigen Ringkrähen nur eine aus Deutschland, und zwar aus Mecklenburg, stammt; alle übrigen gehören den russischen Ostseeprovinzen an.

Die Fundorte sollen nun aufgeführt werden:

1. Nebelkrähe aus Mecklenburg.

1) Nr. 540. Aufgelassen am 10. Oktober 1905 mit 63 Artgenossen an den Korallenbergen bei Rossitten.

Erbeutet am 10. April 1909 in Fahrenholz bei Buchholz bei Rostock, Mecklenburg-Schwerin.

Entfernung: $\left.{ }^{1}\right) 580 \mathrm{~km}$.

Zeit: $\left.{ }^{1}\right) 3$ Jahre, 6 Monate.

Den beringten Fufs, der einer tot auf dem Acker liegenden (wahrscheinlich vergifteten) Krähe abgeschnitten wurde, schickte Herr Ökonomierat Chr. Seer in Fahrenholz freundlichst ein. Am 10. April sind also die russischen Krähen noch so weit im Westen gewesen.

2. Nebelkrähen aus Rufsland.

Zunächst 2 Stück aus Livland.

1) Nr. 782 . A ufgelassen am 21. Oktober 1905 mit 35 Artgenossen an den Korallenbergen bei Rossitten.

Erbeutet am 25. April 1909 bei Neu-Karfseritz, Livländisches Kronsgut, 6 Werst südöstlich von Werro.

Entfernung: $480 \mathrm{~km}$.

Zeit: 3 Jahre, 6 Monate, 4 Tage.

1) Unter „Entfernung“ ist immer die Strecke von der Auflafsstelle (bei Störchen, Schwalben und anderen im Neste markierten Vogeln vom Heimatneste) bis zur Erbeutungsstelle verstanden; unter „Zeit" der Zeitraum vom Anlegen des Ringes bis zur Erbeutung. 
Nachricht unter Beifügung des Ringes, der am Rande ziemlich abgeschliffen ist, durch Herrn C. Linno in Neu-Karfseritz.

2) N r. 738. Aufgelassen am 20. Oktober 1905 mit 48 Artgenossen an den Korallenbergen bei Rossitten.

Erbeutet am 10. Januar 1910 auf dem Stadtgute Jama, das unmittelbar an die Stadt Dorpat angrenzt.

Entfernung: $500 \mathrm{~km}$.

Zeit: 4 Jahre, 2 Monate, 20 Tage.

Nachricht sowohl durch den Schützen, Herrn Verwalter Robert Grün, selbst als auch durch Herrn Benno Ot to in Dorpat.

Die folgende Krähe Nr. 123 stammt aus dem Gouvernement Petersburg.

3) Sie wurde am 12. Oktober 1903 in Rossitten mit noch 3 Artgenossen aufgelassen und fiel am 20. Ma i 1909 bei Gatschina, etwa $30 \mathrm{~km}$ südwestlich von St. Petersburg einem Jäger zur Beute, an derselben Stelle, wo schon am 14. März 1905 eine Rossittener Ringkrähe erbeutet worden war.

Entfernung: $750 \mathrm{~km}$.

Zeit: 5 Jahre, 7 Monate, 8 Tage. Das ist die längste Spanne Zeit bis jetzt für das Tragen eines Ringes. Fufs tadellos gesund. Der Rind trägt noch nicht die Aufschrift „Vogelwarte Rossitten". Er stammt aus den Tagen, als die Vogelwarte ihren Ringversuch begann und zunächst Ringe ohne Firmenaufdruck verwendete.

Herr Prof. D. von Kayg or od off, Excellenz, vom Forstinstitut in St. Petersburg, dem die Vogelwarte schon so manche Förderung ihrer Versuche verdankt, hatte die Güte den beringten Fufs einzuschicken. Es mufs darauf aufmerksam gemacht werden, dafs das Erlegungsdatum in die Brutzeit fällt.

Der nächste Vogel Nr. 598 stammt aus Finland.

4) A ufgelassen am 10. Oktober 1905 mit noch 63 Artgenossen an den Korallenbergen bei Rossitten.

Erbeutet in Kirchspiel Walkjärvi, Dorf Wirkkila $40 \mathrm{~km}$. von der Mündung des Wuoksens in den Ladoga. See. Von einem Bauer T. Wosukainen geschossen.

Mitteilung durch Herrn Ingenieur Albin Collin in Kotka, Finland. Der Brief stammt vom 4. April 1910. So ist anzunehmen, dafs die Erbeutung im Frühjahr 1910 erfolgt ist.

Entfernung: $840 \mathrm{~km}$.

Z eit: Etwa 4 Jahre und 6 Monate.

\section{Störche (Ciconia ciconia).}

Da demnächst eine besondere Arbeit über den Storchzug mit beigefügten Karten erscheint, sollen hier nur die im verflossenen Jahre zurückgemeldeten Ringstörche aufgezählt werden und zwar unter Beibehaltung der im vorigen Jahresberichte gewählten Einteilung. Die mit Störchen erzielten Resultate müssen geradezu 
überraschen. In schönster Deutlichkeit liegt schon jetzt die Zugstrafse von den Küsten der Nord- und Ostsee bis zur Südspitze Afrikas vor unsern Augen.

\section{Die von den Störchen im Herbste verfolgte südöstliche Zugrichtung.}

1) Nr. 1846. Gezeichnet am 26. Juni 1909 in einem Neste bei Gutsbesitzer Wiecker in Bühne bei Osterwieck am Harz durch Herrn Mittelschullehrer W. Voig t in Wernigerode a. H. 4 Junge waren im Neste. Ausgeflogen am 20.-22. VII. Am 1. September 1909 bei Sehma im Erzgebirge etwa $33 \mathrm{~km}$ südlich von Chemnitz in Sachsen erlegt.

Entfernung: $235 \mathrm{~km}$.

Zeit: 2 Monate, 5 Tage.

Zugrichtung genau nach SO. Die betreffenden Storchscharen müssen das der Zugrichtung quer vorgelagerte Erzgebirge überflogen haben, dann durch Böhmen nach Ungarn hinein. Also die Störche des Königreichs Sachsen wählen auch noch die südöstliche Zugrichtung.

Mitteilung durch Herrn Albert Päfsler in Sehma. Der Storch soll schon einen alten Schufs gehabt haben. $\mathrm{Er}$ ist der Schule in Sehma übergeben worden und soll verwendet werden, um die Bestrebungen der Vogelwarte unter der Jugend bekannt zu machen.

2) Nr. 1312. Gezeichnet am 4. Juli 1909 auf einer Scheune des Büdners Bruks in Poppendorf bei Marlow in Mecklenburg-Schwerin durch Herrn Fr. Neckel in Forsthof Bookhorst bei Ribnitz.

Erbeutet am 25. August 1909 auf dem zur Herrschaft Alt- und Neu-Wziesko gehörigen Revier Hellewald, Oberförsterei Tenczinau, Kr. Rosenberg, Obeschlesien.

Zugrichtung parallel der Oder nach Südosten.

Zeit: 1 Monat, 21 Tage.

Entfernung v. Nest: $540 \mathrm{~km}$.

Meldung durch Herrn Oberförster Thalheim in Tenczinau bei Zawisna. Storch befand sich in Gesellschaft von etwa 90 Störchen auf dem Zuge.

Am 16. September 1909 Ring eingeschickt erhalten.

3) Nr. 835: Gezeichnet im Sommer 1909 in Langfelde bei Gr. Zünder, Kr. Danziger Niederung durch Herrn Rittergutsbesitzer W. Braunschweig.

Am 15. August 1909 im Gouvernement Lublin, Polen erbeutet. Nachricht durch Herrn Stanis. Wasniewski in Krakau, Zyblikiewiez-Str. Nr. 9. Die Übersetzung der polnischen Postkarte lautet: „Am 15. August 1909 fand ich am Bein eines getöteten Storches (Ciconia alba) ein Blechplättchen mit der Aufschrift. Vogelwarte Rossitten Germania 835. Der Storch wurde im Königreich Polen im Gouv. Lublin, Kreis Grubes chow, Dorf Gostynier getötet." 
Der Stroch ist jedenfalls immer die Weichsel aufwärts geflogen, dann nordöstlich um die Karpaten, um, etwa dem Dnjester folgend, nach dem schwarzen Meere zu gelangen, oder über die Karpaten nach Ungarn.

$\mathrm{Z}$ eit: etwa $1 \frac{1}{2}$ Monate. (Mufs gleich nach der Abreise erbeutet worden sein.)

Entfern ung: ca. $520 \mathrm{~km}$.

Am 6. 12. 09 Ring eingeschickt erhalten.

4) N r. 195. Gezeichnet am 1. Juli 1909 in Agilla, Ostpreufsen (am Kurischen Haff gelegen) durch Herrn Lehrer Tolk mitt.

Erbeutet am 25. August 1909 im Revier Südenort bei Rosengarten, Kreis Angerburg, Ostpr.

Zeit: 1 Monat, 25 Tage.

Enfernung: $94 \mathrm{~km}$.

Herr Gräfl. Förster M. S ch ü tz e meldet den Fall durch Brief. Der beigelegte Ring hat den Umschlag durchgerieben und ist herausgefallen.

\section{Der Zug nach und in Afrika.}

Die Aufzählung erfolgt von Norden nach Süden. Im vorigen Jahresberichte bestand noch eine Lücke in den Fundstellen von Ringstörchen von Ungarn bis zum blauen Nil in Afrika. Diese ist nun ausgefüllt durch eine Reihe von Fundstellen aus Syrien und Palästina. Die Zugstrafse führt also von Ungarn aus über den Bosporus durch Kleinasien, Syrien, Palästina zur Nilmündung und diesem Flufs immer aufwärts dem Süden zu. Nur Ostafrika wird berührt. In einem Falle ist ein Storch weiter nach Westen ins Innere eingedrungen bis zum Fittri-See.

1) Nr. 772 . Gezeichnet am 29. Juli 1907 auf dem Gehöft des Besitzers Jeros ch in Prostken, Kreis Ly ck Ostpre u fs en, durch Herrn H. Griget in Dombrowsken. Derselbe Herr hat den Storch Nr. 769 in Dombrowsken markiert, der seiner Zeit in der Kalahari-Wüste erbeutet wurde. Hatte nur 5 Ringe erhalten und 4 davon verwendet. Dombrowsken bis Prostken $=7 \mathrm{~km}$.

Durch Schreiben vom 7. September 1909 wird von Herrn A chmed Ophendi Dagostan, Kinetra bei Damaskus, Syrien (Türkei) gemeldet, dafs er am 2l. Juli 1909 auf die Jagd ging und einen Storch heimbrachte mit obigem Ringe. Die Adresse lautet: „Vogelwarte Rossitten 772 Germania.“

Der Erleger hat den Ring und auch einige Federn. Man beachte den Erbeutungstermin: 21. Juli 1909!

Entfernung: $2500 \mathrm{~km}$.

Z eit: 1 Jahr, 11 Monate, 22 Tage.

2) $\mathrm{Nr} .1002$ : Gezeichnet im Juli 1907 auf einer Scheune (Norden) bei Herrn Besitzer Sinnhuber in Cullmen- 
Jennen bei Pictupönen, Kreis Tilsit, Ostpreufsen. Es wurden in dem betreffenden Neste 2 Störche markiert: 1001 und 1002.

Erbeutet am 24. oder 25. April 1909 bei Karietein, etwa $110 \mathrm{~km}$ nordöstlich von $\mathrm{D}$ a maskus in Syrien, an dem Karawanenwege nach Palmyra.

Entfernung: etwa $2580 \mathrm{~km}$.

Z eit: 1 Jahr, 9 Monate.

Der Storch ist jedenfalls auf dem Rückwege begriffen gewesen. So scheinen die Storchscharen von der Nilmündung aus nicht das Mittelländische Meer zu überfliegen, sondern an der Küste entlang durch Syrien und Kleinasien zu ziehen.

Nachricht unterm 5. Mai 1909 durch Herrn Eli ma r Prip, dänischer Missionar. Adresse: Victoria Hospital, Damascus, Syrien.

3) N r. 1520 . Der Ring 1520 ist am 17. Juni 1908 an Herrn Rittergutsbesitzer E. Ulm e r, Quanditten im Samlande, Ostpreufsen, geschickt und auch in der Nähe des Gutes verwendet worden. Der Tag der Anlegung kann nicht mehr genau angegeben werden.

E r b e u tet in der Nähe von A c co (Palästina).

Nachricht durch Frl. Maria Bleicker, Engl. Mission Tiberias, Palästina, im Auftrage eines syrischen Mädchens aus Nazareth, das nicht deutsch versteht, deren Verwandter den Storch geschossen hat. Die Karte stammt vom 31. August 1909, so dafs anzunehmen ist, dafs die Erlegung des Storches im Sommer 1909 stattgefunden hat. Das wäre ein $\mathrm{z}$ we i te s Funddatum aus dortiger Gegend vom Sommer 1909! Näheres über die Erbeutung konnte nicht ermittelt werden.

Entfernung: $2700 \mathrm{~km}$.

4) Nr. 689 . Geze i c h net im Sommer 1907 in Sanskoyen bei Beymchnen, Kreis Darkehmen, Ostpreufsen, bei Herrn Besitzer Koppetsch.

Am 1. April 1908 in der Wüste von Hauran, einer Provinz in Syrien, von einem Farmer geschossen.

Meldung durch Herrn Koury Chartouni, Redakteur vom Journal „le Liban" in Beirut in Syrien. Gleichzeitig gehen 2 Nummern der arabischen Zeitung „Liban“ ein, die Artikel über die Vogelmarkierungen enthalten.

Entfernung: ca. $2700 \mathrm{~km}$.

Zeit: ca. 10 Monate.

Nun führt die Strecke nach Afrika hinüber.

5) Nr. 1976 . Gezeichnet im Sommer 1908 in Schultitten bei Schrombehnen, Kreis Pr. Eylau, Ostpreufsen, von Herrn Majoratsbesitzer von Kalckstein.

Am 15. Mai $190910 \mathrm{Uhr}$ morgens etwa $50 \mathrm{~km}$ südlich von Alexandria in Aegypten von einem beduinischen Aufseher erbeutet. Die genaue geographische Lage ist nach Angabe des Herrn Dr. Alfred Osborne: $30^{\circ} 12^{\prime} 51^{\prime \prime}$ ö. L. Grenwich.

$$
30^{\circ} 50^{\prime} 20^{\prime \prime} \mathrm{n} \text {. Br. }
$$


Von dem Beduinen konnte nicht in Erfahrung gebracht werden, ob es ein Reiher, Storch oder Kranich war.

Entfernung: etwa $2775 \mathrm{~km}$.

Zeit: etwa 10 Monate.

Mitteilung unter Beifügung einer Karte, auf der der Erlegungsort genau eingezeichnet ist, durch Herrn Dr. Alfred Osborne, Präsident der société d'histoire naturelle d'Alexandrie, Alexandria, Aegypten, 21 Rue Nabi Danial. Unterm 4. November 1909 teilt Herr Dr. Osborne mit, dafs der vorliegende Fall in der Sitzung der société pp. vom 1. November 1909 zur Sprache gebracht worden ist. Auch ein Referat in einer dortigen Zeitung ist erschienen.

6) Nr. 3022. Gezeichnet am 1. August 1909 in Pr. Bahnau bei Heiligenbeil, Ostpreufsen durch Herrn Albert Wegel auf dem Gehöft des Herrn Besitzers Seeger, Abbau Pr. Bahnau.

Am 30. November 1909 von Ukerewe-Leuten auf der Westspitze der Uckerewe-Insel im Victoria Nyanza, Deutsch-Ostafrika, gefangen und Herrn Sanitäts-Feldwebel M. Sacher gebracht, der die Marke abnimmt und den Storch lebendig im Lager hält. Er war erschöpft. Meldung unter Beifügung des Ringes durch Herrn Sacher. Die Adresse lautet nur: „An Vogelwarte Rossitten." Der Brief ist am 5. Dezember 09 geschrieben und trifft am 17. Januar 1910, also nach 43 Tagen, in Rossitten ein.

Geographische Lage des Fundortes: $2^{0} \mathrm{~s}$. Br.

Entfernung: $6375 \mathrm{~km}$.

Z eit: 4 Monate.

Am 7. März 1909 hat Herr Sacher bei Ik oma am Südrande des Victoria Nyanza Störche in gröfserer Anzahl gesehen; also auf dem Rückzuge.

7) Nr. ?. Nach einem Berichte von Herrn Dr. Vageler aus Königsberg i./Pr., der im Herbst 1909 von einer Studienreise aus Deutsch Ostafrika heimkehrte, hat Herr v. Arnim p. Adr. Herrn Graf von Pückler, Neu-Brenitz bei Soga Bezirk Daressala am, Deutsch Ostafrika, einen Vogelwarten-Ringstorch geschossen, und zwar entweder auf der Plantage des Herrn Grafen Pückler, Neu Brenitz oder in Mlali bei Morogoro, Bezirk Bagamoyo. Beide Plantagen liegen nicht weit von einander entfernt an der Zentralbahn im Bezirk M or ogoro.

Herr Dr. Vageler hat den Schützen selbst gesprochen. Auf eine Anfrage der Vogelwarte ist noch kein näherer Bescheid aus Afrika eingegangen. So können Ringnummer und Auflafsstation noch nicht angegeben werden.

8) Nr. 2325 . Gezeichnet im Sommer 1909 in Berghoff, Post Jucha, Kreis Lö tz e n, Ostpreufsen, durch Herrn von StrengBerghoff. 
Ende Dezember 1909 dreifsig Meilen nördlich von Rustenburg in der Transvaalrepublik, Südafrika, von einem Boer sterbend gefunden. Der Fall wird vom PolizeiSuperintendenten aus Rustenburg dem Transvaalmuseum in Pretoria gemeldet, von dessen Direktion die Vogelwarte unterm 17. Februar 1910 Nachricht erhält. Se. Excellenz Herr Staatsminister von Moltke in Berlin hat die grofse Güte gehabt, Herrn Dr. Gunning, Direktor des zoologischen Museums in Pretoria, auf die Ringversuche aufmerksam zu machen.

Zeit: ca. 7 Monate,

Entfernung: $8800 \mathrm{~km}$.

Geographische Lage der Erbeutungsstelle: ca. $25^{\circ}$ $15^{\prime} \mathrm{s} . \mathrm{Br}$.

9) Nr. 2251 . Gezeichnet: Am 6. Juli 1909 in Ballupönen, Kreis Goldap, Ostpreufsen, auf dem Gehöft des Herrn Besitzers Stadie durch Vermittelung des Herrn Kreisarztes Dr. med. Schüler in Goldap. Meldung unterm 14. Januar 1910 durch Herrn Georg Sebastian Burger aus Vleeschkraal, Katboschfontein, Wolmaranstad, Transvaal, dafs der mit dem Ring versehene Vogel in der Nähe gefunden worden sei. Der Herr glaubt, dafs noch mehr Ringstörche dort zu finden sind.

Geographische Lage: ca. $27^{\circ} 15^{\prime}$ s. Br.

Entfernung: ca. $9000 \mathrm{~km}$.

Zeit: ca. 6 Monate.

10) Nr. 3056 . Gezeichnet: Anfang Juni 1909 von Herrn Gutsverwalter Wilhelm Born, Grofs-Saalau bei Domnau, Ostpreufsen.

Am 22. Februar 1910 in der Nähe der Polizeistation Utabamhlope bei Estcourt, Natal tot aufgefunden. Der Ring wurde durch das Kaiserlich Deutsche Konsulat in Durban, Natal, eingeschickt.

Ge og raphische Lage: ca. $29^{0}$ s. Br.

Entfernung: ca. $9400 \mathrm{~km}$.

Zeit: ca. 8 Monate.

11) Nr. 2219 . Gezeichnet am 6. Juli 1909 in Jablonsken Kreis Goldap, Ostpreufsen, auf dem Gehöft des Besitzers Mordasch durch Vermittlung des Herrn Kreisarztes Dr. med. Schüler in Goldap.

Erbeutet etwa November 1909 bei Bulwer (auf der Farm von Mr. Allcock Moss Bank) etwa 52 engl. Meilen südlich von der Hauptstadt der britischen Kolonie Natal P i e termarit z bu rg. Herr J. D o u g l a s in Mount Pleasant hat den Fall an das GeologischPaläontologische Institut der Universisät Heidelberg berichtet, von wo ich Nachricht durch Herrn Professor Dr. W. Salomon erhalte.

Ferner hat dieser Fall noch gestanden in den Zeitungen: B. Z. am Mittag vom 15. Februar 1910 und im "Echo" vom 17. Februar 1910. Diese Nummern gehen mir zu. 
Die Notiz im Echo hat Herr F. W. A hrens, Magistrate's Office, Vryheid, Natal, gebracht.

In dieser Notiz steht, dafs die Störche, unter Denen sich der Ringstorch befand, bereits vor 2 Monaten eingetroffen wären.

Danach wäre der Erbeutungstermin et wa Mitte November 1909.

Geograpische Lage der Erbeutungsstelle: ca. $30^{\circ}$ $20^{\prime}$ s. B.

Entfernung: ca. $9500 \mathrm{~km}$.

12) Nr. 1416 . Am 18. Juli 1908 in einem Neste bei Herrn Besitzer Re de m und in Gr. Lat t a na bei Willenberg, Ostpreufsen, durch Herrn Königl. Förster Wolk in Borken bei Willenberg markiert.

Erbeutet im Januar oder Februar 1909 bei Quthing im südlichen Basutolande.

Entfernung: ca. $9600 \mathrm{~km}$.

Zeit: $6-7$ Monate.

Geographische Lage der Erbeutungsstelle: ca. $30^{\circ}$ $25^{\prime}$ s. Br.

Ring zugeschickt erhalten zugleich mit dem beringten Bein No. 1265 aus dem vorigen Jahresbericht durch Herrn A. K. $\mathrm{H}$ a a g ner, Sekretär der South African Ornithologist's Union am 7. Juni 1909.

Unterm 23. November 1909 (Brief trifft am 22. Dezember 09 in Rossitten ein) schreibt Herr $\mathrm{Ha}$ agner noch, dafs beide Störche aus dem Basutolande von Kaffern resp. Schwarzen erlegt wurden. Daher war nichts näheres zu erfahren.

13) Nr. 2349 . Gezeichnet im Sommer 1909 in Treul bei Neuenburg, Westpreufsen bei Herrn L. Dobbrick.

Ende November 1909 (im Brief vom 18. 12. 09 heist es ,vor ungefähr 3 Wochen") in der Nähe von Umzimkulu an der Ostgrenze der Kapkolonie sterbend gefunden. In dem Briefe heifst es: „Die Kaffern, neben deren Kraal der Vogel herunterfiel, waren sehr erschreckt und staunten den Vogel des Ringes wegen an, als ob er vom Himmel gekommen wäre." s. Br.

Geographische Lage des Fundortes: etwa $30^{\circ} 27^{\circ}$

Entfernung: ca. $9600 \mathrm{~km}$.

Zeit: ca. 4 Monate.

Nachricht durch Herrn P. P. Jellowes in Umzimkulu.

Adresse la utet: „Vogelwarte Rossitten (2349) Germany".

Rückkehr der Störche in ihr Heimatgebiet.

1) Nr. 47. Gezeichnet am 20. Juni 1906 in Seligenfeld bei Königsberg i. Preufsen von dem Verfasser dieses Berichtes persönlich. Drei Junge, Nr. $46 ; 47 ; 48$, waren im Neste.

Am 12. August 1909 von Herrn Gutsförster A. Dinter in Fuchshöfen bei Waldau, Kr. Königsberg i. Preufsen verendet aufgefunden. 
Ring eingeschickt bekommen; an den Rändern abgeschliffen, aber sehr gut erhalten; hätte noch 10 Jahre gehalten.

Entfernung: $15 \mathrm{~km}$.

Zeit: 3 Jahre, 1 Monat, 22 Tage.

Der Storch ist also nach 3 Jahren wieder in seiner engeren Heimat angetroffen worden. Er hatte einen Schrotschufs in der rechten Seite.

„Kann sein Brutgeschäft in diesem Jahre verrichtet haben“" schreibt Herr Dinter. Etwa 2000 m von dem verendeten Storche entfernt befand sich ein zweiter Storch.

2) N r. 1. Der Ringfabrikant hatte mich seiner Zeit bei meiner ersten Storchringbestellung mifsverstanden und mehrere Ringe mit „Nr. 1" geschickt. Ich hatte zur Unterscheidung Kerben in die Ringe gefeilt. Die Kerbe war bei dem vorliegenden Ringe deutlich zu sehen.

Gezeichnet am 18. Juni 1906 in Wosegau bei Cranz, Ostpreufsen, bei Herrn Rittergutspächter Sandmann. 3 junge Störche waren im Neste. Die Ringe habe ich persönlich umgelegt.

Am 16. Juli 1909 auf der Herrschaft Rinau, Kreis Königsberg i. Pr. Jagen 16 geschossen. Der Storch safs auf einer am Waldrande allein stehenden Eiche.

Entfernung: $30 \mathrm{~km}$ vom heimatlichen Neste.

Ring getragen: 3 Jahre, 28 Tage.

Herr Förster Klemusch von der Herrschaft Rinau, der dem Ringversuche grofses Interesse entgegenbringt, untersuchte die umliegenden Storchnester, fand sie alle mit 2 Alten besetzt und meint, dafs der Storch Nr. 1 in diesem Jahre nicht gebrütet hat.

Schon seit 3-4 Wochen vor der Erbeutung wurden etwa 8-13 Störche beobachtet, die sich abends immer in Jagen 16 einstellten.

Unterm 9. Juli 1909 hatte Herr Förster Klemusch bereits gemeldet, dafs nach Aussage seiner Kinder (16 und 14 Jahre alt) im Frühjahr 1909 auf seinem Neste ein Ringstorch gewesen war; bis der Herr Förster nach Hause kam, war er schon wieder fort. In dem betreffenden Neste waren im Jahre 1907 und 1908 Störche gezeichnet worden.

3) N r.j 906 . Am 4. Juli 1907 durch Vermittelung des Herrn $\mathrm{K}$ ischke, Neuendorfshof bei Gerdauen, Ostpreufsen, in einem Neste bei Herrn Besitzer Carl Engel in Neuendorf $3 \frac{1}{2} \mathrm{~km}$ nordwestlich von Gerdauen, markiert.

Am 22. Juni 1909 bei Grofs-Karpowen, Kreis Darkehmen, Ostpreufsen, angetroffen.

Entfernung: etwa $28 \mathrm{~km}$; also in dieselbe Gegend zurückgekehrt.

Ring getragen: Fast 2 Jahre (1 Jahr, 11 Monate, 18 Tage).

Nachricht unterm 23. Juni 1909 durch Herrn FrentzelBeyme in Gr. Karpowen. Der Storch befand sich in grölserer 
Gesellschaft und war kein Brutstorch. Der Herr schreibt mir, dafs er für Ringe keine Verwendung habe, da sich in der dortigen Gegend keine Storchnester befinden. Das ist von Interesse, denn man kann daraus schliefsen, dafs der Ringstorch Nr. 906 kein Nest gehabt hat. Am 12. Juli 1909 den beringten Fufs eingeschickt erhalten.

Es folgt ein aufserostpreufsischer Storch.

4) Nr. 485. Ring 485 am 17. Juni 1907 an Herrn F. $\mathrm{Buthmann}$ in Stuckenborstel, Bezirk Bremen, geschickt, aber erst im Sommer 1908 umgelegt.

Der Storch wurde am 28. J u li 1909 auf einer Wiese im Wümmetal bei Ottersberg, Kreis A chim, Provinz Hannover schwer angeschossen aufgefunden. Da an Heilung uicht zu denken war, wurde das Tier getötet und der Ring abgenommen.

Entfernung: ca. $6 \mathrm{~km}$.

Ring getragen: 1 Jahr.

Nachricht unter Beifügung des Ringes unterm 1. August 1909 durch Herrn Apotheker W. E. Müller in Ottersberg, Hannover. Storchkadaver durch Überschwemmung weggetrieben.

Es folgen nun einige Ringstörche, die in Ostpreufsen deutlich g e s e h e n, deren Ringnummeru aber nicht festgestellt worden sind.

5) Herr Rittergutsbesitzer Ulmer in Quanditten im Samlande, Ostpreufsen, berichtet an die Vogelwarte, dafs im Frühjahr 1909 bei Drugehnen ein Ringstorch gesehen worden ist. In jener Gegend hat Herr Ulmer im vorigen Jahre (1908) und auch schon 1907 viele Störche markiert. Herr Ulmer meldet weiter, dafs am 15. Juli 1909 an seinem Inspektor, Herrn Borbstaedt, ein Ringstorch auf 20 Schritt vorbeigestrichen ist.

6) Herr Rittergutsbesitzer C. G ä dek e- Na dra u bei Rudau im Samlande, Ostpreufsen, meldete unterm 26. Juni 1909, dafs in diesem Frühjahre bei Nadrau sich ein gezeichneter Storch gezeigt hat. Er ist nur einen Tag von den Leuten beobachtet worden. In den Nestern in Nadrau sind in den vorhergehenden Jahren Störche markiert worden.

7) Herr Anton Schlesiger in Tolksdorf bei Hogendorf, Ostpreufsen, südöstlich von Brauns berg gelegen, teilt unterm 19. Juni 09 mit, dafs ,ein Storch mit einem Fufsringe eine ganze Zeit lang im Frühjahr 1909 auf dem Neste war, aber nachher weggebissen wurde." Der Herr hat in den Jahren 1907 und 1908 in dem betreffenden Neste markiert. Der beobachtete Storch hatte den Ring um den rechten Fufs; so könnte er vom Jahrgang 1907 gewesen sein, denn da hat der Herr rechts gezeichnet; im Jahre 1908 links.

Zum Schlufs noch ein Storch, der schon bald nach dem Ausfliegen wieder erbeutet worden ist:

8) $\mathrm{Nr}$. 3064. Gezeichnet am 22. Juli 1909 auf der Schulscheune in Gr. Bajohren bei Nordenburg, Ostpreufsen, durch Herrn Lehrer Johr. 
Am 22. August 1909 Ring vom Dominium Willkamm bei $\mathrm{Sk}$ and a u, Ostpreufsen, eingeschickt erhalten.

Entfernung: $15 \mathrm{~km}$.

\section{Lachmöwen (Larus ridibundus).}

Zur Orientierung lege man die Zugkarte zu Grunde, die dem vorigen Jahresberichte beigegeben war. Von Interesse ist es, zu sehen, wie die Hauptmassen der Lachmöwen bei dem so überaus gelinden Winter 1909/1910 nicht so weit nach Süden gegangen sind wie sonst (Pomündung, Tunis). Es liegen in diesem Jahre 4 Möwen von Süddeutschland oder Österreich vor. Wahrscheinlich haben die Zugscharen bis zur Donau die auf der Karte angegebene Strafse benutzt und sind dann diesen Flufs aufwärts gezogen und in den Nebenflüssen vorgedrungen.

1) Nr. 1774. Gezeichnet am 10. Juli 1909 auf dem Bruche bei Rossitten mit noch 99 Artgenossen.

Anfang Januar 1910 an der Regnitz bei Erlangen im nördlichen Bayern geschossen.

Nachricht durch Herrn Julius Hoffmann, Erlangen, Paulistr. $4 \mathrm{I}$.

Zeit: ca. 6 Monate.

Entfernung: $900 \mathrm{~km}$.

Die Möwen gehen, wie die Fundstellen zeigen, in dem abnorm milden Winter 1909/1910 nicht weit nach Süden.

2) Nr. 1877. Gezeichnet am 16. Juli 1909 auf dem Rossittener Möwenbruche.

Am 24. November 1909 mittags auf einem Jagdgebiet ca. $40 \mathrm{~km}$ nordöstlich von $\mathrm{München}$ entfernt an der Isar zwischen den Stationen Marzling und Langenbach geschossen. Die Möwe ist jedenfalls von der Donau aus die Isar aufwärts gezogen.

Nachricht durch Herrn Karl Lindner, Fisch-, Wildbretund Geflügelhandlung, München, Dachauerstr. 32. Die Erbeutungsstelle liegt von München aus die Isar aufwärts. An der Stelle ist ein wasserreiches Gebiet, da sich dort die Isar in zahlreiche Arme teilt.

Zeit: 4 Monate, 8 Tage.

Entfernung: $960 \mathrm{~km}$.

Am 10. 12. 09 trifft die ganze Möwe im Fleisch in Rossiten ein.

3) Nr. 412. Gezeichnet als juv. am 13. August 1906 in Rossitten. (Am Seestrande gefangen, ohne Zweifel vom Bruche stammend).

Am 14. August 1909 morgens im Obinger See an einer Legangel verhängt. Mufste getötet werden. Bemerkenswert, dafs die Möwe zu so früher Jahreszeit schon so weit im Süden war! Ist jedenfalls von der Donau aus den In $\mathbf{n}$ aufwärts gezogen. 
Ring getragen: 3 Jahre 1 Tag.

Entfernung: $972 \mathrm{~km}$.

Nachricht durch Herrn Fr. H. Berger, Seebesitzer in Obing. (Oberbayern). Die Möwe befand sich in Gesellschaft von 7-8 Artgenossen. Die Art ist dort nicht zu häufig, nur ab und $\mathrm{zu}$ in kleinen Flügen.

Die ausgestopfte Möwe ist der Vogelwarte durch Herrn Kunstmaler H a g e, München, Müllersr. 36/1 freundlichst geschenkt worden.

4) Nr. 1866. Gezeichnet am 16. Juli 1909 auf dem Rossittener Möwenbruche als junger Vogel.

Am 2. November 1909 von Herrn Franz Stahrmüller in Zell am See (Salzburg) auf dem Zeller See geschossen. Jedenfalls den Inn oder die Salzach aufwärts gezogen.

Entfernung: $1025 \mathrm{~km}$.

Zeit: 3 Monate 17 Tage.

Am 13. November 1909 ganze Möwe zugeschickt erhalten.

Recht hübsche Ergänzungen und Fortsetzungen der auf der Karte angegebenen westlichen Zugstrafsen stellen die folgenden 3 Möwen dar: Von der französischen Küste aus ist eine Bahn nach England hinüber zu schraffieren, und weiter ist die RhoneZugstrafse nach den Balearen hin zu verlängern. Man wird den Weg an der Küste entlang zu suchen haben. Dafs England bisher noch keine Ringvögel von Deutschland zurückgemeldet hat wird seinen Grund darin haben, dafs man dort den Ringversuchen erst jetzt erhöhtes Interesse zuwendet:

5) Nr. 1289 . Gezeichnet am 16. Juli 1908 auf dem Möwenbruche bei Rossitten. (Halbflügge.)

Am 15. Oktober 1909 an der Küste in der Nähe von Gr. Yarmouth, Norfolk (England) erlegt.

Meldung unterm 18. Oktober 1909 durch Herrn H. F. Witherby, London W. C. 326 High Holborn.

Entfernung: $1290 \mathrm{~km}$.

Zeit: 1 Jahr 3 Monate.

Am 26. November 1909 Fufs mit Ring zugeschickt erhalten.

Veröffentlicht in British Birds Dec. 1909 Vol. III No. 7.

6) Nr. 339 . Gezeichnet am 5. Juli 1906 auf dem Bruche bei Rossitten mit 49 Artgenossen.

Erbeutet am 2. März 1910 am Flusse Medina, Insel Wight, etwa in der Mitte zwischen Cowes und Newport. Tot aufgefunden.

Nachricht unter Einsendung des beringten Fuises durch Herrn H. G. J effery, Newport, Insel Wight, 75 Pyle Street.

Entfernung: $1575 \mathrm{~km}$.

Zeit: 3 Jahre 8 Monate.

7) Nr. 1899. Gezeichnet am 16. Juli 1909 auf dem Bruche bei Rossitten. 
Am 6. Januar 1910 bei Mahon auf Menorca (Balearen) erbeutet. Nachricht unter Beifügung der Spanischen Zeitung „El Bien Publico", Mahon 8. Enero 1910, welche eine Notiz über den Fall enthält, durch Herrn F. Andreu, Directeur de l'Usine Electrique in Mahon.

Entfernung: $2100 \mathrm{~km}$.

Zeit: 5 Monate 20 Tage.

Geographische Lage des Fundortes: $39^{\circ} 50^{\prime} \mathrm{n} . \mathrm{Br}$.

Am 16. Januar Brief in Mahon abgegangen, am 21. Januar eingetroffen, also nach 5 Tagen.

Durch die Weltsprache Esperanto ist die Erbeutung dieser Möwe bekannt geworden.

Es folgen zwei auswärts, nicht in Rossitten, gezeichnete Möwen :

8) Nr. 1687. Gezeichnet im Juli 1909 auf dem Molfsee bei Kiel, Schleswig-Holstein, durch Herrn stud. rer. nat. Ernst Rie de, Kiel, Ringstr. 91 II, mit noch 99 Artgenossen zusammen.

Am 15. A u g u t 1909 bei Saint Valery-sur-Somme, Frankreich, erbeutet; an der Mündung der Somme gelegen.

Die Möwe ist also von Kiel aus nach Durchquerung von Schleswig-Holstein immer an der Küste entlang nach SW. gezogen.

Entfernung: ca. $730 \mathrm{~km}$.

Zeit: etwa 1 Monat.

Nachricht durch Herrn A ug. Drion, Brüssel, 36 Montagne aux herbes potagères.

9) Nr. 1397. Gezeichnet Anfang Juli 1909 auf dem Saspersee, durch. Herrn M. Witt, Neufahrwasser bei Danzig, Westpreufsen, Bergstr. und zwar am linken Fufse.

Am 17. A ugust 1909 von Herrn H. Regier, Rosenort bei Fürstenau Kr. Elbing, Westpr., verendet auf dem Felde aufgefunden, wo der Vogel anscheinend schon einen Tag gelegen hatte und Wunden am Kopfe trug; anscheinend von einem Habicht herrührend.

Ring eingeschickt erhalten.

Entfernung: ca. $40 \mathrm{~km}$.

Ring getragen: etwa $1 \frac{1}{2}$ Monat.

Recht bemerkenswert ist die folgende Brutmöwe:

10) Nr.96. Gezeichnet am 15. Juli 1905 auf dem Bruche bei Rossitten.

Erbeutet am 20. Juni 1907 auf dem Tosmarschen See bei Libau in Kurland, Rufsland.

Dort befindet sich wie auf dem Rossittener Möwenbruche eine Lachmöwen- und Flufsseeschwalben-Kolonie. Aus den umherschwärmenden Brutvögeln ist die Ringmöwe herausgeschossen worden. Also dort haben sich unsere Rossittener Lachmöwen zur Brut eingefunden. Sie sind also noch nördlicher gegangen. Der erste derartige Fall, den ich zu verzeichnen habe. Die Möwe Nr. 96 war im Frühjahr 1907 fortptlanzungsfähig geworden.

Entfernung: $150 \mathrm{~km}$. 
Zeit: 1 Jahr, 11 Monate, 5 Tage.

Dieser interessante Fall hatte in einer russischen Jagdzeitung gestanden, deren Übersendung ich Herrn Adolf Stieren in $\mathrm{Lu}$ g a, Gouvernement St. Petersburg verdanke. Es war darin von einer "Seeschwalbe" die Rede. Die russische Korrespondenz mit dem Schützen selbst, Herrn W. J. Matorin in Narva, Sergiewsche Strafse, Haus Saar, hat Herr Dr. A. Da mpf, Assistent am Zoologischen Museum in Königsberg i./Pr., freundlichst geführt. Am 1./3. 1909 erhielt ich das beringte Bein. Es ist ein Lachmöwenbein.

Zum Schlufs noch 2 bald nach dem Auflassen erbeutete Möwen:

11) Nr. 1713 . Gezeichnet am 10. Juli 1909 mit noch 99 Stück auf dem Bruche bei Rossitten.

Am 16. A ugust 1909 bei Fuchshöfen bei Waldau, Kr. Königsberg i. Pr. bei einer Entenjagd geschossen. Ring eingeschickt durch Herrn Gutsförster A. Dinter in Fuchshöfen.

Entfernung: $54 \mathrm{~km}$.

Zeit: 1 Monat 6 Tage.

12) Nr. 1947 . juv. Gezeichnet am 13. August 1909 in Rossitten. (War in Pillkoppen gefangen.)

Erbeutet am 16. August 1909 bei Labiau, Ostpreufsen.

Entfernung: $37 \mathrm{~km}$.

Ring getragen: 3 Tage.

Nachricht durch Herrn Postmeister Pieper, Labiau.

\section{Silbermöwen. (Larus argentatus).}

Von grofsem Werte war es für die Ringversuche, dafs sowohl die Inhaber der Vogelfreistätten auf dem Memmert bei Juist, Freiherr v. Berlepsch und Graf v. WilamowitzMöllendorf, als auch der Verein, ,Jordsandzur Begründung von Vogelfreistätten an den deutschen Küsten“" durch Herrn Dr. Dietrich in Hamburg der Vogelwarte ihre Mithilfe anboten. Die Versuche erfuhren dadurch eine starke Förderung zunächst nach der wissenschaftlichen Seite hin, denn grofse Brutkolonien stehen den genannten Herren zur Verfügung, sodals sehr zahlreiche Markierungen vorgenommen werden konnten. Ebenso wichtig war aber auch der moralische Gewinn. Wenn solche mafsgebenden Vogelschützler ihre Kräfte zur Förderung der Markierungsversuche zur Verfügung stellen, so mufs man doch von deren Ungefährlichkeit überzeugt sein. Die Vogelwarte spricht für diese unschätzbare Förderung ihren verbindlichsten Dank aus. Gleicher Dank gebührt Herrn Lehrer L e e g e in Ostermarsch, der sich der Mühe des Markierens freundlichst unterzogen hat. Die sämtlichen folgenden Silbermöwen sind von dem genannten Herrn am 13. und 14. Juli 1909 in der grofsen Brutkolonie auf dem Memmert bei $\mathrm{Ju}$ ist markiert worden. Ich gebe deshalb die Auflafsstelle bei den einzelnen Stücken nicht nochmals an. 
Einen dreifachen Gewinn hat das umfangreiche Silbermöwen-Kennzeichnen bis jetzt gebracht:

1) Wir sehen, dafs die erbrüteten jungen Silbermöwen auch im Winter an ihrem Brutplatze selbst, oder in dessen $\mathrm{n}$ ä chster Umgebung bleiben. Ein Zug nach Süden findet nicht statt. Die Entfernungen vom Brutplatze schwanken bis jetzt zwischen $3-205 \mathrm{~km}$. Der Übersicht halber seien die Kilometerzahlen genannt: Fünfmal: $3 \mathrm{~km}, 8 \mathrm{~km}$; sechsmal: $20 \mathrm{~km}, 22 \mathrm{~km}$; siebenmal: $25 \mathrm{~km}, 28 \mathrm{~km}$; zweimal: $35 \mathrm{~km}$; dreimal: $37 \mathrm{~km}$; dreimal: $40 \mathrm{~km}$; zweimal: $47 \mathrm{~km}$; zweimal: $80 \mathrm{~km}, 90 \mathrm{~km}$, $97 \mathrm{~km}, 100 \mathrm{~km}$; zweimal: $118 \mathrm{~km}$; fünfmal: $160 \mathrm{~km}, 205 \mathrm{~km}$. Diese letzte weiteste Fundstelle liegt bei Eckernförde in Schleswig-Holstein.

2) Der Versuch zeigt den grofsen Schaden, den das übliche „Möwenschiefsen“ von seiten der Badegäste anrichtet. 667 Silbermöwen sind am 13. und 14. Juli 1909 beringt worden, davon sind bis jetzt schon 71 Stück zurückgemeldet; das macht 10,6 Prozent Man glaube ja nicht, dafs die Möwen um des Versuches willen getötet worden sind. Alle aufgezählten Stücke wären so wie so verloren gewesen. Durch den Versuch haben sie wenigstens noch einen wissenschaftlichen Zweck erfüllt.

3) Die Vogelwarte bekommt durch die eingesandten Vögel nach und nach eine höchst wertvolle Sammlung von den Entwicklungsstufen der Möwenkleider, deren Alter genau bekannt ist. Ein schöner Anfang ist schon da.

Nun sollen die einzelnen Erbeutungsstellen aufgezählt werden, und zwar nach der Zeitfolge der Erbeutung:

1) Nr. 2480. Am 3. August 1909 auf hoher See unweit von Norderney (etwa $2 \mathrm{~km}$ ) von Hern Bankdirektor Wolff, Posen, Karlstr. 41 geschossen.

Ring getragen: 21 Tage.

Entfernung: etwa $20 \mathrm{~km}$.

Hat sich in ihrer engeren Heimat umhergetrieben.

Am 26. August 1909 trifft die Möwe als Balg auf der Vogelwarte ein.

2) Nr. 2552 . Erbeutet am 15. August 1909 von Herrn Charles A eukens auf der Düne bei Helgoland.

Entfernung: $80 \mathrm{~km}$.

Zeit: 1 Monat, 2 Tage.

Hat sich nach dem Auflassen in der engeren Heimat umhergetrieben.

3) Nr. 2349 . Am 23. August 1909 von Herrn Richard He y m a n n, Norderney, zwischen Norderney und Juist geschossen.

Entfernung: $3 \mathrm{~km}$.

Zeit: 1 Monat, 10 Tage.

Meldung unter Beifügung des Ringes durch Herrn Heymann.

4) N r. 3044. Am 24. August 1909 auf Juist von Herrn Gerhardt geschossen. 
Meldung durch Herrn Gerhardt.

Entfernung: $3 \mathrm{~km}$.

Zeit: 1 Monat, 11 Tage.

Nr. 2359 . Am 24. August 1909 an Herrn Leege in Ostermarsch wieder eingeliefert.

Entfernung: $20 \mathrm{~km}$.

Zeit: 1 Monat, 11 Tage.

6) Nr. 2539 . Erbeutet am 26. August 1909 von Herrn Charles A eukens auf der Düne bei Helgoland.

Entfernung: $80 \mathrm{~km}$.

Zeit: 1 Monat, 13 Tage.

7) Nr. 2946 . Am 28. September 1909 auf Norderney von einem Badegaste, Herrn G. Gölitz, Norderney, Georgstr. 1, angeschwemmt aufgefunden.

Entfernung: $25 \mathrm{~km}$.

Zeit: 2 Monate, 15 Tage.

8) N r. 2996 . Am 1. Oktober 1909 am Südweststrande der Insel Borkum von der Lehrerin Fräulein Nachtigaller, Alverskirchen bei Münster i. W. tot aufgefunden.

Entfernung: $20 \mathrm{~km}$.

Zeit: 2 Monate, 19 Tage.

9) Nr. 2663 . Am 5. Oktober 1909 von Herrn Oberleutnant Wittner, z. Zt. Norderney, Kaiserstrafse 7, bei Norderney geschossen:

Entfernung. $25 \mathrm{~km}$.

Zeit: 2 Monate, 22 Tage.

10) N r. 2575 . Am 6. Oktober 1909 am Deich bei Wybelsum am Dollart in der Nähe Emdens, Ostfriesland, angeschwemmt tot aufgefunden.

Nachricht mit Ring durch Herrn Ökonomierat Wy chgram, Wybelsum, bei Emden.

Entfernung: $40 \mathrm{~km}$.

Zeit: 2 Monate, 23 Tage.

11) Nr. 2911 . Am 10. Oktober 1909 von Herrn Architekt A. Langöhrig am Strande bei Borkum angeschwemmt aufgefunden. (Adr. Hotel Kaiserhof.)

Entfernung: $20 \mathrm{~km}$.

Zeit: 2 Monate, 27 Tage.

12) Nr. 2430. Am 18. Oktober 1909 auf der Insel Neuwerk bei Cuxhaven von Herrn E. Griebel geschossen.

Entfernung: $100 \mathrm{~km}$.

Zeit: 3 Monate, כ Tage.

13) Nr. 2476. Am 19. Oktober 1909 von Herrn Malermeister Mensen in Norderney geschossen.

Nachricht am 19. Oktober durch Herrn John G. Lange in Norderney.

Entfernung: $25 \mathrm{~km}$.

Zeit: 3 Monate, 6 Tage. 
14) Nr. 3062 . Am 6. November 1909 am Nordstrande von Norderney von Herrn Johann Wichmann in Norderney, Osterstr. 9, aufgefunden.

Entfernung: $25 \mathrm{~km}$.

Zeit: 3 Monate, 25 Tage.

15) N r. 2421 . Ende November 1909 bei Helder, Niederlande von einem Jäger geschossen.

Nachricht und Ring unterm 1. Dezember 1909 durch die zoologische Station Helder, Holland (Herr Delsman, zweiter biolog. Assistent).

Entfernung: $160 \mathrm{~km}$.

Zeit: ca. 4 Monate.

16) Nr. 2381 . Am 12. November 1909 bei Delfzijl, Emsmündung, Niederlande, von Herrn Schiffer A. Kappen in Delfzijl geschossen.

Entfernung: $35 \mathrm{~km}$.

Zeit: 4 Monate.

17) Nr. 2860 . Am 13. November 1909 leicht angeschossen bei Juist gefangen.

Nachricht unterm 14. November 1909 von Herrn G. Schmidt-Juist an Herrn Leege-Ostermarsch.

En tfernung: $3 \mathrm{~km}$.

Zeit: ca. 4 Monate.

18) Nr. ?. Der Schiffer Herr A. Kappen in Delfzijl, Niederlande, der die Möwe Nr. 2381 geschossen hat, meldet am 29. November 1909, dafs letzthin „noch so eine Möwe geschossen sei". Nummer habe er vergessen.

Entfernung: $35 \mathrm{~km}$.

Zeit: ca. 4 Monate.

19) $\mathrm{Nr} .2385$. Im November 1909 auf der Jade bei Varel vom Meister des Herrn H. T. Ku per, Dampfziegelei, Wilhelmshaven, Gökerstr. 4, geschossen.

Entfernung: $90 \mathrm{~km}$.

Zeit: ca. 4 Monate.

20) Nr. 3067 . Am 14. November 1909 von Herrn J. F. Schlüter, Wonkendorf bei Eckernförde, SchleswigHolstein, geschossen.

Ganze Möwe mit Ring eingeschickt. Die Möwe ist also durch Schleswig-Holstein nach NO. gezogen.

Entfernung: $205 \mathrm{~km}$.

Zeit: 4 Monate, 1 Tag.

21) Nr. 2347 . Am 17. November 1909 bei Bensersiel am Strande der Nordsee gegenüber der Insel Langeoog von Herrn Emil von Thünen, Hotel „Hof von Harlingerland“, Bensersiel, an der Nordsee tot aufgefunden.

Am 28. Dezember 1909 trifft der Ring auf der Vogelwarte ein.

Entfernung: $48 \mathrm{~km}$.

Zeit: 4 Monate, 4 Tage. 
22) Nr. 2382 . Am 18. November 1909 bei Borkum geschossen. Nachricht durch die Redaktion der Borkumer Zeitung.

Entfernung: $20 \mathrm{~km}$.

Zeit: 4 Monate, 5 Tage.

23) N r. 2591 . Am 27. November 1909 von dem Gärtner Karl Fis cher auf Juist geschossen. Ring durch Herrn Badearzt Dr. A rends-Juist am 1. 12. 1909 eingeschickt erhalten.

Entfernung: $3 \mathrm{~km}$.

Zeit: 4 Monate, 14 Tage.

24) Nr. 2376 . Ende Dezember 1909 bei Helder, Holland, geschossen.

Ring eingeschickt bekommen durch Herrn J. J. Tesch von der zoolog. Station in Helder.

Entfernung: $160 \mathrm{~km}$.

Zeit: ca. 5 Monate.

25) Nr. 2695 . Anfang Dezember 1909 bei Borkum geschossen. Nachricht unter Beifügung des Ringes durch die Redaktion der Borkumer Zeitung.

Entfernung: $20 \mathrm{~km}$.

Zeit: ca. 5 Monate.

26) N r. 3075 . Unterm 12. 12. 1909 durch Herrn Insel- und Strandvogt Neemann auf Baltrum, Kreis Norden, Reg.-Bez. Aurich die Meldung, dals die Möwe auf Baltrum geschossen sei.

Entfernung: $37 \mathrm{~km}$.

Zeit: ca. 5 Monate.

27) N r. 2341 . Unterm 8. Dezember 1909 durch Herrn Insel- und Strandvogt Neemann auf Baltrum, Kreis Norden, Reg.-Bez. Aurich die Meldung, dafs die Möwe in der Nähe von Baltrum geschossen sei. Jedenfalls um den 8. 12. 1909 herum.

Entfernung: $37 \mathrm{~km}$.

Zeit: ca. 5 Monate.

28) Nr. 2924 . Am 12. Dezember 1909 an der Küste von Hornhuizen, Provinz Groningen, Niederlande von Herrn C. van Ho 0 rm, Landbouwer, Hornhuizen, gefangen.

Entfernung: $40 \mathrm{~km}$.

Zeit: 5 Monat.

29, 30) Nr. 2675 und 2964 . Die eine im Winter 1909 auf Norderney, die andere am 12. Dezember 1909 auf dem Kopersand, einer Sandbank südlich vom Memmert, von Fischern erlegt.

Entfernungen: 25 und $8 \mathrm{~km}$.

Zeit: ca. 5 Monate.

Ringe durch Herrn Leege, Ostermarsch, eingeschickt erhalten.

31) Nr. 2622 . Am 22. Dezember 1909 von Herrn Feldwebel H. Junghans bei Cuxhaven geschossen.

Entfernung: $118 \mathrm{~km}$.

Zeit: 5 Monate, 9 Tage. 
32) Nr. 2351 . Am 29. Dezember 1909 in Schweiburg in Oldenburg von Herrn C. Fuhrken geschossen.

Entfernung: $97 \mathrm{~km}$.

Z eit: ca. $5^{1 / 2}$ Monate.

Am 6. 1. 1910 ganze Möwe zugeschickt erhalten.

33) N r. 3057 . Etwa am 1. Januar 1910 bei Greetsiel, Ostfriesland, von Herrn H. Ba almann geschossen.

Entfernung: $22 \mathrm{~km}$.

Zeit: ca. $5^{1 / 2}$ Monate.

34) Nr. 2936 . Am 29. Dezember 1909 auf Baltrum geschossen. Nachricht durch den Herrn Insel- und Strandvogt Gerhard Neemann in Baltrum.

Entfernung: $37 \mathrm{~km}$.

Zeit: ca. $5^{1} / 2$ Monate.

35, 36) N r. 2691 und 2931 . Nr. 2691 am 27. Dezember 1909 und Nr. 2931 am 15. Januar 1910 bei Hornhuizen, Provinz Groningen, Niederlande gefangen.

Ringe eingeschickt durch Herrn C. va $\mathrm{n} \mathrm{H}$ o $0 \mathrm{rm}$, Landbouwer in Hornhuizen.

Der Herr schreibt dazu: Die Möwen ziehen immer von Ost nach West und fast immer über den Deichen.

Entfernung: $40 \mathrm{~km}$.

Zeit: für Nr. $26915 \frac{1}{2}$ Monate.

$$
\text { " Nr. } 29316
$$

37) N r. 2632. Am 4. Januar 1910 auf Norderney erlegt.

Entfernung: $25 \mathrm{~km}$.

Zeit: ca. 6 Monate.

Ring durch Herrn Leege, Ostermarsch, eingeschickt erhalten.

38) Nr. 2686 . Erbeutet um den 20. Januar 1910 bei Helder, Niederlande. Ring durch Herrn Dr. Tesch von der zoolog. Station in Helder eingeschickt erhalten.

Entfernung: $160 \mathrm{~km}$.

Zeit: ca. 6 Monate.

39) N r. 2533 . Erbeutet am 3. Februar 1910 bei Helder, Niederlande. Ring eingeschickt erhalten durch Herrn Dr. Tes ch von der zoolog. Station in Helder.

Entfernung: $160 \mathrm{~km}$.

Zeit: $6^{1 / 2}$ Monate.

40) Nr. 2988. Am 29. Januar 1910 Nachmittag 4 Uhr an der Kugelbake in Cuxhafen von Herrn Hans Beckmann, $\mathrm{Cuxh}$ afen III Steinmauerstr. 111 geschossen. (Ring zugeschickt erhalten.)

Entfernung: $118 \mathrm{~km}$.

Zeit: $61 / 8$ Monate.

Silbermöwe wird "Cumme" in Cuxhaven genannt.

41) N r. 2517 . Ende Januar 1910 auf Norderney geschossen. „Seekorbe“ genannt. Nachricht unterm 31. Januar 1910 durch Jansen Siebelt, Eden Norderney. 
Entfernung: $25 \mathrm{~km}$.

Zeit: $6^{1} / 2$ Monate.

42) Nr. 2339 . Erbeutet Anfang Februar 1910 auf der Insel Rottum. Nachricht durch die Borkumer Zeitung unterm 10. Februar 1910.

Entfernung: $28 \mathrm{~km}$.

Zeit: $61 / 3$ Monate.

43) Nr. 2560 . Am 12. Februar 1910 bei $\mathrm{Cuxhaven}$ von Herrn J. Schwing, Cuxhaven, bei der Kirche erlegt.

Entfernung: $118 \mathrm{~km}$.

Zeit: 7 Monate.

Am 21. Februar 1910 ganze Möwe eingeschickt bekommen.

44) Nr. 2583 . Gefangen jedenfalls Ende Februar an der Küste bei der Gemieinde Ulru m, Provinz Groningen, Niederlande, in einem Vogelnetz.

Nachricht unterm 3. März 1910 durch Herrn Journalist J. de Vries, Zoutkamp, Prov. Groningen Niederlande.

Entfernung: $47 \mathrm{~km}$.

Zeit: ca. $71 / 2$ Monate.

45) Nr. 2445. Erbeutet am 19. März 1910 auf Juist, Nordstrand.

Der ganze Vogel wird von Herrn W. Altmanns in Juist eingeschickt.

Entfernung: $3 \mathrm{~km}$.

Zeit: 8 Monate.

$46-49)$ Nr. $2583 ; 2625 ; 3054 ; 2684$.

Erbeutet: am 20. März 1910 in der Nähe von Vierhuizen, Gemeinde Ulrum, Provinz Groningen, Niederlande, in einem Zugnetze gefangen.

Die 3 zuerst genannten Ringe werden am 29. März 1910 von Herrn J. de Vries, Zoutkamp, Groningen, eingeschickt.

Entfernung: $47 \mathrm{~km}$.

Zeit: 8 Monate.

50) Nr. 2604.

Erbeutet: Am 23. April 1910 an der Südspitze der Insel Texel tot aufgefunden. Den Ring schickt Herr H. C. Delsman, zoologische Station Helder, Holland ein.

Entfernung: $160 \mathrm{~km}$.

Zeit: 9 Monate 10 Tage.

51) Nr. 2617 . Nach Mitteilung von Herrn O. Leege am 10. September 1909 schwer verwundet bei Ostermarsch angetrieben.

52-71) Nach Mitteilung von Herrn 0. Le eg e, Ostermarsch vom 9. 11. 1909 wurden von ihm selbst im Herbst 1909 gegen 20 gezeichnete Silbermöwen verendet oder schwer verwundet auf dem Memmert gefunden. Alle von Badegästen angeschossen. Sie sind weiter ab auf dem Watt angeschossen und haben dann ihre Geburtsstätte wieder aufgesucht. 


\section{v. Strandvögel (Tringen und Totaniden).}

Da ich im Jahre 1904 schon mit 13 aufgelassenen Strandvögeln einen Erfolg zu verzeichnen hatte, so richtete ich im vergangenen Jahre mein Augenmerk darauf, das Markieren von Strandvögeln in etwas gröfserem Mafsstabe vorzunehmen. Es gelang mir 207 hier auf dem Durchzuge gefangene Alpenstrandläufer $\mathrm{zu}$ kennzeichnen, und so wissen wir nun, wie die folgenden Fundorte zeigen, mit einem Male, wo die Strandläuferschwärme, die ich jahraus jahrein auf der hiesigen Vogelwiese beobachte, überwintern: das südliche England, und die Südküsten Frankreichs sind die Winterquartiere.

\section{Alpenstrandläufer (Tringa alpina).}

1) Nr. 462 . Gezeichnet am 3 August 1909 in Rossiten mit 45 Artgenossen zusammen.

Am 15. Dezember 1909 von Herrn H. Brown jun., Paglesham House, Rochford, Essex in England, etwa $50 \mathrm{~km}$ östlich von London geschossen. Am Flusse Roach; an der Küste.

Der Herr macht dem „Field“ Mitteilung, und Herr Scher re n schreibt mir über den Fall.

Entfernung: $1400 \mathrm{~km}$.

Zeit: 4 Monate, 12 Tage.

Die Strandvogelscharen sind also immer an der Küste entlang nach SW. gezogen und dann über den Kanal nach England. Herr E. Marcuse-London teilt mit, dafs Tringen in grofsen Schwärmen an der Ostküste Englands überwintern und bis zum Frühjahre beiben bei mildem Winter, wie er fast immer dort herrscht. Unterm 3. Januar 1910 teilt Herr S. W. Coleman in London S. E. 352 Upland Road, East Dulwich dasselbe mit; als Fundstelle: die Salzsümpfe bei Southend an der Küste.

Nach den Angaben des Schützen kommen die Strandläufer dort zu hunderten vor. Sie erscheinen ungefähr im September oder Oktober und ziehen ungefähr im April wieder weg. Das erlegte Exemplar hatte sich in einem Flug 50-60 Stück befunden. Es ist gegessen worden. Der Schütze hat nur noch den Ring.

2) Nr. 504. Gezeichnet: am 3. August 1909 mit 45 Artgenossen in Rossitten, also an demselben Tage wie das vorhergehende Stück.

Erbeutet: am 1. März 1910 an der Mündung der Gironde an der Rhede von Verdon in Frankreich.

Herr A. Morel, Villa Louise Jeanne, Le Verdon, hat den Vogel bei der Strandvogeljagd mit noch etwa 100 Stück Artgenossen zusammen erbeutet. Der Herr schickt eine Karte-mit der Ansicht der Erlegungsstelle ein: eine Bucht mit ganz flachem Strande und Sandbänken. Ein Gebiet, so recht geeignet für Tringen.

Entfernung: $1875 \mathrm{~km}$. 
Zeit: 7 Monate.

Danach steht also fest, dafs manche der fraglichen Strandvogelschwärme von England aus (oder dieses Land ganz übergehend) an der französischen Küste weiter nach Süden gewandert sind.

3) Nr. 911 . Tringa alpina juv. Am 15. Juli 1909 auf meinem Hofe in Rossitten mit noch 13 Artgenossen zusammen aufgelassen.

Am 16. Juli 1909, also am Tage darauf, gegen Abend auf der Vogelwiese bei Rossitten von mir aus einem grofsen Fluge Strandvögel herausgeschossen.

Ein Beispiel dafür, dafs sich der Vogel ungehindert wieder unter seine Artgenossen gemischt hat. Ein belästigter, sich unbehaglich fühlender, sonst gesellig lebender Vogel trennt sich immer von der grofsen Gesellschaft ab. Ich sah dem Vogel vor dem Schusse nichts Besonderes an.

Ring ganz gelb geworden.

Heller Wasserläufer Totanus littoreus juv.

4) $\mathrm{Nr} .1046$. Gezeichnet am 13. August 1909 in Rossitten.

Am 21. August 1909 , also nach 8 Tagen, bei Mewischfelde, Post Kurzebrack, Westpreufsen, an der Weichsel von Herrn Lehrer Littmanski geschossen.

Entfernung: $200 \mathrm{~km}$.

Zeit: 8 Tage.

Fufs mit Ring eingeschickt erhalten. Merkwürdig, dafs der Vogel so weit die Weichsel aufwärts gegangen ist; Fundstelle etwa $68 \mathrm{~km}$ vom Seestrande entfernt.

Der Vogel war in kleinerer Gesellschaft. Strandvogelschaaren kommen um diese Zeit jährlich dort an, manchmal in recht grofsen Schwärmen.

Dafs der Vogel, der ganz gesund war, geschossen wurde, war Zufall nach dem Berichte des Schützen.

Ring ganz mit Schlamm bedeckt.

\section{Flu[s-Seeschwalben. (Sterna hirundo.)} zeichnet.

1) Nr. 1030 . juv. Am 6. August 1909 in Rossitten ge-

War in Pillkoppen gefangen. Stammt ohne Zweifel vom Rossittener Bruche und ist dort im Sommer 1909 erbrütet.

Nach Mitteilung von Herrn Präparator Schuchmann in Königsberg ist die Seeschwalbe von Herrn vo n Eck, Kampken bei Tromitten am Haff geschossen.

Herr Assessor Tischler hatte den präparierten Vogel bei Herrn Schuchmann im August 1909 gesehen und mich darauf aufmerksam gemacht.

Die Erlegung ist bald nach dem Auflassen geschehen. 
2) Nr. 406 . (Drosselring.) Gezeichnet am 13./14. Juli 1909 von Herrn Lehrer Leege auf dem Memmert bei Juist. Dort erbrütet.

Am 28. August 19093 Uhr nachmittags bei Salennelles an der Mündung der Orne in Frankreich, westlich der SeineMündung von Herrn P. Marié, chateau de Pontault-Combault, Seine-Marne geschossen. Bei ruhigem und klaren Wetter. $4 \mathrm{~km}$ vom Ufer entfernt vom Boot aus.

Nachricht durch Herrn Marié selbst.

Die Sterna ist immer an der Küste entlang nach SW. gezogen.

Entfernung: ca. $725 \mathrm{~km}$.

Zeit: 1 Monat 14 Tage.

Notiz darüber hat im St. Hubert Club de France, Paris gestanden. Diese Notiz schickt mir Herr Professor R. Poncy, Genf, Roches 9, freundlichst ein.

Am 6. Dezember 1909 trifft der Balg ein. Normales Jugendgefieder. Fufs tadellos gesund.

\section{Schwalben.}

1) Nr. 711 . Delichon urbica, Mehlschwalbe. Am 15. Juli 1906 in einem Neste aus der am alten Vogelwarten-Museum in Rossitten befindlichen Kolonie gefangen. Ich zeichnete im Jahre 190611 Stück aus dieser Kolonie, und zwar am 12. Juli 5, am 13. Juli 3, am 15. Juli 3 Stück. Alles alte Exemplare.

Am 19. Juli 1909 fing ich das vorliegende Stück Nr. 711 aus einem Neste heraus, das sich innerhalb einer Kolonie befand, die an einem Stalle war, der etwa $100 \mathrm{~m}$ vom alten Museum entfernt stand. Die Nester am alten Vogelwarten-Gebäude waren im vergangenen Winter vom Regen und Sturm weggefegt worden. Darum hat sich die Kolonie von dort weggezogen.

Ring getragen: 3 Jahre, 4 Tage.

Die Schwalben sind also an den alten Brutort heimgekehrt! Ringschwalbe hat gebrütet! Sie war ganz gesund. Gewicht der Schwalbe: 18,8 g bei ganz normaler Leibeskonstitution. Am 19. Juli liefs ich die Schwalbe gleich nach dem Fangen wieder fliegen. Am 20. fing ich sie nochmals aus demselben Neste, tötete sie und nahm das Nest ab. Es lagen 4 Eier darin. Alles ist für die Sammlung der Vogelwarte präpariert worden. Es wird mir natürlich nicht einfallen, jede weitere Ringschwalbe zu sammeln, aber dieses erste Belegstück wollte ich mir doch nicht entgehen lassen. Die ganze Kolonie schien am 19. Juli noch Eier zu haben. So spät!

Im Anschlufs an diesen Fall möchte ich folgendes mitteilen:

Herrn W. I wa h n in Perdollen bei Laukischken, Kreis La biau, Ostpreufsen meldet unterm 18. Juli 1909, dafs er eine in seinem Stalle nistende Schwalbe gezeichnet hätte, die ununterbrochen in fünf Jahren an dasselbe Nest zurückkehrte. - Unterm 26. 7. 1909 teilt mir der Herr auf meine Anfrage noch weiter mit, dafs 
die Schwalbe eine Stallschwalbe (H. rustica) gewesen sei. Direkt gezeichnet hätte er sie nicht, aber sie wäre kenntlich gewesen an dem gelben Bauchgefieder und hätte ohne zu suchen gleich nach ihrer Ankunft dasselbe Nest immer wieder angenommen.

\section{Purpurreiher. (Ardea purpurea.)}

1) Nr. 2468. Gezeichnet von Herrn Dr. J. Th. O u demans, Amsterdam, P. Potterstr. 12. im Sommer 1909 bei Amsterdam. Hier liegt ein zweiter Fall vor, dafs ein Verein, der den Naturschutz ausübt, die Ringversuche fördert, denn Herr Dr. Oude m a n s gehört dem Vorstande des "Vereins für Naturdenkmalpflege“ in Amsterdam an. Am 26. Juli 1909 wurde dieser Reiher in der Nähe von Amsterdam gefangen und an die Königl. zoologische Genossenschaft "Natura Artis Magistra" in Amsterdam abgeliefert.

Nachricht durch Herrn Direktor Dr. C. H e r b er t, Amsterdam.

2) Nr. 2469 . Gezeichnet am 2. Juli 1909 im Na ard ermeer bei Amsterdam in Holland von Herrn Dr. J. Th. Oudemans, Amsterdam, Paulus Potterstraat 12 eigenhändig. Das Naardermeer gehört dem „Verein für Naturdenkmalpflege" in Amsterdam.

Es sind im Jahre 19094 Löffelreiher und 16 Purpurreiher dort beringt worden, alle im Naardermeer. Alles Junge dieses Jahres. Alle waren schon sehr grofs und konnten tüchtig laufen.

Geschossen wurde dieser beringte Reiher in der Sumpfjagd von Guemps bei Calais in Frankreich. Also an der Küste nach SW. weiter gewandert.

Nachricht unterm 9. 12. 1909 durch Herrn Paul Delori, Gutsbesitzer, Mitglied der Deutschen Landwirtschafts-Gesellschaft.

Entfernung: $280 \mathrm{~km}$.

Zeit: ca. 5 Monate.

Der Herr schreibt, dafs der Vogel der dort Bütor genannt wird, "vor einiger Zeit" von einem Jäger geschossen wurde.

\section{Mäusebussard. (Buteo buteo.)}

Nr. 1851. Am 31. Juli 1909 von Herrn Majoratsherrn HelmutBaron von K l eist in K era ling en Kurland, einem längere Zeit in Gefangenschaft gehaltenen Bussard umgelegt.

Am 13. Okt o ber 1909 von Herrn Rittmeister a. D. Gustav Lemke, Rockeimswalde bei Grünhayn, Kreis Wehlau, Ostpreufsen erlegt. Der Bussard trug den Ring am linken Fang.

Der Bussard ist nach Mitteilung des Herrn Baron v. Kleist nach Markierung und Freilassung noch mehrere Wochen hindurch täglich in die Vorküche gekommen, um sich unter Ausstossung seines Schreies die Atzung zu holen. Er hörte auf den Naumen "Olaf" und auf Pfiff.

Entfernung: $280 \mathrm{klm}$.

\section{Rebhuhn. (Perdix perdix.)}

1) Nr. 1048. Gezeichnet am 19. Juli 1909 bei Lisden in Livland durch Herrn Harald Baron Loudon. 
Am 13. September $19091 / 4 \mathrm{~km}$ von der Auflassungsstelle entfernt von einem Habicht geschlagen aufgefunden.

2) Nr. 1049. Gezeichnet am 19. Juli 1909 bei Lisden in Livland durch Herrn Harald Baron Loudon.

Am 12. Januar 1910 vom Forstwächter bei $L$ is d en wieder geschossen. Herr Baron Loudon bemerkt dazu: "Ist also nicht fortgezogen. Allerdings ausnahmsweise warmer Winter. Die Felder sind fast immer schneelos."

Zeit: 6 Monate.

\section{Dompfaffen. (Pyrrhula pyrrhula.)}

Nr. $130 ; 126 ; 110 ; 108 ; 119 ; 122$. Von einer Anzahl Dompfaffen, die Herr Harald Baron Loudon in Lisden per Wolmar Livland im Januar 1910 gezeichnet hatte, wurden mehrere gleich an demselben Tage, einige auch nach $15 \mathrm{Tagen}$ an demselben Orte wieder gefangen und freigelassen.

\section{Verzeichnis}

der für die Vogelwarte präparierten Vogelbrustbeine:

1 Alca torda Eisalk.

1 Colymbus nigricollis Schwarzhalssteifsfufs.

1 Larus canus Sturmmöwe.

1 , ridibundus Lachmöwe.

3 " minutus Zwergmöwe.

3 Sterna hirundo Flufsseeschwalbe.

2 " minuta Zwergseeschwalbe.

1 Hydrochelidon nigra Trauerseeschwalbe.

1 Somateria mollissima Eiderente.

2 Nyroca fuligula Reiherente.

2 "hyemalis Eisente.

2 Anser fabalis Saatgans.

1 " albitrons Bläfsgans.

1 " erythropus Zwerggans.

2 Branta bernicla Ringelgans.

1 Cygnus cygnus Singschwan.

2 Charadrius hiaticula Sandregenpfeifer.

1 dubius Flufsregenpfeifer.

1 Vanellus vanellus Kiebitz.

7 Tringa alpina Alpenstrandläufer.

4 Totanus pugnax Kampfläufer.

1 " ochropus Waldwasserläufer.

4 " glareola Bruchwasserläufer.

1 Limosa lapponica Pfuhlschnepfe.

1 Numenius arquatus Grofser Brachvogel.

1 " phaeopus Regenbrachvogel.

1 Fulica atra Bläfshuhn.

2 Ardea cinerea Fischreiher.

1 Tetrao tetrix Birkhuhn. 
1 Circus macrourus Steppenweihe.

1 Astur palumbarius Hühnerhabicht.

1 Aquila pomarina Schreiadler.

2 Haliaetus albicilla Seeadler.

1 Pandion haliaetus Fischadler.

2 Falco peregrinus Wanderfalk.

4 Cerchneis merilla Zwergfalk.

1 Bubo bubo Uhu.

2 Asio otus Waldohreule. Syrnium aluco Waldkauz.

3 Surnia ulula Sperbereule.

2 Nyctala tengmalmi Rauhfufskauz.

3 Dendrocopus maior Grofser Buntspecht.

1 Picus viridis Grünspecht.

1 Coracias garrulus Blaurake.

3 Apus apus Mauersegler.

1 Delichon urbica Mehlschwalbe.

2 Corvus cornix Nebelkrähe.

2 Colaeus monedula Dohle.

1 Pica pica Elster.

4 Sturnus vulgaris Star.

1 Acanthis cannabina Bluthänfling.

8 Loxia curvirostra Fichtenkreuzschnabel.

-1 Emberiza calandra Grauammer.

1 " citrinella Goldammer.

1 " hortulana Ortolan.

1 Anthus obscurus Strandpieper.

1 Certhia familiaris Baumläufer.

1 Troglodytes troglodytes Zaunkönig.

1 Acrocephalus arundinaceus Rohrdrossel.

1 Locustella fluviatilis Flufsrohrsänger.

1 Phylloscopus sibilator Waldlaubsänger.

3 Erythacus cyaneculus Weifssterniges Blaukehlchen. Zusammen 111 Stück, aufserdem 2 Iltisschädel.

\section{Aufgestellte Säugetiere:}

1 Mus decumanus Wanderratte $\bigcirc$ (Schwärzling) Rossitten.

1 Crossopus fodiens Wasserspitzmaus $\sigma^{T}$

1 Arvicola amphibius Wasserratte $\sigma^{\top}$

3 Säugetiere.

\section{Säugetierbälge:}

3 Mus silvaticus Waldmaus Ulmenhorst.

3 " spec.

2 agrarius Brandmaus

" agrarius Brandmaus "

1 "decumanus Wanderratte Rossitten.

3 Arvicola arvalis Feldwühlmaus Ulmenhorst.

1 " amphibius Wasserratte Rossitten.

13 Säugetierbälge. 


\section{Untersuchungen über die Schnelligkeit des Vogelfluges.}

Wenn das Jahr 1910 vielleicht den Namen „Kometenjahr“6 bekommen wird, weil unsere Erde bereits vor kurzem den Besuch eines jener wunderbaren Vagabunden im Weltenraum empfing und noch mehrere derartige Visiten in nächster Zeit zu erwarten bat, so verdient das verflossene Jahr 1909 gewifs den Namen „Flugjahr". Staunend haben wir gestanden und haben die Menschen frei in der Luft umherschweben sehen. Was man früher nie für möglich gehalten hätte: riesige Strecken Landes, ja Meere sind in bestimmter Richtung von Menschen überflogen, fest gesteckte Ziele sind $\mathrm{zu}$ festgesetzter Zeit von Flugmaschinen erreicht, - kurz die für uns bisher mehr oder weniger unpassierbare Luft ist vom schaffenden Menschengeiste erobert worden. So mag es vielleicht nicht unangebracht sein, in unserem Jahresbrichte 1909 eine kleine Untersuchung über den Flug der Vögel zu bringen, zumal bei den menschlichen Flugversuchen, wie sie jetzt an der Tagesordnung sind, die gefiederten Bewohner der Lüfte meist als Vorbild gedient haben.

Aber nicht die Technik des Vogelfluges soll uns beschäftigen, sondern seine Schnelligkeit. Gleich von vornherein mufs bemerkt werden, dals die Geschwindigkeit des Vogelfluges nur zu leicht überschätzt wird. Man sieht einen Vogel vorbeistreichen. 0 , wie schnell das geht! denkt man, da ist er den Blicken bereits entschwunden. Da wünscht man sich selbst Flügel zu haben, um nachzufliegen. Und weil alles Unerreichbare nur zu leicht idealisiert wird und weil ferner für Bewegungen in der Luft der Mafsstab zur genauen Beurteilung fehlt, da spricht man dann von fabelhaften Geschwindigkeiten, und der Ausdruck ,schnell wie ein Vogel" ist zum geflügelten Worte gestempelt worden.

Genaue positive Angaben aber darüber, wie schnell unsere Vögel tatsächlich fliegen, gibt es zur Zeit noch recht wenig Wohl finden sich Notizen über diesen Gegenstand in, der Literatur zerstreut. Da sitzt Jemand im Eisenbahnzuge, oder im Automobil. Eine Krähe fliegt plötzlich neben ihm auf, in der Fahrtrichtung abstreichend. Sie überholt entweder das Fahrzeug, oder bleibt zurück oder hält Strich, und aus diesem Umstande berechnet dann der Beobachter, der die Geschwindigkeit seiner Fortbewegung ungefähr kennt, die Schnelligkeit des Krähenfluges. Oder man läfst einen am Neste gefangenen Brutvogel so und soviel Meter oder Kilometer von seiner Niststelle entfernt fliegen und pafst dann auf, in welcher Zeit er sein Heim wieder erreicht. In der Beziehung spielt die bekannte Schwalbe von Compiègne in der Literatur eine grofse Rolle. Oder man beobachtet die Zeit, welche gewisse Zugvögel, von denen man an$\mathrm{n}$ i $\mathrm{m} \mathrm{m}$, dafs sie gerade Flugrichtung innehalten, gebrauchen, um von einem Orte bis zu einem anderen weit abgelegenen zu gelangen. Auf diesem Verfahren baut z. B. H. Gätke seine Theorie über 
die Schnelligkeit des Krähenfluges auf, die wir unten noch näher berühren werden. Als Beobachtungsstrecke benutzte er die Linie von Helgoland bis zur englischen Küste. Man hat auch ein besonderes Verfahren vorgeschlagen, einen fliegenden Vogel durch die gespannte Hand anzuvisieren und aus der Zeit, die er gebraucht, um die zwischen den Fingerspitzen gelegene Strecke zurückzulegen, die Schnelligkeit seines Fluges zu ermitteln. (K u rt Loos in den Orn. Monatsber., Aprilheft 1903.)

Schliefslich sei auch noch darauf hingewiesen, dafs die Brieftaubenzüchter durch die Veranstaltung von Preis- und Wettflügen fortwährend Material zur Beurteilung der Schnelligkeit des Vogelfluges liefern. Und obgleich sichs in solchen Fällen um Haustiere handelt, die künstlich mehr oder weniger trainiert und abgerichtet sind, so haben doch die Beobachtungen an Brieftauben bis jetzt vielleicht das einwandfreieste Material gebracht. Es verdient hier besonders eine Studie von Dr. Heinrich Ernst Ziegler Erwähnung: „Die Geschwindigkeit der Brieftauben“, Abdruck aus den Zoologischen Jahrbüchern Zehnter Band, Jena 1897. Der Verfasser kommt bei seinen überaus sorgfältigen Untersuchungen sicher zu recht genauen Resultaten.

Immerhin mufs zugegeben werden, dafs man bei den genannten Verfahren sehr oft auf "Schätzung“" und „Annahme“" angewiesen ist. Entweder sind die Versuchstiere nach dem Abfliegen dem Auge des Beobachters überhaupt entrückt; so bei den Versuchen mit aufgelassenen Brutvögeln, oder bei den Gätke'schen Untersuchungen auf der Strecke Helgoland-England, und auch bei dem Brieftauben-Preisfliegen. Wer weifs nun, was die Vögel während dieser Zeit des Unbeobachtetseins treiben? Halten sie ohne Aufenthalt gerade Richtung inne? Und darauf kommt es doch an. Oder man ist gezwungen, auf geschätzten Entfernungen oder Schnelligkeiten seine Resultate aufzubauen, was natürlich deren Genauigkeit stark beeinträchtigt.

Hat man aber wirklich in einem günstigen Falle, etwa durch eine Automobilfahrt ermittelt, dafs ein fliegender Vogel die und die Schnelligkeit aufwies, so ist einem damit immer noch nicht gedient, da man bei der angestellten Beobachtung nicht auch die herrschende Luftströmung in Rücksicht gezogen hat und so noch im Unklaren über die Eigengeschwindigkeit des Vogels ist. Denn das ist immer fest zu halten: Die Ortsbewegungen, die von den fliegenden Vögeln vorgenommen werden, sind ganz und gar abhängig und stehen ganz unter Einflufs der jeweiligen Windrichtung und Windstärke. Auch diese festzustellen und in Beziehung zur beobachteten Schnelligkeit des Fluges zu bringen, darauf kommt es an, denn nur so erfährt man die Eig engeschwindigkeit der Flieger. Und zwar kommt die Luftströmung in Betracht, die gerade an der Stelle herrscht, wo sich die Versuchstiere befinden. Es kann der Wissenschaft weniger 
daran liegen, zu erfahren, welche Schnelligkeiten manche Vögel unter ganz verschieden gearteten und immerfort wechselnden Bedingungen - als solche darf man Windrichtung und Windstärke bezeichnen - erreichen, sondern sie will ermitteln, welche Eigengeschwindigkeit die einzelnen Vogelarten aufweisen. Ehe wir darüber einigermafsen Klarheit bekommen, mag noch eine ganze Weile vergehen, da es gar nicht einfach ist, und da manche günstigen Umstände zusammentreffen müssen, um die fraglichen Werte draufsen in der Natur mit einigermafsen befriedigender Genauigkeit festzustellen.

Üher die physikalischen Gesetze, denen der frei in der Luft fliegende Vogel unterworfen ist, herrscht oft noch mancherlei Unklarheit, die sich am deutlichsten dadurch dokumentiert, dafs bei Erörterung der viel umstrittenen Frage, ob der Vogelzug mit oder gegen den Wind vor sich geht, oft allen Ernstes als Beweis die Behauptung in's Feld geführt wird: $m$ it dem Winde könnten die Vögel schon deshalb nicht ziehen, weil ibnen dann die Federn von hinten aufgeplustert würden. Solcher Behauptung liegt vielleicht eine öfter zu beobachtende Scene vom Hühnerhofe zu Grunde, wenn der stolze Hahn um eine zugige Ecke herumschreiten will, wobei ihm die Halskrause vom Winde gefafst und nach der Seite aufgebläht wird, sodafs ihm das Wenden unmöglich wird, dafs er „die Kare nicht kriegen kann“ sagt man in Thüringen. Bei der Abwehr solcher Vorstellungen führt Karl Baltz in seinem Artikel: „Die Geheimnisse des Vogelfluges" (Monatshefte des Allgemeinen Deutschen JagdschutzVereins XIII. Jahrgang Nr. 15) als Gegenstücke zum Aufplustern der Federn unter anderem auch die von manchen Forschern aufgestellten irrigen Behauptungen an, dafs die scharf sehenden Vögel ihre Augen auf den Seiten haben, weil sonst der beim Fluge entstehende kolossale Luftzug das Sehvermögen beeinträchtigen würde, oder dafs die fliegenden Vögel nicht wittern können, weil über ihren Körper fortwährend ein Luftstrom hinweggeht, der die riechende Substanz nicht dazu kommen läfst, auf die Geruchsnerven zu wirken und dergl.

Wohl, so lange der Vogel mit seinen Eüfsen auf der Erde, oder auf dem Dache, oder auf dem Baume einen festen Stützpunkt hat, da kann der Wind mit ihm sein Unwesen treiben. Er kann ihn schütteln und rütteln, kann ihm die Federn sträuben, die Flügel herumwerfen $u$. s. w. Sobald er aber aufgeflogen ist und die Schnelligkeit des Windes angenommen oder überholt hat, dann herrscht um ihn herum ,ruhige Luft" und sei es bei starkem Sturm, denn er bewegt sich ja im Medium schwebend mit diesem immer mit. Der einzige Druck, den er fühlt, das ist der aus seiner Ei g e ngeschwindigkeit sich ergebende Luftwiderstand. Als Jäger kann man oft eine Beobachtung machen, die das Gesagte erhärtet. 
Wir befinden uns bei starkem Winde auf der Hühnersuche. Alle Völker, die wir antreffen, stehen gegen den Wind auf, wobei im ersten Momente ein Durcheinanderfliegen bei unregelmäfsigen Bewegungen stattfindet. Der Wind spielt noch mit den Hühnern, und da soll man nach alter Jägerregel nicht schiefsen, da das Ziel unsicher ist. Dann plötzlich eine Schwenkung des ganzen Volkes wie auf Kommando, und nun streichen die Vögel, die jetzt die Geschwindigkeit des Windes erreicht haben, in schönster Gleichmälsigkeit mit dem Winde ab. Jetzt halt drauf, Jäger!

Wenn wir uns das alles vergegenwärtigen, dann wundern wir uns auch nicht mehr über manche recht grofse von Vögeln erzielten Schnelligkeiten. Wir fragen uns dabei immer, was hat daran der Wind getan, und was der Vogel selbst? Sicher nutzen die Vögel die für sie günstigen Luftströmungen auf ihren weiten Zügen nach Möglichkeit aus, nur dürfen wir nicht die fabelhaften Geschwindigkeiten in Anspruch nehmen, wie es G ätke z. B tut. An und für sich würde den Vögeln das schnelle Dahinsausen mit dem Winde nichts schaden, aber der Vogel ist nicht ausschliefslich ein Lufttier, sondern auch ein Erdentier. Er will und darf die Herrschaft über die Erde nicht verlieren, soweit Landen, Richtung einhalten u. a. in Betracht kommen. Darum ist tatsächlich zu beobachten, dafs bei starkem Sturm aller Vogelzug ruht.

Es ist also festzuhalten, dafs die von den Vögeln in der Luft vorgenommenen Ortsbewegungen sich zusammensetzen aus der Eigengeschwindigkeit und der Geschwindigkeit, des Windes. -

Schon im VI. Jahresberichte der Vogelwarte Rossitten (Journ. f. Ornithologie, Oktoberheft 1907) habe ich gleichsam als Ankündigung einen kurzen Artikel über praktische Versuche zur Erforschung der Vogelzuges gebracht. Die gauze damals angewandte Methode war noch sehr primitiv, zudem fehlte auch noch die Rücksichtnahme auf Windrichtung und Windstärke bei den Berechnungen. Es ist eben gar nicht leicht, wenn man von der Versuchsstelle fernab wohnt, die günstigen Tage abzupassen und dann mit allen möglichen Instrumenten umherzuziehen, um die Versuche vorzunehmen. Jetzt steht der Vogelwarte die mitten in der Zugstrafse gelegene Dünenhütte "Ulmenhorst" zur Verfügung. Das ganze Verfahren ist damit bedeutend vereinfacht. Ich habe weiter

\section{die Methode}

zu verbessern gesucht, die wir zunächst kurz betrachten wollen. In der Nähe von „, Ul m e nhorst “, wo die Nehrung verhältnismäfsig schmal ist, halten die Vögel meist recht gut die gerade Zugrichtung inne. Sie überfliegen freies Dünengelände, zeigen sich also dem 
Beschauer frei und offen. Dort sind innerhalb der Zugstrafse zwei Beobachtungsstellen markiert, die genau $1 / 2$ Kilometer von einander entfernt liegen. Diese beiden Posten werden durch zwei mit Pfählen ausgefluchtete Linien dargestellt, die senkrecht zur Zugrichtung verlaufen. Man kann also durch Anvisieren stets genau den Augenblick feststellen, wenn ein Vogel die Fluchtlinien überfliegt.

Ein tragbares Feldtelephon, ein sogenannter Artillerie-Lautsprecher, verbindet die beiden Beobachtungsposten.

Auf einem in der Nähe ganz frei gelegenen Dünenhügel steht ein nach der Windrose orientierter Windrichtungsmesser. Ein mit der Fahne in Verbindung stehender Zeiger, der' sich auf einer Kreisskala dreht, ermöglicht die Ablesung der Windrichtung nach Graden. Daneben befindet sich auf einer Stange ein Schalenkreuz-Anemometer zur Messung der Windstärke. Dazu soll bemerkt werden, dafs die Vögel sehr oft gerade in Höhe der aufgestellten Instrumente fliegen. Jedenfalls erstreckt sich die Feststellung der Windverhältnisse auf die Luftschicht, in der die Vögel ziehen, die zu Versuchszwecken dienen.

Ein günstiger Herbstzugtag ist angebrochen. ${ }^{1}$ ) Die Vögel fliegen nicbt in dicht gedrängten Scharen, sondern mehr einzeln, wie wirs gebrauchen können. Die Versuche sollen beginnen. Zunächst wird die Zugrichtung der Vögel festgestellt, die im Herbste hier auf der Nehrung fast immer von NNO. nach SSW. verläuft. Dann werden Windrichtung und Windstärke abgelesen und notiert. Dieselben Ablesungen finden auch $\mathrm{nach} B$ eendigung der Versuche statt, um bei veränderten Verhältnissen eventuell das Mittel ziehen zu können. Die übrigen meteorologischen Verhältnisse stehen mir so wie so von jedem Tage zur Verfügung, da mit der Vogelwarte eine meteorologische Station verbunden ist.

Nun begebe ich mich an den einen Beobachtungsposten, und zwar im Herbste an den nördlichen, der von den ziehenden Vögeln zuerst getroffen wird, mein Gehilfe bezieht den südlich gelegenen. Jetzt kommt eine Krähe recht schön Richtung haltend gleichmärsigen Fluges angestrichen. In dem Augenblick, wenn sie meine Fluchtlinie passiert, setze ich eine SekundenStoppuhr in Gang. Nun drücke ich auf den Knopf des Telephons und verständige mich mit meinem Gehilfen. Durch Hin- und Herfragew überzeuge ich mich, dafs wir beide eine und dieselbe Krähe meinen; weicht der Versuchsvogel etwa von seiner Bahn $a b$, oder hält er sich durch Schweben längere Zeit auf, dann wird er einfach ausgemerzt. Jedenfalls ist es möglich, den

1) Die Versuche erstrecken sich bis jetzt ausschliefslich auf den Herbst. 
gewählten Vogel beim Durchfliegen der Versuchsstrecke immer unter Kontrolle zu halten, wobei zu berücksichtigen ist, dafs es für ein gutes Auge sehr wohl möglich ist, einen mittelgrofsen Vogel 500 Meter weit zu verfolgen. Durch Übung kommt man bald so weit, dafs die Verständigungen mit dem Gehilfen sehr schnell und glatt verlaufen. Sobald die Versuchskrähe die Fluchtlinie am zweiten Beobachtungsposten überfliegt, bekomme ich ein Telephonzeichen und stoppe gleichzeitig die Sekundenuhr. So habe ich also mit möglichster Genauigkeit die Zeit festgestellt, die von der Krähe gebraucht worden ist, um $500 \mathrm{~m} \mathrm{zu}$ durchfliegen. An günstigen Tagen kann ich bald einen zweiten und dritten Versuchsvogel vornehmen, aber manchmal will es schlecht passen. Die Vögel fliegen ungünstig, sie halten die abgesteckte Strecke nicht inne, oder gehen zu hoch; dann kann man lange erwartungsvoll stehen, und der kalte Herbstwind pfeift einem um die Ohren.

Nun folgt die Auswertung oder Berechnung: Es ist also bis jetzt festgestellt worden, wieviel Sekunden die Krähe gebraucht hat, um $500 \mathrm{~m}$ zu durchfliegen. Daraus wird berechnet, wieviel Meter sie in ein er Sekunde zurückgelegt hat. Das sollen beispielsweise $8 \mathrm{~m}$ sein. Die Zugrichtung war von NNO. nach SSW. Der Wind wehte direkt entgegen aus SSW. mit einer Geschwindkeit von $5 \mathrm{~m}$ p. Sek. Dann beträgt die Eig engeschwindigkeit der Krähe $8 \mathrm{~m}+5 \mathrm{~m}=13 \mathrm{~m}$ p. Sek.

Würde der Wind in einem anderen Falle, aber bei denselben angenommenen Geschwindigkeiten direkt von hinten wehen, dann betrüge die Eigengeschwindigkeit des Vogels $8 \mathrm{~m}-5 \mathrm{~m}$ $=3 \mathrm{~m}$ p. Sek.

Nun trifft aber der Wind für gewöhnlich unter einem bestimmten Winkel von der Seite auf die Zugrichtung auf. Dann ermittle ich die Eigengeschwindigkeit folgendermafsen:

Ich trage mir die beobachtete Geschwindigkeit, sie soll $8,8 \mathrm{~m}$ p. Sek. betragen, in einem bestimmten Mafsstabe (hier immer in Centimetern) auf. Der Wind kommt aus Westen und trifft unter einem Winkel von $112^{1} / 2^{0}$ auf die Zuglinie auf. Die Windstärke $=7,7 \mathrm{~m}$ p. Sek. Ich trage also diesen Winkel an den Endpunkt der $8,8 \mathrm{~cm}$ langen Strecke an und schneide auf dem freien Schenkel 7,7 cm ab. Nun verbinde ich die beiden freien Endpunkte, messe die betreffende Strecke und erhalte die Eigengeschwindigkeit von $13,75 \mathrm{~m}$ p. Sek. Wenn man sich ferner in dem entstandenen Dreieck einen Vogel in der Richtung der ermittelten Eigengeschwindigkeit normal eingezeichnet denkt und ihn dann parallel bis in die be obachtete Flugrichtung verschiebt, dann erhält man die etwas verdrehte Stellung, die der Vogel bei Wind zur Richtung seines Fluges einnimmt. Er würde im vorliegenden Falle über die linke Schulter fliegen, die Längsachse des Körpers nach der Seite, woher der Wind kommt, abgelenkt. Diese schiefe Stellung fällt bei starkem Winde oft sehr in die Augen. 
Es ist demnach durchaus nicht richtig, anzunehmen, dafs die Vögel stets genau in der Richtung fliegen wohin der Schnabel zeigt.

In der geschilderten Weise habe ich nun in den letzten Zugperioden versucht, von verschiedenen Vogelarten die Eig engeschwindigkeit ihres Fluges zu ermitteln. Es sei ausdrücklich bemerkt, dafs es sich dabei nur um den $\mathrm{Zu}$ gflug der betreffenden Vögel handelt.

Darüber noch ein Wort. Der Nichtkenner zeigt oft grofses Erstaunen, wenn ein routinierter Vogelbeobachter schon auf weite Entfernung einen fliegenden Vogel auf seine Artzugehörigkeit richtig anspricht. Er hat so etwas nicht für möglich gehalten. Würde man den Beobachter jedesmal fragen: ,woran hast du denn den Vogel eigentlich erkannt?" er möchte oft die Antwort schuldig bleiben. Am „Flugbild" sagt man für gewöhnlich. Das ist richtig. Aber worin bestehen denn die Unterschiede der einzelnen Flugbilder untereinander? Das ist oft nicht leicht zu sagen. Wohl kann man auf runde und kurze oder lange und spitze Flügel hinweisen; man kann gerade abgeschnittenen oder gegabelten Schwanz, abgerundeten und spitzen Kopf anführen und dergleichen mehr. Man mag sich das alles auch nach Abbildungen ganz genau einprägen; kommt man aber nachher hinaus in die Praxis, dann versagt das angeeignete Wissen doch. Warum? Weil neben der äufseren fest gegebenen Form der sich beim Fluge ganz besonders präsentierenden Teile des Vogelkörpers auch noch die Art und Weise in Betracht kommt, wi e der Vogel seinen Flugapparat gebraucht. Schnelle oder langsame Flügelschläge, Haltung der Flügel und des Schwanzes, Lage des Halses u. s. w. verdienen in der Hinsicht Erwähnung. Oft sind's kleine minutiöse Unterschiede, über die sich der Beobachter selbst erst nach einigem Nachdenken Rechenschaft geben kann, deren Kenntnis ihm aber in der Praxis unbewufst stets gegenwärtig ist. Es sei z. B. an die einander ähnlichen Flugbilder von Seidenschwänzen und Staren, Wildtauben und Dohlen, Sperbermännchen und Merlinfalken, Rauchfufs- und Mäusebussarden erinnert.

Wenn also schon das Auseinanderhalten der Flugbilder von verschied en en Vogelarten zuweilen Kopfzerbrechen bereiten kann, um wieviel schwieriger wird's sein, innerhalb ein und derselben Spezies verschiedene Flugarten zu unterscheiden. Und doch gibt es solche. Von Spiel- und Balzflügen müssen wir absehen. Die machen sich so augenfällig kenntlich und sind so charakteristisch für manche Vogelarten, dafs sie allein schon zum Ansprechen der betreffenden Spezies auf weite Entfernungen hin genügen. (z. B. Kiebitz, Baumpieper, Grünfink, Girlitz). Es handelt sich vielmehr um solche Flüge, die rein der Fortbewegung dienen. Man kann da etwa unterscheiden den Flug bei der Nahrungssuche; der gemächlich verläuft, wenn die 
Nahrung vom Boden oder aus dem Wasser aufgenommen werden soll (z. B. Bussard, Weihen, Turmfalke, Fischadler, Möwen), oder reifsend schnell, falls die lebende Beute im Fluge $\mathrm{zu}$ erhaschen ist (Schwalben, Falken, Ziegenmelker). Ferner den Flug zu den Schlafplätzen (Stare, Krähen), oder den Flug auf der Flucht, den Flug beim Ortswechsel auf kurze Entfernungen und schliefslich auch den Zugflug. Alle diese Flugarten, so ähnlich sie untereinander sind, tragen doch für ein geübtes Auge charakteristische Merkmale an sich, die mit Worten schwer ausgedrückt werden können. Wenn eine Krähe oder eine Wildtaube sich vom Boden erhebt, so kann man's ihr gewöhnlich schon ausehen, ob sie nur einen Platzwechsel auf kurze Entfernung vornehmen will, um in der Nähe sitzende Artgenossen aufzusuchen, oder ob sie für immer abstreicht. Ganz anders fliegen die Krähen dagegen, wenn sie den Uhu umschwärmen und noch anders, wenn der Schufs ertönt und alles auseinanderstiebt. Natürlich spielt bei allen diesen Unterscheidungen die verschiedene Geschwindigkeit eine grofse Rolle, weshalb oben ausdrücklich hervorgehoben werden mufste, dafs sich die nachfolgenden Untersuchungen ausschliefslich auf den $\mathrm{Zug}$ flug beziehen. Untersuchungen über andere Flugarten fallen vielleicht anders aus. Dieser Zugflug ist ausgezeichnet durch grofse Stetigkeit. Die Erde und alles, was da unten locken könnte, ist für die auf der Wanderschaft befindlichen Vögel nicht vorhanden; irgendwelchen Ablenkungen sind die Zugscharen nicht zugänglich, gewisse Triebe und Regungen scheinen ganz einzuschlafen, und da ziehen dann die Buchfinken ruhig neben ihren Erbfeinden den Finkenhabichten dahin, und die Schwanzmeisen, die sonst beim Umherstreichen das kleinste Buschwerk "nicht unbesucht lassen können, fliegen hoch in der Luft über das einladendste Gestrüpp hinweg. Das ganze Trachten ist darauf gerichtet, vorwärts zu kommen.

Weniger wird nach den auf der Vogelwarte Rossitten vorliegenden Beobachtungen der Zugflug durch übergrofse Schnelligkeit charakterisiert. Das zeigen auch die unten aufgeführten Werte. Noch nie habe ich hier auf der Nehrung eine Beobachtung gemacht, die mich hätte veranlassen können, solche enormen Zuggeschwindigkeiten anzuehmen, wie sie sich sonst in der Literatur vorfinden. Es mögen nun die bis jetzt erzielten Resultate folgen:

\section{Nebelkrähe. (Corvus cornix.)}

Der am häufigsten zu beobachtende Vogel. Von ihm liegen auch die meisten Resultate vor. Die Nebelkrähe macht beim $\mathrm{Zugflug}$ durchschnittlich vier Flügelschläge in der Sekunde.

1) 11 . Oktober 1908 vormittags $8,15-9,30 \mathrm{Uhr}$.

Bew ölkung: hell, Sonnenschein.

Temperatur: früh $7 \mathrm{Uhr}: 9,4^{\circ} \mathrm{C}$. Nachm. $2 \mathrm{Uhr}: 15,6^{\circ} \mathrm{C}$. 
Windrichtung: SSW. $\left(172^{1} / 2^{01}\right)$ Wind also fast steil von vorn.

Zugrichtung: NNO.-SSW.

Zughöh e: $10-25 \mathrm{~m}$.

Windstärke: $4,4 \mathrm{~m}$ p. Sek.

Beobachtete Geschwindigkeiten beim Durchfliegen v on $500 \mathrm{~m}$ : $54 ; 58 ; 58 ; 59 ; 57 ; 54$ Sek. ${ }^{2}$ ) $=$ Durchschnitt 56, 7 Sek.

Ermittelter Wert für 1 Sek.: $8,8 \mathrm{~m}$.

Eigengeschwindigkeit: 13,2 m p. Sek.

2) 12 . Oktober 1908 , vormittags $7,30-8 \mathrm{Uhr}$.

Bewölkung: wenig bedeckt, Sonnenschein.

Temperatur: früh 7 Uhr $12,6^{\circ} \mathrm{C}$. Nachm. 2 Uhr $14,0^{\circ} \mathrm{C}$.

Windrichtung: W. $\left(112^{1} /{ }^{0}\right)$.

Zugrichtung: NNO.-SSW.

Zughöhe: $3-4 \mathrm{~m}$.

Windstärke: $7,7 \mathrm{~m}$ p. Sek.

Beobachtete Geschwindigkeit beim Durchfliegen von $500 \mathrm{~m}$ : 57 Sek.

Ermittelter Wert für 1 Sek.: $8,8 \mathrm{~m}$.

Eigengeschwindigkeit: $13,75 \mathrm{~m}$ p. Sek.

Der Krähenzug geht heute mehr in einzelnen Trupps, weniger in Kettenform vor sich. Es traten zuweilen Zugpausen ein. Das deutet meist auf ungünstiges Wetter. Regen.

Um 2 Uhr Nachmittags umzieht sich der Himmel; es droht

3) 18. Oktober 1908 , vormittags $9,30-10,10$. Uhr.

Bewölkung: hell, Sonnenschein.

Temperatur: früh 7 Uhr $2,8^{\circ}$ C. Nachm. 2 Uhr $4,3^{\circ} \mathrm{C}$.

Windrichtung: OSO. $\left(77^{1} / 2^{0}\right)$

Zugrichtung: NNO.-SSW. Schnabel nach SSO.

Zughöhe: $40-60 \mathrm{~m}^{3}$ )

Windstärke: $10,4 \mathrm{~m}$.

Beobachtete Geschwindigkeit beim Durchfliegen von $500 \mathrm{~m}$ : $32 ; 33 ; 32 ; 31 ; 31$ Sek.=Durchschnitt 31,8 Sek.

1) Die hinter der Windrichtung in Klammern stehende Zahl bedeutet immer den Winkel, den die Richtung des Windes zur Richtung des Zuges bildet. Je grölser dieser Winkel ist, um so mehr kommt der Wind von vorn. worden.

2) Sechs Versuchsvogel sind also dabei nacheinander herangezogen

3) Die für "Zughohe" angegebenen Werte sollen sagen, in welcher Höhe der Ha uptkrăhenzug an dem betreffenden Tage vor sich ging. Zu den Versuchen wurden immer solche Vogel herangezogen, die moglichst niedrig flogen, weil sich die am besten kontrollieren liefsen und auch in fast gleicher Hohe mit den aufgestellten Instrumenten flogen. 
Ermittelter Wert für 1 Sek.: $15,7 \mathrm{~m}$.

Eigengeschwindigkeit: $16,85 \mathrm{~m}$ p. Sek.

4) 25 . Oktober 1908 , vormittags $8,45-10 \mathrm{Uhr}$.

Bewölkung: Hell, Sonnenschein.

Temperatur: früh 7 Uhr: $2,1^{\circ}$ C. Nachm. 2 Uhr: $7,1^{\circ} \mathrm{C}$.

Windrichtung: Der Wind wechselt. Um 8,45: OSO. (etwa $77^{1} / 2^{0}$ ), um $10 \mathrm{Uhr}$ : SO. (etwa $112^{1} /_{2}{ }^{0}$ ). (Im Mittel $95^{\circ}$ ). $\mathrm{Zugrichtung:} \mathrm{NNO.-SSW.} \mathrm{Schnabel} \mathrm{nach} \mathrm{SSO.} \mathrm{gerichtet.}$

Zughöhe: $3-30 \mathrm{~m}$, meist $25 \mathrm{~m}$.

Windstärke: $7-7-8,5 \mathrm{~m}$, im Mittel $8,1 \mathrm{~m} \mathrm{p}$. S.

Beobachtete Geschwindigkeiten beim Durchfliegen v on $500 \mathrm{~m}$ : $39 ; 42 ; 40 ; 38 ; 43 ; 40 ; 33 ; 45 ; 40 ; 45 ; 40 ; 43$; $46 ; 43 ; 49$ Sek. = Durchschnitt 41,7 Sek.

Ermittelter Wert für 1 Sek: $12 \mathrm{~m}$.

Eigengeschwindigkeit: 15 m p. Sek.

Die Krähen fliegen beute oft recht wenig stetig.

5) 26 . Oktober 1908 vormittags $7,45-9 \mathrm{Uhr}$.

Bewölkung: hell, Sonnenschein; schönes Wetter.

Temperatur: früh $7 \mathrm{Uhr}: 1,7^{\circ} \mathrm{C}$. Nachm. 2 Uhr: $6,9^{\circ} \mathrm{C}$. Windrichtung: OSO. $\left(92^{1 / g^{0}}\right)$

Zugrichtung: NNO.-SSW.

Zughöhe: $3-30 \mathrm{~m}$.

Windstärke: $7,4 \mathrm{~m}$ p. Sek.

Be obachtete Ges c hwindigkeiten beim Durchfliegen von $500 \mathrm{~m}: 36 ; 36 ; 36 ; 36 ; 36 ; 38 ; 34 ; 33 ; 33 ; 36$ Sek.=Durchschnitt 35,4 Sek.

Ermittelter Wert für 1 Sek.: $14,1 \mathrm{~m}$.

Eigengeschwindigkeit: 16,2 m p. Sek.

6) 26 . Oktober 1908 , nachmittag s 1-1,45 Uhr.

Bewölkung: hell, Sonnenschein.

Temperatur: Nachm. 2 Uhr: $6,9^{\circ} \mathrm{C}$.

Windrichtung: OSO. $\left(87^{1} / 2^{0}\right)$.

Zugrichtung: NNO.-SSW.

$\mathrm{Zughöhe:} 50-60 \mathrm{~m}$.

Windstärke: $5,8 \mathrm{~m}$.

Beobachtete Geschwindigkeiten beim Durchfliegen vo n $500 \mathrm{~m}: 37 ; 32 ; 36 ; 35 ; 35 ; 33 ; 35 ; 30 ; 39$ Sek. $=$ Durchschnitt 34,7 Sek.

Ermittelter Wert für 1 Sek.: $14,4 \mathrm{~m}$.

Eigengeschwindigkeit: $\mathbf{1 5 , 2 5} \mathrm{m}$ p. Sek.

$\mathrm{Da}$ der Wind gegen beute früh nachgelassen hat, fliegen die Krähen höher.

7) 27. Oktober 1908 , vormittags $7,30-8,30 \mathrm{Uhr}$.

Bewölkung: hell, Sonnenschein; schöner Tag.

T'emperatur: früh 7 Uhr: $1,6^{\circ}$ C., Nachm. 2 Uhr: $7,0^{\circ} \mathrm{C}$. 
Windrichtung: OSO. $\left(102^{1 / 2}{ }^{0}\right)$.

$\mathrm{Zugrichtung:} \mathrm{NNO.-SSW.}$

Zughöh e: $40-50 \mathrm{~m}$.

Windstärke: $6,4 \mathrm{~m}$ p. Sek.

Beobachtete Geschwindigkeiten beim Durchfli egen von $500 \mathrm{~m}$ : $39 ; 35 ; 39 ; 41 ; 38 ; 38 ; 40 ; 37 ; 33$ Sek. $=$ Durchschnitt 37,8 Sek.

Ermittelter Wert für 1 Sek.: $13,2 \mathrm{~m}$.

Eigengeschwindigkeit: $\mathbf{1 5 , 9} \mathrm{m} \mathrm{p}$. Sek.

Zum Versuche wurden nur die niedrig fliegenden Vögel herangezogen.

8) 28. Oktober 1908 , vormittags $7,30-8,45$.

Bewölkung: hell, Sonnenschein; schöner Tag.

Temperatur: früh 7 Uhr $2,4^{\circ} \mathrm{C}$. Nachm. 2 Uhr: $7,6^{\circ} \mathrm{C}$.

Windrichtung: SSO. $\left(127^{1 / 2} \mathbf{2}^{0}\right)$.

Zugrichtung: NNO-SSW.

Zughöhe: $10-30 \mathrm{~m}$.

Windstärke: $5,3 \mathrm{~m}$ p. Sek.

Beobachtete Geschwindigkeiten beim Durchf li egen von $500 \mathrm{~m}: 45 ; 47 ; 57 ; 48 ; 59$ Sek. $=$ Durchschnitt 51,2 Sek.

Ermittelter Wert für ] Sek.: $9,8 \mathrm{~m}$.

Eigengeschwindigkeit: $13,7 \mathrm{~m}$ p. Sek.

Die Vögel flogen heute recht günstig für die Versuche. Man bemerkt heute sehr deutlich, wie der gegen die vorhergehenden Tage mehr von vorn kommende Wind die Vorwärtsbewegung aufhält. (Vergleiche die heutigen Geschwindigkeiten beim Durchfliegen von $500 \mathrm{~m}$ mit den gleichen Werten oben vom 18. Oktober 08.)

9) 30. Oktober 1908 , vormittags $7,30-9,45$ Uhr. Regen.

Bewölkung: bedeckt, feuchte aber klare Luft, es droht

Temperatur: früh 7 Uhr: $9,4^{\circ}$ C. Nachm. 2 Uhr: $8,5^{\circ}$ C.

Windrichtung: NNW. $\left(80^{\circ}\right)$.

Zugrichtung: NO.-SW. Schnabel nach W.

Zughöhe: $20-30 \mathrm{~m}$.

Windstärke: $6,4 \mathrm{~m}$.

Beobachtete Geschwindigkeiten beim Durchfliegen v on $500 \mathrm{~m}$ : $37 ; 43 ; 37 ; 35 ; 37 ; 33$ Sek. $=$ Durchschnitt 37 Sek.

Ermittelter Wert für 1 Sek.: $13,5 \mathrm{~m}$.

Eigengeschwindigkeit: $\mathbf{1 3 , 9} \mathrm{m}$.

Als Versuchsobjekte werden auch solche Vögel genommen, die noch niedriger fliegen wie $20-30 \mathrm{~m}$.

Die Zugrichtung ist heute von NO.-SW.

10) 26. Oktober 1909, vormittags 11-12 Uhr.

Bewölkung: halb bedeckt, zuweilen Sonnenschein.

Temperatur: früh $7 \mathrm{Uhr}: 8,0^{\circ}$ C. Nachm. 2 Uhr: $10,6^{\circ} \mathrm{C}$. 
Windrichtung: WSW. $\left(132^{1} / 2^{0}\right)$.

Zugrichtung: NNO.-SSW.

Zughöhe: $30-100 \mathrm{~m}$.

Windstärke: $4,1 \mathrm{~m}$.

Beobachtete Geschwindigkeit beim Durchfliegen von $500 \mathrm{~m}$ : 52 Sek.

Ermittelter Wert für 1 Sek.: $9,6 \mathrm{~m}$.

Eigengeschwindigkeit: 12,8 m p. Sek.

11) 28 . Oktober 1909 , vormittags $9,15-10,15 \mathrm{Uhr}$. schein.

B ew ölku ng: zunächst bedeckt, dann heller; auch Sonnen-

Temperatur: früh $7 \mathrm{Uhr}: 8,6^{\circ} \mathrm{C}$, nachm. $2 \mathrm{Uhr}: 11,1^{\circ} \mathrm{C}$.

Wind richtung: SO. $\left(112^{1 / 2}{ }^{0}\right)$.

Zugrichtung: NNO.-SSW.

$\mathrm{Zughöhe:} 50-60 \mathrm{~m}$.

Windstärke: $5,5 \mathrm{~m}$ im Mittel.

Beobachtete Geschwindigkeiten beim Durchfliegen von $500 \mathrm{~m}: 42 ; 46 ; 45 ; 35$ Sek. = Durchschnitt 42 Sek.

Ermittelter Wert für 1 Sek.: $11,9 \mathrm{~m}$.

Eigengeschwindigkeit: 14,9 m p. Sek.

12) 28. Oktober 1909 , nachmittags $3-3,45$ Uhr.

Bewölkung: halb bedeckt, meist Sonnenschein.

Temperatur: Nachm. 2 Uhr: $11,1^{\circ} \mathrm{C}$.

Wind richtung: SO. $\left(112^{1 /{ }^{0}}\right)$.

Zugrichtung: NNO.-SSW. Schnabel nach S.

$\mathrm{Zugh}$ öhe: $50-60 \mathrm{~m}$.

Windstärke: $5,3 \mathrm{~m} \mathrm{p}$. S. im Mittel.

Beobachtete Geschwindigkeiten beim Durchfliegen von $500 \mathrm{~m}: 45 ; 41 ; 45 ; 55$ Sek. $=$ Durchschnitt 46,5 Sek.

Ermittelter Wert für 1 Sek.: $10,8 \mathrm{~m}$.

Eigengeschwindigkeit: $13,7 \mathrm{~m}$ p. Sek.

13) 29 . Oktober 1909; vormittags $9-10,15 \mathrm{Uhr}$.

B ew ölkung: hell, Sonnenschein, schöner J'ag.

Temperatur: früh $7 \mathrm{Uhr}: 7,3^{0} \mathrm{C}$, Nachm. 2 Uhr: $11,3^{0} \mathrm{C}$.

Windrichtung: SSO. $\left(127^{1} /{ }^{0}\right)$.

Zugrichtung: NNO.-SSW.

$\mathrm{Zu}$ ghöhe: $3-20 \mathrm{~m}$.

Windstärke: $6,6 \mathrm{~m}$ p. Sek.

Beobach te te Geschwindigkeiten beim Durchfliegen v on $500 \mathrm{~m}: 46 ; 55 ; 55 ; 54$ Sek. = Durchschnitt 52,5 Sek.

Ermittelter Wert für 1 Sek.: $9,5 \mathrm{~m}$.

Eigengeswindigkeit: $\mathbf{1 4 , 5} \mathrm{m}$ p. Sek.

Um $10 \mathrm{Uhr}$ vormittags flaut der Wind ganz plötzlich auf $2,9 \mathrm{~m}$ p. Sek. ab. Da fliegen die Krähen sofort höher, 50-60 m hoch.

14) 29 . Okto ber 1909 , nachmittags $2,30-3$ Uhr.

Bewölkung: hell, Sonnenschein; schöner Tag. 
Temperatur: Nachm. 2 Uhr: $11,3^{\circ} \mathrm{C}$.

Windrichtung: SO. $\left(114^{1} /{ }^{0}\right)$.

Zugrichtung: NNO.-SSW.

$\mathrm{Zughöhe:} \mathrm{ca.} 50 \mathrm{~m}$.

W indstärke: $3,3 \mathrm{~m}$ p. Sek.

Beobachtete Geschwindigkeiten beim Durchflieg e n v n $500 \mathrm{~m}: 46 ; 43 ; 46 ; 46$ Sek. = Durchschnitt 45,2 Sek.

Ermittelter Wert für 1 Sek.: $11,1 \mathrm{~m}$.

Eigengeschwindigkeit: $12,8 \mathrm{~m} \mathrm{p}$. Sek.

15) 30 . $0 \mathrm{ktober} 1909$, vormittags 8-9 Uhr.

B ew ölk u n : heller Tag, meist Sonnenschein.

Te m per a t u r: früh 7 Uhr: $9,0^{\circ} \mathrm{C}$, nachm. 2 Uhr: $11,7^{\circ} \mathrm{C}$.

W ind ric h tung: SSO. $\left(127^{1} / 2^{0}\right)$.

Z ugrichtung: NNO.-SSW.; Schnabel nach S.

$\mathrm{Zughöhe:} 3-20 \mathrm{~m}$.

Windstärke: $5,1 \mathrm{~m}$ p. Sek.

Beobachtete Geschwindigkeiten beim Durchfliege n von $500 \mathrm{~m}: 45 ; 47 ; 60 ; 50$ Sek. = Durchschnitt 50,5 Sek.

Ermittelter Wert für 1 Sek.: $9,9 \mathrm{~m}$ p. Sek.

Eigeng eschwindigkeit: 13,6 m p. Sek.

16) 1. November 1909 , vormittags $8-9$ Uhr.

Bewölkung: früh hell, von Mittag an bedeckt.

Te m per a t u r: früh $7 \mathrm{Uhr}: 6,1^{\circ} \mathrm{C}$., nachm. $2 \mathrm{Uhr}: 8,2^{\circ} \mathrm{C}$.

Wind richtung: SSO.-S. $\left(142^{1 / g^{0}}\right)$.

$\mathrm{Zugrichtung:} \mathrm{NNO.-SSW.}$

$\mathrm{Zughöh} \mathrm{e:} 20-40 \mathrm{~m}$.

Wi ndst ärke: $3,5 \mathrm{~m}$ p. Sek.

Beobachtete Geschwindigkeiten beim Durchfliegen vo n $500 \mathrm{~m}: 59 ; 58$ Sek. = Durchschnitt 58,5 Sek.

Ermittelter Wert für 1 Sek. : $8,5 \mathrm{~m}$.

Eigengeschwindigkeit: $\mathbf{1 1 , 4 5} \mathrm{m}$ p. Sek.

Die Krähen fliegen heute sehr ungleichmässig.

17) 1 . Novem ber 1909 , v orm it ag s $11,15-11,45 \mathrm{Uh} \mathrm{r}$.

Bewölkung: früh hell, von Mittag an bedeckt.

Te mperatur: früh $7 \mathrm{Uhr}: 6,1^{\circ} \mathrm{C}$., nachm. $2 \mathrm{Uhr}: 8,2^{\circ} \mathrm{C}$.

W ind ric h t u ng: SSW. -SW. $\left(170^{\circ}\right)$.

$\mathrm{Zug}$ rich tung: NNO.-SSW.

$\mathrm{Zugh}$ ö h e: ca. $80 \mathrm{~m}$.

Wi ndst ärke: $2,9 \mathrm{~m}$ p. Sek.

Beobachtete Geschwindigkeiten beim Durchfliegen vo n $500 \mathrm{~m}: 46 ; 53$ Sek. = Durchschnitt 49,5 Sek.

Ermittelter Wert für 1 Sek.: $10,1 \mathrm{~m}$.

Eigengeschwindigkeit: $13 \mathrm{~m} \mathrm{p}$. Sek. 
18) 4. November 1909 vormittags $9,15-10,15 \mathrm{Uhr}$.

B ew ölkung: bedeckt, dicke Wolken, etwas Regen.

Te m p e r a tu r: früh $7 \mathrm{Uhr}: 7,2^{\circ} \mathrm{C}$, nachm. $2 \mathrm{Uhr}: 9,2^{\circ} \mathrm{C}$. Windrichtu ug: NNW. $\left(52^{1 / 2}{ }^{0}\right)$.

Z u g r i c h t ung: NNO.-SSW. Schnabel n. W.

$\mathrm{Zughöh}$ e: $80-100 \mathrm{~m}$.

Wi ndstärke: $8,2 \mathrm{~m}$ p. Sek.

Beobachtete Geschwindigkeiten beim Durchfliegen von $500 \mathrm{~m}: 40 ; 34 ; 37 ; 35 ; 40 ; 29 ; 28 ; 27$ Sek. $=$ Durchschnitt 33,85 Sek.

Ermittelter Wert für 1 Sek.: $14,8 \mathrm{~m}$ p. Sek.

Eigengeschwindigkeit: $11,8 \mathrm{~m}$ p. Sek.

Wie die beobachteten Geschwindigkeiten beim Durchfliegen von $500 \mathrm{~m}$ zeigen, flogen die Krähen heute sehr unregelmäfsig. Bei den gröfseren Werten hielten sie sich unterwegs durch einiges Schwenken etwas auf, bei den kürzeren liefsen sie sich vom Winde nehmen und sausten dahin.

Ich bestimme daher der Genauigkeit halber die Eigengeschwindigkeit für die Werte über 30 Sek. und u n ter 30 Sek. noch besonders und bekomme für den 1. Fall: 10,6 m, und für den 2. Fall $14,4 \mathrm{~m}$ Eigengeschwindigkeit.

So liegen also für die Nebelkrähe, alle Resultate zusammengefafst, folgende ermittelten Eigengeschwindigkeiten in Sekundenmetern vor: 13,$2 ; 13,75 ; 16,85 ; 15 ; 16,2 ; 15,25 ; 15,9 ; 13,7 ; 13,9$; 12,$8 ; 14,9 ; 13,7 ; 14,5 ; 12,8 ; 13,6 ; 11,45 ; 13 ; 14,4 ; 10,6 ; 11,8 \mathrm{~m}$.

Daraus ergibt sich ein Durchschnit von $13,9 \mathrm{~m}$ Eigengeschwindigkeit für die Sekunde, von $834 \mathrm{~m}$ für die Minute und von $50,040 \mathrm{~km}$ für die St unde.

Zum Vergleich soll nun das herangezogen werden, was Dr. $\mathrm{Z}$ i e g le r in der oben angeführten Schrift auf Seite 15 über den uns beschäftigenden Gegenstand sagt:

„Die Eigengeschwindigkeit der Nebelkrähe (Corvus cornix) ist etwa doppelt so grofs wie die Eigengeschwindigkeit der Brieftaube; G a e t k e stellte fest, dafs die Nebelkrähen auf dem Herbstzuge 3 Stunden brauchen, um von Helgoland zur englischen Küste zu fliegen (H. Gaetke, die Vogelwarte Helgoland, p. 209 ff.); er berechnet daraus die Geschwindigkeit auf 27 deutsche Meilen in der Stunde $(200 \mathrm{~km}$ in der Stunde, $3333 \mathrm{~m}$ in der Minute ${ }^{1}$ ); mir ergibt die Berechnung eine etwas kleinere Zahl; da die Entfernung von England ${ }^{2}$ ) zur englischen Küste nur (je nach der Richtung) $450-550 \mathrm{~km}$ beträgt, so komme ich zu einer Geschwindigkeit von $150-183 \mathrm{~km}$ in der Stunde, also 2500-3000 $\mathrm{m}$ in der Minute ${ }^{3}$ ). Die Krähen ziehen vou Ost

1) $=55,5 \mathrm{~m}$ in der Sekunde.

2) Soll „Helgoland“ heifsen.

s) $=41,7-50 \mathrm{~m}$ in der Sekunde. J. Th. 
nach West, und es geht ${ }^{1}$ ) gewöhnlich zur Zeit des Fluges ein Ostwind von mäfsiger Stärke; schätzt man die Geschwindigkeit des Windes auf $300 \mathrm{~m}$ in der Minute und subtrahiert dieselbe, so erhält man als Eigengeschwindigkeit der Krähen 2200$2700 \mathrm{~m}$ in der Minute."

Daraus ergeben sich $36,7-45 \mathrm{~m}$ Eigengeschwindigkeit für die Sekunde, und 132-162 km für die Stunde, also über d r e i m a l gröfsere Werte als die oben durch die praktischen Versuche ermittelten.

Wo liegt da der Fehler? Denn ein solcher ist ohne Zweifel zu verzeichnen. Meines Erachtens darin, dafs die bei Helgoland und an der englischen Küste beobachteten Versuchskrähen nicht identisch gewesen sind. Derselbe Irrtum würde entstehen, wenn ich mir etwa von meinen Danziger Freunden telegraphieren lassen wollte, wann an guten Zugtagen die ersten frühmorgens über „Ulmenhorst" hinwegziehenden Krähen nach Danzig gelangen, und wenn ich darauf Berechnungen aufbauen wollte. Hin nach Danzig kommen die bei Rossitten beobachteten Zugkrähen. Das haben die Ringversuche deutlich bewiesen; aber würde ich die gleichen Schwärme gemeldet bekommen, die ich hier bei Ulmenhorst als Versuchstiere ausgewählt habe? So können grofse Irrtümer entstehen, wenn bei Schnelligkeitsversuchen die als Versuchsobjekte dienenden Vögel den Augen des Beobachters sich entziehen dürfen und müssen. Nach den durch die Versuche der Vogelwarte ermittelten Werten würden die Nebelkrähen bei einer Eigengeschwindigkeit von rund $50 \mathrm{~km}$ pro Stunde für die Strecke Helgoland bis englische Küste (zu $500 \mathrm{~km}$ angenommen) nicht 3 Stunden, sondern 10 Stunden gebrauchen. Diese Zeit würde für vollständige Windstille gelten. Natürlich $\mathrm{k}$ ö $\mathrm{n} n \mathrm{e} n$ die Krähen mit Hilfe eines günstig wehenden Nackenwindes die bezeichnete Strecke in kürzerer Zeit zurücklegen. Sollen sie aber schon nach 3 Stunden am Ziele sein, dann müfste der Wind mit einer Schnelligkeit von $32,1 \mathrm{~m}$ pr. Sek. wehen, denn dann würde sich die Ortsbewegung der ziehenden Krähen aus der ermittelten Eigengeschwindigkeit von 13,9 m und der Windgeschwindigkeit von $32,1 \mathrm{~m}$ p. Sek. zusammensetzen und es würde die notwendige Ortsbewegung von $46 \mathrm{~m}$ pr. Sek. zustande kommen. Eine Windstärke aber von $32,1 \mathrm{~m}$ p. Sek. bedeutet vollen Sturm. Man bedenke, dafs die Wild'schen Windfahnen, die auf den meteorologischen Stationen meist zur Messung der Windstärke benutzt werden, nur bis $35 \mathrm{~m} \mathrm{p}$. Sek. anzeigen. B e i solchem Sturme ruht aller Vogelzug. Zum Vergleich sei angegeben, dafs die Nebelkrähen von Rossitten aus geradlinig nach SW. über die beiden Nehrungen gemessen, nach meinen $\mathrm{Be}-$ rechnungen in 3 Stunden am Südrande der Danziger Bucht, etwa $20 \mathrm{~km}$ vor Danzig sein würden. (Bei Windstille.)

1) Soll wohl "weht" heifsen. J. Th. 
Es könnte mir entgegengehalten werden, dafs die Krähen bei Helgoland über See schneller fliegen als auf der Kurischen Nehrung über Land. Im vorigen Herbste war ich auf Helgoland, habe auch Krähenzug dort beobachtet, allerdings nur ganz wenig, habe aber keinen Unterschied zwischen der Zugweise von dort und hier feststellen können. Und doch müfste einem ein dreimal schnelleres Fliegen sofort aufgefallen sein, da einem gerade das Bild von ziehenden Krähen durch die langjährigen Beobachtungen ich möchte sagen in Fleisch und Blut übergegangen ist. Ich mufs gestehen, dafs ich mir gar keine Vorstellung davon machen kann, wie das aussehen soll, wenn eine Nebelkrähe mit einer Geschwindigkeit von $45 \mathrm{~m}$ in der Sekunde durch die Luft saust.

Bei Ermittelung der Eingengeschwindigkeit der Briefta u be n kommt Dr. Zieg ler den tatsächlichen Verhältuissen ohne Zweifel sehr nahe. Er sagt: „Bei Flügen auf grofse Entfernungen (100 bis $600 \mathrm{~km}$ ) ist die Eigengeschwindigkeit der besten Briebtauben (d. h. ihre Geschwindigkeit bei Windstille) auf etwa 1100 bis $1150 \mathrm{~m}$ pro Minute zu schätzen". Das sind für die Sekunde 18,3-19,2 m, und für die Stunde 66-69 km. Der Verfasser gewinnt diese Werte dadurch, dafs er verschiedene Flüge bei Preisfliegen unter Berüksichtigung des Windes vergleicht.

\section{Saatkrähe. (Corvus trugilegus.)}

1) 28 . Oktober 1909 , vormittags $9,15-10,15 \mathrm{Uhr}$.

Bewölkung: zunächst bedeckt, dann heller, auch Sonnenschein.

Temperatur: früh $7 \mathrm{Uhr}: 8,6^{\circ} \mathrm{C}$., nachm. $2 \mathrm{Uhr}: 11,1^{\circ} \mathrm{C}$.

Windrichtung: SO. $\left(112^{1 / 2^{0}}\right.$.)

Zugrichtung: NNO.-SSW.

Zughöhe: $50-60 \mathrm{~m}$.

Windstärke: $5,5 \mathrm{~m}$ p. Sek.

Beobachtete Geschwindigkeit beim Durchfliegen v on $500 \mathrm{~m}$ : 42 Sek.

Ermittelter Wert für 1 Sek.: $11,9 \mathrm{~m} \mathrm{p}$. Sek.

Eigengeschwindigkeit: $\mathbf{1 4 , 9} \mathrm{m}$ p. Sek.

2) 28 . 0 ktober 1909 , nachmittags $3-3,45 \mathrm{Uhr}$.

Bew ölkung: halb bedeckt, meist Sonnenschein.

Te mperatur: Nachm. 2 Uhr: $11,1^{\circ} \mathrm{C}$.

Windrichtung: SO. $\left(112^{1 / 2^{0}}\right.$.)

$\mathrm{Zugrichtung:} \mathrm{NNO-SSW.} \mathrm{Schnabel} \mathrm{nach} \mathrm{Süden.}$

$\mathrm{Zughöh} \mathrm{e:} 50-60 \mathrm{~m}$.

Windstärke: $5,3 \mathrm{~m}$ p. Sek.

Beobachtete Geschwindigkeiten beim Durchfliegen von $500 \mathrm{~m}: 46,46,41$ Sek. = Durchsch nitt 44,3 Sek.

Ermittelter Wert für 1 Sek.: $11,3 \mathrm{~m}$ p. Sek.

Eigengeschwindigkeit: $14,2 \mathrm{~m}$. Sek. 
Für die Saatkrähe liegen also folgende Eigengeschwindigkeiten vor: 14,9 und $14,2 \mathrm{~m}$ pro Sekunde $=$ Durchschnitt 14,5 m.

Ergibt pro Minute $=870 \mathrm{~m}$.

pro Stunde $=52,2 \mathrm{~km}$.

\section{Dohle. (Colaeus monedula.)}

1) $26.0 \mathrm{ktober} 1908$, vormittags 7,45-9 Uhr.

Bewölkung: hell, Sonnenschein; schönes Wetter.

Te mperatur: früh $7 \mathrm{Uhr}: 1,7^{\circ} \mathrm{C}$, nachm. $2 \mathrm{Uhr} 6,9^{\circ} \mathrm{C}$.

Windrichtung: OSO. $\left(92^{1} / 2^{0}\right.$.)

$\mathrm{Zugrich}$ tung: NNO.-SSW.

$\mathrm{Zugh}$ öhe: $3-30 \mathrm{~m}$.

Windstärke: $7,4 \mathrm{~m}$ p. Sek.

Beobachtete Geschwindigkeit beim Durchfliegen von $500 \mathrm{~m}$ : 39 Sek.

Ermittelter Wert für 1 Sek. : $12,8 \mathrm{~m}$.

Eigengeschwindigkeit: $15 \mathrm{~m}$ p. Sek.

2) 27 . 0 ktober 1908 , vormittags $7,30-8,30 \mathrm{Uhr}$.

B ew ölkung: hell, Sonnenschein; schöner Tag.

Temperatur: früh $7 \mathrm{Uhr}: 1,6^{\circ} \mathrm{C}$, nachm. $2 \mathrm{Uhr}: 7^{\circ} \mathrm{C}$.

Wind ric ht ung: OSO. $\left(102^{1} / 2^{0}\right.$.)

$\mathrm{Zugrich}$ tung: NNO.-SSW.

Zughöhe: $40-50 \mathrm{~m}$.

Windstärke: $6,4 \mathrm{~m}$ p. Sek.

Beobachtete Geschwindigkeiten beim Durchfliegen von $500 \mathrm{~m}: 28 ; 30$ Sek. = Durchschnitt 29 Sek.

Ermittelter Wert für 1 Sek.: $17,2 \mathrm{~m}$ p. Sek.

Eigengeschwindigkeit: 19,65 m. p. Sek.

3) 28 . Oktober 1908 , vormittags 7,30-8,45 Uhr.

Bewölkung: hell, Sonnenschein; schöner Tag.

Tem peratur: früh $7 \mathrm{Uhr}: 2,4^{\circ} \mathrm{C}$., nachm. $2 \mathrm{Uhr}: 7,6^{\circ} \mathrm{C}$.

Wind richtung: SSO. $\left(1271 / 2^{0}\right.$.)

$\mathrm{Zug}$ richtung: NNO.-SSW.

$\mathrm{Zughöh}$ e: $10-30 \mathrm{~m}$.

Windstärke: $5,3 \mathrm{~m}$ p. Sek.

Beobachtete Geschwindigkeit beim Durchfliegen von $500 \mathrm{~m}$ : 39 Sek.

Ermittelter Wert für 1 Sek.: $12,8 \mathrm{~m}$ p. Sek.

Eigengeschwindigkeit: 16,55 m p. Sek.

Für die Dohle folgende Eig engeschwindigkeiten: 15,0; 19,65 und $16,55 \mathrm{~m}=$ Durchschnitt $17,1 \mathrm{~m} \mathrm{p}$. Sek.

pro Minute: $1,026 \mathrm{~km}$.

pro Stunde: $61,560 \mathrm{~km}$. 


\section{Star. (Sturnus vulgaris.)}

28. 0 kto ber 1908 , vormittag s $7,30-8,45 \mathrm{Uhr}$.

B ew ölkung: hell, Sonnenschein; schöner Tag.

Temperatur: früh $7 \mathrm{Uhr}: 2,4^{\circ} \mathrm{C}$., nachm. $2 \mathrm{Uhr}: 7,6^{\circ} \mathrm{C}$.

Windrichtung: SSO. $\left(127{ }^{1} /{ }^{\circ}\right.$.)

$\mathrm{Zugrich}$ tung: NNO.-SSW.

$\mathrm{Zughöh} \mathrm{e:} 10-20 \mathrm{~m}$.

Windstärke: $5,3 \mathrm{~m}$ p. Sek.

Beobachtete Geschwindigkeiten beim Durchfliegen von $500 \mathrm{~m}: 32 ; 27$ Sek. $=$ Durchschnitt 29,5 Sek.

Ermittelter Wert für 1 Sek.: $16,9 \mathrm{~m}$ p. Sek.

Eigengeschwindigkeit: $20,6 \mathrm{~m}$ p. Sek.

pro Minute: $1,236 \mathrm{~km}$.

pro Stunde: $74,160 \mathrm{~km}$.

Die Stare geben sehr gute Resultate, weil sie so schön gleichmäfsig und geradlinig fliegen; in kleineren oder gröfseren di cht gedrängten Trupps. Zum Versuche wurden der Genauigkeit halber die kleinsten gewählt. Sie erreichen von den in der vorliegenden Untersuchung aufgeführten Vogelarten die grölste Geschwindigkeit, was schon äufserlich bei der Beobachtung sofort in Erscheinung tritt. Bei den Staren kann man von einem förmlichen Dahinsausen reden. Von den ziehenden Krähen, Dohlen und Kleinvögeln hört man wenig Geräusch, während ein in voller Fahrt befindlicher Starflug ein starkes Brausen und Schwirren verursacht.

Nun ist es mir schon aufgefallen, dafs die von fliegenden Vögeln ausgehenden Geräusche $\mathrm{zu}$ verschiedenen Jahreszeiten verschieden sind, stärker oder schwächer. Ich habe aber nicht weiter darüber nachgedacht. Bei meinem Aufenthalte jetzt in Helgoland bin ich aufgeklärt worden: Ist der Vogel schön fett, dann braust er, magere Vögel fliegen stumm. Das ist allgemeine Ansicht auf jener Insel. Der richtige Helgoländer hört's schon am Fluge, ob's den Braten lohnt oder nicht. Sicherlich liegt da irgend eine Wahrheit zugrunde, und man sieht, was es draufsen in der Natur am lebenden Vogel noch alles zu beobachten und festzustellen gibt.

\section{Sperber. (Accipiter nisus.)}

1) 26 . Oktober 1908 , nachmittags $1-1,45 \mathrm{Uhr}$.

Bew ölkung: hell, Sonnenschein.

Temperatur: Nachm. 2 Uhr: $6,9^{\circ} \mathrm{C}$.

Windrichtung: OSO. $\left(87^{1} /{ }^{\circ}\right)$.

Zugrichtung: NNO.-SSW.

Zughöhe: ca. $50 \mathrm{~m}$.

Windstärke: $5,8 \mathrm{~m}$ p. Sek.

Beobachtete Geschwindigkeit beim Durchfliegen von $500 \mathrm{~m}$ : 55 Sek.

Journ. f. Orn. LVIII. Jahrg. Juli 1910. 
Ermittelter Wert für 1 Sek.: 9,1 m. p. Sek.

Eingengeschwindigkeit: $\mathbf{1 0 , 6} \mathrm{m}$ p. Sek.

2) 30. Oktober 1908 , vormittags $7,30-9,45 \mathrm{Uhr}$. Regen.

Bewölkung: bedeckt, feuchte aber klare Luft, es droht

Temperatur: früh 7 Uhr: $9,4^{\circ}$ C. machm. 2 Uhr: $8,5^{\circ} \mathrm{C}$.

Windrichtung: NNW. $\left(80^{\circ}\right)$.

Zugrichtung: NNO.-SSW.

Windstärke: $6,4 \mathrm{~m}$. p. Sek.

Beobachtete Geschwindigkeit beim Durchfliegen von $500 \mathrm{~m}$ : 40 Sek.

Ermittelter Wert für 1 Sek.: $12,5 \mathrm{~m}$ p. Sek.

Eigengschwindigkeit: $\mathbf{1 0 , 5 5} \mathrm{m}$ p. Sek.

3) 28 . Oktober 1909, vormittag s 9,15-10,15 Uhr. schein.

Bewölkung: zunächst bedeckt dann heller; auch Sonnen-

Temperatur: früh 7 Uhr: $8,6^{\circ}$ C. nachm. 2 Uhr: $11,1^{\circ} \mathrm{C}$.

Windrichtung: SO. $\left(112^{1} /{ }^{0}\right)$.

Zugrichtung: NNO.-SSW.

Windstärke: $5,5 \mathrm{~m}$ p. Sek.

Beobachtete Geschwindigkeit beim Durchfliegen von $500 \mathrm{~m}$ : 52 Sek.

Ermittelter Wert für 1 Sek.: $9,6 \mathrm{~m}$ p. Sek.

Eigengeschwindigkeit: $\mathbf{1 2 , 7 5} \mathrm{m}$ p. Sek.

4) 30 . Oktober 1909 , vormittags $8-9$ Uhr.

Bew ölkung: heller Tag, meist Sonnenschein.

Temperatur: früh $7 \mathrm{Uhr}: 9,0^{\circ} \mathrm{C}$. nachm. $2 \mathrm{Uhr}: 11,7^{\circ} \mathrm{C}$.

Windrichtung: SSO. $\left(127^{1 / 2} \mathbf{2}^{0}\right)$.

Zugrichtung: NNO.-SSW.

Windstärke: $5,1 \mathrm{~m}$ p. Sek.

Beobachtete Geschwindigkeit beim Durchfliegen von $500 \mathrm{~m}$ : 60 Sek.

Ermittelter Wert für 1 Sek.: $8,3 \mathrm{~m}$ p. Sek.

Eigengeschwindigkeit: $\mathbf{1 2 , 1} \mathrm{m}$ p. Sek.

Folgende Eigengeschwindigkeiten für Sperber: 10,$6 ; 10,55 ; 12,75$ und $12,1 \mathrm{~m} \mathrm{p}$. Sek. $=$ Durchschnitt $11,5 \mathrm{~m}$. Für die Minute: $690 \mathrm{~m}$.

Ohne Zweifel "wird die geringe Geschwindigkeit dieses kleinen gewandten Räubers überraschen. Ich bemerke aber nochmals ausdrücklich, dafs sich die vorliegenden Untersuchungen nur auf den $\mathrm{Zu}$ g flug erstrecken. Und wie fliegt der Sperber? Recht gemächlich, ich möchte sagen fast schwerfällig; nie etwa sausend, wie dann, wenn's hinter einer Meise hergeht. Einen Sperber aus einer in der Zugstrafse gelegenen Deckung aus der Luft herabzuschiefsen ist Kinderspiel. Dabei hat der Sperber die Gewohnheit, ziemlich ungleichmärsig zu fliegen. Jetzt mit rasch 
aufeinander folgenden Flügelschlägen wenig fördernd, dann plötzlich ohne Flügelschlag ein Stück vorwärts schiefsend. Und solche Flugart gehört nicht etwa unter die Ausnahmefälle, sondern wie ich schon öfter in den Jahresberichten bemerkt habe, führt zuweilen im Herbst vier Wochen lang eine Sperberzugkette tagtäglich die Nehrung entlang, und die einzelnen Exemplare fliegen alle in gleicher Weise; das ist normaler Zug. Die Zughöhe schwankt ziemlich; etwa von $10-60 \mathrm{~m}$. Zu den Versuchen wurden natürlich recht günstig fliegende Stücke ausgewählt.

\section{Wanderfalke. (Falco peregrinus.)}

28. Oktober 1909 , vormittags $9,15-10,15 \mathrm{Uhr}$.

Bewölkung: zunächst bedeckt, dann heller; auch Sonnenschein.

Temperatur: früh 7 Uhr: $8,6^{\circ} \mathrm{C}$. nachm. $2 \mathrm{Uhr}: 11,1^{\circ} \mathrm{C}$.

Windrichtung: SO. $\left(112^{1 / 2}{ }^{0}\right)$.

Zugrichtung: NNO.-SSW.

Windstärke: $5,5 \mathrm{~m}$ p. Sek.

Beobachtete Geschwindigkeit beim Durchfliegen von $500 \mathrm{~m}$ : 37 Sek.

Ermittelter Wert für 1 Sek.: $13,5 \mathrm{~m}$ p. Sek.

Eigengeschwindigkeit: $\mathbf{1 6 , 4 5} \mathrm{m}$ p. Sek.

Für die Minute $987 \mathrm{~m}$.

" " Stunde: $59,22 \mathrm{~km}$.

Was vorhin vom Sperber gesagt worden ist, gilt in noch erhöhtem Mafse vom Wanderfalken, dem Könige unter unsern Fliegern. Der soll weniger schnell vorwärts kommen, als der Star? Ja. Ich sehe den Wanderfalken nie anders ziehen und ich habe hier in ,Ulmenhorst" oft Gelegenheit, den stolzen Vogel täglich, zuweilen in mehreren Exemplaren auf der Wanderung zu beobachten - als mit unruhigen, schnell aufeinanderfolgenden Flügelschlägen vorwärts strebend. Verfolgt man so einen Vogel so weit die Augen reichen, eine Übung die zur Schulung des Blickes nicht warm genug empfohlen werden kann, so würde man dieses in der Ferne flatternd erscheinende Tier gewifs nicht für einen Wanderfalken halten, wenn man ihn nicht eben am schönen leuchtenden Bartstreifen sicher bestimmt hätte.

Ganz anders wird das Bild, wenn's einmal einem solchen Räuber einfällt (was aber verhältnismäfsig selten vorkommt), während der Reise auf eine Dohle oder Wildtaube Jagd zu machen. 0 , wie da der Flügelbug eingeknickt wird, und wie der Vogel einem abgeschossenen Pfeile gleich vorwärts schnellt. Da bleibts nicht bei 16 Metern in der Sekunde; - und doch sieht man diesen Falken verhältnismäfsig oft fehl stofsen; ob mit Absicht oder unbeabsichtigt mag dahin gestellt bleiben. Der "nie fehlende“ Stofs des Wanderfalken existiert nur in ausgeschmückten Erzählungen über Beizjagd und Ritterfräuleins; er ist das Gegen- 
stück zu der „nie fehlenden“ „treuen“ Büchse in den Jägerzeitungen.

\section{Heringsmöwe. (Larus fuscus.)}

1) 30 . Oktober 1908 , vormittags $7,30-9,45 \mathrm{Uhr}$. Regen.

Bewölkung: bedeckt, feuchte aber klare Luft; es droht

Temperatur: früh 7 Uhr: $9,4^{\circ} \mathrm{C}$. nachm. 2 Uhr: $8,50 \mathrm{C}$.

Windrichtung: NNW. (800).

Zugrichtung: NO.-SW.

Windstärke: $6,4 \mathrm{~m} \mathrm{p}$. Sek.

Beobachtete Geschwindigkeit beim Durchfliegen von $500 \mathrm{~m}$ : 38 Sek.

Ermittelter Wert für 1 Sek.: $13,2 \mathrm{~m}$ p. Sek.

Eigengeschwindigkeit: $\mathbf{1 3 , 6 5} \mathrm{m}$ p. Sek.

2) 26. Oktober 1909, vormittags 11-12 Uhr.

Bewölkung: halb bedeckt, zuweilen Sonnenschein.

Temperatur: früh $7 \mathrm{Uhr}: 8,0^{\circ} \mathrm{C}$. nachm. $2 \mathrm{Uhr}: 10,60 \mathrm{C}$.

Windrichtung: WSW. (1550).

Zugrichtung: NO.-SW.

Windstärke: $4,1 \mathrm{~m}$ p. Sek.

Beobachtete Geschwindigkeit beim Durchfliegen von $500 \mathrm{~m}$ : 54 Sek.

Ermittelter Wert für 1 Sek.: $9,2 \mathrm{~m}$ p. Sek.

Eigengeschwindigkeit: $14 \mathrm{~m}$ p. Sek.

Für die Heringsmöwen folgende Eigengeschwindigkeiten: 13,65 und $14 \mathrm{~m}=$ Durchschnitt 13,8 m p. Sek.

Für die Minute: $828 \mathrm{~m}$.

" , Stunde: $49,680 \mathrm{~km}$.

Die ermittelten" Geschwindigkeiten gelten für den Flug, wie er den Möwen eigen ist, wenn sie am Seestrande entlang ziehen. Diese Züge geben, wie die Ringversuche gezeigt haben, mit grofser Regelmäfsigkeit vor sich.

\section{Mantelmöwe. (Larus marinus.)}

30. Oktober 1908 , vormittags $7,30-9,45 \mathrm{Uhr}$.

Bewöl ku ng: bedeckt, feuchte aber klare Luft; es droht Regen.

Temperatur: früh $7 \mathrm{Uhr}: 9,4^{\circ} \mathrm{C}$., nachm. $2 \mathrm{Uhr}: 8,5^{\circ} \mathrm{C}$.

Windrichtung: NNW. $\left(80^{\circ}\right)$.

Zugrichtung: NO.-SW.

Windstärke: $6,4 \mathrm{~m}$ p. Sek.

Beobachtete Geschwindigkeit beim Durchfliegen von $500 \mathrm{~m}$ : 37 Sek.

Ermittelter Wert für 1 Sek.: $13,5 \mathrm{~m}$ p. Sek.

Eigengeschwindigkeit: $\mathbf{1 3 , 9} \mathrm{m}$ p. Sek.

Für die Minute: $834 \mathrm{~m}$.

" "Stunde: $50,040 \mathrm{~km}$. 
Die Geschwindigkeiten sind genau dieselben wie bei der Nebelkrähe.

\section{Finken. $\left.{ }^{1}\right)$}

1) 11 . Oktober 1908 , vormittags $8,15-9,30 \mathrm{Uhr}$.

Bew ölkung: hell, Sonnenschein.

Temperatur: früh 7 Uhr: $9,4^{\circ} \mathrm{C}$., nachm. $2 \mathrm{Uhr}: 15,6^{\circ} \mathrm{C}$. Windrichtung: SSW. $\left(172^{1} / 2^{0}\right)$. Wind also fast steil von vorn.

Zugrichtung: NNO.-SSW.

Wind stärke: $4,4 \mathrm{~m}$ p. Sek.

Beobachtete Geschwindigkeiten beim Durchfliegen von $500 \mathrm{~m}: 47 ; 50 ; 50$ Sek. = Durchnitt: 49 Sek.

Ermittelter Wert für 1 Sek.: $10,2 \mathrm{~m} \mathrm{p}$. Sek.

Eigengeschwindigkeit: $14,55 \mathrm{~m}$ p. Sek.

2) 25 . Oktober 1908 , vormittags $8,45-10 \mathrm{Uhr}$.

Bewölkung: hell, Sonnenschein.

Temperatur: früh $7 \mathrm{Uhr}: 2,1^{\circ} \mathrm{C}$., nachm. $2 \mathrm{Uhr}: 7,1^{\circ} \mathrm{C}$.

Windrichtung: Der Wind wechselt. Um 8,45 Uhr: 0 SO. (etwa $77^{1 / 2^{\circ}}$ ), um $10 \mathrm{Uhr}$ : SO. (etwa $112^{1} /^{\circ}$ ), (im Mittel: $95^{\circ}$ ). Zugrichtung: NNO.-SSW.

Windstärke: $7,7-8,5 \mathrm{~m}$, im Mittel: $8,1 \mathrm{~m}$ p. Sek.

Beobachtete Geschwindigkeiten beim Durchfliegen von $500 \mathrm{~m}: 43 ; 41 ; 45 ; 39$ Sek. $=$ Durchschnitt: 42 Sek.

Ermittelter Wert für 1 Sek.: $11,9 \mathrm{~m}$ p. Sek.

Eigengeschwindigkeit: $\mathbf{1 4 , 9} \mathrm{m}$ p. Sek.

3) 28 . 0 ktober 1908 , vormittags $7,30-8,45 \mathrm{Uhr}$.

Bewölkung: hell, Sonnenschein, schöner Tag.

Temperatur: früh $7 \mathrm{Uhr}: 2,4^{\circ} \mathrm{C}$, nachm. $2 \mathrm{Uhr}$ : $7,6^{\circ} \mathrm{C}$.

Windrichtung: SSO. $\left(127^{1} / 2^{\circ}\right)$.

Zugrichtung: NNO.-SSW.

Windstärke: $5,3 \mathrm{~m}$.

Beobachtete Geschwindigkeiten beim Durchfliegenvon $500 \mathrm{~m}: 47 ; 48 ; 48 ; 49 ; 48$ Sek. =Durchschnitt: 48 Sek.

Ermittelter Wert für 1 Sek.: $10,4 \mathrm{~m}$ p. Sek.

Eigengeschwindigkeit: $14,25 \mathrm{~m}$ p. Sek.

4) 28 . Oktober 1909 , vormittags $9,15-10,15 \mathrm{Uhr}$. schein.

Bew ölkung: zunächst bedeckt, dann heller, auch Sonnen-

1) Anm.: Mit der Bezeichnung „Finken“ sind die Kleinvogelflüge gemeint, die sich aus Buchfinken (Fringilla coelebs) (vorwiegend) und Bergfinken (Fr. montifringilla) zusammensetzen. Ihre Zughöhe schwankt zwischen etwa $10-40 \mathrm{~m}$. Zum Versuche wurden die kleinsten Flüge herangezogen. Das Eintreffen der Spitze des Fluges am Ziel wurde markiert. 
Temperatur: früh $7 \mathrm{Uhr}: 8,6^{\circ} \mathrm{C}$., nachm. $2 \mathrm{Uhr}: 11,10 \mathrm{C}$. Windrichtung: SO. $\left(112^{1 / 2}{ }^{0}\right)$.

Zugrichtung: NNO.-SSW.

Windstärke: $5,5 \mathrm{~m}$ p. Sek.

Beobachtete Geschwindigkeit beim Durchfliegen von $500 \mathrm{~m}$ : 38 Sek.

Ermittelter Wert für 1 Sek.: $13,2 \mathrm{~m}$ p. Sek.

Eigengeschwindigkeit: $\mathbf{1 6 , 1 5} \mathrm{m}$ p. Sek.

5) 29 . 0 ktober 1909 , vormittags $9-10,15 \mathrm{Uhr}$.

B ew ölkung: hell, Sonnenschein; schöner Tag.

Temperatur: früh 7 Uhr: $7,30 \mathrm{C}$., nachm. 2 Uhr: $11,30 \mathrm{C}$.

W ind ric h t ung: SSO. $\left(127^{1 /} / \mathrm{s}^{0}\right)$.

$\mathrm{Zugrichtung:} \mathrm{NNO.-SSW.}$

W indstärke: $6,6 \mathrm{~m}$ p. Sek.

B e obach tete Geschwindigkeiten beim Durchfliegen von $500 \mathrm{~m}: 48 ; 48 ; 48$ Sek. $=$ Durchschnitt: 48 Sek.

Ermittelter Wert für 1 Sek.: $10,4 \mathrm{~m}$ p. Sek.

Eigengeschwindigkeit: $15,3 \mathrm{~m}$ p. Sek.

6) 30. Oktober 1909 , vormittags $8-9 \mathrm{Uhr}$.

Bewölkung: heller Tag; meist Sonnenschein.

Temperatur: früh $7 \mathrm{Uhr}: 9,0^{\circ} \mathrm{C}$, nachm. $2 \mathrm{Uhr}: 11,7^{\circ} \mathrm{C}$.

Windrichtung: SSO. $\left(127^{1} /{ }^{\circ}\right.$.)

Zugrichtung: NNO.-SSW.

W indstärke: $5,1 \mathrm{~m}$ p. Sek.

Beobachtete Geschwindigkeiten beim Durchfliegen von $500 \mathrm{~m}$ : $52 ; 58$ Sek. = Durchschnitt 55 Sek.

Ermittelter Wert für 1 Sek.: $9,1 \mathrm{~m}$ p. Sek.

Eigengeschwindigkeit: $\mathbf{1 2 , 8} \mathrm{m}$ p. Sek.

Folgende Eigengeschwindigkeiten für Finken liegen vor: $14,55,14,9,14,25,16,15,15,3$ und $12,8 \mathrm{~m}=$ Durchschnitt: 14,6 m p. Sek.

Für die Minute: $876 \mathrm{~m}$.

" "Stunde: $52,560 \mathrm{~km}$.

\section{Zeisige. ${ }^{1}$ )}

28. Oktober 1908 , vormittags $7,30-8,45 \mathrm{Uhr}$.

B ewölkung: hell, Sonnenschein; schöner Tag.

Temperatur: früh $7 \mathrm{Uhr}: 2,4^{\circ} \mathrm{C}$, nachm. $2 \mathrm{Uhr}: 7,6^{\circ} \mathrm{C}$.

Windrichtung: SSO. $\left(127^{1} / \mathrm{s}^{\circ}\right.$.)

Zugrichtung: NNO.-SSW.

Windstärke: 5,3 m. p. Sek.

1) Erlenzeisige (Chrysomitris spinus) oder Birkenzeisige (Acanthis linaria). Zughohe ebenso wio bei den Finken. 
Beobachtete Geschwindigkeiten beim Durchfliegen von $500 \mathrm{~m}: 34 ; 43 ; 48$ Sek. = Durchschnitt 42,7 Sek.

Ermittelter Wert für 1 Sek. : 11,7 m p. Sek.

Eigengeschwindigkeit: $\mathbf{1 5 , 5} \mathrm{m}$ p. Sek.

Für die Minute: $930 \mathrm{~m}$.

" "Stunde: $55,800 \mathrm{~km}$.

\section{Kreuzschnabel. (Loxia curvirostra.)}

1) 28 . Oktober 1909 , vormittags $9,15-10,15 \mathrm{Uhr}$. schein.

Bewölkung: zunächst bedeckt, dann heller; auch Sonnen-

Temperatur: früh 7 Uhr: $8,6^{\circ} \mathrm{C}$, nachm. $2 \mathrm{Uhr}: 11,1^{\circ} \mathrm{C}$.

Windrichtung: SO. $\left(112^{1} / 2^{0}\right.$.)

Zugrichtung: NNO.-SSW.

$\mathrm{Zughöh} \mathrm{e:} 30-40 \mathrm{~m}$.

Windstärke: $5,5 \mathrm{~m}$ p. Sek.

Beobachtete Geschwindigkeit beim Durchfliegen von $500 \mathrm{~m}$ : 37 Sek.

Ermittelter Wert für 1 Sek. $13,5 \mathrm{~m}$ p. Sek.

Eigengeschwindigkeit: $\mathbf{1 6 , 4 5} \mathrm{m}$ p. Sek.

2) 29 . Oktober 1909 , vormittags $9-10,15 \mathrm{Uhr}$.

B ew ölkung: hell, Sonnenschein; schöner Tag.

Temperatur: früh $7 \mathrm{Uhr}: 7,3^{\circ} \mathrm{C}$, nachm. $2 \mathrm{Uhr}: 11,3^{\circ} \mathrm{C}$.

Windrichtung: SSO. $\left(127^{1} / 2^{\circ}\right.$.)

$\mathrm{Zugrichtung:} \mathrm{NNO.-SSW.}$

$\mathrm{Zughöhe:} 30-40 \mathrm{~m}$.

Windstärke: $6,6 \mathrm{~m}$ p. Sek.

Beobachtete Geschwindigkeit beim Durchfliegen von $500 \mathrm{~m}: 42$ Sek.

Ermittelter Wert für 1 Sek.: 11,9 m p. Sek.

Eigengeschwindigkeit: 16,\%5 m p. Sek.

Folgende Eigengeschwindigkeiten für Kreuzschnäbel: 16,45 m und $16,75 \mathrm{~m}=$ Durchschnitt $\mathbf{1 6 , 6} \mathrm{m}$ pr. Sek.

Für die Minute: $996 \mathrm{~m}$.

" "Stunde: $59,760 \mathrm{~km}$.

Gelegentlich der grofsen Kreuzschnabelinvasion vom Jahre 1909 fand auf der Kurischen Nehrung und speziell bei ,Ulmenhorst" ein regelrechter Zug dieser Vögel statt. In kleinen Trupps, zuweilen in ganz beträchtlicher Höhe von $4-500 \mathrm{~m}$ wanderten die Kreuzschnäbel, ihre Lockrufe beständig ausstofsend, fast täglich nach Süden. An solchen Zügen sind die Schnelligkeitsversuche angestellt worden. Natürlich wurden nur möglichst niedrig fliegende Vögel gewählt. 
Im folgenden sollen die gewonnenen Resultate in einer Tabelle zusammengestellt werden. $\mathrm{Zusammenfassend}$ und e rlä u ternd ist dazu zu bemerken:

1) Der Grölse der Durchschnitts-Eig e ngeschwindigkeit nach ergeben die untersuchten Vogelarten folgende Reihenfolge:

1. Star mit . . . . . . . . 20,6 m. p. Sek.

2. Dohle mit . . . . . . . 17,1 " " "

3. Kreuzschnabel mit . . . . 16,6 " " "

4. Wanderfalke mit . . . . . 16,45 " " "

5. Zeisige mit . . . . . . 15,5 " " "

6. Finken mit . • . • . . . 14,6 " " "

7. Saatkrähe mit . . . . . . 14,5 " " "

8. und 9. Nebelkrähe und Mantelmöwe mit 13,9 " " "

10. Heringsmöwe mit . . . . 13,8 " " "

11. Sperber mit . . . . . . 11,5 " " "

2) Die Eigengeschwindigkeiten sind innerhalb ein und derselben Spezies nicht immer gleich. Die gleichgearteten Vögel ziehen also $\mathrm{zu}$ verschiedenen Zeiten verschieden schnell. In der Nebelkrähen-Serie z. B. sind die Extreme: 16,85 und andererseits $10,6 \mathrm{~m}$. p. S., mit einer Differenz also von $6,25 \mathrm{~m}$; in der Finkenserie 16,15 und 12,8 m, mit einer Differenz 3,35 m. Eine Eigengeschwindigkeit von 13-14 Metern bei 4 Flügelschlägen pro Sekunde scheint den Nebelkrähen am geläufigsten und bequemsten zu sein. Die zunehmende Stärke des Windes, auch wenn er nicht günstig ist, also mehr oder weniger von vorn kommt, scheint die Eigengeschwindigkeit günstig $\mathrm{zu}$ beeinflussen. Die ziehenden Vögel scheinen also bei starkem Winde ihr Vorwärtskommen beschleunigen $\mathrm{zu}$ wollen.

3) Bei den verzeichneten 41 einzelnenVersuchen ist derWinkel 33 mal über $90^{\circ}$, der Wind weht also mehr oder weniger von vorn, und nur $8 \mathrm{mal} \mathrm{unter} 90^{\circ}$ bei mehr oder weniger steilem Nackenwind, woraus ersichtlich, dafs die Zugvögel den Gegenwind durchaus nicht scheuen. Die gröfste Windstärkte bei den Fällen über $90^{\circ}$ ist $8,1 \mathrm{~m} \mathrm{p}$. Sek., bei den Fällen unter $90^{\circ} 10,4 \mathrm{~m}$ p. Sek.

Dabei ist allerdings zu berücksichtigen, dafs Gegenwind die wandernden Vögel stets aus der Höhe herabzieht und damit günstige Bedingungen zum Anstellen von Schnelligkeitsversuchen schafft.

4) Die Regel, dafs Gegenwind die Ortsbewegung der fliegenden Vögel verlangsamt, kann dahin ergänzt werden, dafs es gleichgiltig ist, ob der Wind direkt von vorn, oder mehr von der Seite kommt. Wenn er im zweiten Falle stärker ist als im ersten, so ist die hemmende Wirkung dieselbe. Der Vogel mufs bei Seitenwind immer den Abtrieb ausgleichen. (cf. in der Tabelle die ersten beiden Krähenversuche.) 
Am Schlufs der Tabelle sind einige andere Geschwindigkeiten angegeben worden, die Vergleiche mit den ermittelten Geschwindigkeiten der Zugvögel zulassen. Dazu soll noch bemerkt werden, dafs sich in einer der letzten Nummern des „Schiefswesens", Nr. 22 11. Band, Beilage zu Nr. 41, Band 54 der „Deutschen Jägerzeitung", Neudamm eine mit „0. M.“ unterzeichnete Notiz findet: „Bewegungsgeschwindigkeit des Wildes". Dort wird gesagt, dafs solche Messungen bereits in den achtziger Jahren in England ausgeführt und in The Field veröffentlicht worden sind. Dazu wurden Rebhühner und Fasanen wie bei Treibjagden aufgescheucht und gezwungen, über eine genau abgemessene Strecke zu fliegen, wobei die Flugzeiten festgestellt werden konnten. Dabei erreichten Rebhühner 12-15 ms, Fasanen sogar 17-18 ms. Nach einer ebenda stehenden anderen Mitteilung, die auf Messungen eines deutschen Jägers beruht, sollen Rebhühner in einer Sekunde 10-16 m, die Stockente 10-17 m, der Birkhahn 12-18 m, der Fasan 15-20 m und die Wildtaube 16-22 m zurücklegen. Leider geht aus den Angaben nicht hervor, ob sich's um Eigengeschwindigkeiten handelt, ob also Windstärke und Windrichtung bei den Berechnungen mit in Betracht gezogen worden sind, denn nur solche Untersuchungen haben wissenschaftlichen Wert. Ich wollte es aber nicht unterlassen, die angegebenen Werte vergleichungshalber zu bringen.

Die Schnelligkeitsversuche sollen auf der Vogelwarte Rossitten fortgesetzt werden. Vielleicht geben sie Veranlassung zur Nachahmung und Nachprüfung, sodals die nach der Richtung hin noch bestehende Lücke in der ornithologischen Forschung nach und nach ausgefüllt wird.

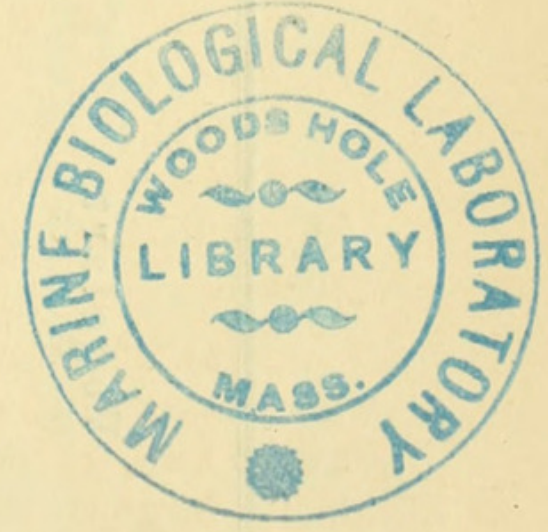




\begin{tabular}{|c|c|}
\hline 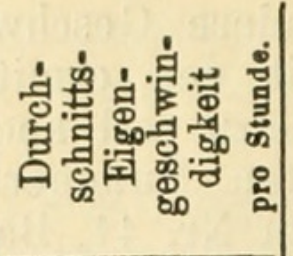 & 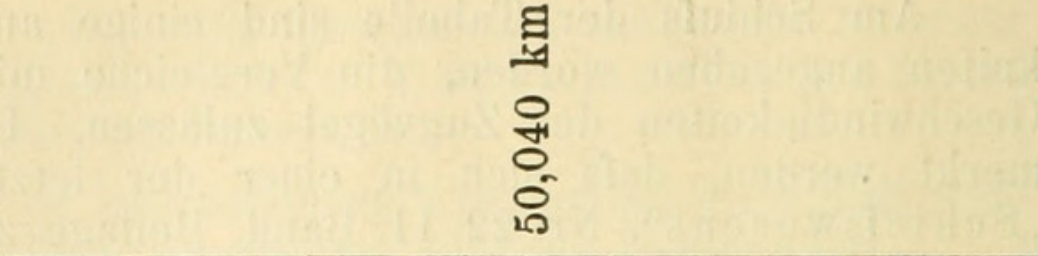 \\
\hline 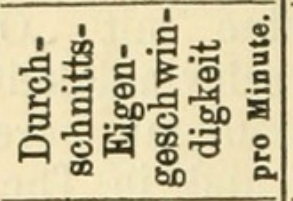 & $\begin{array}{l}\text { a } \\
\infty \\
\infty\end{array}$ \\
\hline 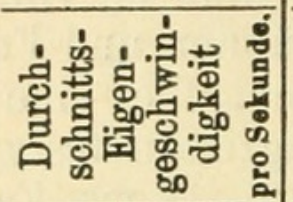 & 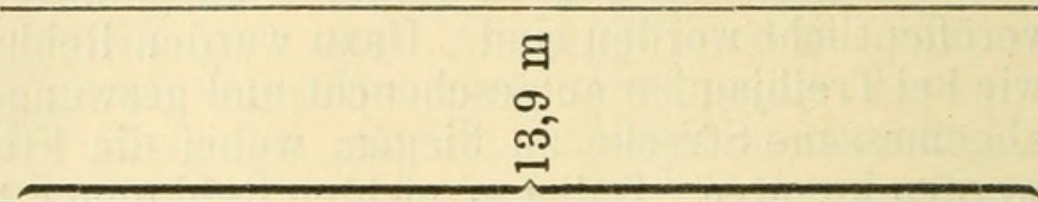 \\
\hline 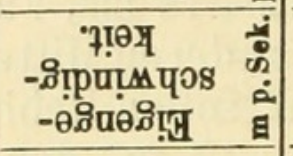 & 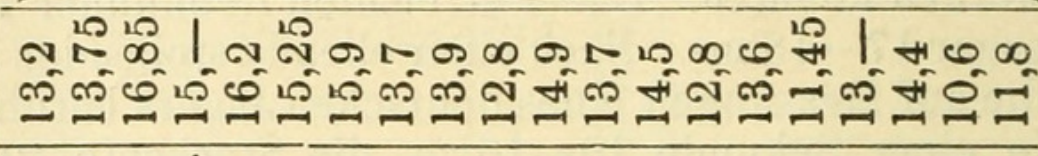 \\
\hline 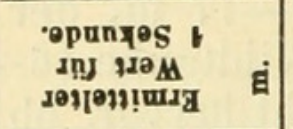 & 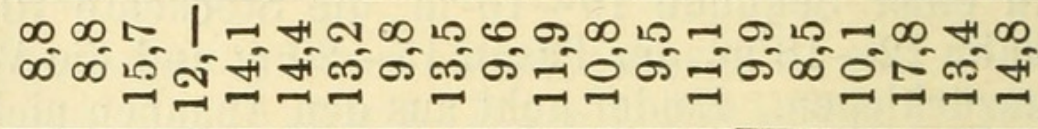 \\
\hline 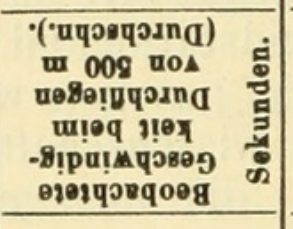 & 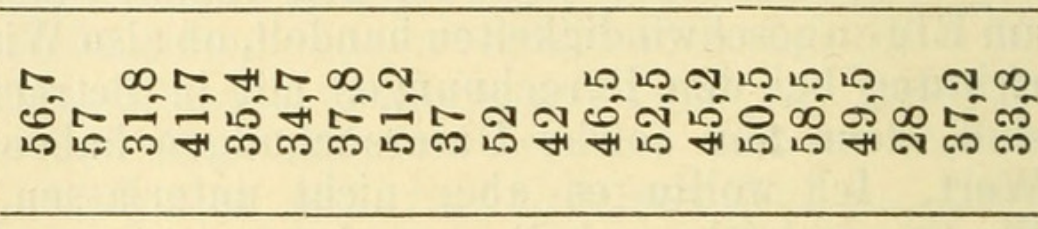 \\
\hline 富裹 & 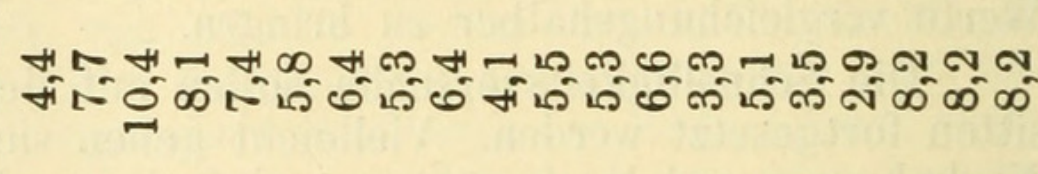 \\
\hline 可 & 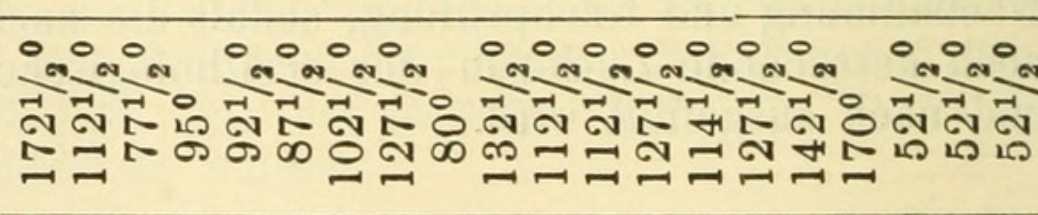 \\
\hline 壳 & 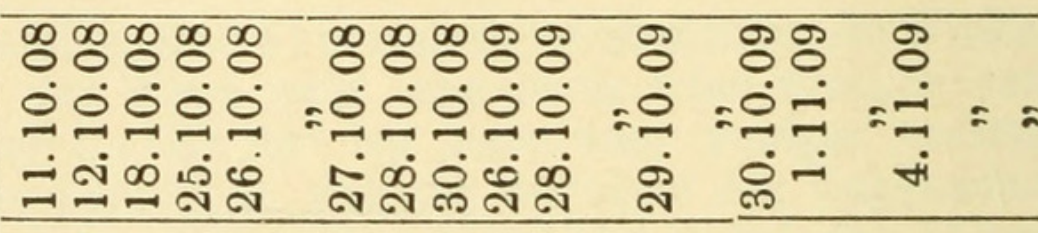 \\
\hline 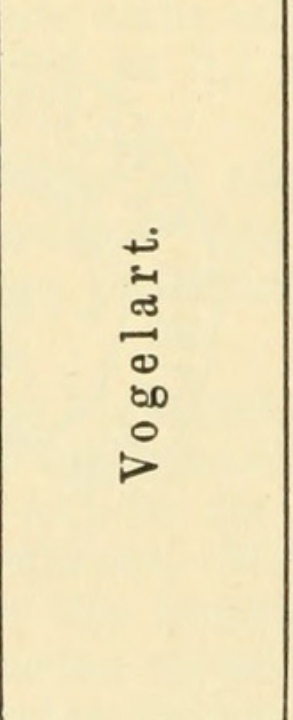 & 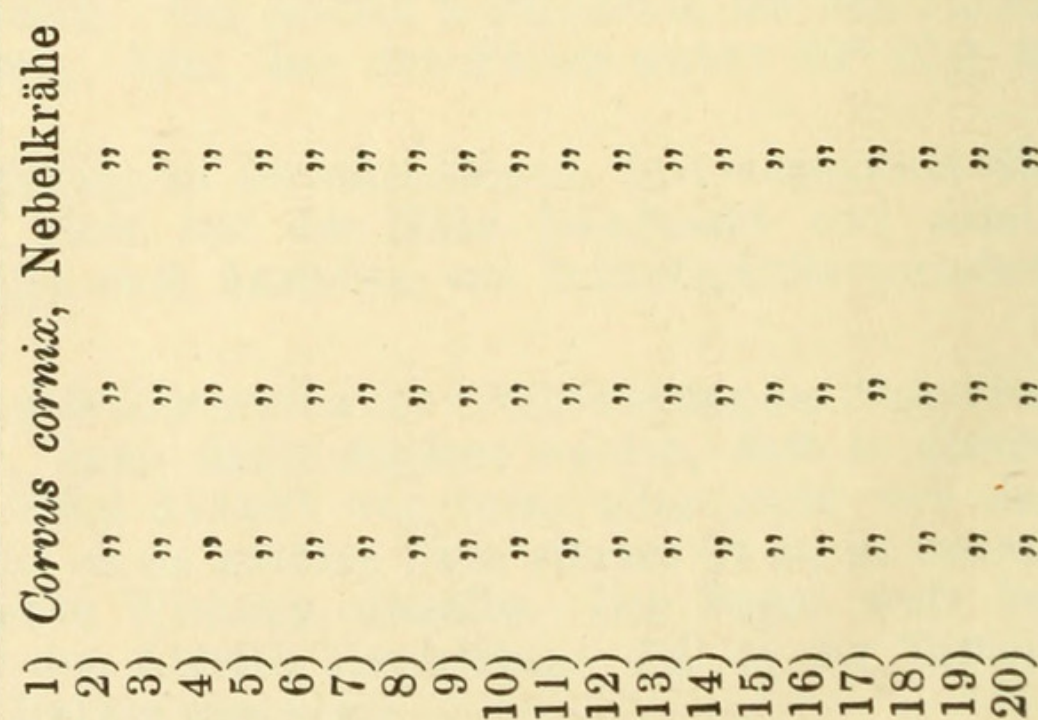 \\
\hline
\end{tabular}




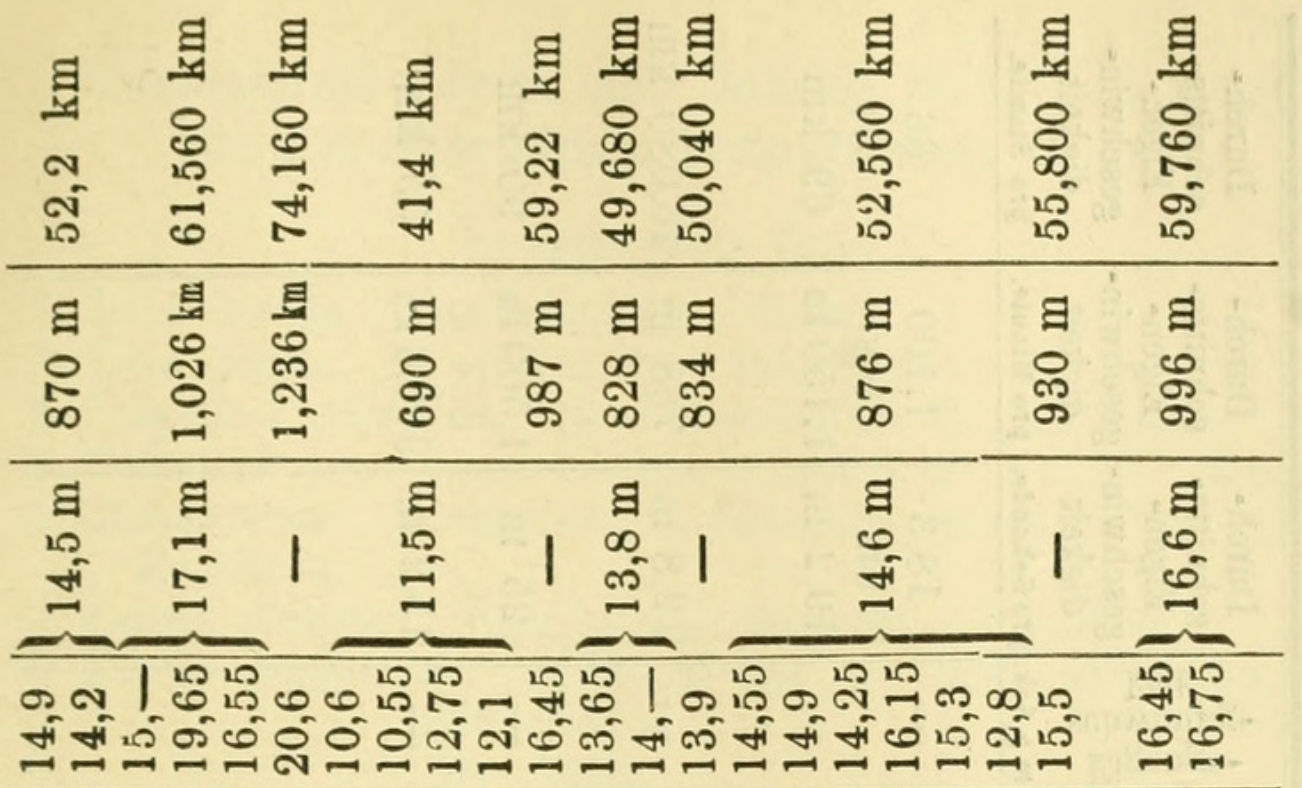

ต ๓ $\infty$ ต

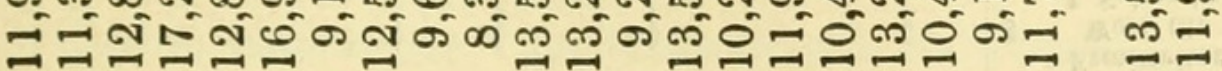

개 개

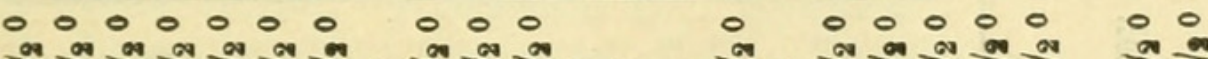

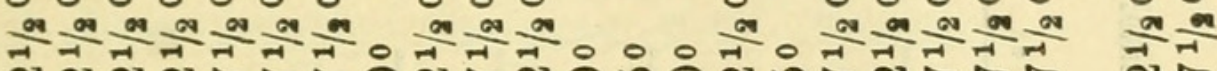
ब

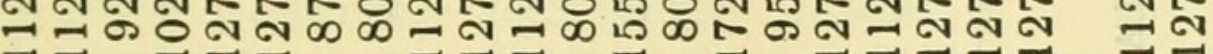

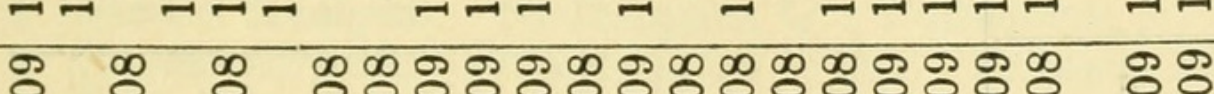

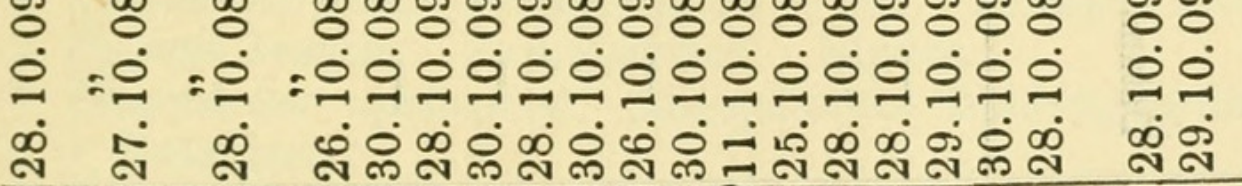
兽 总

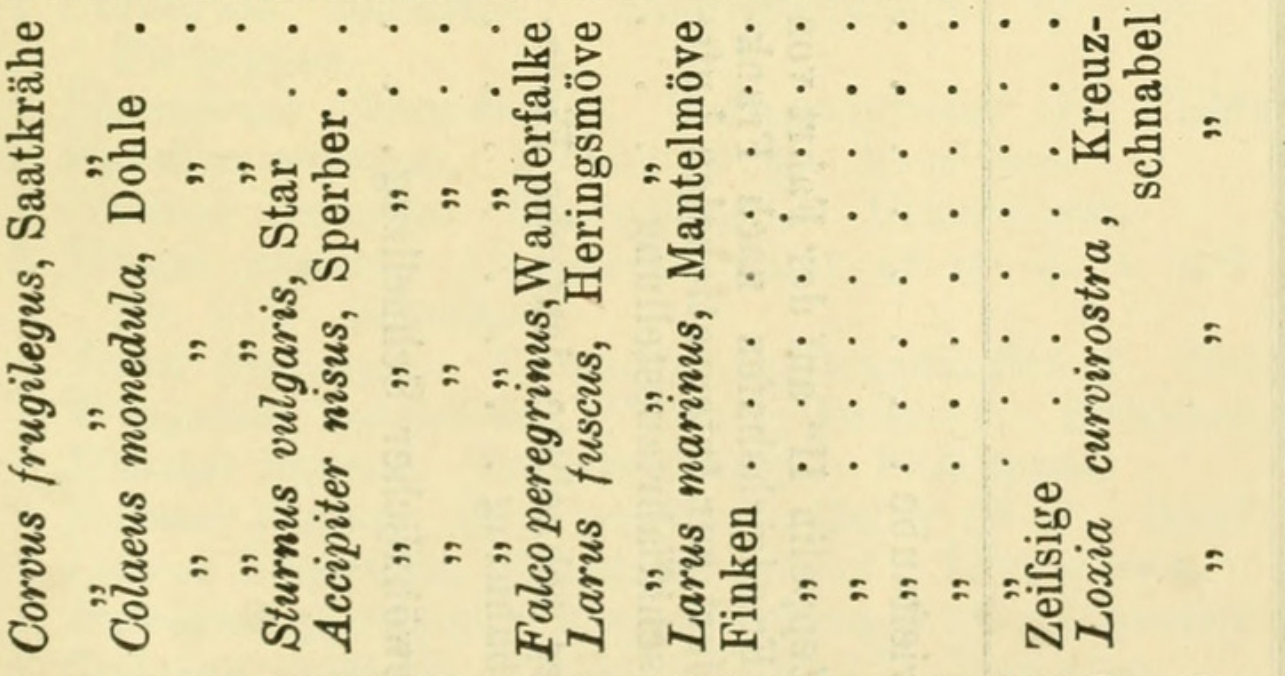
몰 


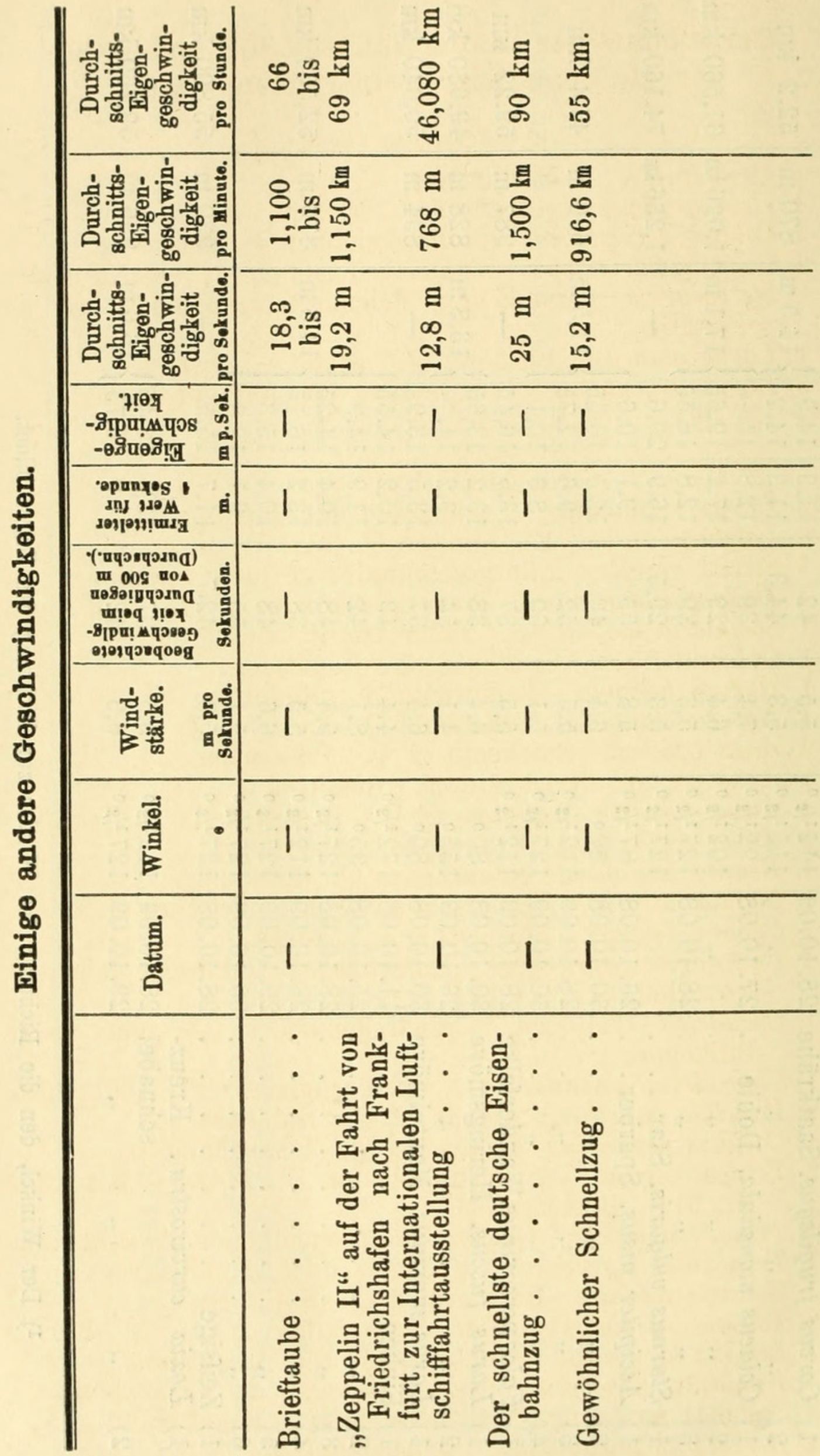


Verzeiohnis der in den Jahren 1908 und 1909 für die Sammlung präparierten Vögel.

a) aufgestellte Vögel.

1 Uria troille. Trottellumme. Cranz.

1 Uria grylle. Gryllteist ơ. Rossitten.

1 Colymbus cristatus. Haubensteifsfufs 오. Rossitten.

2 Colymbus grisegena. Rothalssteifsfufs ơ juv., ㅇ. Rossitter.

1 Stercorarius parasiticus. Schmarotzerraubmöwe of ad. Rossitten.

1 Larus glaucus. Eismöwe $\bigcirc$ Varietät. Rossitten.

3 Larus argentatus. Silbermöwen juv. mit Fufsringen.

Nr. 2351.
Nr. 2560 .
Nr. 2480.

5 Larus ridibundus. Lachmöwen mit Fufsringen.

2 Larus minutus. Zwergmöwe $ᄋ$, juv. Rossitten.

1 Sterna minuta. Zwergseeschwalbe $\sigma^{\nearrow}$ juv. Pillkoppen.

1 Hydrochelidon nigra. Trauerseeschwalbe ơ juv. Pillkoppen.

1 Somateria mollissima. Eiderente Q. R. Rossitten.

1 Oidemia fusca. Samtente ơ. Rossitten.

1 Nyroca fuligula. Reiherente or. Rossitten.

1 Nyroca clangula. Schellente Q.

2 Anas boschas. Stockente ơ $0^{\top}$. Pillkoppen.

1 Anas crecca. Krickente ơ. Rossitten.

2 Anser fabalis. Saatgans ơ Q $^{*}$. Rossitten.

1 Anser erythropus. Zwerggans. Allenstein.

1 Branta leucopsis. Nonnengans Q. Pillkoppen.

1 Cygnus atratus. Trauerschwan $\stackrel{+}{\circ}$ juv. Frisches Haff.

1 Cygnus bewicki. Zwergschwan. Nidden.

1 Charadrius apricarius. Europäischer Goldregenpfeifer ơ. Rossitten.

1 Chradrius hiaticula. Sandregenpfeifer $\$$ mit Eiern. Pillkoppen.

1 Charadrius alexandrinus. Seeregenpfeifer $\sigma^{\top}$. Pillkoppen.

2 Vanellus vanellus. Kiebitz ơ O. Rossitten.

1 Calidris arenaria. Sanderling 0 . Ulmenhorst.

3 Tringa alpina. Alpenstrandläufer ○ $^{\Upsilon}$ Oุ. 1 mit Ring Nr. 911. Rossitten.

1 Trina temmincki. Grauer Zwergstrandläufer ơ. Rossitten.

1 Tringoides hypoleucos. Flufsuferläufer ơ. Rossitten.

1 Totanus totanus. Rotschenkel ơ. Pillkoppen.

2 Totanus fuscus. Dunkler Wasserläufer $\sigma^{x} \sigma^{x}$. Rossitten.

1 Limosa lapponica. Pfuhlschnepfe $\sigma^{\top}$. Ulmenhorst.

1 Numenius phaeopus. Regenbrachvogel $\sigma^{\star}$. Ulmenhorst.

1 Scolopax rusticola. Waldschnepfe ơ. Rossitten.

1 Syrrhaptes paradoxus. Steppenhuhn ơ. 
2 Ciconia ciconia. Weifser Storch juv. Losgehnen. RhodesiaSüdafrika Ring Nr. 163.

1 Accipiter nisus. Sperber $\sigma^{\top}$ juv. Pillkoppen.

2 Buteo buteo. Mäusebussard $\sigma^{\top}$. Rossitten und Pillkoppen.

1 Buteo Zimmermannae. Falkenbussard $\sigma^{x}$. Rossiten.

1 Archibuteo lagopus. Rauhfufsbussard ơ. Rossitten.

1 Pandion haliaetus. Fischadler $\sigma^{x}$. Perwelk.

2 Cerchneis merilla. Merlinfalk $\sigma^{x}$ ad. $\&$ juv. Rossitten.

1 Bubo bubo. Uhu ơ. Preil, Kurische Nehrung.

1 Strix flammea. Schleiereule Ǫ. Rossitten.

2 Dendrocopus maior. Grofser Buntspecht ơ ad. $\sigma^{x}$ juv. Rossitten.

1 Picus viridis. Grünspecht 오. Stampelken.

1 Delichon urbica. Mehlschwalbe ${ }^{\top}$ mit Ring Nr. 711 und Nest. Rossitten.

1 Delichon urbica. Mehlschwalbe O weifse Varietät. Ulmenhorst.

1 Muscicapa atricapilla. Trauerfliegenschnäpper ơ. Rossitten.

2 Corvus cornix. Nebelkrähe mit Ring

Nr. 1704.

Nr. 503.

1 Fringilla coelebs. Buchfink $\sigma^{x}$ juv. gelbe Varietät. Rossitten.

1 Chrysomitris spinus. Erlenzeisig $\sigma^{\top}$. Ulmenhorst.

1 Serinus hortulanus. Girlitz $\sigma^{x}$. Rossitten.

3 Loxia curvirostra. Fichtenkreuzschnabel $\sigma^{7}$ ad. $Q$ juv. Rossitten.

2 Passerina nivalis. Schneeammer $\sigma^{\top} \sigma^{\top}$. Rossitten.

4 Aegithalus caudatus. Schwanzmeise $\sigma^{x} \sigma^{\top} \sigma^{\top} \sigma^{x}$. Ulmenhorst. 82 Vögel.

b) Vogelbälge.

1 Urinator arcticus. Polartaucher Q. Rossitten.

3 Stercorarius parasiticus. Schmarotzerraubmöwe $\sigma^{\top}$ 오. Rossitten.

1 Larus marinus. Mantelmöwe. Rossitten.

2 Larus canus. Sturmmöwe ơ 1 ?. Rossitten, Ulmenhorst.

1 Larus ridibundus. Lachmöwe Q $_{\text {. Rossitten. }}$

4 Larus minutus. Zwergmöwe $0^{x} \sigma^{x}$ 우. Rossitten.

2 Sterna hirundo. Flufsseeschwalbe ơ $\sigma^{T}$. Rossitten, Königsberger Seekanal.

2 Sterna minuta. Zwergseeschwalbe $\sigma^{x} \sigma^{x}$. Königsberger Seekanal, Pillkoppen.

1 Oidemia fusca. Samtente ơ. Rossitten.

1 Nyroca ferina. Tafelente $\sigma^{x}$. Rossitten.

1 Nyroca hyemalis. Eisente ㅇ․ Rossitten.

4 Tringa alpina. Alpenstrandläufer $\sigma^{\top} \sigma^{\top}$ 우. Rossitten.

2 Totanus pugñx. Kampfläufer ơ우. Rossitten, Königsberger Seekanal. 
1 Totanus fuscus. Dunkler Wasserläufer 오. Rossitten.

1 Totanus littoreus. Heller Wasserläufer ? Rossitten.

1 Totanus ochropus. Waldwasserläufer ㅇ. Rossitten.

1 Totanus glareola. Bruchwasserläufer $Q$. Rossitten.

1 Limosa lapponica. Pfuhlschnepfe $\sigma^{x}$. Ulmenhorst.

1 Numenius arquatus. Grofser Brachvogel ㅇ. Ulmenhorst.

3 Scolopax rusticola. Waldschnepfe $\sigma^{\top}$ Uㅇ․ Ulmenhorst.

1 Crex crex. Wachtelkönig $\sigma^{\top}$. Ulmenhorst.

1 Ortygometra porzana. Tüpfelsumpfhuhn 오. Nidden.

1 Columba oenas. Hohltaube ơ. Rossitten.

3 Perdix perdix. Rebhuhn $\sigma^{x} \sigma^{x} \sigma^{x}$ Rossitten.

1 Lophortyx californicus. Schopfwachtel $\sigma^{x}$. Düren-Rheinland mit Zeichen versehen.

2 Astur palumbarius. Hühnerhabicht $\sigma^{x} \sigma^{x}$ juv. Rossitten, Landsberg Ostpr.

5 Astur nisus. Sperber $\sigma^{x} \sigma^{x} \sigma^{x} \sigma^{x} \sigma^{\rtimes}$. Pillkopen, Ulmenhorst.

4 Buteo buteo. Mäusebussard $\sigma^{x}$ 우오. Rossitten, Ulmenhorst.

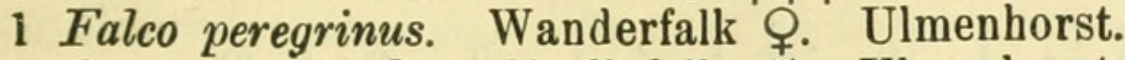

1 Cerchneis merilla. Merlinfalk ơ. Ulmenhorst.

1 Cerchneis vespertinus. Rotfufsfalk ơ juv. Ulmenhorst.

7 Asio otus. Waldohreule $\sigma^{\top} \sigma^{\top} \sigma^{\nwarrow}$ 우우․ Rossitten, Pillkoppen, Nidden, Ulmenhorst.

1 Asio accipitrinus. Sumpfohreule? Ulmenhorst.

1 Syrnium aluco. Waldkauz $\sigma^{x}$. Rossitten.

5 Dendrocopus maior. Buntspecht $\sigma^{x} \sigma^{x} \sigma^{x}$ 우. Ulmenhorst.

1 Coracias garrulus. Blaurake $\sigma^{x}$. Ulmenhorst.

5 Apus apus. Mauersegler $0^{\top}$ 우우 1? Ulmenhorst.

1 Delichon urbica. Mehlschwalbe ơ. Ulmenhorst.

2 Muscicapa grisola. Grauer Fliegenschnäpper. Ulmenhorst.

2 Lanius excubitor. Raubwürger $\sigma^{7}$ ㅇ․ Rossitten, Werdohl.

4 Corvus cornix. Nebelkrähe $\sigma^{\top} \sigma^{\top}$ 우우. Rossitten, Ulmenhorst.

2 Corvus cornix. Nebelkrähe, Köpfe mit monströsen Schnäbeln.

2 Colaeus monedula. Dohle $\sigma^{x} \sigma^{x}$. Ulmenhorst.

1 Pica pica. Elster ㅇ․ Thorn.

1 Nucifraga caryocatactes. Tannenheher $ᄋ$. Rossitten.

6 Sturnus vulgaris. Star $0^{x} \sigma^{x} 0^{x}$ 우우. Ulmenhorst.

2 Passer domesticus. Haussperling. Rossitten, Ulmenhorst.

4 Fringilla coelebs. Buchfink $\sigma^{\top} \sigma^{\top}$ 우. Ulmenhorst.

2 Chrysomitris spinus. Erlenzeisig $\sigma^{7}$ ㅇ. Ulmenhorst.

13 Loxia curvirostra. Fichtenkreuzschnabel 9 o $^{\top} 4$ ㅇ. Rossitten, Ulmenhorst.

2 Emberiza citrinella. Goldammer 우. Rossitten.

4 Anthus trivialis. Baumpieper $\sigma^{x} \sigma^{x} \sigma^{x}$ ㅇ․ Ulmenhorst.

2 Anthus campestris. Brachpieper ${\sigma^{\Upsilon}}^{\Upsilon}$. Kunzen.

1 Anthus obscurus. Strandpieper $Q_{\text {. Helgoand. }}$

2 Budytes flavus. Kuhstelze

1 Alauda arvensis. Feldlerche $\sigma^{x}$. Rossitten.

3 Certhia familiaris. Baumläufer $\sigma^{x} \sigma^{\top} 1$ ? Ulmenhorst. 
2 Parus maior. Kohlmeise $\sigma^{\top} \sigma^{\top}$. Ulmenhorst.

1 Parus ater. Tannenmeise $\sigma^{x}$. Ulmenhorst.

1 Parus cristatus. Haubenmeise $\sigma^{x}$. Rossitten.

2 Aegithalus caudatus. Schwanzmeise $\sigma^{x}$ Q. Ulmenhorst.

1 Troglodytes troglodytes. Zaunkönig $\sigma^{T}$. Ulmenhorst.

1 Phylloscopus trochilus. Fitislaubsänger $\sigma^{7}$. Ulmenhorst.

4 Turdus musicus. Singdrossel $\sigma^{\top} \sigma^{\top}$ 우. Rossitten, Ulmenhorst.

3 Turdus iliacus. Weindrossel ơ $0^{\top}$ Q . Rossitten, Ulmenhorst.

2 Turdus pilaris. Wachholderdrossel 우. Rossitten.

1 Turdus merula. Amsel ㅇ․ Rossitten.

1 Saxicola oenanthe. Steinschmätzer $\sigma^{x}$. Rossitten.

1 Pratincola rubetra. Braunkehliger Wiesenschmätzer ㅇ․ Ulmenhorst.

1 Erithacus phoenicurus. Gartenrotschwanz $\sigma^{\top}$. Ulmenhorst. 153 Vögel.

\section{Dentsche Ornithologische Gesellsehaft.}

\section{Bericht über die März-Sitzung $\mathbf{1 9 1 0}$.}

Verhandelt, Berlin, Montag d. 7. März, abends 8 Uhr im Architekten-Vereinshause, Wilhelmstr. 92.

Anwesend die Herren Kracht, Jung, Koske, K. Neunzig, Haase, Schnöckel, K. Kothe, Freiherr Geyrv. Schweppenburg, Krause, v. Treskow, O. Neumann, Schalow, Reichenow, Deditius, Heinroth.

Als Gäste die Herren A. Brehm, K. Hofmann und Frau Heinroth.

Vorsitzender Herr Schalow, Schriftführer Herr Heinroth.

Anschliefsend an die Verlesung des Protokolles der Februarsitzung macht Herr Reichenow die Mitteilung, dafs er sich an den Direktor der Helgoländer biologischen Station, Herrn Prof. Heincke im Sinne des Herrn Weig old gewandt und erfahren habe, dal's dort gerade Personalveränderungen vor sich gehen und Aussicht auf Einrichtung einer Vogelwarte ist.

Herr Hofmann hält hierauf unter Vorlegung zahlreicher von ihm selbst an Ort und Stelle gesammelter ostafrikanischer Vögel einen längeren Vortrag, der anderweitig erscheinen wird.

Herr K. Kothe kam auf die von ihm in der letzten Sitzung vorgelegten Stieglitze zurück; er sprach über den hellen Schnabel und die hellen Beine. Der helle Schnabel soll, wie es auch einige Bälge gut zeigten, im Frühjahr sich finden. Desgleichen hält Herr K. Kothe es für möglich, dafs auch die Beine, die bei jungen und bei Gefangenschaftsvögeln stets hell sind, im Frühjahr hell gefärbt sind und zum Herbst mit dem Schnabel zugleich dunkler werden. Bei genügendem Brutvogelmaterial wäre diese 


\section{$2 \mathrm{BHL}$ Biodiversity Heritage Library}

1910. "IX. Jahresbericht (1909) der Vogelwarte Rossitten der Deutschen

Ornithologischen Gesellschaft." Journal

$f u$

r Ornithologie 58, 531-676. https://doi.org/10.1007/bf02090109.

View This Item Online: $\underline{\text { https://www.biodiversitylibrary.org/item/43496 }}$

DOI: https://doi.org/10.1007/bf02090109

Permalink: https://www.biodiversitylibrary.org/partpdf/142710

\section{Holding Institution}

MBLWHOI Library

\section{Sponsored by}

MBLWHOI Library

\section{Copyright \& Reuse}

Copyright Status: No known copyright restrictions as determined by scanning institution.

This document was created from content at the Biodiversity Heritage Library, the world's largest open access digital library for biodiversity literature and archives. Visit BHL at https://www.biodiversitylibrary.org. 